\title{
Economic Evaluation of PUвLLATIONS Solar Energy Systems in Commercial Buildings
}

\section{Methodology and Case Studies}

NBSIR 82-2540

U.S. Department of Commerce National Bureau of Standards National Engineering Laboratory Center for Building Technology Washington, DC 2ก?34

Rosalie T. Ruegg

G. Thomas Sav

Jeanne W. Powell

E. Thomas Pierce

July 1982

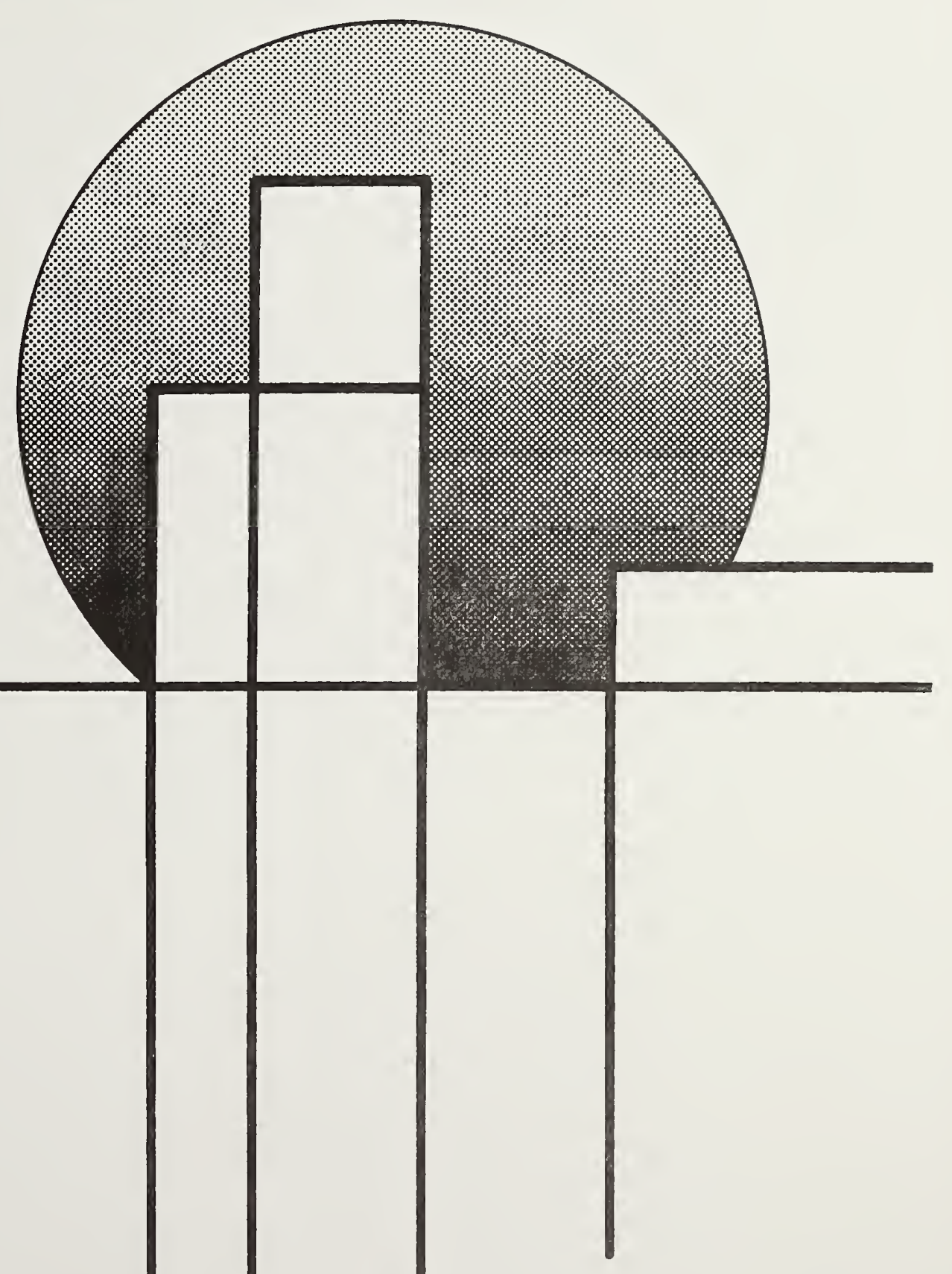

$-Q C \longrightarrow$

100

.056

$32-2540$

1932

C.2 

Economic Evaluation of Solar Energy Systems in Commercial Buildings: Methodology and Case Studies

Rosalie T. Ruegg

G. Thomas Sav Jeanne W. Powell

E. Thomas Pierce

U.S. DEPARTMENT OF COMMERCE National Bureau of Standards National Engineering Laboratory Center for Building Technology Washington, DC 20234

July 1982

Prepared for:

U.S. Department of Energy

Office of Solar Heat Technologies

Active Heating and Cooling Division

Washington, D.C. 20585

U.S. DEPARTMENT OF COMMERCE, Malcolm Baldrige, Secretary NATIONAL BUREAU OF STANDARDS, Ernest Ambler, Director 


\section{ABSTRACT}

This report develops a comprehensive economic optimization model for evaluating the economic feasibility of active solar energy systems to provide service hot water and combined space heating/service hot water in commercial buildings. The model is demonstrated in a number of case studies for office buildings and retail stores. Data and assumptions for use in the model are compiled for the selected case studies. Using these data, the model is applied to estimate present value net savings (or net losses) of the solar energy systems over a 20-year life cycle. Break-even values for hot water loads, solar energy system costs, and current and future energy prices are also calculated to determine the minimum conditions under which the solar energy systems become cost effective for the selected buildings. Economic optimization paths which show the optimal solar collector areas and the corresponding present value of net savings (or net losses) associated with a range of hot water loads are developed in the case studies. Sensitivity analysis is conducted for key variables. The relationship between total life-cycle costs and the solar fraction is tested for selected cities to demonstrate how net savings (net losses) change as the solar fraction is increased. In its approach, this report is of interest to solar analysts; in its results, to the solar policy, research, and building communities.

Key words: building economics; commercial buildings; economic analysis; energy economics; life-cycle costing; solar energy 
The study on which this report is based was conducted by the Applied Economics Group, Center for Building Technology, National Bureau of Standards (NBS), for the Office of Solar Heat Technologies, Active Heating \& Cooling Division, Washington, D.C. 20585, U.S. Department of Energy (DoE), under Interagency Agreement No. E (49-1) - 3800, EA-77-A-01-6100, Task 9.

This report is one of several related documents prepared under this contract. It is the technical analysis report which details the economic model and the data, assumptions, and findings of selected case studies of solar economic feasibility. It is addressed primarily to the research and policy communities. Additional products include papers and articles [1-8] which were prepared in full or in part from the technical work described herein.

It is to be stressed that, while the model is widely applicable to the evaluation of solar energy for commercial buildings, the feasibility results for the case studies are founded on a host of assumptions which are varfable among buildings of like size, function, and geographlc location, not to mention buildings that are different from those studied. The reader should use caution and judgment in extending results or conclusions contained in this report to other buildings. 


\section{ACKNOWLEDGMENTS}

The authors wish to thank all of those persons who contributed to the study, particularly Dr. Roger Bezdek, formerly Chief of the Barriers and Incentives Branch of the U.S. Dept. of Energy, for his direction and support of the project.

Special appreciation is extended to Dr. Harold Marshall, Leader of the NBS Applied Economics Group, for his continuing guidance and contributions to the project, to Mr. James Gross, Division Chief, and to Mr. Robert Dikkers, Leader of the NBS Solar Technology Group, for their valuable advice and administrative support throughout the project. Credit and appreciation are due to Mr. Joel Levy of the Applied Economics Group for his extensive work on revising, extending, and documenting the computer program used to apply the model in the case studies of economic feasibility.

Helpful editorial and technical assistance was provided by Dr. Kent Reed, Dr. Samuel Silberstein, Mr. Larry Salomone, and Ms. Patricia Christopher of the NBS Center for Building Technology, and by Mr. Robert Atkins of the NBS Institute for Computer Sciences and Technology. Credit is also due Mr. Philip Decker, NBS student worker, who assisted with the computer analyses, Ms. Sieglinde Fuller who assisted with the manuscript preparation, and Mrs. Brenda Thompson who typed the report. 


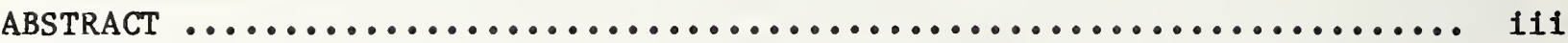

PREFACE $\ldots \ldots \ldots \ldots \ldots \ldots \ldots \ldots \ldots \ldots \ldots \ldots \ldots \ldots \ldots \ldots \ldots \ldots \ldots \ldots \ldots \ldots \ldots \ldots \ldots \ldots \ldots$ iv

ACKNOWLEDGMENTS ....................................... v v

LIST OF FIGURES $\ldots \ldots \ldots \ldots \ldots \ldots \ldots \ldots \ldots \ldots \ldots \ldots \ldots \ldots \ldots \ldots \ldots \ldots \ldots \ldots \ldots \ldots \ldots \ldots \ldots$ ix

LIST OF TABLES .......................................

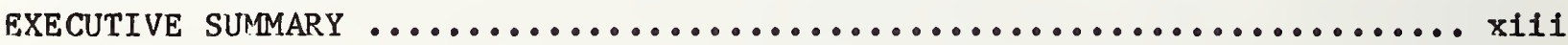

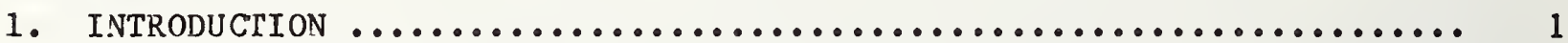

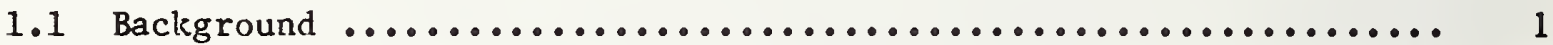

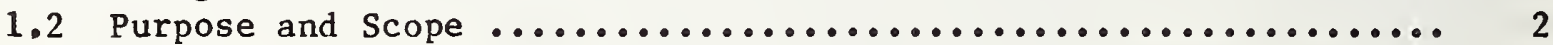

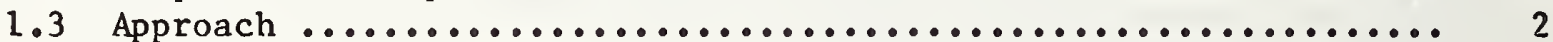

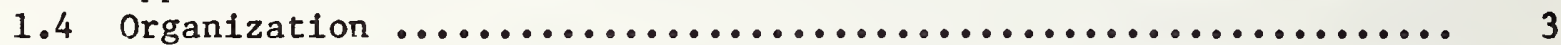

2. ECONOMIC MODELING ................................... 4

2.1 Model Requirements ................................... 4

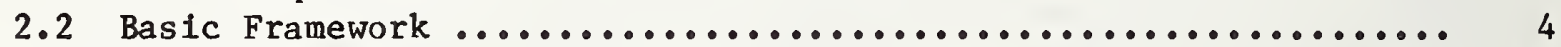

2.3 Algebraic Model ..................................... 15

2.4 Using the Model to Determine Net Life-Cycle Savings,

Optimal System Size, Break-Even Values, Years to Payback,

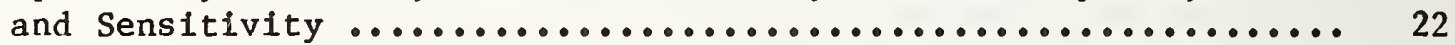

2.4.1 Net Life-Cycle Savings and Optimal System Size ......... 22

2.4 .2 Break-even Values ............................ 22

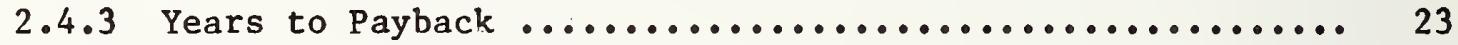

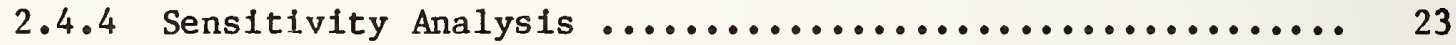

2.5 Simplified Model for Solar Hot Water Analysis .............. 24

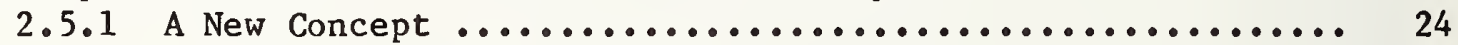

2.5.2 Universal Economic Optimization Paths ............... 24

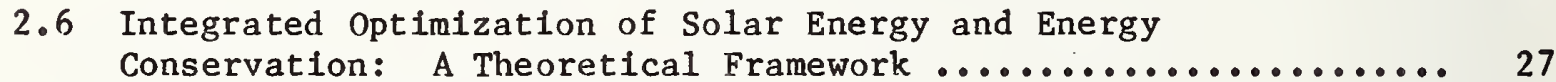

2.6.1 Economic Foundations ......................... 27

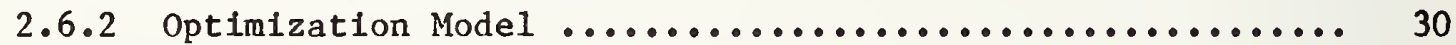

3. CASES SELECTED FOR STUDY: BUILDINGS, BUILDING SYSTEMS, AND

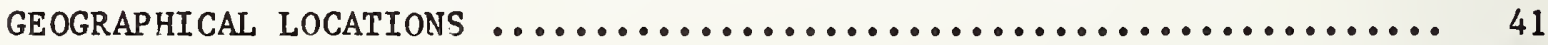

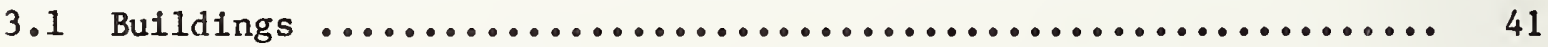

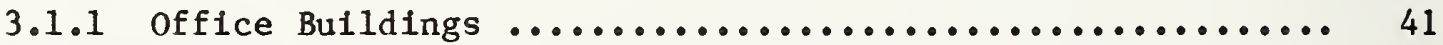

3.1.2 Retall Stores .............................. 44

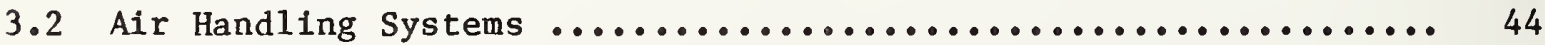

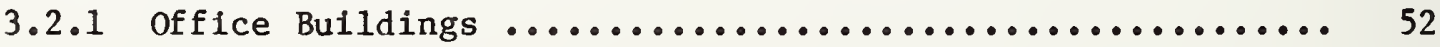

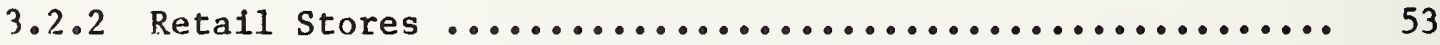

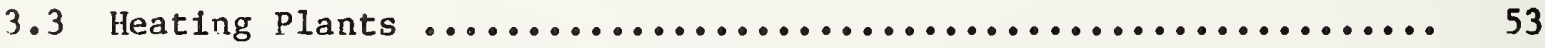

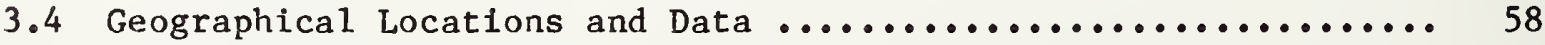

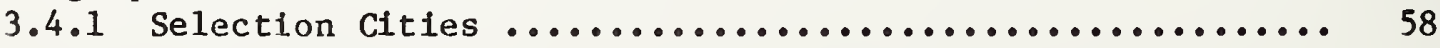

3.4 .2 Geographical Data .......................... 58

4. DATA AND ASSUMPTIONS FOR CASE STUDIES ....................... 64

4.1 Heating and Hot Water Requirements ..................... 64 
4.1.1 BLAST Transient Load Mode1--Space Heating ............ 64

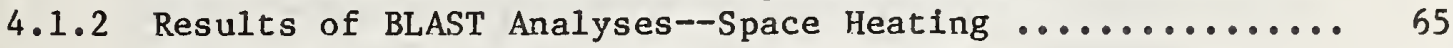

4.1 .3 Buflding Loads Model--Service Hot Water ............. 67

4.2 Solar Energy System Performance ........................ 59

4.3 Purchase and Installation Costs of the Solar

Energy System ................................... 70

4.3.1 Estimating Fixed and Variable System Costs ........... 70

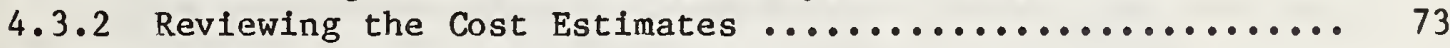

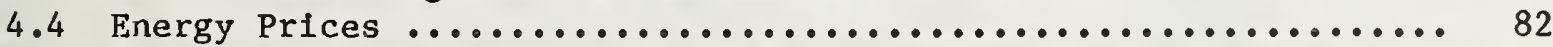

4.5 Financial Variables--Discount, Borrowing, and Inflation Rates .. 82

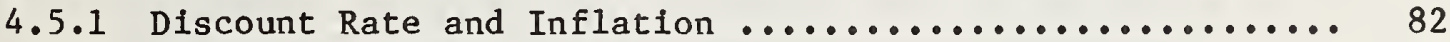

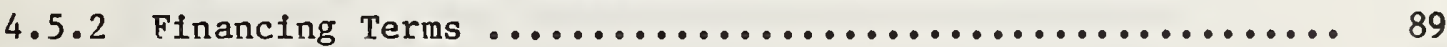

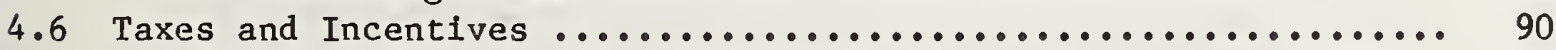

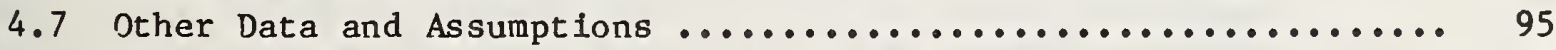

4.7.1 Operation, Maintenance and Repair Costs .............. 95

4.7.2 Solar Energy System Life and Salvage Value ........... 95

4.8 Summary of Economic Parameters Common to All Cities .......... 95

5. CASE STUDY RESULTS .................................... 97

5.1 Case Study Results for Solar Service Hot Water Heating Systems

Under Base-Case Assumptions .......................... 97

5.1 .1 Summary Overview and Comparisons .................. 97

5.1.2 Detalled Results for Selected Case Studies ............. 104

5.2 Case Study Results for Solar Combined Space Heating and

Service Water Heating Systems ........................ 112

5.2.1 Results Compared for Two Sets of Assumptions .......... 112

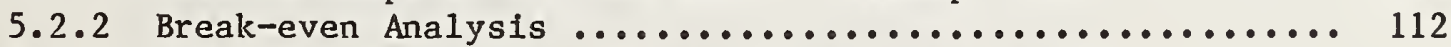

5.2.3 Effects of Financing, Taxes, Incentives, and

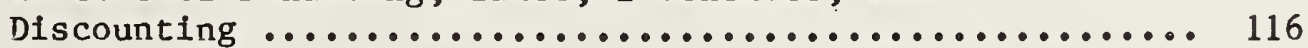

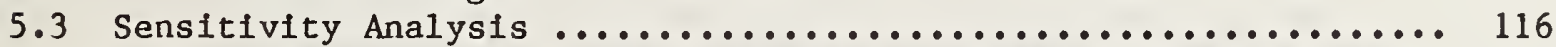

5.3.1 Sensitivity of Solar Cost Effectiveness to System Size .. 116

5.3.2 Sensitivity of Solar Life-Cycle Costs to Selected

Economics Assumptions: Phoenix Case Study for New

Office Buildings ........................... 120

5.4 The Changing Status of Solar Economic Feasibility .......... 120

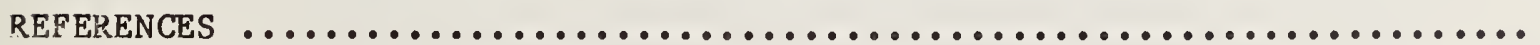

APPENDIX A - Mathematical Programming and Stochastic Modeling:

Exploratory Research ......................... A-1

A. 1 - The Importance of Multivariate Analysis in

Solar Design .............................. A-1

A.2 - Classification Framework for Solar Design

Variables ................................. A -5

A.3 - Mathematical Programming as a Potential Tool for

Solar Analysis ........................... A-5 
A.4 - The McGarity-Revelle Solar Performance Model ........... A-7

A.5 - Solution Properties of the McGarity-Revelle Linear

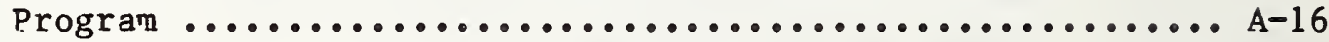

A.6 - Mathematical Relationships Employed in the Solar Energy Linear Program and a Listing of Mathematical Notations ................................. A-18

A.6.1 - Component Performance Relationships ................... A-18

A.6.2 - Combination of Performance Formulas for Linear Program Format ..................................A

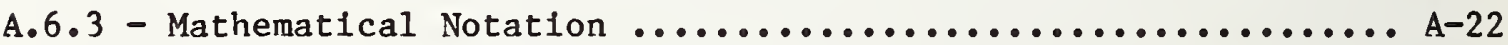

A.7 - Derivations of Solution Properties of the McGarityRevelle I.Inear Programming Model ................... A-24

A. 8 - Test Results: The Linear Program Compared with TRNSYS ...................................A A-31

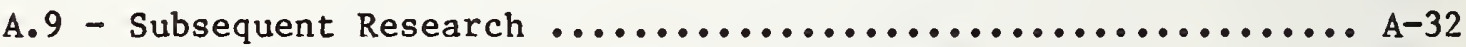

A.10- Stochastic Modeling of Weather Variables ............. A-32

APPENDIX B - Computer Program Used to Apply the Economic Evaluation Model to Selected Case Studies for Combined Space Heating and Hot Water 
Figure 2.1 Figure 2.2

Figure 2.3

Figure 2.4 Figure 2.5 Figure 2.6 Figure 2.7 Figure 2.8 Figure 2.9

Figure 2.10

Figure 3.1 Figure 3.2 Figure 3.3 Figure 3.4 Figure 3.5

Figure 3.6 Figure 3.7

Figure 3.8

Figure 3.9

Figure 4.1

Figure 4.2

Figure 4.3

Figure 4.4

Figure 5.1

Figure 5.2

Figure 5.3
LCC Trade-Off Between Solar Energy and Auxiliary Energy ..... Determining the Cost-Minimizing Size of the Combined Solar/ Auxil1ary Energy System: U-shaped TLCC $_{C, s}$ Curve ........... 11 Determining the Cost-Minimizing Size of the Combined Solar/ Auxiliary Energy System: Monotonically Rising Curve ....... 12 Determining the Cost-Effective Solar Investment .......... 13 Minimizing Losses from a Solar Investment ................ 14 An Uneconomical Solution for a Solar Energy System ......... 16 Universal Economic Optimization Path: Generic Form ........ 28 Integrated Optimization Procedure: Load Reduction ......... 32 Integrated Optimization Procedure: Solving for the Combination of Conservation, Solar, and Nonsolar Inputs to Thermal Comfort ................................. 33 Integrated Optimization Procedure: Compressed Mode1 ....... 34

Schemata of office Buildings ...................... 46 Office Building Load Schedules ...................... 47 Schemata of Retail Stores .......................... 49 Retail Bullding Load Schedules ..................... 50 Annual Heating and Cooling Energy Consumption of a Building with Alternative Mechanical Systems in Four Geographical Locations .................................. 51

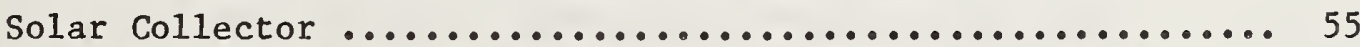
Schematic Diagram of a Combined Solar Service Hot Water System for a Commercial Building .................... 56 Schematic Diagram of a Solar Space Heating/Hot Water System for a Commercial Building .......................... 57 Climatic Regions and Cities Selected for study ........... 59

Solar Universal Performance Curves for Estimating the Performance of a Combined Solar Space Heating and Service Hot Water System for a Commercial Building ............... Solar Universal Performance Curves for Estimating the Performance of a Solar Service Hot Water System for a Commercial Building ............................. Comparison of Two Cost Functions: The NBS-Estimated Cost Function for a Combined Space Heating/Hot Water System for New Construction Versus the Regression-fitted Cost Function for 43 Sample Demonstration Projects ............ 78 World Oil Prices: Recent History and Alternative Future Projections, 1960-1995

Break-even Results: Minimum Hot Water Issage Rates (Gallons Per Minute) for Solar Energy System Cost Effectiveness ...... 101

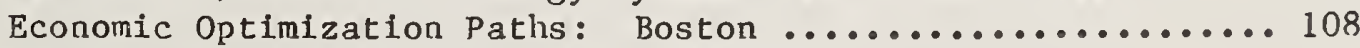
Economic Optimization Paths for Phoenix .............. 111 
Figure 5.4 Impact of Financing, Taxes, Incentives, and Discounting on Solar Cost Effectiveness: New Office in Phoenix, 011 Auxiliary system ............................. 117

Figure 5.5 Solar Cost Effectiveness as a Function of the Solar Fraction: Phoenix ............................... 118

Figure 5.6 Solar Cost Effectiveness as a Function of the Solar Fraction: Bismarck .............................. 119

Figure 5.7 Life Cycle Costs of the Solar Energy System as a Function

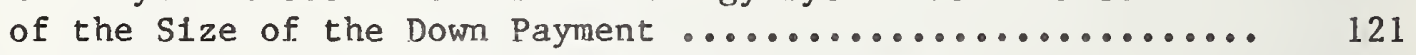

Figure 5.8 Life Cycle Costs of the Solar Energy System as a Function of the Size of the Energy Tax Credit ..................... 122

Figure 5.9 Life Cycle Costs of the Solar Energy System as a Function of the Length of the Depreciation Period ................ 123

Figure 5.10 Jife Cycle Costs of the Solar Energy System as a Function of the Purchase and Installation Cost ............... 124

Figure A.1 Sensitivity of Solar Acquisition Cost to Storage Volume/ Collector Area Ratio for Given Solar Fractions and "Typical" Storage Cost ........................... A-3

Figure A.2 Sensitivity of Solar Acquisition Cost to Storage Volume/ Collector Area Ratio for Given Solar Fractions and High Storage Cost .............................. A-4

Figure A.3 Diagram of a Solar Energy System with Designation of

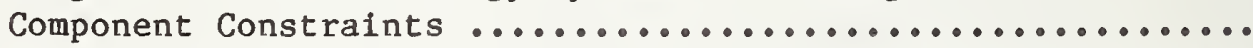

Figure A.4 Solar Water and Space Heating System Diagram Showing Energy Flow and Temperature Parameters .......................... A-23

Figure A.5 Comparison of Performance Test Results for a Commercial Solar Water Heating System in Boulder, Colorado: Linear

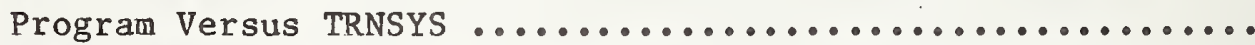
A-33

Figure A.6 Comparison of Performance Test Results for a Residential Solar Water and Space Heating System in Madison, Wisconsin: Linear Program Versus TRNSYS 
Table 2.1 Definition of Symbols Used in Section $2 \ldots \ldots \ldots \ldots . \ldots$

Table 3.1

Table 3.2

Table 3.3

Table 3.4

Table 3.5

Table 3.6

Table 3.7

Table 4.1

Table 4.2

Table 4.3

Table 4.4

Table 4.5

Table 4.6

Table 4.7

Table 4.8

Table 4.9

Table 4.10

Table 4.11

Table 4.12

Table 5.1

Table 5.2

Table 5.3

Table 5.4

Table 5.5

Table 5.6

Table 5.7

Table 5.8
Types of Commercial Buildings ....................... Estimated Floor Space by Type of Nonresidential Buildings ... Office Building Construction Characteristics .............. Retail Store Construction Characteristics ................ Annual Insolation Values for Selected Cities .............. Water Supply Temperatures Used in Analysis of Service Hot

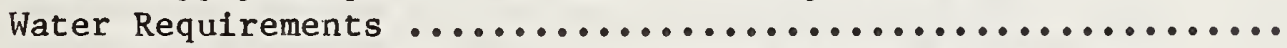
Ground Temperatures Used in Analyses of Space Heating Requirements ................................

Estimated Annual Space Heating Requirements of the Selected Buildings ..................................... Estimated Annual Hot Water Requirements of the Selected Buildings ....................................

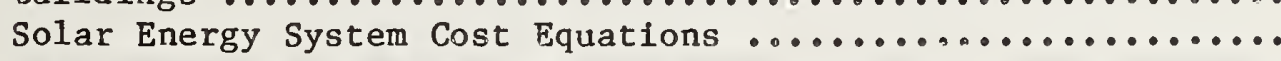

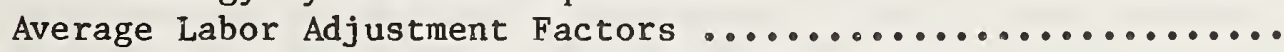
Acquisition Costs for 262 Nonresidential Solar Demonstration Projects, By Type of System ............... 1978 Energy Prices and Projected Rates of Changes .......... Early-1980 Energy Prices and Projected Rates of Changes ..... Mid-1980 Energy Prices and Projected Rates of Change ........ Total Present Value of 1 Million Btu ( $1 \mathrm{GJ}$ ) of Energy Purchased Each Year Over 20 Years ...................... Cost of Capital -- Average Returns on Debt and Equity in Nonfinancial Corporations ........................ Rates of Sales Tax, Property Tax, and State Income Tax by City ....................................... 66 68 74 75

Economic Analyses of Solar Hot Water for a New Office Building with an Electric Resistance Backup System: Case

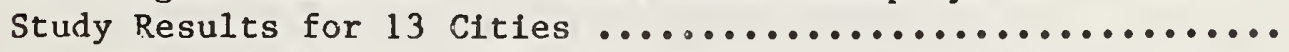
with an Electric Resistance Backup System: Case Study

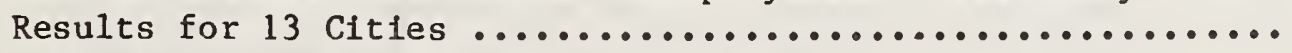

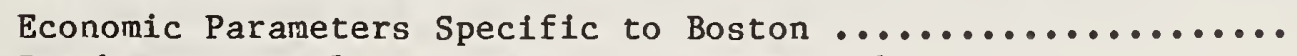
Break-even Results : Boston, Hot Water only ..............

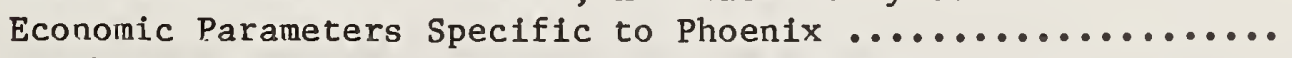
Break-even Results: Phoenix, Hot Water Only .............. Economic Evaluation Results for Four Selected Cities Based on Early-1980 and Mid-1980 Energy Prices and Federal Tax

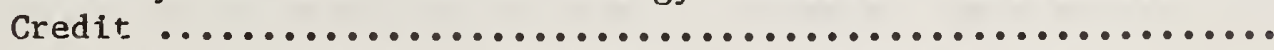
Break-even Analysis of Base-Year Fuel Prices and Fuel Escalation Rates for Selected Cases Based on Early-1980 Assumptions 


\section{LIST OF TABLES (Continued)}

$\underline{\text { Page }}$

Table 5.9 Break-even Analysis of System Cost for Selected Cases Based on Early-1980 Assumptions .................... 115

Table 5.10 The Changing Status of Solar Economic Feasibility ......... 125

Table A.1 Classification of Solar Design Variables ............... A-6

Table A.2 Sumnary of Observations on the Solution Properties of the McGarity-Revelle Linear Program ................... A-19

Table B.1 City File for Boston ................................... B-17

Table B.2 Sample Program Printout ........................... B-18 


\section{EXECUTIVE SUMMARY}

The total energy use of commercial bulldings in the U.S. For space heating and service water heating is nearly half that of residential bulldings. However, they account for a substantially smaller part of the use of solar energy systems. Space heating and service water heating for commercial buildings is a large, but for the most part unrealized, potential market for solar energy.

This report is a resource document for investigating the economic feasibility of commercial bullding applications of solar energy. It documents in deta11 an economic model for evaluating commercially used solar energy systems, and guides in the use of the model for economic feasibility studies. It demonstrates the model in a number of case studies which (1) assess the cost effectiveness of selected solar energy systems under representative conditions, (2) investigate through break-even analysis the necessary conditions for minimum cost effectiveness, and (3) analyze future prospects under alternative conditions.

The economic evaluation model takes a life-cycle costing approach and inciudes full treatment of taxes and Federal and State incentives. It is used to determine the optimally sized solar energy system and the present value net dollar savings or losses for the building type, location, auxiliary fuel type, and other specified data and assumptions. Break-even values of key parameters are calculated to determine the necessary conditions for solar energy to be equal in dollar cost effectiveness to the energy systems with which it is compared. Life-cycle net savings or losses corresponding to a wide range of solar fractions can be calculated to determine the sensitivity of costs to system size. Data and assumptions can be modified to reflect changes in tax laws, financing terms, depreciation rules, and other conditions affecting economic feasibility. (The computer progran used to apply the model is presented as appendix $B$ to the report.)

A simplified version of the model for the evaluation of solar hot water systems is presented. The simplified model reduces the search for the optimally sized solar hot water system to a single deterministic equation. Analysis of this equation supports the construction of "universal economic optimization paths" which can show the optimal solar energy system size and corresponding net savings or losses for a range of hot water loads. This model can be used to extend evaluation results to a range of hot water loads.

The evaluation of solar energy systems by mathematical programming techniques is explored. Although this approach is not sufficiently developed to apply as a principal evaluation tool for a feasibility study, the theoretical approach is significantly extended.

The case studies focus on commercial bulldings representative of a large share of the commercial bullding stock, and on 13 city locations accounting for major variations in U.S. solar radiation and temperature characteristics and also reflecting regional diversity in taxes, incentives, and other economic paraneters. 
The selected buildings are not buildings specifically designed to optimize solar gain or daylighting. They are (1) an existing three-story office building with metal curtain-wall construction, an occupancy of 300 people, single-glazed windows, uninsulated walls and roof, a floor area of $2,700 \mathrm{~m}^{2}$ $\left(30,000 \mathrm{ft}^{2}\right)$, equipped with two constant-volume air-handling systems; (2) a new three-story office building identical to the existing building except that it conforms to ASHRAE 90-75 energy conservation standards and is equipped with two variable-volume air-handling systems and an energy economizer cycle; (3) an existing one-story retail store with metal curtain wall construction, a floor area of $460 \mathrm{~m}^{2}\left(5,000 \mathrm{ft}^{2}\right)$, an occupancy of 100 people, uninsulated walls and roof, and equipped with a single constant-volume air-handling system; and (4) a new one-story retail store identical to the existing store except that, like the new office building, it conforms to the ASHRAE 90-75 standard for the building envelope and is equipped with an energy-efficient variablevolume air-handling system. The nonsolar heating plants for these buildings are assumed to be conventional hot water boilers fired alternatively by electricity, natural gas, and distillate fuel oil.

The cities selected for the regional case studies are Apalachicola, FL; Bismarck, ND; Boston, MA; Charleston, SC; Fort Worth, TX; Los Angeles, CA; Madison, WS; Miami, FL; Nashville, TN; Omaha, NE; Phoenix, AZ; Seattle, WA; and Washington, DC. The economic evaluation is based on a detalled analysis of the energy requirements of the selected buildings in the different locations estimated by the BLAST loads analysis program, as well as on other region-specific data.

The solar energy systems are assumed to be high quality liquid systems with double-glazed, flat-plate collectors. The hot water system for the retail stores is assumed to be an "off-the-she $1 \mathrm{f}$ " system. The hot water system for the office buildings and the combined space heating/hot water system for the retail stores and the office buildings are assumed to be custom designed and engineered. Solar energy system performance is estimated by the LASL Solar/ Building Load Ratio Method, which is incorporated in the economic evaluation model.

The reader is cautioned that the general conclusions that can be drawn about solar cost effectiveness on the basis of case study results are limited. There is no single answer. Results are strongly dependent on a number of factors that are either variable over place and/or time, or uncertain, or both, such as climatic conditions; building and user characteristics; system cost, performance, durability, maintainability, and operating energy requirements; and current and projected prices of other energy sources. Furthermore, it should be realized that economic feasibility may be dependent on decision criteria other than the quantitative cost-effectiveness data. Reflecting the difficulty to generalize results, the case study results are secondary, and the development and illustration of a methodology that can be used to address the dynamics of solar economic performance over time are primary.

A constrained optimization analysis was used in the case studies to determine the size of the solar energy system which will maximize net dollar savings or minimize net dollar losses. Reflecting the relative prices of the different 
energy sources, the optimal solar fractions and system sizes (constrained to be greater than 0 ) were found to be substantially larger-and solar economic greater--when the auxiliary system was assumed to be an electric resistance system rather than an o11-fired furnace. In turn, the oil-furnace resulted in larger solar fractions and system sizes than did the gas furnace.

A comparison of case study results for the combined solar space heating/hot water system for the office bulldings and retall stores showed a slightly better economic performance for the systems applied to the office bulldings, other things being equal. A comparison of the results for the new and existing buildings showed a better economic performance for systems applied to the new buildings, other things again being equal.

An analysis of the relationship between net savings and solar fraction was made in the case studies to determine the impact of system size on economic performance. By providing a measure of the dollar consequences of increasing or decreasing system size, this kind of information is particularly valuable in those cases where factors other than direct energy-related costs are important to the decision to choose solar (e.g., the need for an alternative energy supply to operate the building during fuel curtallments). In some of the case studies, net dollar savings or losses were found to change little over a wide range of sizes of the solar energy system, indicating only a smali cost penalty for selecting a solar energy system larger than the economically optimal size based on direct life-cycle costs. In the Phoenix case study, for example, economic performance of the combined system in office bulldings was best for a system supplying between 40 percent and 50 percent of the load, but there was little change up to a size providing a solar fraction of about 75 percent. In some of the case studies, however, substantial dollar penalties were estimated for choosing the size of the solar energy system without regard to economic optimization. For example, in the Bismarck case study, net losses were found to increase rapidly as the solar fraction was raised beyond the level determined to be economically optimal.

The break-even analysis allows the reader to compare current values of solar energy system costs and energy prices with the minimum calculated values necessary to move solar from a net loss to a net savings outcome for the case study applications examined. Again taking the Bismarck case study as an example, the breakeven analyses showed that the price of oil for heating in the new office building would have to be about twice that in mid-1980 in order for heating by solar to be as cost effective as oil heating (given other data and assumptions of the case and taking into account deductions of fuel costs from taxable income). Alternatively, future escalation in the price of oil would have to be 1.8 times the projected rate as of mid-1980.

Based on the initially assumed data and assumptions (1978 energy prices for water heating and early-1980 energy prices for combined systems), solar space heating and water heating were found not to be cost effective in the case studies examined. Sensitivity analysis was used to investigate the importance of the parameters and the changes in the data and assumptions necessary for cost effectiveness. For example, the cost effectiveness of the solar hot water systems was found to be critically sensitive to the amount of hot water used. 
With higher hot water usage rates than those initially assumed, the solar water heating moved towards cost effectiveness against electric resistance water heating in some of the cities, principally Phoenix, Boston, Bismarck, Nashville, and, for small scale applications in Los Angeles, even with the understated 1978 energy prices and escalation rates.

In addition to changing the parametric values for the purpose of conducting sensitivity analysis, the data were updated during the course of the study to reflect changes in projected energy prices, the size of the Federal tax credit, and projected financing terms and depreciation rules. These changes affected the results dramatically, substantially improving the economic performance of the case study systems.

The table below gives comparative examples of results based on the initial set of data and assumptions for the combined system analysis and for the revised data and assumptions, showing in some cases changes from large net losses to significant net savings. The cost effectiveness of solar energy is, in other words, shown by the case studies to change over time and events, and to vary with location and application. Periodic reassessment is necessary for a valid appraisal of its current economic status.

\section{Changing Solar Cost Effectiveness Over Time*}

\begin{tabular}{|c|c|c|c|}
\hline City & Fuel Type & $\begin{array}{c}\text { Early-1980 } \\
\text { Energy Prices } \\
10 \% \text { Federal } \\
\text { Tax Credit } \\
\text { Less Favorable } \\
\text { Financing Terms } \\
(\$ 1,000)\end{array}$ & $\begin{array}{c}\text { Mid-1980 } \\
\text { Energy Prices } \\
15 \% \text { Federal } \\
\text { Tax Credit } \\
\text { More Favorable } \\
\text { Financing Terms } \\
(\$ 1,000)\end{array}$ \\
\hline Bismarck, ND & $\begin{array}{l}\text { Electricity } \\
\text { Oil }\end{array}$ & $\begin{array}{l}-15.8 \\
-17.3\end{array}$ & $\begin{array}{l}+25.2 \\
+10.1\end{array}$ \\
\hline Phoenix, AZ & $\begin{array}{l}\text { Electricity } \\
\text { Oil }\end{array}$ & $\begin{array}{l}-13.5 \\
-18.8\end{array}$ & $\begin{array}{l}+8.1 \\
-2.3\end{array}$ \\
\hline Boston, MA & $\begin{array}{l}\text { Electricity } \\
\text { Oil }\end{array}$ & $\begin{array}{l}-18.7 \\
-22.0\end{array}$ & $\begin{array}{l}+13.2 \\
-7.5\end{array}$ \\
\hline Charleston, SC & $\begin{array}{l}\text { Electricity } \\
\text { Oil }\end{array}$ & $\begin{array}{l}-18 \cdot 0 \\
-20.4\end{array}$ & $\begin{array}{l}-5.7 \\
-8.0\end{array}$ \\
\hline
\end{tabular}

* Based on case study results for new 3-story office building and current and projected energy prices and Federal tax credits existing at two points in time (early 1980 and mid 1980), and projected financing terms under the Solar Energy and Energy Conservation Bank (which were not realized). 


\section{INTRODUCTION}

\subsection{BACKGROUND}

Total energy demands for space heating and service hot water in commercial buildings in the United States are about 40 percent as great as in residential buildings $[9,10]^{*}$. Yet of the approximately 100,000 solar energy systems now installed on buildings in this country, about 98,000 are estimated to be on residential buildings and less than 2,000 are on commercial buildings [11]. of the total sales of solar collectors (in terms of collector surface area) in a recent year, 82 percent went for residential applications and only 18 percent for nonresidential applications [12]. While commercial buildings provide a large potential market for solar energy systems, that market is as yet largely untapped.

Paralleling the small demand for solar energy systems for commercial buildings is a relatively small body of economic literature on the topic. Residential use of solar energy for space heating and hot water appears to have received considerably more attention by economists and other analysts than has commercial use.1 Few economic studies have been made of solar energy systems for commercial buildings. Studies that have been conducted looked mainly aic rental single-family housing, at small nonresidential buildings whose energy requirements are dominated by the building envelope, and at a single, particular comrnercial building. 2

Two factors which have probably combined to dampen the interest of the typical comrnercial building owner in solar energy are the following: (1) The size and complexity of many commercial buildings necessitate the use of specially designed and engineered solar energy systems that typically cost substantially more to purchase and install than most systems for residential use. (2) Considerable uncertainty usually exists concerning the short- and long-term performance of large commercial building systems and the effects of part-loading on the operation of a conventional backup energy system.

The limited experience with solar energy systems for commerciai buildings has meant less documentation of the thermal performance of these systems than for residential systems. Moreover, the great diversity of commercial buildings by type and energy requirement has made it much more difficult to develop genera1ized profiles of cost and performance than has been possible for residential buildings.

* Numbers in brackets designate references listed at the end of the paper. (References 1 through 8 were cited in the Preface.)

1 For examples of economic studies of solar energy systems for residential buildings, see [13-18].

2 For examples of economic studies of solar energy systems for commercial buildings, see $[19,20]$. 
Another reason for the greater emphasis on residential use of solar energy is the difference in the Federal tax treatment of residential and commercial energy operating costs. To a commercial building owner, these costs are deductible as a business expense, but they are not deductible to the owner/occupant of a house. Hence, a dollar of fuel cost reduction constitutes a dollar of savings to a homeowner, but only about fifty cents of after-tax savings to many commercial building owners.

Despite the limited activity in this area, our national energy goal of reducing reliance on foreign oil, together with the spiralling costs of operating commercial buildings, make it important to examine the economics of solar energy systems for commercial buildings. To make well-informed investment decisions, to estimate the potential of solar energy in meeting the nation's energy needs, and to formulate energy policy, it is important to know if solar energy systems for commercial buildings are cost effective under existing market conditions, and, if not, under what conditions they might be cost effective.

\subsection{PURPOSE AND SCOPE}

This report is intended to broaden understanding of the economics of solar energy for commercial buildings. The evaluation model that is developed provides a tool for addressing many economic questions facing investors and policy makers. The compilation of data, discussion of assumptions, and applications of the model in case studies serve as guides for others who wish to make similar studies. The results and conclusions of the case studies provide indications of the current status and future potential of solar economic feasibility for an important share of the commercial building market--office buildings and retail stores of a design representative of much of the existing building stock.

\subsection{APPROACH}

A comprehensive economic optimization model employing a life-cycle costing approach is developed as the tool of analysis. This model allows the determination of the least-cost combination of solar energy and nonrenewable energy necessary to meet a commercial building's energy requirements, the economic performance of the optimally sized solar energy system, the minimum conditions for system cost effectiveness, and the sensitivity of the results to values of key parameters.l

1 At the time this study was undertaken, there were no other comprehensive economic optimization models available for the analysis of commercially applied solar energy systems, and no detailed assessment and comparison of the economic analysis models contained in the larger computer simulation programs had been made. Now a number of the computer programs for analyzing the thermal performance of entire building energy systems or of solar energy systems alone contain relatively comprehensive subroutines for carrying out an economic analysis. These include SOLCOST, F-Chart, BLAST, and DOE-2. However, a recent evaluation of the economic models of these programs showed that none of them provided all of the features desired for performing this study. (See Ref. 54, p. 69 for a list of the economic evaluation features not provided by these other models.) 
Case studies of economic feasibility are performed by applying the model to four types of solar-equipped commercial buildings-a new and an existing office building and a new and an existing retail store--representative of a large share of the commercial building inventory. Thirteen city locations accounting for major variations in U.S. solar radiation and temperature characteristics are selected as the basis for the regional case studies. The envelopes and mechanical systems of these hypothetical, representative buildings are characterized in detail, and a comprehensive building energy load analysis program is used to estimate their energy requirements in each of the 13 different cities. Solar energy systems are characterized for the four types of buildings and their cost functions are estimated. The solar load ratio performance model is used to estimate the thermal contribution of the solar energy systems.

Data and assumptions needed to use the model are compiled for the selected buildings, systems, and locations; and factors to consider in setting parametric values are discussed. Regional variations in the costs of energy and solar energy equipment, tax rates, and incentives are taken into account.

Economic feasibility results are given for the case studies based on alternative conditions. Comparisons are made among various locations, buildings, and sys tems.

\subsection{ORGANIZATION}

The report is organized into five sections and two appendices. Section 2 contains the economic modeling. Section 3 describes the buildings, building systems, geographical locations, and environmental data selected for the case studies. Section 4 specifies the data and assumptions used in the case studies. It describes the thermal analyses of the buildings and the performance model for evaluating the solar energy systems. It defines the cost-estimating functions developed for the case studies, provides tables of data for present and projected future energy prices, and describes the determination of a discount rate, borrowing rate, inflation rate, investment life, nonfuel cperating and maintenance cost, and salvage value for use in applying the economic model in the case studies. The applicable tax rates and governmental incentives are also provided.

Section 5 describes the case study results. First, the results are given for base-case data and assumptions. An analysis is provided of the different factors contributing to cost-effectiveness results and comparisons are made for the different building types, different conventional fuel alternatives, and different regions. The scope of the analysis is then extended by relaxing the base-case conditions and testing the outcomes to other conditions. The impact on economic feasibility of revised energy price projections, more favorable depreciation rules, increased incentives, improvements in financing terms, and changes in the inflation rate are assessed.

Appendix A describes a mathematical programming approach to solar optimization. Appendix B lists and describes the computer program used to apply the economic evaluation model in the case studies. 


\section{ECONOMIC MODELING}

First, for perspective, the major requirements for a comprehensive economic feasibility model are discussed. Then, the basic framework of the model is depicted graphically and explained. This is followed by the algebraic formulations. Special features and variations of the basic model are then presented. Preliminary modeling to include trade-offs between solar energy and energy conservation is shown. Potential limitations of the model are discussed. In appendix A, the approach and results of an exploratory effort to develop mathematical programming and stochastic models as alternative tools for solar economic optimization are described.

\subsection{MODEL REQUIREMENTS}

A model with trade-off capability is needed to identify and evaluate the economically efficient solar energy system. The model should account for the significant factors affecting the economic performance of each alternative considered. It should account for the significant components of both shortterm and long-term costs and savings, and should treat taxes and other factors of concern to commercial building owners. In this study, this requirement is met by using a comprehensive life-cycle costing model which incorporates the major parameters affecting the cost effectiveness of commercial building investments.

Modeling capability is needed to evaluate different types of solar energy systems as compared with different types of nonsolar energy systems. In this study, this requirement is met by incorporating into the model the necessary technical performance models and data, the appropriate environmental data, and the cost models and price data for each type of system to be considered.

As a tool of policy analysis, the model should facilitate the impact assessment of alternative policies and events on solar economic feasibility. This study provides this feature on a microeconomic level by incorporating into the model the capability for sensitivity analysis and break-even analysis. It does not include a market penetration component to estimate aggregate commercial use of solar energy under different scenarios.

\subsection{BASIC FRAMEWORK ${ }^{2}$}

The economic evaluation model calculates the net life-cycle dollar savings or losses attributable to solar energy and determines the combination of solar

1 A list of the symbols used in section 2 is provided at the end of section 2 .

2 The description of the model presumes familiarity of the reader with the fundamentals of benefit-cost and life-cycle cost analysis. For a general reference to these techniques, see a benefit-cost or engineering economics textbook [21, 22]. For a simplified guide to these techniques applied to solar energy and energy conservation decisions, see [23]. For a more detailed treatment of the same topic, see $[24,25]$. 
energy and conventional energy that will maximize net savings or minimize net losses from solar. The model does this by finding the difference (TLCS) between the Iife-cycle costs of a nonsolar energy system used alone (TLCC $100 \% c$, where subscript $c$ denotes the nonsolar energy system) and a combined solar/auxiliary energy system $\left(\mathrm{TLCC}_{\mathrm{c}, \mathrm{s}}\right.$, where subscripts $\mathrm{c}$, s denote the combined solar/nonsolarauxiliary energy system). That is,

$$
\mathrm{TLCS}=\mathrm{TLCC}_{100 \% \mathrm{C}}-\mathrm{TLCC}_{\mathrm{C}, \mathrm{s}}
$$

where

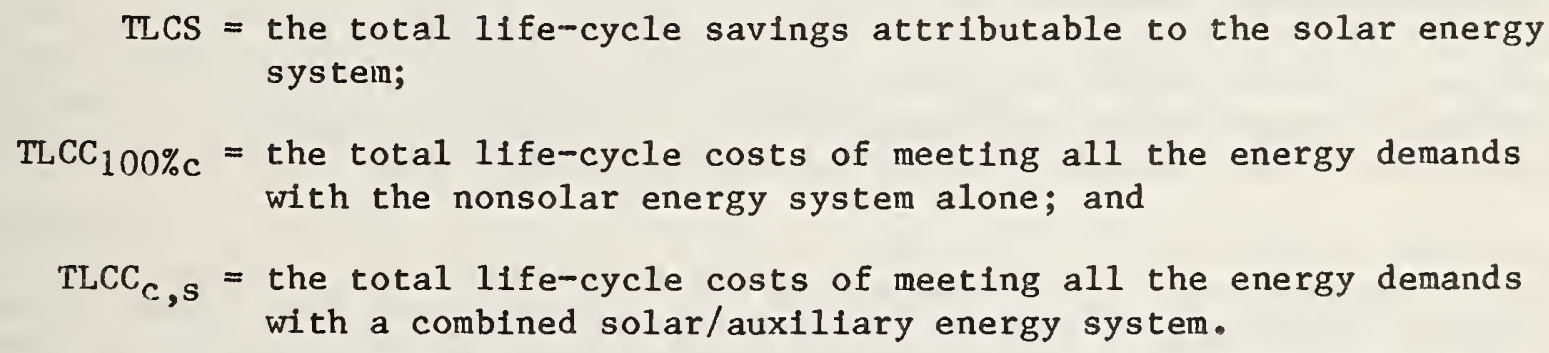

The model is developed for the case that the nonsolar energy system is a conventional type system such as a gas or oll furnace, electric resistance system or heat pump. To use the model to evaluate solar energy relative to, or in combination with, other renewable energy systens that are, like solar, eligible for special tax credits and other incentives, requires modification of the model to add those special incentives to the calculation of $\mathrm{TLCC}_{100 \% \mathrm{c}}$.

By applying the model iteratively to successively larger sizes of the solar energy system being considered, the trade-offs between solar and auxiliary energy costs can be determined. This enables the identification of the economically optimal size of the solar energy system.

The life-cycle costs each of the solar energy system, the auxiliary energy system, and the nonsolar energy system used alone consist of system acquisition costs, operating and maintenance costs, repair and replacement costs, salvage or resale values, financing costs, taking into account the time value of money. Additionally, the auxiliary energy system and the nonsolar energy system entail fuel costs. If the auxiliary and the nonsolar energy systems are assumed identical in that only fuel costs differ between them, like costs will cancel out of equation $l$ and can be omitted from the evaluation. The costs are adjusted for the financial effects of taxes and government incentives at the local, state, and Federal levels.

Simplifications employed in the model include the following: (1) The size of the solar energy collector array is assumed to be the key varlable in the optimization procedure. (2) The type, capacity, and nonenergy costs of the auxillary energy system are assumed to be constant regardless of the size of the solar energy system. (3) Energy loads of the bullding are inputs to the model (1.e., trade-offs between energy conservation and energy supply are not internal to the model). (4) Average meteorological data are used to predict the economic performance of the solar energy system (i.e., the stochastic nature 
of meteorological data is not taken into account). (5) The time of the initial solar investment is given (i.e., the dynamics of optimal investment timing are not incorporated into the model). Each of these assumptions is discussed briefly below.

The design of a solar energy system involves a large number of variables, such as storage type and volume, heat exchanger size, collector type, number of glazings and surface type, collector tilt, and collector size. Using an iterative computer search procedure, such as that used in the case studies, to optimize solar economic performance across all design variables would require massive computations. To reduce computational requirements, a convention widely used in solar optimization studies is to optimize with respect to a single design parameter, collector size. Using this approach, the variable costs of storage volume and other system components are assumed to change in direct proportion to the change in collector costs as the collector array is increased.

Previous studies have investigated at least six design parameters to determine their effects on optimal system design and life-cycle costs. Lö and Tybout, in their 1970 and 1973 articles, "Solar House Heating" [26] and "Cost of House Heating with Solar Energy" [13], discussed the effects of the following parameters on system performance and cost: heat transfer coefficient of insulation on the storage tank, heat capacity of the collector, angle of the collector tilt, number of glass plates, heat storage, and collector area.

Löf and Tybout varied these six parameters to determine the least-cost combination for providing solar heating in each of eight cities in different climate regions. Each paraneter was varied while the others were kept constant at levels thought at the time to be near their optimal economic values. Löf and Tybout found the cost of delivering energy to be more sensitive to collector area than to other variables. Also, they verified that storage tank insulation and collector heat capacity have little impact on system performance and costs, and that collector tilt relative to latitude has only a small effect over a wide range of tilt angles and a wide range of latitudes. A constant relationship of latitude plus $10^{\circ}$ to $20^{\circ}$ was shown to be an appropriate tilt assumption in estimating solar performance. In addition, they described the trade-off between optical and thermal losses with double-glazed versus singleglazed collectors, showing that atmospheric conditions appear to justify increased optical loss to reduce thermal loss.

In their examination of the relationship between thermal storage capacity and cost, Lö and Tybout found only a moderate dependency over a wide range of storage sizes. However, they found that varying storage size above and below the optimal size has a greater effect on cost than varying the tilt angle. Their test results showed the optimal range for water storage to be 49-73 $\mathrm{kg} / \mathrm{m}^{2}\left(10-15 \mathrm{lbs} / \mathrm{ft}^{2}\right)$ of collector in the three cities tested.

This work by Löf and Tybout has been an important source of evidence for modeling solar economic performance as a single variable optimization problem. Since Lof and Tybout found that collector area has a greater effect on the cost of providing heat than other variables, collector area has commonly been the only design variable subjected to the optimization routine in determining 
minimum cost design. A linear relationship between storage and collector area in solving solar system design problems has usually been assumed. For systems using water as the storage medium, values in the range of $49-73 \mathrm{~kg} / \mathrm{m}^{2}(10-15$ lbs/ft ${ }^{2}$ of collector area have typically been used in sizing storage and in estimating the costs and performance of the systems.

The results obtained by Klein, Beckman, and Duffie [27] from simulations for several storage capacities in Madison generally agreed with those of Lö and Tybout. They used a storage capacity of approximately $73 \mathrm{~kg} / \mathrm{m}^{2}$ (15 $1 \mathrm{~b} / \mathrm{ft}^{2}$ ) to design solar systems and to predict solar performance. There is, however, also some evidence that the relationships among storage volume, collector area, and costs have not been adequately explored and that more attention to storage volume/collector area trade-offs may be warranted under certain conditions. This issue is discussed in appendix A, and mathematical programming is explored as a tool for optinizing system design with respect to both collector area and storage volume.

A second simplification to the model is the assumption that the costs of equipment, repair, and maintenance for the auxiliary system are constant regardless of the use of solar energy in combination with it. The assumption of constant equipment costs for the auxiliary system is consistent with the currently prevailing practice of providing a full capacity conventional backup systern capable of meeting the entire energy load, in order to compensate for the stochastic nature of solar energy. If the solar/auxiliary system is then compared with a nonsolar energy system identical to the auxiliary system, the nonenergy cost elements of both systems cancel out of the model. This simplification is used in the case studies presented in section 5. However, it cannot be used if the purpose is to compare plant capacity trade-offs, in addition to energy cost trade-offs.

A third simplifying assumption is that the energy loads of the buildings are constant, based on an existing or planned level of energy conservation. That is, the model lacks the capability of analyzing in an integrated context the potential trade-offs between supplying energy (via either solar or auxiliary means) and reducing the energy requirements through investments in energy conservation.

This limitation is to some extent compensated for in the case studies by (1) examining the selected buildings for two levels of energy conservation as represented by the new (energy conserving) and the existing (less conserving) versions of the buildings, and (2) assuming a night-time temperature setback and a reduction in fan operation at night for all buildings examined. 1

1 While the versions of the model and computer programs used for the case studies do not provide for energy supply/energy conservation trade-offs, a theoretical framework for making these trade offs was developed in conjunction with this study and is described in section 2.6. Further work in this area is underway. 
A fourth simplifying assumption is that stochastic variations in weather data can be ignored in evaluating solar economic performance. The significance of this simplification -- which produces deterministic rather than probabilistic estimates of solar performance -- depends chiefly on the sensitivity of the bullding owner to failure of the solar energy system to meet consistently a given percentage of his or her energy needs and costs. For example, in some circumstances, a building owner's objective may be a solar energy system sized to meet a minimum fraction of the load with a given level of confidence, rather than a system sized to minimize building life-cycle costs. (Stochastic modeling of solar energy is discussed in appendix $A_{0}$ ) On the other hand, the nonstochastic model used here has the advantages of less extensive data and computational requirements.

A fifth simplifying assumption, that of a static time frame, also offers the advantage of greater computational ease. Its disadvantage is the failure to consider the economic consequence of alternative starting times for the solar investment. For example, a solar project may show a negative cash flow over part of the life cycle, and a positive cash flow over the remainder, in which case, it might be economically efficient to defer the project even if net life-cycle savings are currently positive.

It would be economically efficient to defer the project to avoid the initial losses, unless project deferral would raise initial investment costs sufficiently to increase the initial losses rather than diminish them. (This might occur, for example, if the choices were between investing earlier and including solar in a new bullding at a relatively low installation cost versus waiting and having the project be a retrofit application to the existing building at a relatively high installation cost.)

The trade-off between solar energy system costs and auxiliary energy costs is depicted graphically in figure 2.1, where collector area (A) is measured along the horizontal axis, and life-cycle ( $\$$ ) costs are measured along the vertical axis. The curve labeled LCC $_{S}$ illustrates the costs of purchasing, installing, maintaining, and operating the solar energy system. The $\mathrm{LCC}_{S}$ curve is assumed to increase linearly with collector area; that is, each additional unit of collector is assumed to cause a uniform increase in system cost. The $\mathrm{LCC}_{\mathrm{s}}$ curve intersects the cost axis above the origin, reflecting the assumption of "fixed costs" $\left(F_{X}\right)$, i.e., costs of components of the solar energy system that are minimum prerequisites for the functioning of even the smallest collector area.

The curve labeled $\mathrm{LCC}_{\mathrm{c}}$ depicts the costs of the auxiliary energy system. Its shape reflects the assumption that the amount of reduction in conventional energy costs associated with a given incremental change in the size of the solar collector declines in size as the percentage of the load met by solar increases. This would be particularly descriptive of solar space heating systems or cooling systems which are subject to changing seasonal demands, and, hence, exhibit significant excess capacity during parts of the year if they are sized to meet a large part of the yearly load. The $\mathrm{LCC}_{\mathrm{C}}$ curve is shown to "bottom out" -- not declining to zero - because of the assumption that equipment and maintenance costs of the auxiliary system renain constant over all sizes of the solar energy system. 
Figure 2.1 LCC Trade off between Solar Energy and Auxiliary Energy

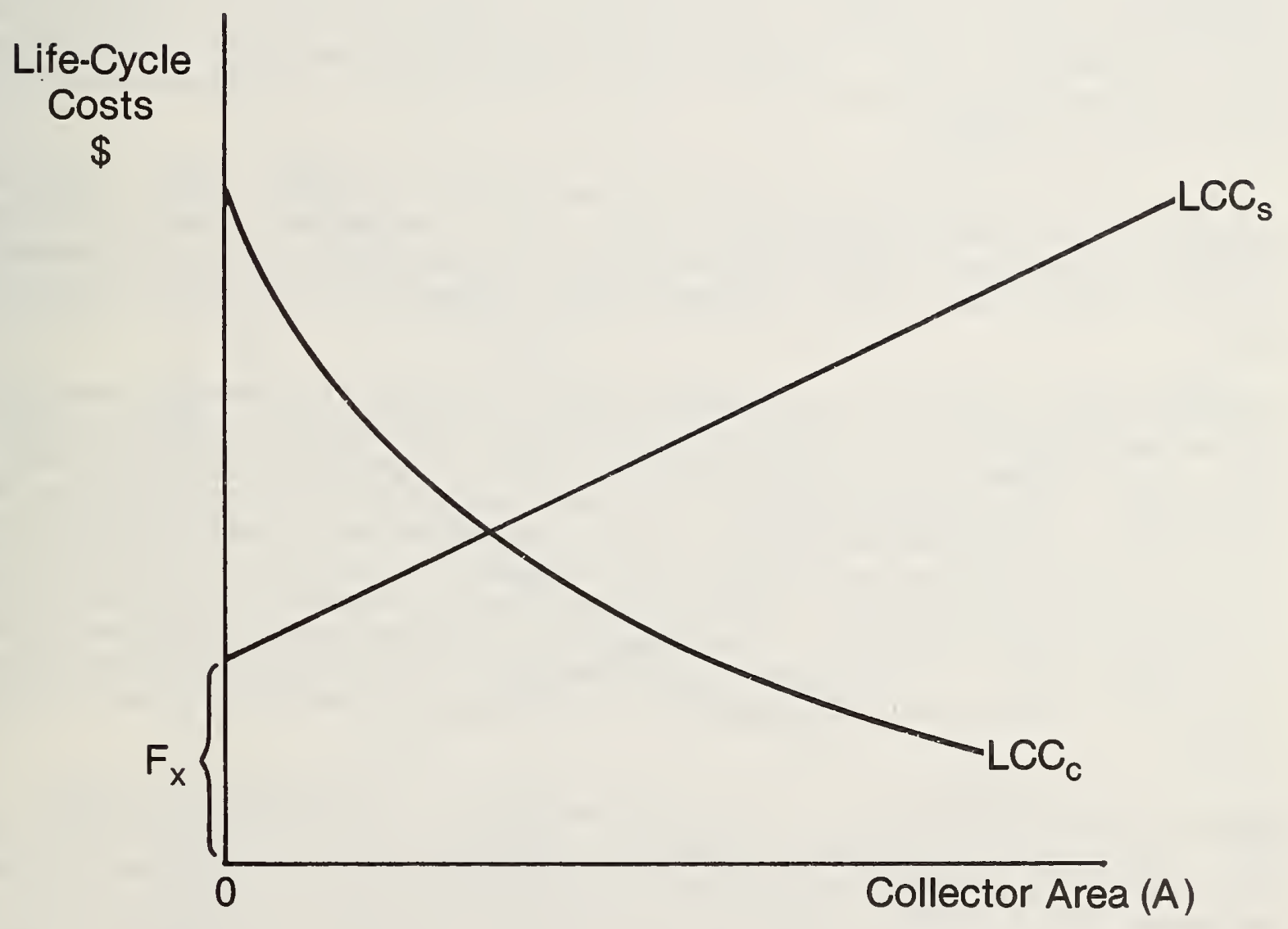


The net cost impact of increasing solar collector area depends on the relative slopes of the two curves. If, for a given increase in collector area, auxiliary energy costs fall faster than solar energy costs rise, total life-cycle costs for the combined solar/auxiliary system will fall. As long as this relationship holds, total life-cycle costs of the combined energy system can be reduced by expanding the size of the solar energy system. But if, as collector area is increased, solar costs rise faster than auxiliary energy costs fall, total life-cycle costs will rise.

This effect can be seen by summing the two curves vertically as is shown in figures 2.2 and 2.3. In figure 2.2, TLCC $C, s$ is a U-shaped curve. It decreases initially, reaches a minimum value at $A^{*}$, and thereafter increases. Beyond $A^{*}$, solar energy costs rise faster than auxiliary energy costs fall, causing total life-cycle costs to rise. At point $A^{*}$ the decrease in auxiliary energy costs just balances the increase in solar energy costs associated with an additional unit of collector area.

In figure 2.3, $\mathrm{TLCC}_{\mathrm{C}}, \mathrm{s}$ is an increasing function of collector area. This curve describes the situation where solar energy costs continuously rise faster than auxiliary energy costs fall as the size of the solar energy system is expanded. The size of the solar energy system for which life-cycle costs are minimized is zero.

The cost effectiveness of the combined system relative to a nonsolar energy system used alone can be depicted graphically by comparing the TLCC $_{c, s}$ curve with a curve showing the total life-cycle costs of a nonsolar energy system $\left(\operatorname{TLCC}_{100 \% c}\right)$. Given the assumption that the nonsolar system used alone is the same as the solar auxiliary system, and that the equipment and nonenergy costs of the auxiliary system are constant with respect to the size of the solar component, the life-cycle cost of the nonsolar energy system can be illustrated by a horizontal line, $\mathrm{TLCC}_{100 \% \mathrm{c}}$, intersecting the vertical axis at the same point as the $\mathrm{LCC}_{c}$ curve. A life-cycle net savings (or net losses) curve for solar, TICS, can be derived by taking the difference between the $\mathrm{TLCC}_{\mathrm{c}, \mathrm{s}}$ and $\mathrm{TLCC}_{100 \% \mathrm{c}}$ curves.

Figure 2.4 illustrates one of the possible shapes the TLCS curve may take. TLCS, the difference between TLCC $100 \% c$ and $\mathrm{TLCC}_{\mathrm{c}, \mathrm{s}}$, first increases from a negative value to a positive value, reaches a positive maximum at $A^{*}$, and thereafter decreases, again becoming negative. In the illustration, the combined solar/ auxiliary energy system is shown conceptually to be cost effective relative to the nonsolar energy system over a range of solar energy system sizes. Moreover, it is shown that the size of the solar energy system represented by $A^{*}$ of collector area is economically desirable in that it maximizes TLCS. Any other syster size will provide less than maximum savings over the designated life. Because it maximizes TLCS, $A^{*}$ is referred to as the "economically optimal size". Note that the TLCS curve reaches its maximum value at $A^{*}$ coincident with the minimum value of $\mathrm{TLCC}_{\mathrm{C}, \mathrm{s}}$. That is, maximizing TLCS is equivalent to minimizing $\operatorname{TLCC}_{\mathrm{C}, \mathrm{s}} \cdot$

In figure 2.5, TLCC $c$, s attains the same generic shape as illustrated in figure 2.4, but unlike figure 2.4, it always remains above the $\operatorname{TLCC}_{100 \% c}$ curve. This 
Figure 2.2 Determining the Cost-Minimizing Size of the Combined Solar/ Auxiliary Energy System: U-shaped $\mathrm{TLCC}_{\mathrm{C}, \mathrm{s}}$ Curve

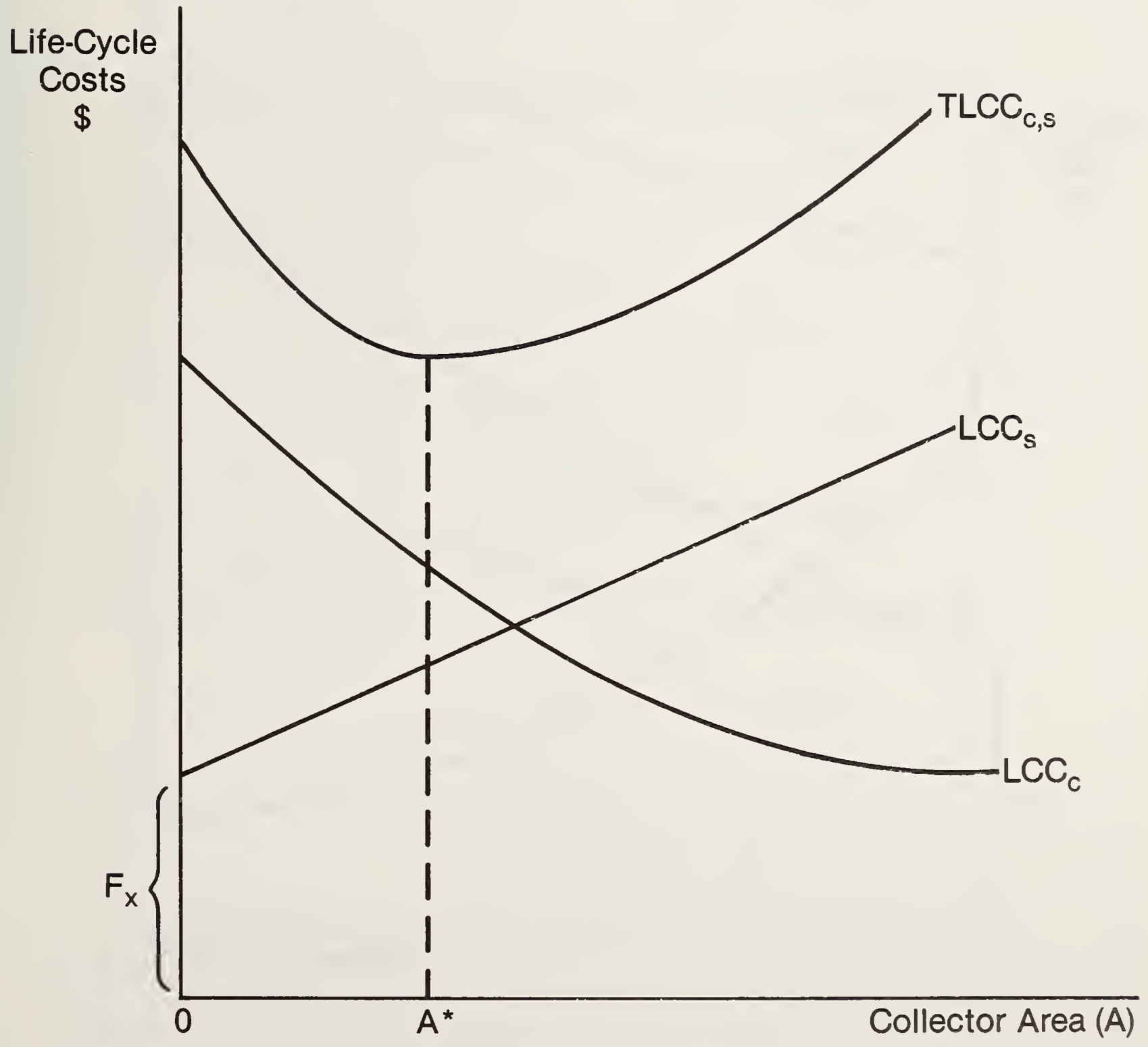


Figure 2.3 Determining the Cost-Minimizing Size of the Combined Solar/ Auxiliary Energy System: Monotonically Rising Curve

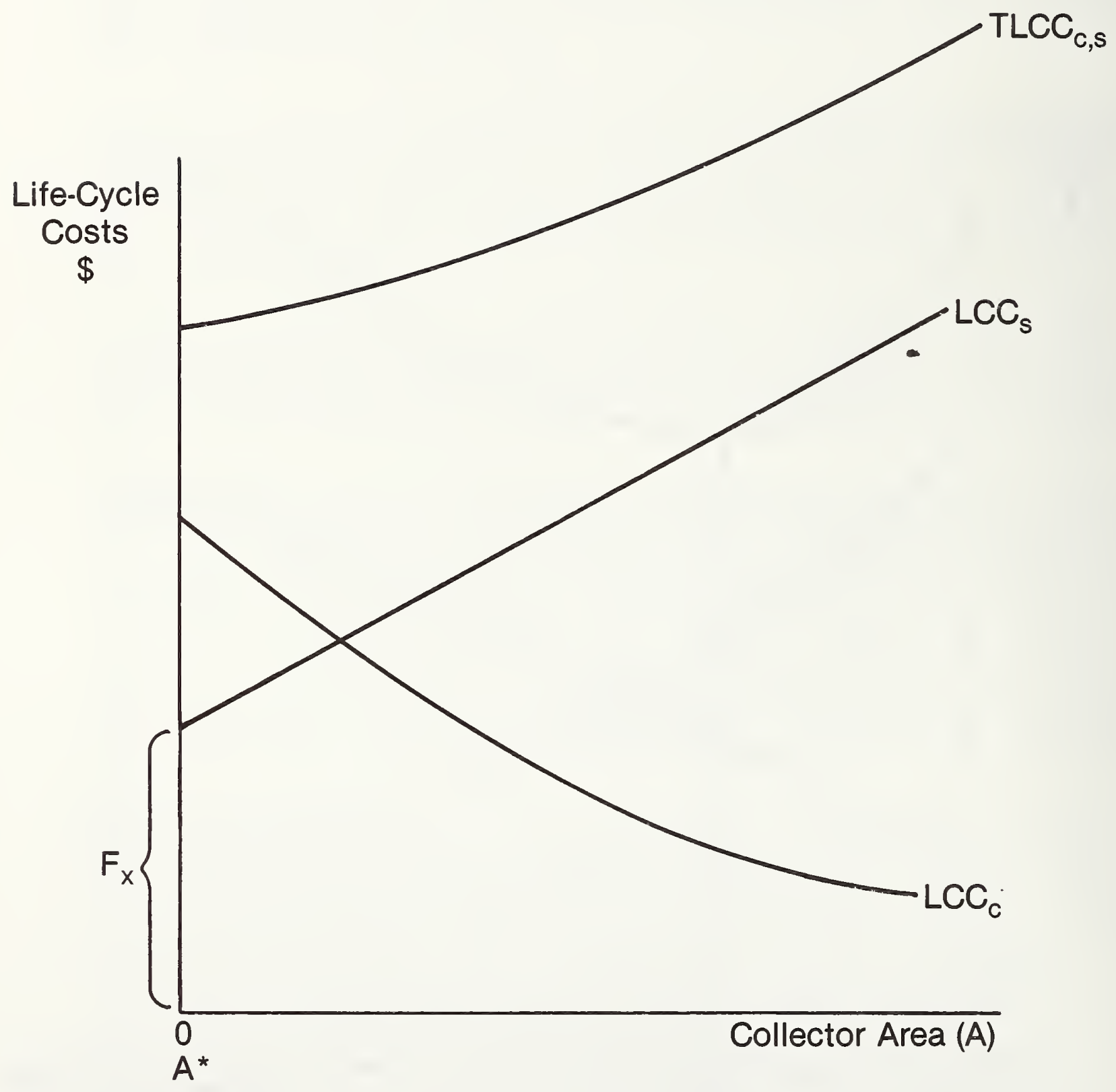


Figure 2.4 Determining the Cost-Effective Solar Investment

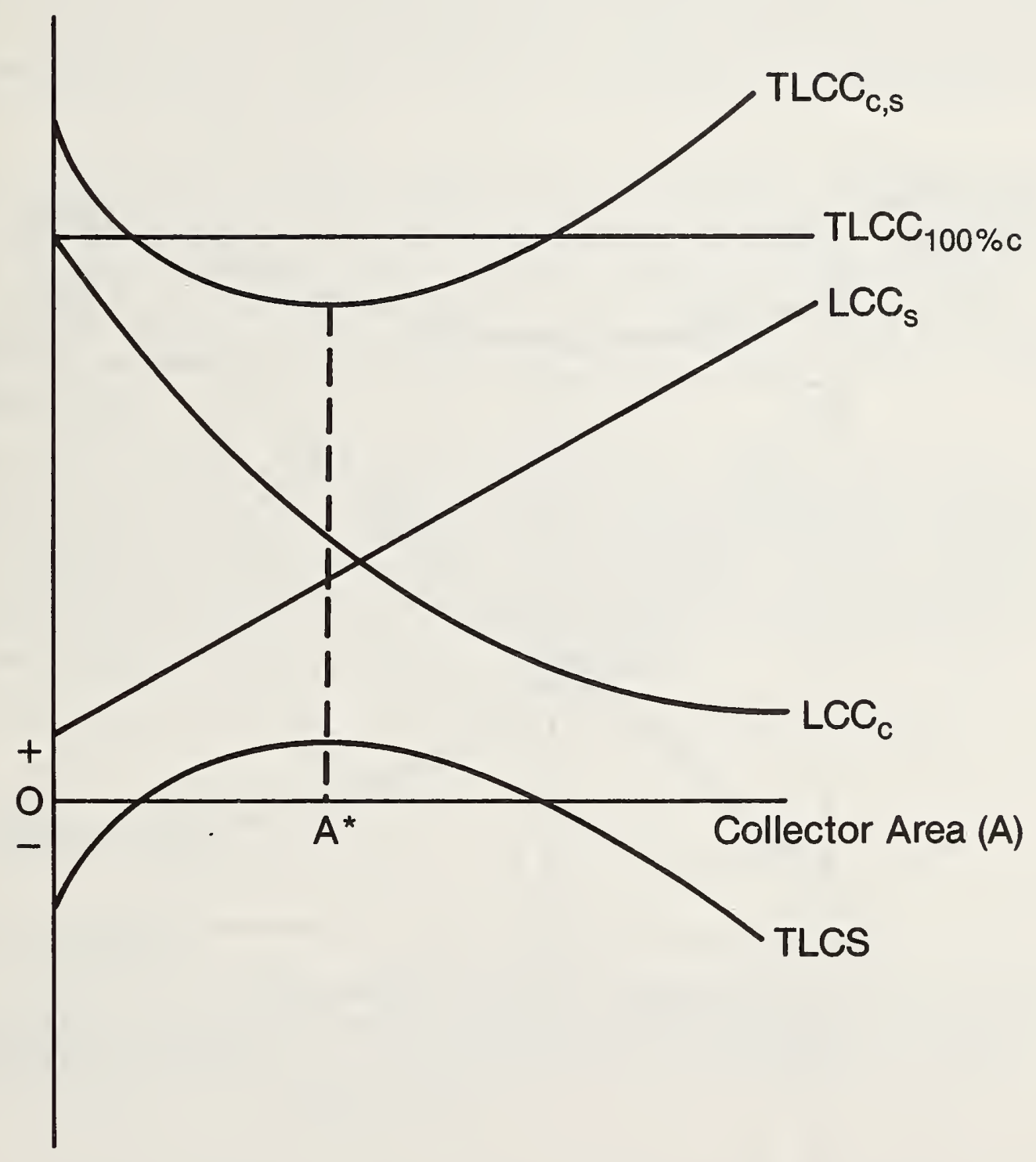


Figure 2.5 Minimizing Losses from a Solar Investment

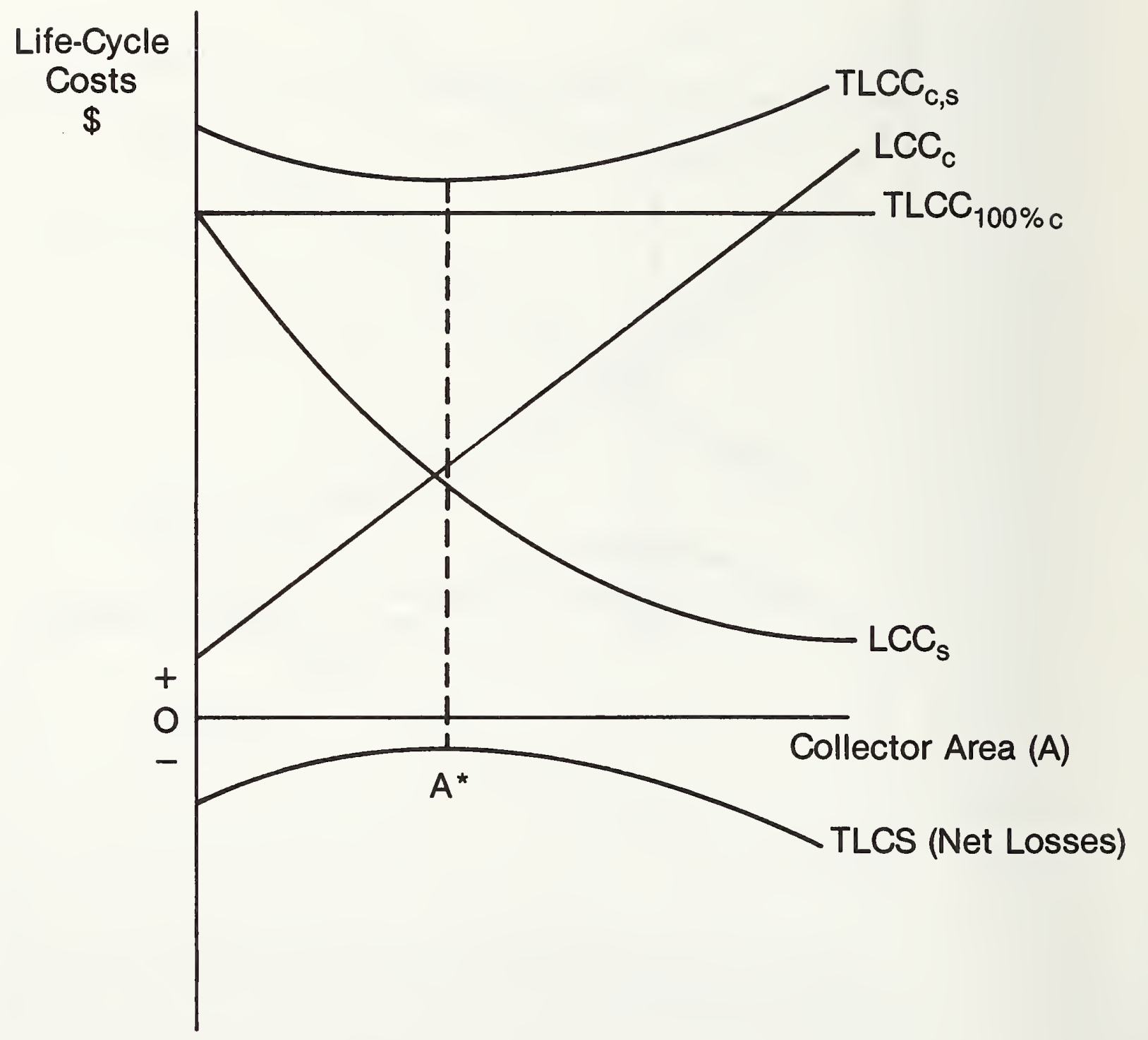


illustrates the case in which TLCS is negative for all system sizes, and the investment in solar energy does not pay based on the costs included in the mode1. (There may be important, but difficult-to-quantify effects omitted from the $11 \mathrm{fe}$-cycle cost model, whose consideration would affect the investment decision.) If, in the case depicted, a solar energy system were to be installed despite its apparent lack of cost effectiveness, the collector area designated $A^{*}$ is economically optimal in the sense that it minimizes the quantifled losses associated with having the system.

In figure 2.6, which corresponds to figure 2.3, the $\operatorname{TLCC}_{C, s}$ curve is continuously increasing and always remains above the TLCC $100 \% c$ curve. As a result, TLCS is again negative for all system sizes, and becomes increasingly negative as the system becomes larger. In this case, solar energy is uneconomical based on the costs included in the model, and, furthermore, it is not possible to minimize losses with a solar energy systen size larger than zero.1

\subsection{ALGEBRAIC MODEL}

Using present value analysis, and taking into account capital, maintenance and operating costs of the solar energy system, State and Federal income tax deductions for business expenses related to the solar and auxiliary energy systems, tax credits and other incentives for utilization of solar energy in commercial bulldings, property and sales taxes attributable to ownership of the solar energy system, salvage value and energy costs of the auxiliary energy system, equation $l$ may be restated as follows:

$$
\text { TLCS }=E-[I n-V-S-T C-D-W+G+P+M+R+(l-F) \cdot E]
$$

equivalently, or,

$$
\mathrm{TLCS}=[\mathrm{E} \cdot \mathrm{F}]-[\mathrm{In}-\mathrm{V}-\mathrm{S}-\mathrm{TC}-\mathrm{D}-\mathrm{W}+\mathrm{G}+\mathrm{P}+\mathrm{M}+\mathrm{R}],
$$

where

$E=$ present dollar value, after income taxes, of energy costs for the nonsolar energy system to be used in lieu of the combined solar/auxiliary energy system (since the nonsolar energy system is assumed identical to the auxiliary system, $E=\operatorname{TLCC}_{100 \% c}$, and

1 In FEDSOL, a computer code developed by the National Bureau of Standards for the National Bureau of Standards economic optimization analysis of solar energy systems for Federal buildings, a minimum size constraint can be imposed on system size to prevent a solar optimization solution of zero. The Department of Energy's "Solar in Federal Buildings" program, for which the computer code was prepared, does not require system cost effectiveness, but does require that system economics be considered [28].

2 If more than one type of fuel is affected by the user of solar, equation 2 or 3 can be expanded to repeat the energy cost calculation for each fuel type and the results summed. 
Figure 2.6 An Uneconomical Solution for Solar

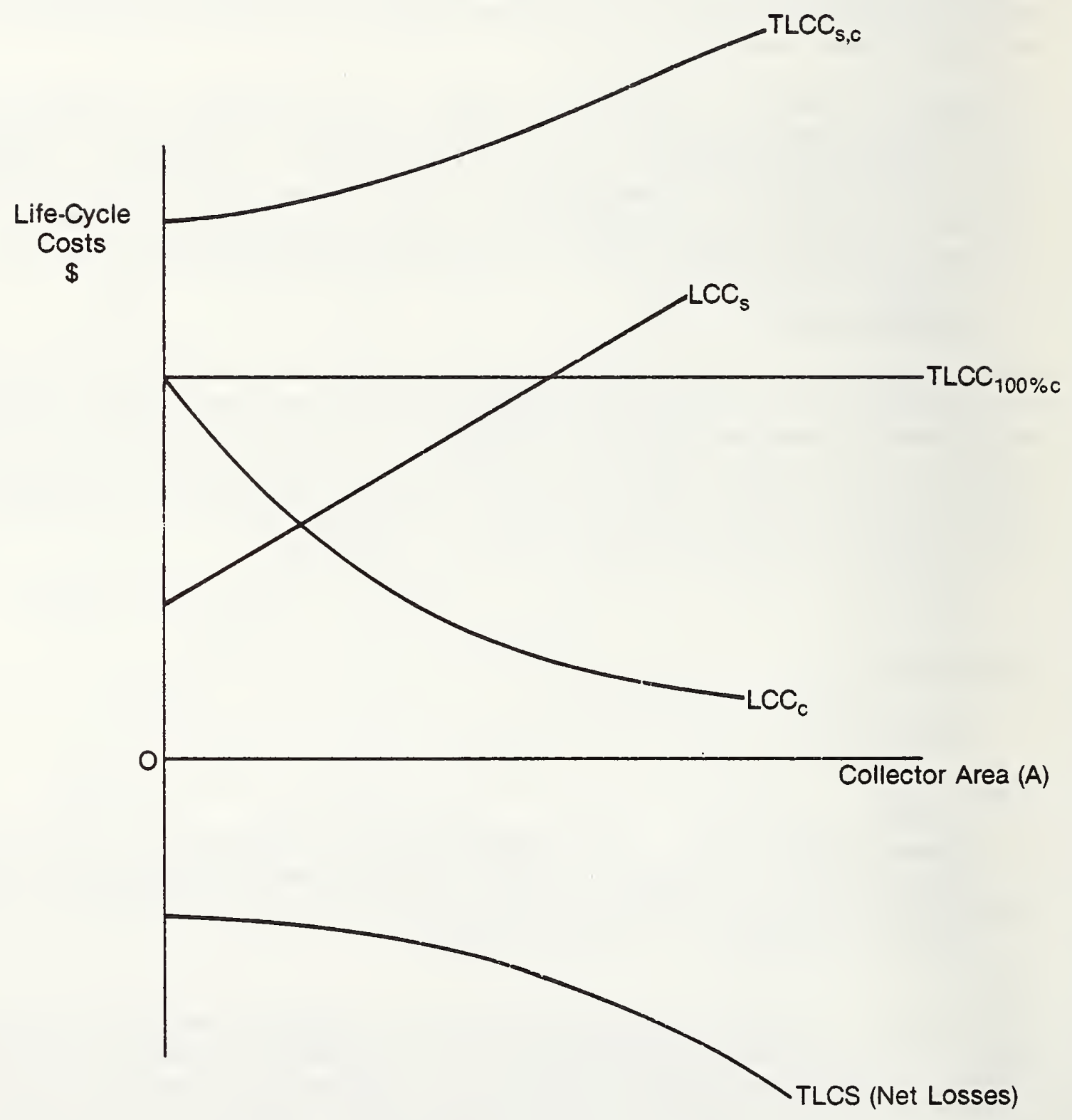


$E=P_{c} \cdot U P W_{d, n_{j}, e_{j}}^{*} \cdot Q \cdot(1-t)$,

$\mathrm{P}_{\mathrm{C}}=$ the present price (including sales tax) per unit of fuel, stated in terms of the same physical unit of measure as 0 .

$\mathrm{UPW}_{\mathrm{d}, \mathrm{n}_{j}, \mathrm{e}_{j}}^{*}=$ a uniform present worth factor based on a selected nominal discount rate, $d$, for $n$ years (the length of of the study period), and modified to include $j=1$ to $k$ projected rates of energy price escalation, occurring in consecutive time intervals, where $n_{j}$ represents the number of years contained contained in the interval over which the $j$ th escalation rate occurs. For a constant rate of price escalation $\left(e_{1}\right)$ over $n_{1}$ years,

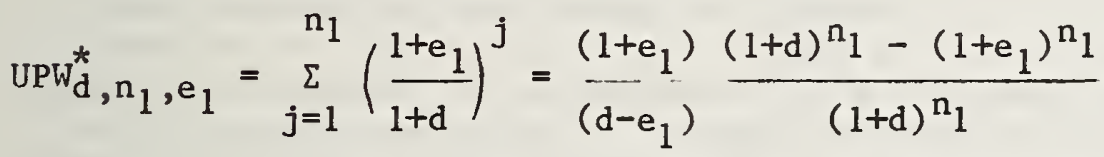

For changing rates of price escalation $\left(e_{1}, e_{2}\right.$, and $e_{3}$ ) over three intervals $\left(\mathrm{n}_{1}, \mathrm{n}_{2}\right.$, and $\left.\mathrm{n}_{3}\right)$,

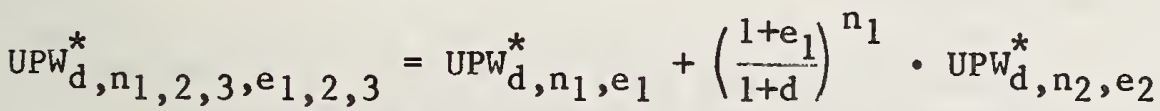

$$
+\left(\frac{1+e_{1}}{1+d}\right)^{n_{1}} \cdot\left(\frac{1+e_{2}}{1+d}\right)^{n_{2}} \cdot u^{\prime} w_{d, n_{3}, e_{3}}^{*}
$$

where each $U P W_{d, n_{j}}^{*}, e_{j}$ is calculated according to the equation for the above constant rate case, $\mathrm{UPW}_{\mathrm{d}, \mathrm{n}, \mathrm{e}^{*}}^{*}$

(The model allows for three rates of three periods of price projections provided by DoE's Energy Information Administration, the source of the energy price data used to apply the model. If desired, the discount rate could also be allowed to vary.)

$Q=$ total annual quantity of nonsolar energy purchased, taking into account the relevant energy load(s) (L) of the building and the efficiency of the nonsolar energy equipment $(\gamma)$, i.e., $Q=L / \gamma$.

(If quantity is to be expressed in sales units of energy such as liters (gallons) of oil, it is, of course, also necessary to take into account the energy content $(u)$ per sales unit of energy, $i . e ., Q=L / \gamma \cdot u$.

$t=$ the bullding owner's composite Federal, state and local marginal income tax rate.

$\mathrm{F}=$ the annual fraction of the building's energy requirements met by the solar energy system, as estimated or predicted by a solar performance model. 
Using the solar load ratio method, the relationship between collector area (A) and the annual solar fraction (F) in a given climate and for a given building load is predicted by the following equations:

$$
F=(a \cdot A / L) \sum_{j=1}^{12} I_{j} \text { for } 0 \leq A \cdot I_{j} \cdot L_{j} \leq Z_{l}
$$

and

$$
F=1-b / L \sum_{j=1}^{12} I_{j} \exp \left(-c \cdot A \cdot I_{j} / L_{j}\right) \text { for } Z_{1} \leq A \cdot I_{j} / L_{j} \leq Z_{2} \text {, }
$$

where $A=$ solar collector area; $I_{j}=$ solar radiation incident on a tilted collector surface in month $\mathrm{j} ; \mathrm{L}_{j}=$ domestic hot water load or combined space heating and domestic hot water load in month $j ; a, b$, and $c$ are parameters which depend on the type of collector and the hot water or heating coil design temperature; and exp is notation for the constant e, (equal approximately to 2.718). $Z_{1}$ and $Z_{2}$ are the endpoints of the intervals within which the approximations of equations 7 and 8 are correct; their values differ according to whether the system is for domestic hot water only or combined space heating and domestic hot water. (Note: the value of $F$ is assumed in the model to remain constant over the $11 \mathrm{fe}$ of the system.)

(The economic model can be modified to operate with other solar performance models. Alternatively, the economic model can be separated from the solar performance model and modifled to recelve precalculated solar performance data as direct input.)

In $=$ the present value of capital investment costs associated with designing, purchasing, and installing a solar energy system, including financing costs, i.e.,

$$
\text { In }=\left(F_{x}+v \cdot A\right)\left(\alpha+(1-\alpha)\left(U C R \frac{1}{12}, 12 m\right)\left(U P W_{d, m}\right)\right) \text {, }
$$

where $F_{X}=$ fixed cost and $v \cdot A=$ variable cost times collector area for labor and materials associated with acquiring the solar energy system, including costs of design, purchase, and installation, $1 . e$. ,

$$
F_{X}+v \cdot A=\left(F_{X L}+v_{L} \cdot A\right)(1+r)\left(1+t_{S L}\right)+\left(F_{X M}+v_{M} \cdot A\right)\left(1+t_{S M}\right)
$$

where $F_{X L}$ and $F_{X M}$ represent the flxed costs assoclated with labor and materlals, respectively; $v_{L}$ and $v_{M}$ represent the variable costs proportional to collector area; $r$ is a reglonal labor cost adjustment factor (a single, national market is assumed to exist for materials); $t_{S L}$ and $t_{S M}$ represent state sales tax rates applicable to labor services and materials; and $\mathrm{A}=$ collector area.

$\alpha=$ fraction of the system contract $\cos t\left(F_{x}+v \cdot A\right)$ placed as an initial down payment. 

UCR $i, 12 m=$ uniform capital recovery factor for calculating monthly $\frac{1}{12}$ payments of principal and interest based on an annual loan rate, $i$, and a loan life of $m$ years. $\begin{aligned} \mathrm{UPW}_{\mathrm{d}, \mathrm{m}}= & \text { uniform present worth factor based on a discount rate, } \mathrm{d} \text {, and a } \\ & \text { loan life of } \mathrm{m} \text { years. }\end{aligned}$

$V=$ the present value of resale, net of disposal costs, remaining at the end of the evaluation period of $n$ years. Expressed as a function of the initial contract cost,

$V=s\left(F_{x}+v \cdot A\right)\left(S P W_{d, n}\right)$,

where $s$ is the nominal resale value as a fraction of the initial contract cost remaining in $n$ years.

$S=$ the present value of the decrease in income taxes due to State sales tax deductions from Federal income tax. (Because this deduction is assumed to accrue close to the time the system is purchased, no discounting is included in the formulation.)

$S=t\left[t_{S L}\left(F_{X L}+v_{L} \cdot A\right)(1+r)+t_{S M}\left(F_{X M}+v_{M} \cdot A\right)\right]$

$\mathrm{TC}=$ present value of Federal and State government tax credits.

$T C=\left(F_{x}+v \cdot A\right)\left[\left(C_{F}\right)\left(S P W_{d, j}\right)+\left(C_{S}\right)\left(U P W_{d, g}\right)\right]$,

where $C_{F}=$ Federal solar tax credit as a percent of system acquisition costs; $S P W_{d, j}=$ single present worth factor for discount rate, $d$, and the year, $j$, in which the credit is taken; $C_{S}=$ effective state solar tax credit, net of Federal income tax adjustments (see. section 4.6 for further explanation of the treatment of State tax credits); and $U \mathrm{PW}_{\mathrm{d}} \mathrm{g}_{\mathrm{g}}=$ the uniform present worth factor for $g$, the number of years over which the State credit is taken.

$D=$ the present value of the decrease in income taxes owed due to capital depreciation deductions from taxable income. Depreciation may be modeled in several different ways. Using the straight-line method,

$D=\left[\left(F_{x}+v \cdot A\right)-S / t\right]\left(1-\frac{s}{(1+z)^{n}}\right) \cdot t \cdot \ell-1 \cdot U P W_{d, \ell}$

where $\ell=$ the depreciation period, $n=$ the length of the study period, and $z=$ the rate of general price inflation.

Using the declining balance method with switchover to straight-line depreclation when the annual straight-line amount exceeds the annual declining balance amount, 
where $\mathrm{y}=$ the depreciation rate (e.g., 1.75) and $\mathrm{d}=$ the discount rate. (At the time the case studies were performed, the maximum accelerated rate on new nonresidential real property was 150 percent. For used nonresidential real property, the straight-line or other IRS approved method giving "a reasonable allowance" could be used. New residential rental property could, under specified conditions, be depreciated using the 200 percent declining balance method, while used residential property was subject to the straightline method or the 125 percent declining balance method if the building's useful life was 20 years or more. Business equipment qualifying as IRS Code Section 1245 property could be depreciated under the 200 percent declining balance method. Componente depreciation of real property could be used to reduce the depreciation period, though not generally to change the depreciation method. The depreciation provisions were changed by the Economic Recovery Tax Act of 1981. A revised version of the computer code now in preparation will incorporate the changes. For a description of past and current depreciation procedures, see $[29,30]$. )

$\mathrm{W}=$ the present value of the decrease in income taxes due to loan interest deductions, $i . e .$, for $d \neq i$,

$$
W=t(1-\alpha)\left(F_{X}+v \cdot A\right)\left[12 U C R \frac{1}{12}, 12 m \cdot U P W_{d}, m+\phi\left(1-\frac{12}{1} U C R \frac{1}{12}, 12 m\right)\right],
$$

where

$$
\phi=\frac{\left(1+\frac{i}{12}\right)^{12}(1+d)^{m}-\left(1+\frac{i}{12}\right)^{12(m+1)}}{(1+d)^{m}\left[(1+d)-\left(1+\frac{1}{12}\right)^{12}\right]},
$$

and

$\mathrm{UCR}_{12}{ }_{1,12 \mathrm{~m}}=\frac{\frac{i}{12}\left(1+\frac{i}{12}\right)^{12 \mathrm{~m}}}{\left(1+\frac{i}{12}\right)^{12 \mathrm{~m}}-1}$

and

$\mathrm{m}=$ the life of the loan, $12 \mathrm{~m}=$ the number of mortgage payments, and $i=$ the annual loan rate.

$G=$ the present value of capital gains taxes due at the end of the study period, i.e.,

$G=s\left(1-\frac{1}{(1+z)^{n}}\right)\left(F_{x}+v \cdot A\right) \cdot t_{c g} \cdot s P w_{d, n}$

where $t_{c g}=$ combined State and Federal capital gains tax, and other terms are as defined above. 
(Capital gains taxes are modeled according to provisions in effect prior to passage of the Economic Recovery Tax Act of 1981; for revised rules regarding capital gains and depreciation recapture tax, see [30].)

$\mathrm{P}=$ the present value, after income taxes of property tax payments attributable to the solar energy system. Expressed as a rate applied to the initial contract cost,

$$
\begin{aligned}
p= & t_{p}(1-t)\left(F_{x}+v \cdot A\right)\left(\frac{n-w}{n}\right)^{f}\left(\frac{1+z}{1+d}\right)^{f}\left[1-\left(\frac{n-w}{1+d}\right)^{n+1-f}\left(\frac{1+z}{1+d}\right)^{n+1-f}\right] . \\
& {\left[\frac{n(1+d)}{1+z-z n+n d}\right], }
\end{aligned}
$$

where $t_{p}=$ the effective property tax rate, $n=$ length of study period, $\omega=$ system deterioration or obsolescence rate, i.e.,

$\omega=n\left[\frac{1-s}{1+z}\right]^{1 / n}$,

where $s=$ nominal resale value as a fraction of initial cost, $z=$ inflation rate), and $f=$ number of years for which property taxes are deferred $(a=1$, if no deferral).

$M=$ the present value, after income taxes, of yearly recurring costs of operating, maintaining and repairing the solar energy system (including any insurance costs net of reimbursables). Expressed as a fraction, $m$, of the initial contract costs,

$M=m\left(F_{x}+v \cdot A\left(U P W_{d, n, z}^{*}\right)(1-t)\right.$,

where UPW $W_{d, n, z}^{*}=$ a modified uniform present worth factor based on a discount ráté, d, n years, and a general price inflation rate, $z$.

(Energy costs (electricity) required for operating the motor-driven parts of the solar energy system are not separately identified from nonfuel operating and maintenance costs of the system. If adequate estimates of electricity operating costs are ayailable, this element of cost can be separately modeled, using the UPW $\mathrm{d}_{, \mathrm{n}_{j}}^{*}, \mathrm{e}_{\mathbf{j}}$ factor to account for
escalation.)

$\mathrm{R}=$ the present value, after income taxes, of all maintenance, repair, and replacement costs that do not recur annually.

$$
R=\sum_{j=1}^{n} \bar{R}_{j}\left(S P W_{d, j, z}\right)(1-t)
$$


where $\bar{R}_{j}$ is the cost of maintenance, repair, and replacement in year $j$; and $\mathrm{SPW}_{\mathrm{d}, j, z}=$ a modified single present worth factor based on discount rate, $d$, year $\mathrm{j}$, and a general price inflation rate, $z$.

2.4 USING THE MODEL TO DETERMINE NET LIFE-CYCLE SAVINGS, OPTIMAL SYSTEM SIZE, BREAK-EVEN VALUES, YEARS TO PAYBACK, AND SENSITIVITY

\subsubsection{Net Life-Cycle Savings and Optimal System Size}

The basic mode1, as represented by equations (2) through (21), calculates the net present value savings of a solar energy project of a given type and size. To determine which size of a given type of system is optimal in the sense of maximizing TLCS (or minimizing net losses if TLCS is negative), the collector area for a given type of system can be incremented over a wide range of values and the corresponding TLCS's calculated. The system size, $A^{*}$, for which TLCS is maximum (-TLCS is minimum) can then be identified. This operation is facilitated by computer search. (The computer code developed to implement the optimization analysis employs dynamic programming search techniques to reduce computing time. See appendix B.)

The TLCS results are estimates of the economic feasibility of the solar energy project built to different scales, stated in terms of present value dollars. The TLCS for system size $A^{*}$ is an estimate of the long-term cost effectiveness of the project to the commercial investor if it is built to the "optimal" scale. A positive value for TLCS means that the solar investment is estimated to earn a return over and above the "opportunity cost of money" as indicated by the value of the discount rate used in the equations. (The concept of opportunity cost and the discount rate are discussed briefly in section 4.5. For additional explanation, see [21-25].) A negative value of TLCS indicates that the solar investment is estimated to be uneconomical in terms of the direct savings to the commercial investor.

By inspecting the entire schedule of TLCS values and collector areas (as represented graphically by the TLCS curve in figures 2.4 through 2.6 ), the economic penalty, in terms of decreased net savings or increased net losses, from installing a system of "nonoptimal" size can be determined. This penalty can be balanced against the possible benefits of a larger- or smaller-thanoptimal system that are not captured by the life-cycle cost model. For example, expanding the solar energy system beyond the optimal size may decrease dependence on conventional fuel supplies and reduce the vulnerability to fuel shortages and the threat of unscheduled shut-down. On the other hand, constraints on collector size such as a limited avallable space for installation or a limited capital budget, may dictate a size smaller than that indicated by the model.

\subsubsection{Break-even Values}

The basic model set forth above is extended in the computer code (appendix B) to provide additional analytical. capability. One extension is to compute the break-even value of key parameters whenever the TLCS for the optimally sized system is negative. The parameters subjected to the break-even analysis are 
(1) solar investment costs (divided into fixed and variable cost components) (2) base-year fuel prices, and (3) future fuel price escalation rates. The break-even analysis identifies the change in the values of these parameters that are necessary to achieve a TLCS of zero, that is, a break-even point for the solar energy investment whereby the optimally sized solar energy system in combination with the auxiliary system will cost the same over the life cycle as the nonsolar energy system.

This is done for each of the above three cost parameters by changing the value of the designated parameter in steps and reoptimizing the collector area at each step until TLCS approaches zero. The break-even value of the parameter and corresponding solar fraction and collector area are thereby obtained.

Two interesting characteristics of the break-even solutions may be noted: Given the TLCS formulation in section 2.3 , the factor by which fixed and variable investment costs must be reduced in order for the investment to break even is the inverse of the factor by which the base-year fuel price must be increased. Secondly, the optimal collector area and the solar fraction will be larger under the break-even cost conditions than under the initial conditions upon which a negative TLCS is obtained.

The break-even analysis serves two purposes: (1) It establishes minimum conditions for an investment in solar to be cost effective, and thereby provides a broader basis for extrapolating study results to other cases and (2) it provides information that may be useful for formulating solar policy.

\subsubsection{Years to Payback}

The basic algebraic model is further extended in the computer code (appendix B) to determine the elapsed time until the investment pays for itself. This payback computation takes into account estimated escalation in energy prices, the opportunity cost of capital through use of the discount rate, and all other parameters included in the basis model. It is a "discounted payback" measure, in contrast to a "simple payback" measure. Payback is, in fact, another application of break-even analysis where time is the parameter evaluated for its minimum value.

The payback measure is provided because it is popular among business investors and provides useful information to those who are particularly concerned about the turnover rate of investment funds. It should be cautioned, however, that the payback measure is an unreliable and incomplete indicator of an investment's economic profitability, and an investment with a longer payback period may be more profitable than an investment with a shorter payback period, depending on comparative net returns after payback is achieved.

\subsubsection{Sensitivity Analysis}

By using alternative values for the key parameters in the model, it is possible to evaluate the sensitivity of the solar investment to variations in those parameters. This process, called "sensitivity analysis," can be used to identify variables of particular economic significance, to test results for the 
consequence of estimating errors due to uncertainty regarding data and assumptions, and to assess the effects of alternative policies and changing conditions. The computer program developed to implement this model (appendix B) provides a sensitivity test of TLCS to solar collector size.

\subsection{SIMPLIFIED MODEL FOR SOLAR HOT WATER ANALYSIS}

\subsubsection{A New Concept}

A simplified version of the basic economic evaluation model described in sections 2.2 to 2.4 was developed to facilitate the solar economic analysis for a range of energy requirements for hot water. The simplified version of the model incorporates all of the elements specified in section 2.3, but reduces the search for the economically optimal size of the solar hot water syster to a single deterministic equation.

This modified solar hot water model, therefore, makes it possible to identify the economically optimal solar energy system size without using the iterative computer search procedure. Moreover, an analysis of the resulting equation indicates that the solar collector area which maximizes total life-cycle savings (TLCS) is a linear function of the annual hot water load, and the economically optimal fraction of the hot water load supplied by solar is constant over a range of loads. This finding suggests that the results of system optimization based on a given hot water load can be extended to a range of loads. This approach is used in the case studies to construct "universal economic optimization paths" which generalize, to some extent, the results to similar buildings with larger and smaller hot water loads. The derivation and use of the paths are explained further below.

\subsubsection{Universal Economic Optimization Paths}

A universal economic optimization path is defined as a locus of points describing the solar collector areas which maximize total life-cycle savings for various levels of commercial hot water loads. Graphically, the path shows the economically optimal collector area as a function of the annual hot water 1oad. Because geographical location affects both the thermal and economic performance of a solar energy system, a different path exists for different geographical locations. In addition, for a given climate region, an entire family of paths can be derived based on different economic assumptions. The results constitute sensitivity analyses. Families of curves can be used to conduct quantitative assessments of the impact of alternative governmental actions on the economic feasibility of solar energy.

Universal economic optimization paths are developed by combining the equation from the solar hot water performance model with the total life-cycle savings equation, optimizing for collector area, and substituting the optimal collector area back into the system performance equation to find the optimal solar fraction. The model is dependent upon the use of annual values of domestic hot water loads and solar radiation, in place of monthly values, in the solar performance equation. This is a suitable approach when monthly thermal loads are equal or show little variation. Water supply temperatures vary over a much 
narrower range than air temperatures. Los Alamos Scientific Laboratory (LASL) has confirmed that annual data can be used for analyzing systems for domestic hot water, without substantial loss of accuracy [40].

Using annual values for hot water loads and solar radiation, TLCS may be expressed as follows:

$$
\operatorname{TLCS}=\overline{\mathrm{X}} \cdot \mathrm{L}(1-\mathrm{b} \exp (-\mathrm{c} \cdot \mathrm{A} \cdot \mathrm{I} / \mathrm{L}))-\left(\mathrm{F}_{\mathrm{X}}+\mathrm{v} \cdot \mathrm{A}\right) \overline{\mathrm{Y}}-\mathrm{R},
$$

where

$$
\begin{aligned}
& \bar{X}={ }_{\gamma} P_{c}(1-t) \cdot U P W_{d, n_{j}, e_{j}}^{*} \\
& \bar{Y}=\left(\frac{I n-V-S s_{1}-T C-D-W+G+M}{F_{X}+v \cdot A}\right)
\end{aligned}
$$

and all terms are as defined in section 2.3, except that, for simplicity, $S$, tax savings due to sales tax deductions, is redefined as $S_{S}$, with the distinction dropped between the sales tax due on labor versus materials; $1 . e ., \mathrm{S}_{\mathrm{S}}=$ $t \cdot t_{s}\left(F_{X}+v \cdot A\right)$, where $t_{s}$ is the State sales tax rate; and $F_{X}+v \cdot A$ is assumed to aggregate labor and materials costs, preadjusted for the regional labor adjustment factor and sales tax.

Note that only the nonlinear range of the solar load ratio function (1.e., A $\geq$ $0.8 \mathrm{~L} / \mathrm{I}$ ) is relevant in the TLCS maximization problem. If solar energy is cost effective, it will not pay to stop the collector area, A, short of the nonlinear range; that is, the maximum point on the TLCS curve will always occur in the nonlinear range or at $\mathrm{A}=0$.

The economically optimal collector area $\left(A^{*}\right)$ can be determined by differentiating equation 22 with respect to $A$ and setting the result equal to zero. The solution for $A^{*}$ can then be expressed as follows:

$$
A^{*}=\frac{L}{c \cdot I} \ln \left(\frac{b \cdot c \cdot I \cdot \bar{X}}{v \cdot \bar{Y}}\right)
$$

The economically optimal annual fraction $\left(F^{*}\right)$ of hot water load met by solar is obtained by substituting $A^{*}$ above into the solar performance model as represented by the following equation:

$$
F=1-b \exp (-c \cdot A \cdot I / L) \text {, }
$$

where $\mathrm{L}$ is the annual hot water load, 1.e., $\mathrm{L}=\sum_{j=1}^{12} \mathrm{~L}_{\mathrm{j}}$; and $\mathrm{I}$ is the annual

incident solar radiation on a tilted surface, $1 . e ., I=\sum_{j=1}^{12} I_{j}$. 
Hence,

$$
F^{*}=1-b \exp \left(-c \cdot A^{*} \cdot I / L\right) \text {. }
$$

By applying the economic concept of elasticity to the formulations for optimal collector area (eq. 25) and optimal solar fraction (eq. 27), one can observe the important relationships anong the optimal values of these variables that enable the optimization results for one load to be generalized to different loads.

The elasticity of $A^{*}$ with respect to $L\left(\varepsilon_{A^{*}, L}\right)$ is defined as the percentage change in $A^{*}$ resulting from a given percentage change in $L$, expressed as a ratio to the percentage change in $L$.

Algebraically,

$$
\varepsilon_{A^{*}, L}=\frac{\% \Delta \text { in } A^{*}}{\% \Delta \text { in } L}=\frac{L}{A^{*}} \cdot \frac{\partial A^{*}}{\partial L},
$$

where $\partial A^{*} / \partial L$ represents the first partial derivative of $A^{*}$ with respect to $L$. From equations 25 and 28 , we find that $\varepsilon_{A^{*}, L}=1$. Hence, for any area of equivalent incidence of solar radiation ( $i . e$. , holding I constant), a given percentage change in the annual hot water load ( $L$ ) produces an equal percentage change in the economically optimal collector area ( $\left.A^{*}\right)$, all other factors being equal.

The ratio $A^{*} \cdot I / L$ remains unchanged for varlations in $\mathrm{L}$, and, because $A^{*} \cdot I / L$ is constant for different hot water loads, $F^{*}$ is independent of $\mathrm{L}$. As illustrated by again using the elasticity concept,

$$
\varepsilon_{F^{*}, L}=\frac{\% \Delta \text { in } F^{*}}{\% \text { in } L}=\frac{L}{F^{*}} \cdot \frac{\partial F^{*}}{\partial L}=0
$$

Since a given percentage change in the load causes no change in solar fraction, the economically optimal fraction is unique and independent of the hot water load for a given set of economic parameters and radiation values. 1

Economic optimization paths showing the optimal collector size ( $A^{*}$ ) for different hot-water loads (L) can be established on the basis of the results presented above. The optimization paths are applicable only to solar hot water systems in geographical locations which have the same amount of annual solar radiation and to which the same technical and economic assumptions would apply.

Figure 2.7 illustrates a universal economic optimization path. The optimal collector area $\left(A^{*}\right)$ is measured on the horizontal axis, the annual hot-water load ( $L)$, on the vertical axis in the upper part of the figure. As was demonstrated above, $A^{*}$ is a linear function of $L$, and $F^{*}$ is independent of $\mathrm{L}$; therefore, $\mathrm{F}^{*}$ is constant along the optimization path.

$1 \mathrm{~F}^{*}$ is independent only of those changes in the hot water load that alter neither the assumed cost estimating equations nor the technical performance relationships. 
TLCS is measured on the vertical axis of the lower part of figure 2.7. The curve for total life-cycle savings (TLCS) increases with increasing loads (L) and the corresponding increasing optimal collector areas ( $\left.A^{*}\right)$.

Larger hot water loads imply that larger absolute savings can be realized by installing a solar system. As the load and corresponding optimal collector area become smaller, savings decline and at some critical level ( $L_{c}$ in fig. 2.7), TLCS reaches zero. Below the critical level, TLCS is negative. The critical value of $\mathrm{L}, \mathrm{L}_{\mathrm{C}}$, is determined as follows:

$$
L_{C}=\frac{F_{X} \cdot \bar{Y}+R}{\bar{X}\left(1-\frac{v \cdot \bar{Y}}{c \cdot I \cdot \bar{X}}\right)-\frac{v \cdot \bar{Y}}{c I} \ln \left(\frac{b \cdot c \cdot I \cdot \bar{X}}{v \cdot \bar{Y}}\right),}
$$

where all parameters are as previously defined.

Equation (30) indicates that the value of $\mathrm{L}_{c}$ in figure 2.7 depends directly upon the fixed cost components of the solar energy system, other things being equal. As fixed costs decline, $\mathrm{L}_{\mathrm{C}}$ declines.

Several immediately practical uses of this universal path methodology are suggested. First, it could be an extremely valuable tool for developing regional guidance to the commercial building conmunity on the optimal sizing and cost effectiveness of solar hot water systems. Second, the methodology could be used to conduct a comprehensive analysis of the sensitivity of optimal design with respect to selected parameters. Third, the methodology could be a useful tool for facilitating the analysis and development of efficient Federal and State solar incentive programs. 1

\subsection{INTEGRATED OPTIMIZATION OF SOLAR ENERGY AND ENERGY CONSERVATION: A THEORETICAL FRAMEWORK}

This section describes an extension of the economic optimization framework to incorporate the analysis of trade-offs between solar energy and energy conservation in buildings. It draws upon the findings of the preceding section regarding the unitary elasticity of $A^{*}$ with respect to $L$ and the independence of $\mathrm{F}^{*}$ with respect to $\mathrm{L}$, to simplify the integrated optimization procedure.

\subsubsection{Economic Foundations}

The primary economic objective in designing or retrofitting the heating/cooling components of a building is to provide at the lowest possible life-cycle cost a destred level of thermal comfort, comprising temperature, humidity, and other related attributes (and taking into account related factors such as lighting). The minimum cost search considers the technical substitution

1 A more thnrough treatinent of the model and examples of its use for sensitivity analysis and policy analysis is provided by Sav in "Universal Economic Optimization Paths for Solar Heat Water Systems in Commercial Buildings," Energy [31]. 
Figure 2.7 Universal Economic Optimization Path: Feneric Form

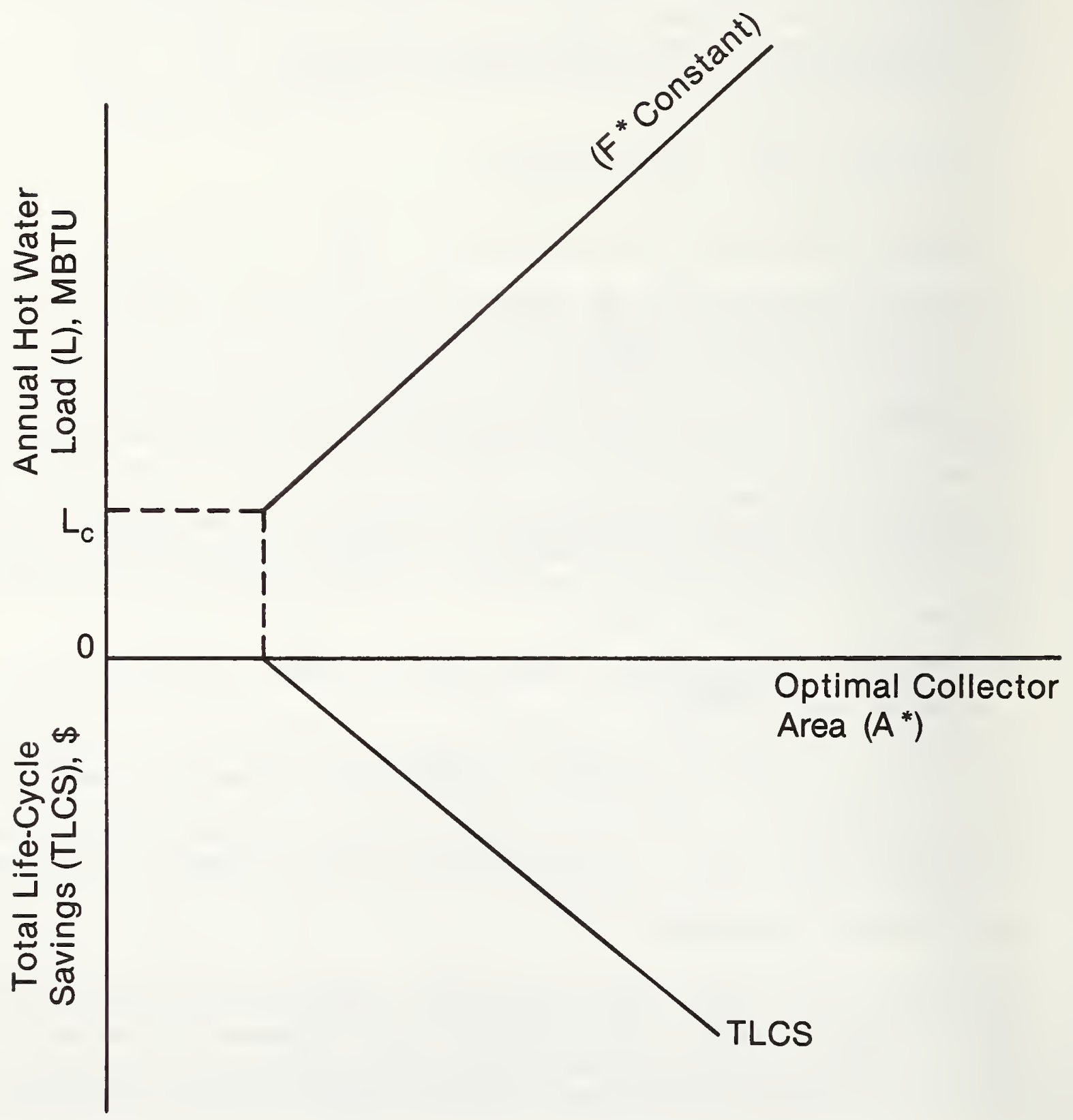


between inputs and the relative prices of inputs. Holding all inputs constant except those concerning the building envelope and the energy system(s), tradeoffs exist between ( 1 ) energy conservation alternatives which improve the thermal integrity of the building envelope, and therefore reduce the bullding's thermal load, and (2) energy system alternatives, e.g., nonsolar and solar energy systems, which satisfy given thermal loads. Economic optimality is attained when the marginal dollar expenditure for each input per marginal unit of thermal comfort obtained from that input is equal for all inputs. This optimality condition may be stated algebraically as follows:

$$
\frac{\mathrm{MC}_{\mathrm{C}}}{\mathrm{MP}_{\mathrm{C}}}=\frac{\mathrm{MC}_{\mathrm{s}}}{\mathrm{MP}_{\mathrm{s}}}=\frac{\mathrm{MC}_{\mathrm{LR}}}{\mathrm{MP}_{\mathrm{LR}}},
$$

where MC represents marginal cost, MP marginal product, and subscripts $c$, $s$, and LR represent, respectively, nonsolar energy inputs, solar energy inputs, and load reduction (energy conservation) inputs.

In other words, the search is for a given combination of energy conservation inputs (load reduction options) and energy system inputs which will minimize the total life-cycle costs of achieving a desired level of thermal comfort (or maximize the net life-cycle savings from the total investment).

Holding a11 factors constant except thermal load (L) as determined by the thermal integrity of the building envelope, and noting that alternative energy systems can satisfy $L$, thermal comfort, $k$, can be expressed as follows:

$k=k\left(q_{C}, q_{S}, q_{L R}\right)$,

where $\mathrm{q}_{c}$ represents a quantity of nonsolar energy input, $\mathrm{q}_{s}$ a quantity of solar energy input, qLR a quantity of load reduction obtained by upgrading the thermal integrity of the building envelope, and all inputs are expressed in a common unit measure such as the Joule (Btu).

The cost (C) of achieving various levels of $k$ can be described by a family of isocost curves:

$$
c=p_{c}\left(q_{c}\right) \cdot q_{c}+p_{s}\left(q_{s}\right) \cdot q_{s}+p_{L R}\left(q_{L R}\right) \cdot q_{L R}
$$

where $p_{1}\left(q_{i}\right)$, subscripted $c, s$, or LR, is an expression which gives the price of the $1^{\text {th }}$ input as a function of the level of the $i^{\text {th }}$ input used.

Once a target level of thermal comfort (say $k$ ) is determined, the economic objective is to minimize $C$ subject to the constraint of $k=k$. The minimum cost combination of inputs $q_{C}, q_{S}$, and $q_{L R}$ can be obtained by using the technique of the Lagrange multiplier:

$\min c=p_{C}\left(q_{C}\right) \cdot q_{C}+p_{s}\left(q_{s}\right) \cdot q_{S}+p_{L R}\left(q_{L R}\right) \cdot q_{L R}-\lambda\left[k-k\left(q_{c}, q_{s}, q_{L R}\right)\right]$

where $\lambda$ is the Lagrange multiplier and is interpreted as the marginal cost of producing thermal comfort (k). 
From equation (34), the optimality condition is found to be the following:

$$
\frac{p_{c}+p_{c}^{\prime} q_{c}}{k_{c}^{\prime}}=\frac{p_{s}+p_{s}^{\prime} s}{k_{s}^{\prime}}=\frac{p_{L R}+p_{L R}^{\prime} q_{L R}}{k_{L R}^{\prime}}
$$

The numerator of each ratio in equation 35 is the marginal cost (MC) of the respective input. The denominator is the marginal product (MP) of the input in producing thermal comfort $(k)$. Hence, this is consistent with the optimality condition stated at the outset in equation 31.

Since initially all inputs except thermal load were held constant, it follows that marginal products are all expressed in a common unit, e.g., Joule (Btu). The ratios of the marginal products are therefore unity and the optimality condition can be restated in the following familiar form:

$$
M C_{C}=M C_{S}=M C_{L R}
$$

Economic optimality is attained when the marginal costs of all inputs are equal.

\subsubsection{Optimization Mode1}

When the optimality condition stated in equation 36 is achieved, total life-cycle costs of maintaining a given level of thermal comfort are minimized or alternatively net life-cycle savings from the investment in thermal comfort are maximized. These alternative criteria provide the impetus for an empirically workable optimization model and are discussed below. The first criterion is achieved by minimizing the following equation:

$$
T L C C L j=\underset{c}{L C C L j}+\underset{s}{L C C L j}+\underset{L R}{L C C}
$$

where TLCC represents total life-cycle costs, and LCC subscripted c, s, and LR represents the life-cycle cost of nonsolar energy inputs, solar energy inputs, and load reduction inputs, respectively. The superscript $\mathrm{L}_{\mathrm{j}}$ represents alternative loads.

Equation 37 describes a family of TLCC curves, each corresponding to a different load, $L_{j}$. The empirical form of equation 37 differs depending on the nature of economic and technical trade-offs among the size (capacity) of the solar energy system, the size of the nonsolar energy system, and the leve 1 of energy conservation. If, for simplicity, it is assumed that there are no capacity reductions in the nonsolar energy system as the size of the solar energy system is expanded, $\mathrm{LCC}_{\mathrm{c}}$ consists only of conventional fuel costs. LCC $\mathrm{LR}_{\mathrm{L}}$ presents the most difficulty for empirical investigation. It is building-design design specific and depends upon the initial design load against which the costs of load reductions are to be evaluated.

The alternative to the TLCC minimization criterion, the TLCS maximization criterion, is achieved by maximizing the value of the following equation: 


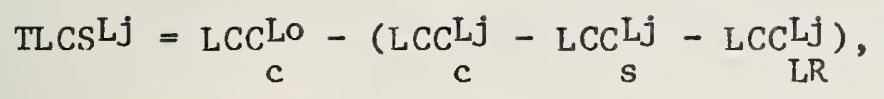

where $\mathrm{LCC}_{\mathrm{L}}^{\mathrm{Lo}}$ represents the sum of the initial space heating $\left(\mathrm{L}_{\mathrm{Ho}}\right)$ and hot water ( $\left.L_{W}\right)$ loads from which load reduction options are evaluated. (Note that $\mathrm{L}_{j}=\mathrm{L}_{\mathrm{Hj}}+\mathrm{L}_{\mathrm{W}}$, where $\mathrm{L}_{\mathrm{W}}$ represents a fixed hot water load which is unaffected by energy conservative design in the building envelope.)

Maximization of equation 38 is equivalent to the minimization of equation 37. Both are consistent with the optimality condition of equating the marginal costs of alternative inputs given by equation 36 .

Figures 2.8 through 2.10 graphically depict the integrated optimization procedure. Figure 2.8 shows a generic LCC $_{\mathrm{LR}}$ function. The horizontal axis measures the fraction $(\beta)$ by which the initial space heating load ( $\mathrm{L}_{\mathrm{Ho}}$ ) is reduced. $\mathrm{LCC}_{\mathrm{LR}}$ for various load reductions are measured along the vertical axis. The lower scale in Figure 2.8 shows the combined space heating and hot water load $\left(L_{j}=L_{H j}+L_{W}\right)$ corresponding to each $\beta$.

Eigure 2.9 shows in the upper portion a family of TLCC curves. In the middle portion are TLCS curves; and in the lower portion, solar performance curves for alternative loads $\left(\mathrm{L}_{j}{ }^{\prime} \mathrm{s}\right)$. The figure also shows, a life-cycle cost curve $\left(\mathrm{LCC}_{C}^{\mathrm{LO}}\right.$ ) for a nonsolar energy system providing all of the energy to meet the initial load of $\mathrm{L}_{O}$, used to derive the TLSC curves. For any given load, the optimal collector area $\left(A_{j}^{*}\right)$, which is indicated on the horizontal axis, and the fraction of load supplied by solar $\left(F_{j}^{*}\right)$, which is indicated on the lower segment of the vertical axis, occurs at the minimum point on the TLCCLj curve or the corresponding maximum point on the TLCSLj curve. The optimal amount of nonsolar energy input is simply $\left(1-F_{j}^{*}\right)$. The optimal combination of all inputs, including load reduction options, occurs at the minimum point on the lowest TLCCLj curve among the family of TLCCLj curves or the corresponding maximum point on the highest TLCSLj curve. For example, the optimal combination of all inputs in figure 2.9 occurs at the minimum point on the TLCCLl curve, which is the same as the maximum point on the TLCSLl curve. The optimum is found to be $A_{1 *}^{* *}$ of solar collector area, $F_{1}^{* *}$ fraction of the load by solar, $1-F^{* *}$ fraction of the load met by nonsolar energy input, and $\beta_{1}^{* *}$ of load reduction, corresponding to a combined thermal load of $\mathrm{L}_{1}=\mathrm{L}_{\mathrm{H} l}+\mathrm{L}_{\mathrm{W}}$.

As reported in section 2.5, preliminary investigations indicate that the elasticity of $A^{*}$ with respect to $L_{j}$ (defined as the percentage change in $A^{*}$ per percentage change in $\mathrm{L}_{j}$ ) may be approximately unity under certain conditions. Since solar performance as measured by the solar fraction (F) is a function of the ratio of $A^{*}$ to $L_{j}$, changes in $F^{*}$ would be nearly invariant with respect to changes in thermal loads $\left(L_{j}\right)$. If the elasticity of $F^{*}$ with respect to $L_{j}$ were approximately zero, there would be little or no movement in $F_{j}^{*}$ for different $\mathrm{L}_{\mathrm{j}}$ 's in the southeast quadrant of figure 2.9.

Based on these concepts, the optimization procedure can be considerably compressed according to the graph shown in figure 2.10. Various combined space heating and hot water loads $\left(L_{j}\right)$ are shown on the upper portion of the vertical axis; optimal collector areas $\left(A^{*}\right)$ corresponding to each $L_{j}$ are shown on the 
Figure 2.8 Integrated Optimization Procedure: Load Reductions

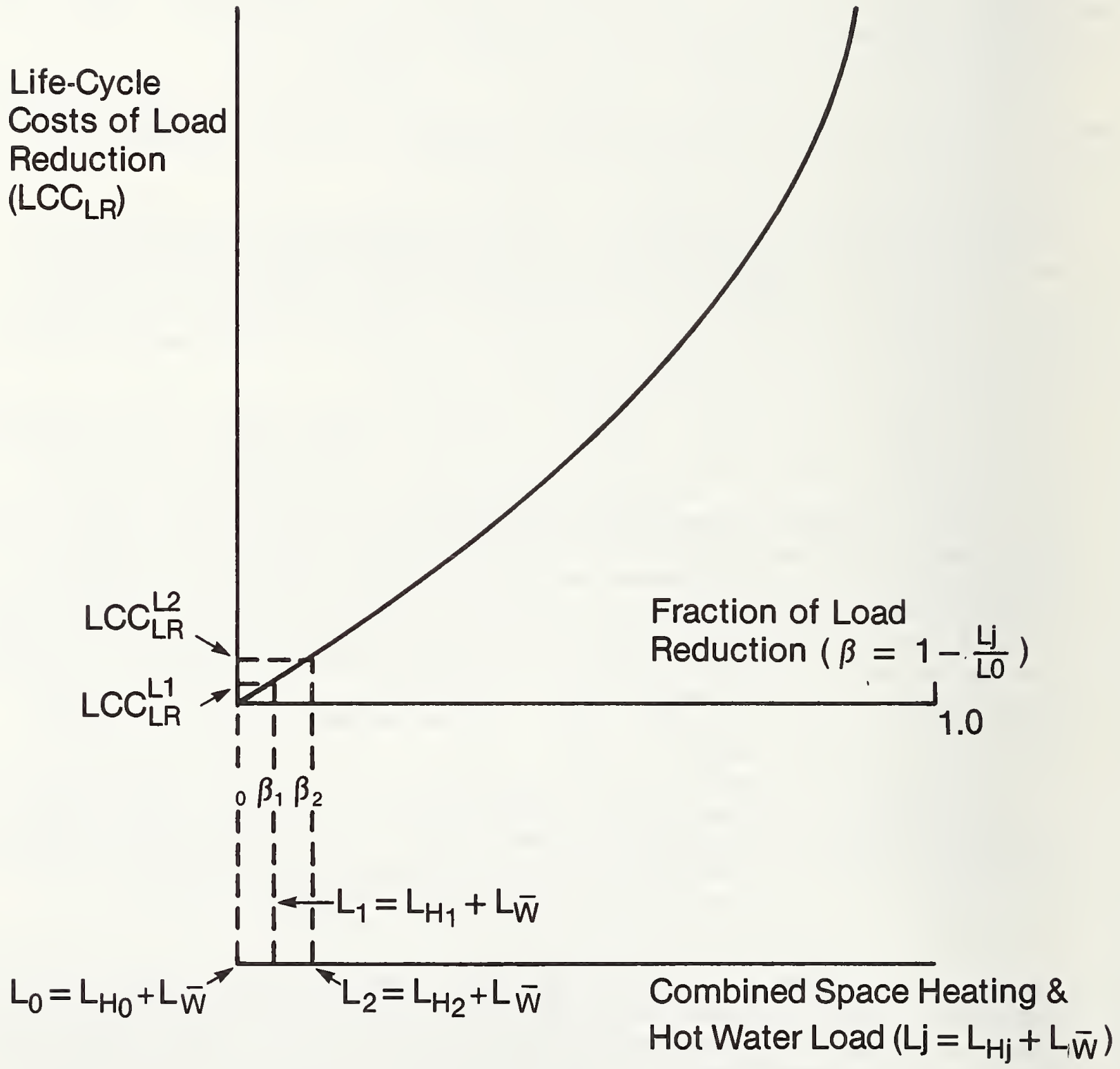




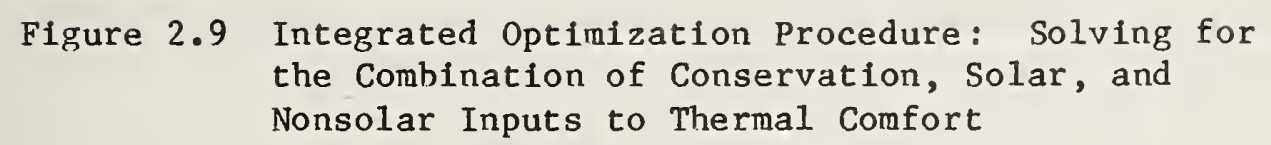
Nonsolar Inputs to Thermal Comfort

Fraction of Combined Space Heating Load $\left(\mathrm{L}_{\mathrm{H}_{\mathrm{j}}}\right)$ and Hot Water Heating Load $\left(L_{\bar{W}}\right)$ Supplied by Solar (F)

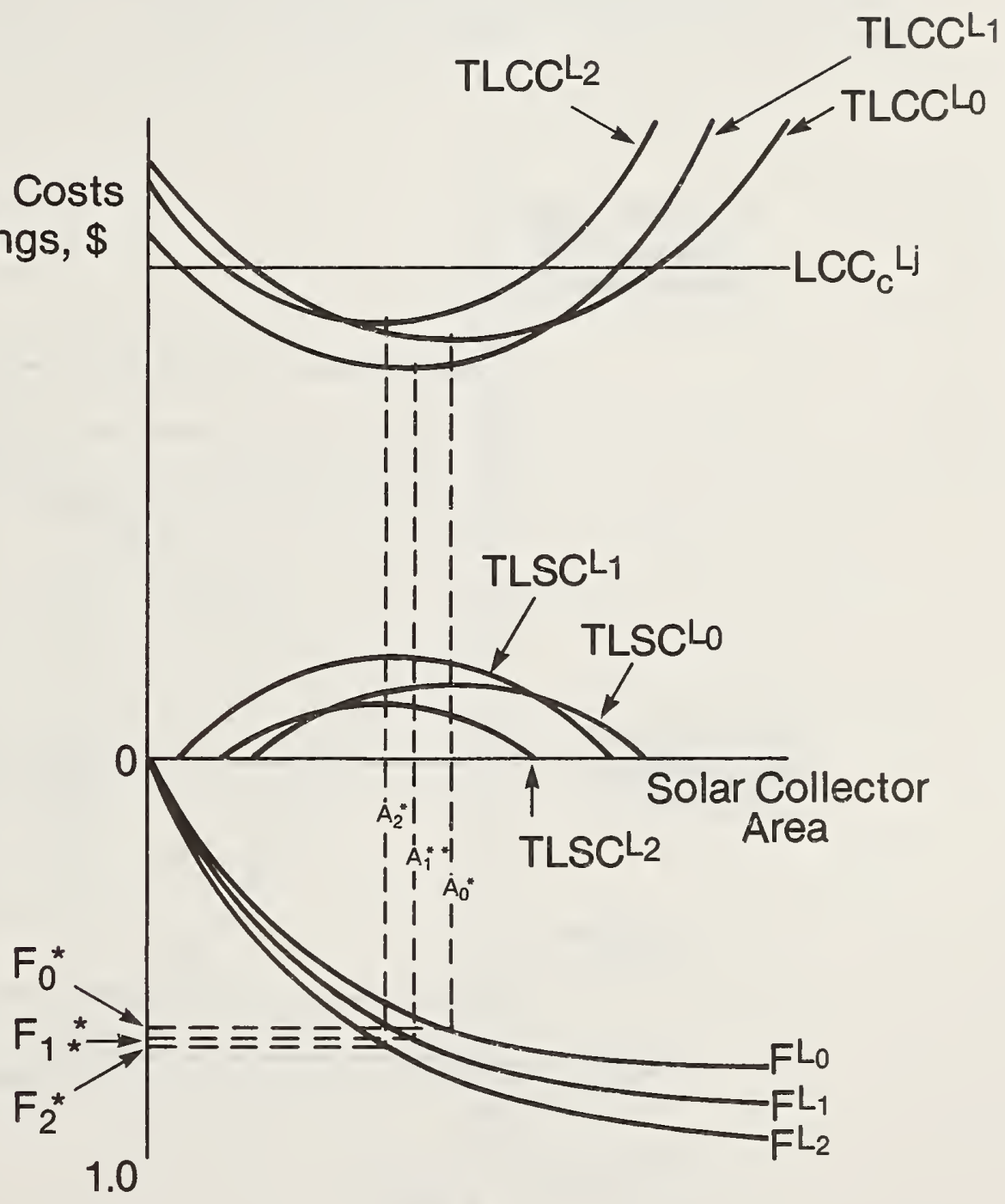


Figure 2.10 Integrated Optimization Procedure: Compressed Model

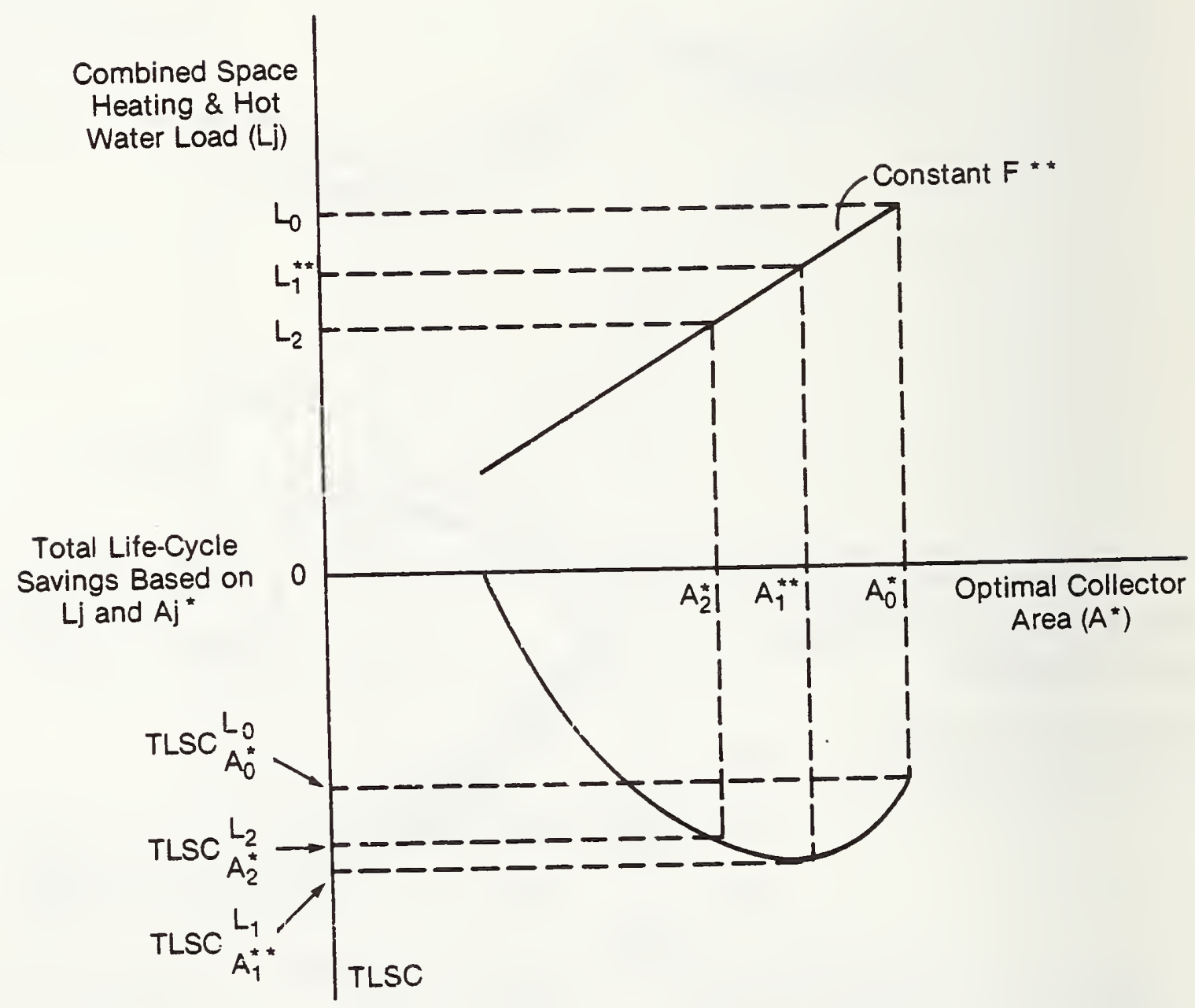


horizontal axis. $L_{0}$ is the initial load. The constant $F * *$ path relates $L_{j}$ 's to $A^{*}$ 's. The $F^{* *}$ path is constant assuming that $F^{* *}$ is uniquely determined and independent of $\mathrm{L}_{j}$. In the lower part of the figure, the locus of points corresponding to the maximum values of the family of TLCSLJ curves is plotted against the optimal collector areas $\left(\mathrm{A}^{*}\right)$. The "global optimum" in figure 2.10 occurs at the maximum point on this curve. Thus, figure 2.10 indicates all the relevant optimization information in an extremely compressed form: $\mathrm{A}^{* *}, \mathrm{~L}^{* *}, \mathrm{~F}^{* *}$, and, by derivation, $1-F^{* *} .1$

1 These findings regarding the elasticity of $A^{*}$ with respect to $L_{j}$ and the relationship between $\mathrm{F}^{*}$ and $\mathrm{L}_{j}$ are based on the analysis of solar service water heating. They can be extended to the analysis of space heating only if the annual solar fraction can be expressed in a single equation as a function of collector area and load. The problem of jointly optimizing the building envelope, the mechanical system, and the solar energy system is a topic of current research by NBS Applied Economics Group, Center for Applied Mathematics. 
Table 2.1 Definitions of Symbols Used in Section 2

A

$A_{j}^{*}$

$A^{* *}$

$\alpha$

$\beta$

$B * *$

C

$\mathrm{C}_{\mathrm{F}}$

$\mathrm{C}_{\mathrm{S}}$

D

$\mathrm{E}$

F

$\mathrm{F}_{\mathrm{x}}$

$\mathrm{F}_{\mathrm{XL}}$

$\mathrm{F}_{\mathrm{XM}}$

$\mathrm{F}^{\star}$

$F^{* *}$

G

= solar collector surface area

= economically optimal size of collector area, in terms of maximizing TLCX, based on a given energy load $\mathbf{j}$

= "global" optimal solar collector area, in terms of maximizing TLCS, taking into account energy conservation investments

= number of years by which property taxes are deferred

= fraction of the solar system contract as ( $\left.F_{X}+v A\right)$ placed as an initial downpayment

= fraction by which the initial space heating load ( $\mathrm{L}_{\mathrm{Ho}}$ ) is reduced by energy conservation

= the "global" optimal fraction of space heating load reduction taking into account solar and nonsolar energy

$=$ cost of achieving various levels of thermal comfort

= Federal solar tax credit as a percent of system acquisition costs

= effective state solar tax credit net of Federal income tax adjustment

$=$ the present value of the decrease in income taxes owed due to capital depreciation deductions from taxable income

= present dollar value, after income taxes, of energy costs for the nonsolar energy system

= the annual solar fraction of a building's energy requirements met by a solar energy system

= fixed cost for labor and materials associated with acquiring the solar energy system, including cost of design, purchase, and installation

= fixed labor cost of acquiring the solar energy system

= fixed materials cost of acquiring the solar energy system

= the optimal solar fraction based on a given energy load

= the "global" optimal solar fraction taking into account energy conservation investments yielding alternative energy loads denoted by subscript $j$

= present value of capital gains taxes due at the end of the study period 


\section{Table 2.1 - (continued)}

$\gamma \quad=$ efficiency coefficient of nonsolar energy equipment

$I_{j} \quad=$ solar radiation incident on a tilted collector surface in month $j$

In = the present value of capital investment costs associated with designing, purchasing, and installing a solar energy system, including financing costs

$k=$ level of thermal comfort

$\overline{\mathrm{k}} \quad=$ target level of thermal comfort

$\lambda \quad=$ Lagrange multiplier

L $\quad=$ annual hot water load

$\mathrm{L}_{\mathrm{c}} \quad$ = critical hot water load below which the solar energy system is not cost effective

$\mathrm{L}_{\mathrm{j}} \quad$ = space heating and domestic hot water load associated with a level of energy conservation denoted by the subscript $j$

$\mathrm{L}_{\mathrm{O}} \quad=$ initial domestic hot water load or combined initial space heating and domestic hot water load prior to energy conservation

$\mathrm{L}_{\mathrm{W}} \quad=$ hot water load

$\mathrm{L}_{\mathrm{W}}^{-} \quad=$ fixed hot water load unaffected by energy conservation design in the building envelope

$\mathrm{L}_{\mathrm{H}_{j}} \quad=$ space heating load associated with a level of energy conservation denoted by the subscript $j$.

$\mathrm{L}_{\mathrm{H}} \quad=$ initial space heating load prior to energy conservation

LCC $_{c}=$ life-cycle costs of the auxiliary energy system

$\mathrm{LCC}_{\mathrm{S}}=$ life-cycle costs of purchasing, installing, maintaining and operating the solar energy system (but not including energy costs for the auxiliary energy system)

$\mathrm{LCC}_{\mathrm{C}}^{\mathrm{L}_{\mathrm{j}}} \quad=$ life-cycle costs of nonsolar energy inputs given load $\mathrm{j}$

$\underset{L_{j}}{L_{j}} \quad=$ life-cycle costs of solar energy inputs given load $j$ 


\section{Table 2.1 (continued)}

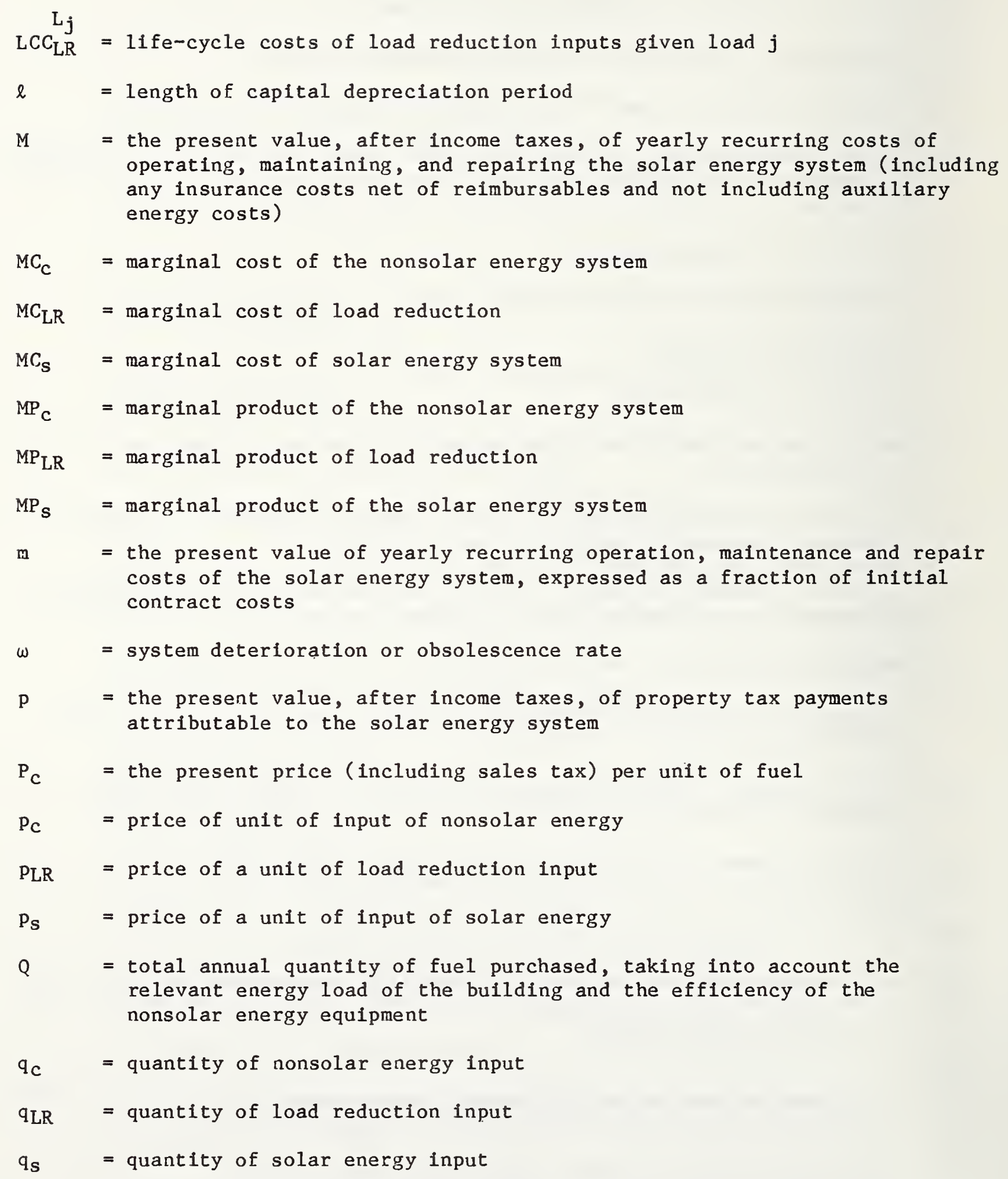


Table 2.1 (continued)

$\mathrm{R}$

$R_{j}$

$r$

S

$\mathrm{S}_{\mathrm{S}}$

$S P W_{d, j, z}$

$\mathrm{SPW}_{\mathrm{d}, \mathrm{n}}$

s

TC

TLCC $_{c, s}=$ total Iffe-cycle cost associated with a combined solar/auxiliary energy system

$=$ the present value, after income taxes, of all maintenance, repair and replacement costs that do not recur annually

$=$ the cost of maintenance, repair and replacement in year $j$

= regional labor cost adjustment factor

= the present value of the decrease in income taxes due to state sales tax deductions from Federal income tax distinguishing between tax on labor and tax on materials)

= present value of tax savings due to sales tax deductions (not distinguishing between sales tax on labor and sales tax on materials

= single present worth factor based on discount rate, $d$ and the year, $j$, and a general price inflation rate, $z$

= single present worth factor based on discount rate, $\mathrm{d}$, and $\mathrm{n}$ years

$=$ nominal resale value as a fraction of the initial contract cost

$=$ present value of Federal and State government tax credits

TLCC $_{100 \% c}=$ total life-cycle costs of meeting all energy demands with a nonsolar energy system alone

$\operatorname{TLCC}^{\mathrm{L}} j=$ total 1 ife-cycle costs for energy-related building components, given load $\mathrm{j}$

$\operatorname{TLCC}_{C}^{\mathrm{L} O} \quad=$ total life-cycle costs of a nonsolar energy system providing all of the energy to meet the initial load, $\mathrm{L}_{\mathrm{O}}$

TLCS = life-cycle net savings (or, if negative, net losses) for solar

t $\quad=$ the building owner's composite Federal and state marginal income tax rate

$t_{\mathrm{p}} \quad=$ effective property tax rate

${ }^{t} \mathrm{cg}=$ combined state \& Federal capital gains tax

${ }^{\mathrm{S}} \mathrm{SL} \quad=$ state sales tax rate applicable to labor services

${ }^{\mathrm{S}} \mathrm{SM} \quad=$ state sales tax rate applicable to materials

UPW $_{d, g}=$ uniform present worth factor based on discount rate, $d$, and the number of years, $g$, over which the state tax credit is taken. 


\section{Table 2.1 (continued)}

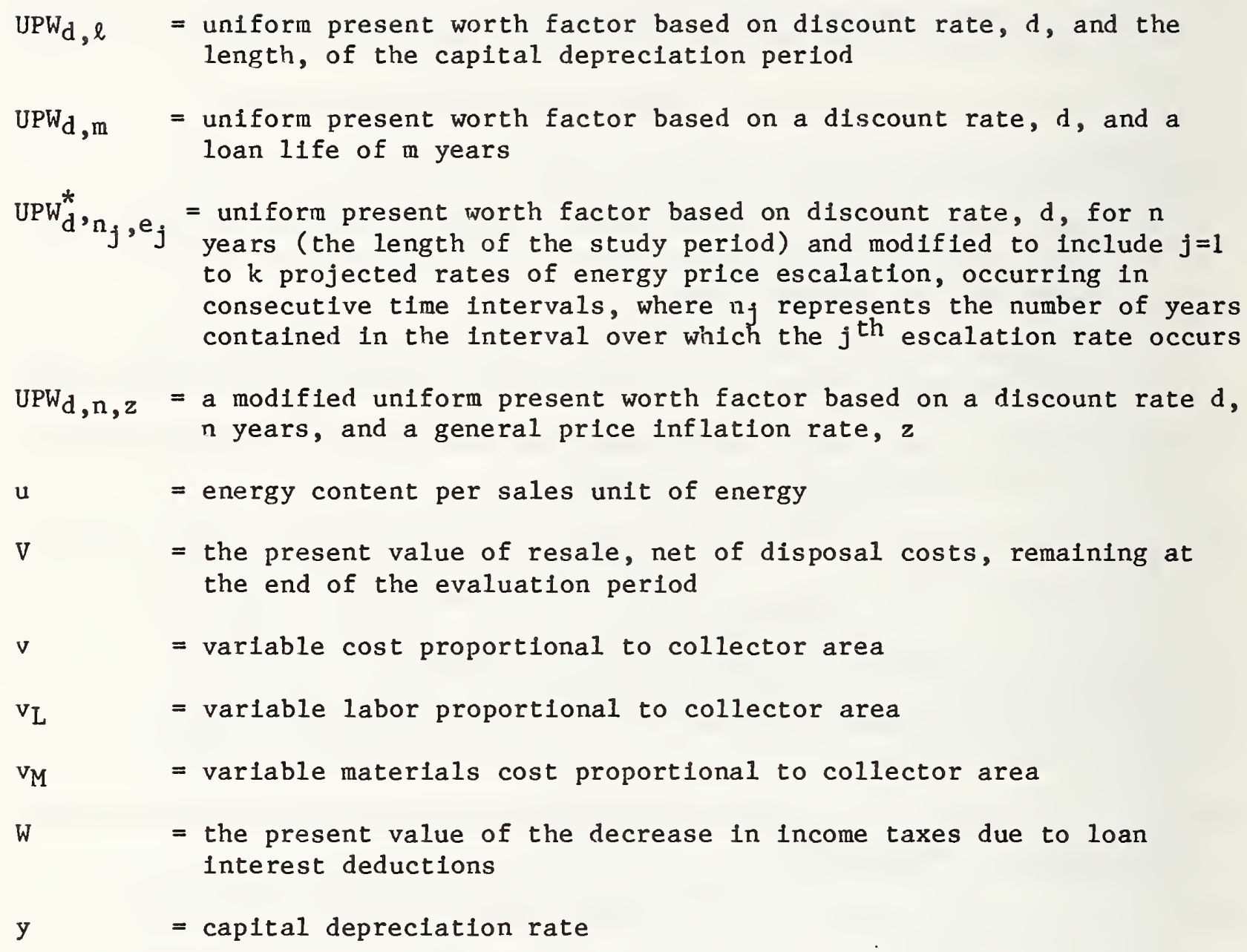


3. CASES SELECTED FOR STUDY: BUILDINGS, BUILDING SYSTEMS, AND GEOGRAPHICAL LOCATIONS

\subsection{BUILDINGS}

Case studies were performed for several selected types of comercial buildings. The population of commercial buildings from which the selection was made is illustrated in table 3.1. This list, taken from a building construction valuation manual, outlines seven major categories composed of 23 subcategories of commercial buildings [34].

Office buildings and retail stores were selected for case study because they are major users of energy [35]. Their selection is also supported by a comparison of building types by floor space, as shown in table 3.2. Of the total floor space of the nonresidential buildings shown, offices and retail/ wholesale buildings account for the largest share--about one third.1

The case study buildings are hypothetical, but selected to be representative of their class. They are a three-story office building and a single-story retail store--each with two alternative envelope designs.2 For each type of building, one envelope design, designated "conventional," is intended to represent much of the existing inventory that has been constructed with little attention to energy conservation. The other design for each building type, designated "energy conserving," represents conventional-type buildings constructed in accordance with ASHRAE 90-75 [39]. The conventional designs were used to assess the feasibility of retrofitting solar energy systems to existing office buildings and retail stores; the energy conserving designs were used to assess the use of solar energy in new office buildings and retail stores. It should be noted that none of the building designs were specified to take optimal advantage of solar energy nor of daylighting.

\subsubsection{Office Buildings}

The three-story office building is $30 \mathrm{~m}$ ( $100 \mathrm{ft}$ ) 1ong by $30 \mathrm{~m}$ (100 ft) wide, with metal curtain-wall construction. The new building design has double-glazed windows and insulated exterior wall and roof. The existing building design has single-glazed windows and uninsulated exterior walls and roof. There are 15 therral zones within the building, modeled in the thermal analysis as 10 zones, with the first and second floor zones combined vertically. Both the new and the existing versions of the office building were assumed to have an average occupancy during peak operating hours of 300 people, with occupancy extending

1 In establishing the scope of this study, it was jointly agreed by the U.S. Department of Energy (DoE) and the U.S. Department of Housing and Urban Development (HUD) that this study, under the sponsorship of DoE, would not consider apartment buildings.

2 Honeywell, Inc., Energy Resources Center, a consulting engineering firm, provided descriptions of the buildings and system specifications under contract to NBS [36]. 
Table 3.1 Types of Commercial Buildings ${ }^{a}$

\begin{tabular}{|c|c|}
\hline MAJOR CATEGORIES & SUBCATEGORIES \\
\hline Mercantile & $\begin{array}{l}\text { Banks, Drive-ins, Laundries, Office Building, } \\
\text { Stores, Supermarkets }\end{array}$ \\
\hline Medical & Clinics, Hospitals, Nurses' Residences \\
\hline Entertainment & Bowling Alleys, Clubs, Theaters \\
\hline Garages & Parking, Sales \& Service \\
\hline Service Stations & Stations \\
\hline Residential & Apartments, Hotels, Motels \\
\hline Miscellaneous & $\begin{array}{l}\text { Grain Elevators, Lumber Storage, Trucking } \\
\text { Terminals, Warehouses }\end{array}$ \\
\hline
\end{tabular}

a This classification excludes "industrial buildings," such as mills, factories, and plants; "institutional buildings," such as dormitories, gymnasiums, and libraries; and "agricultural structures."

Source: The Anerican Appraisal Company, Boeckh Building Valuation Manual, Vol. II, Commercial [34]. 


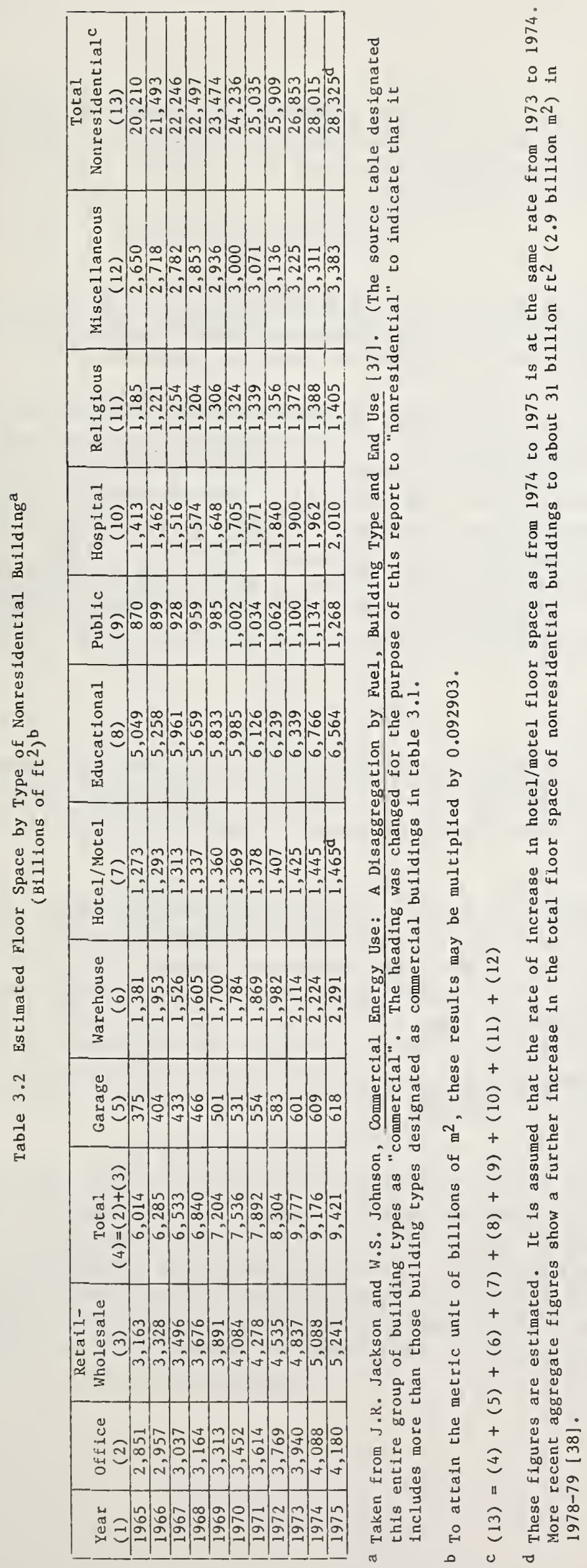


over 10 hours per day, five days per week. Table 3.3 gives further description of the construction characteristics of the new and existing office buildings. Figure 3.1 shows the office building layout and the exterior faces. Figure 3.2 shows the office building load schedules.

\subsubsection{Retail Stores}

The one-story retail store is a rectangular building, $29 \mathrm{~m}$ (95 ft) long by $16 \mathrm{~m}$ (53 ft) wide, of metal curtain-wall construction. It is assumed to have an average occupancy extending over 12 hours per day, 6 days per week.

The new version of the store was assumed to be less energy conserving than the new office building, though representative of new stores constructed in accordance with ASHRAE 90-75. (R-values of exterior walls are set at $1.14 \mathrm{~m} 2 \cdot \mathrm{K} / \mathrm{W}$ (6.45) in the new retail store, as compared with $1.84 \mathrm{~m} 2 \cdot \mathrm{K} / \mathrm{W}(10.45)$ in the new office building.) The existing retail store has an envelope with thermal characteristics like those of the existing office building. Table 3.4 gives further description of the construction characteristics of the new and existing retail stores. Figure 3.3 shows the layout and outside faces. Figure 3.4 shows the building load schedules. The retail store was assumed to have three thermal zones (see figure 3.3).

\subsection{AIK HANDLING SYSTEMS}

The energy requirements of commercial buildings are considerably affected by the type of heating and cooling systems used. Hence, it is important in estimating the energy requirements of a building to specify the characteristics of the mechanical systems.

The importance of the mechanical system on building energy use is demonstrated by figure 3.5 , which shows the simulated energy requirements of a two-story office building fitted with different mechanical systems. For each of four different cities in the U.S., runs were repeated for the building with from six to eight different mechanical heating and cooling systems. Figure 3.5 shows the building's energy consumption in each location for different mechanical systems. The amount of energy required is shown to vary by a factor as high as about seven, depending upon the design and operation of the mechanical system [40].

The study referenced above looked at eight different systems; there are, however, approximately 25 different types of heating and air conditioning systems--with additional subclassifications within many of the types--identified in the ASHRAE Handbook and Product Directory [41]. Many different types of systems are in use in existing buildings, and different types continue to be installed in new buildings. Like the diversity of building types, the diversity of mechanical systems in these buildings makes it difficult to generalize case study results to other buildings. 
Table 3.3 Office Building Construction Characteristics

\begin{tabular}{|c|c|c|}
\hline $\begin{array}{c}\text { Surface } \\
\text { Description }\end{array}$ & New Office Building & Existing office \\
\hline Windows* & $\begin{array}{l}\text { Insulating glass } \\
{\left[1.3 \mathrm{~cm}\left(1 / 2^{*}\right) \text { air space }\right]} \\
\mathrm{R}=\left(.36 \mathrm{~m}^{2} \cdot\right) \mathrm{K} / \mathrm{W}(2.04)\end{array}$ & $\begin{array}{l}0.6 \mathrm{~cm}\left(1 / 4^{\prime \prime}\right) \text { single pane glass } \\
\mathrm{R}=\left(.15 \mathrm{~m}^{2} \cdot \mathrm{K}\right) / \mathrm{W}(.88)\end{array}$ \\
\hline Exterior Doors* & $\begin{array}{l}\text { Insulating glass } \\
{\left[1.3 \mathrm{~cm}\left(1 / 2^{* \prime}\right) \text { air space }\right]} \\
\mathrm{R}=\left(.36 \mathrm{~m}^{2} \cdot \mathrm{K}\right) / \mathrm{W}(2.04)\end{array}$ & $\begin{array}{l}0.6 \mathrm{~cm}\left(1 / 4^{\prime \prime}\right) \text { single pane glass } \\
\mathrm{R}=\left(.15 \mathrm{~m}^{2} \cdot \mathrm{K}\right) / \mathrm{W}(.88)\end{array}$ \\
\hline Interior Walls ${ }^{+}$ & $\begin{array}{l}1.3 \mathrm{~cm}\left(1 / 2^{\prime \prime}\right) \text { gypsum board } \\
10.2 \mathrm{~cm}\left(4^{\circ}\right) \text { metal frame } \\
1.3 \mathrm{~cm}\left(1 / 2^{\prime \prime}\right) \text { gypsum board } \\
\mathrm{R}=\left(.32 \mathrm{~m}^{2} \cdot \mathrm{K}\right) / \mathrm{W}(1.83)\end{array}$ & $\begin{array}{l}1.3 \mathrm{~cm}\left(1 / 2^{\prime \prime}\right) \text { gypsum board } \\
10.2 \mathrm{~cm}\left(4^{\prime \prime}\right) \text { metal frame } \\
1.3 \mathrm{~cm}\left(1 / 2^{\prime \prime}\right) \text { gypsum board } \\
\mathrm{R}=\left(.32 \mathrm{~m}^{2} \cdot \mathrm{K}\right) / \mathrm{W}(1.83)\end{array}$ \\
\hline Exterior Walls ${ }^{+}$ & $\begin{array}{l}5.1 \mathrm{~cm}\left(2^{\prime \prime}\right) \text { metal curtain wall } \\
10.2 \mathrm{~cm}\left(4^{\circ}\right) \text { metal frame } \\
5.1 \mathrm{~cm}\left(2^{\prime \prime}\right) \text { rigid insulation } \\
1.3 \mathrm{~cm}\left(1 / 2^{\prime \prime}\right) \text { gypsum board } \\
\mathrm{R}=\left(1.84 \mathrm{~m}^{2} \cdot \mathrm{K}\right) / \mathrm{W}(10.45)\end{array}$ & $\begin{array}{l}5.1 \mathrm{~cm}\left(2^{*}\right) \text { metal curtain wall } \\
10.2 \mathrm{~cm}\left(4^{*}\right) \text { metal frame } \\
\text { No insulation } \\
\mathrm{R}=\left(.35 \mathrm{~m}^{2} \cdot \mathrm{K}\right) / \mathrm{W}(2.00)\end{array}$ \\
\hline Upper Floors & $\begin{array}{l}\text { Carpet }- \text { pad } \\
7.6 \mathrm{~cm}\left(3^{\prime \prime}\right) \text { concrete reinforced } \\
\quad \text { floor } \\
{\left[1.1 \mathrm{~m}\left(3.5^{\prime}\right) \text { air space }\right]} \\
R=\left(.59 \mathrm{~m}^{2} \cdot \mathrm{K}\right) / \mathrm{W}(3.37)\end{array}$ & $\begin{array}{l}\text { Carpet - pad } \\
7.6 \mathrm{~cm}\left(3^{\prime \prime}\right) \text { concrete reinforced } \\
\text { f1oor } \\
{\left[1.1 \mathrm{~m}\left(3.5^{\prime}\right) \text { air space] }\right.} \\
\mathrm{R}=\left(.59 \mathrm{~m}^{2} \cdot \mathrm{K}\right) / \mathrm{W}(3.37)\end{array}$ \\
\hline Roof (Flat) & $\begin{array}{l}1.0 \mathrm{~cm}\left(3 / 8^{\prime \prime}\right) \text { built-up roofing } \\
5.1 \mathrm{~cm}\left(2^{\prime \prime}\right) \text { roof insulation } \\
\text { Metal deck } \\
{\left[1.1 \mathrm{~m}\left(3.5^{\prime}\right) \text { air space }\right]} \\
\mathrm{R}=\left(1.20 \mathrm{~m}^{2} \cdot \mathrm{K}\right) / \mathrm{W}(6.82)\end{array}$ & $\begin{array}{l}1.0 \mathrm{~cm}\left(3 / 8^{\prime \prime}\right) \text { built-up roofing } \\
\text { No insulation } \\
\text { Metal deck } \\
{\left[1.1 \mathrm{~m}\left(3.5^{\prime}\right) \text { air space }\right]} \\
\mathrm{R}=\left(.22 \mathrm{~m}^{2} \cdot \mathrm{K}\right) / \mathrm{W}(1.26\end{array}$ \\
\hline Ceiling & $\begin{array}{l}1.3 \mathrm{~cm}\left(1 / 2^{\prime \prime}\right) \text { ceiling panel } \\
\mathrm{R}=\left(.22 \mathrm{~m}^{2} \cdot \mathrm{K}\right) / \mathrm{W}(1.25)\end{array}$ & $\begin{array}{l}1.3 \mathrm{~cm}\left(1 / 2^{\prime \prime}\right) \text { ceiling panel } \\
\mathrm{R}=\left(.22 \mathrm{~m}^{2} \cdot \mathrm{K}\right) / \mathrm{W}(1.25)\end{array}$ \\
\hline Main F1oor & $\begin{array}{l}10.2 \mathrm{~cm}\left(4^{\prime \prime}\right) \text { concrete slab } \\
\text { No insulation } \\
\mathrm{R}=\left(.08 \mathrm{~m}^{2} \cdot \mathrm{K}\right) / \mathrm{W}(.48)\end{array}$ & $\begin{array}{l}10.2 \mathrm{~cm}\left(4^{\prime \prime}\right) \text { concrete slab } \\
\text { No insulation } \\
\mathrm{R}=\left(.08 \mathrm{~m}^{2} \cdot \mathrm{K}\right) / \mathrm{W}(.48)\end{array}$ \\
\hline
\end{tabular}

Source: Honeywe11, Inc., Energy Resources Center [36].

* R-values include surface resistances.

+ Studs spaced $61 \mathrm{~cm}\left(24^{\prime \prime}\right)$. 


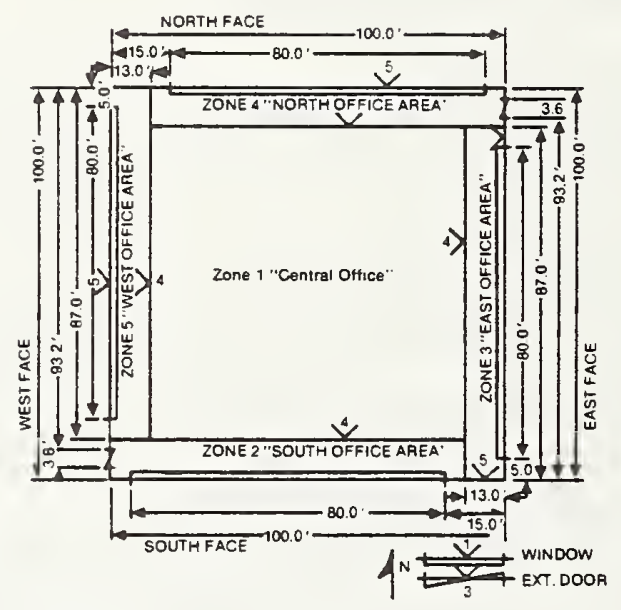

Interior Layout

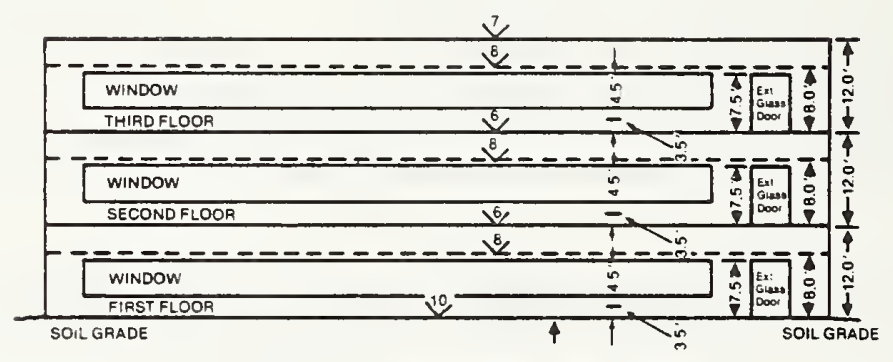

Outside View of East and West Faces

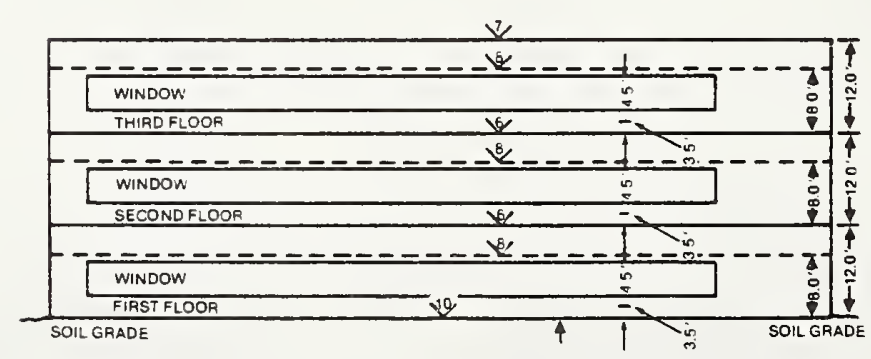

Outside View of North and South Faces

Source: Honeywell, Inc., Energy Resources Center [36]. 


\section{Figure 3.2 Office Building Load Schedules}

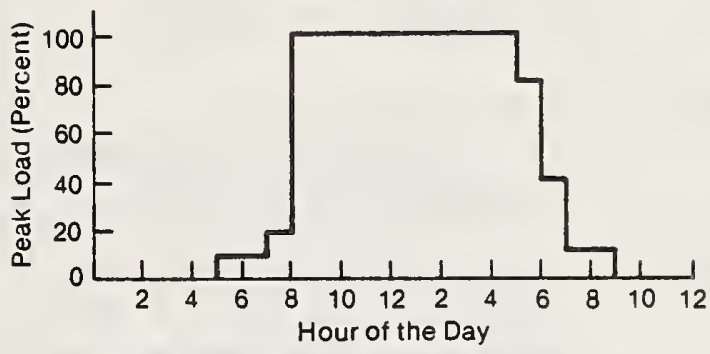

Office Building People Load Schedule

[Average Number of People During Peak Hours of Operation $=300$ ]

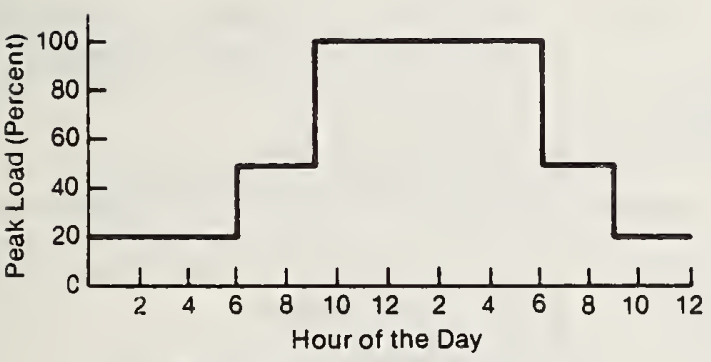

Office Building Light Schedule [Light at Peak Load $=26.9 \mathrm{~W} / \mathrm{m}^{2}$ $\left.\left(2.5 \mathrm{~W} / \mathrm{ft}^{2}\right)\right]$

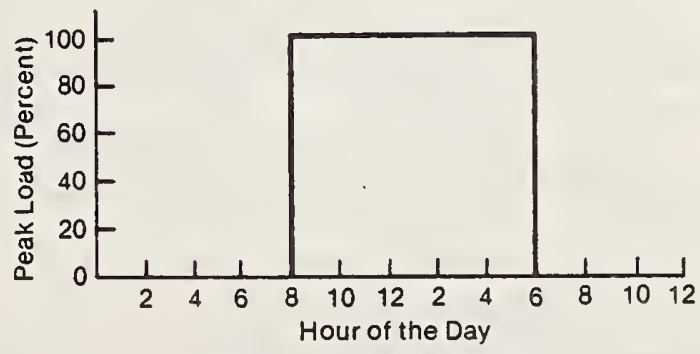

Office Building Hot Water Schedule

[Maximum Hot Water Demand $=568 \mathrm{l} / \mathrm{hr}$ or $\left.\left.1.577 \times 10^{-4} \mathrm{~m}^{3} / \mathrm{s}\right)(150 \mathrm{gal} / \mathrm{hr})\right]$

Source: Honeywe11, Inc., Energy Resources Center [36]. 
Table 3.4 Retail Store Construction Characteristics

\begin{tabular}{|c|c|c|}
\hline $\begin{array}{c}\text { Surface } \\
\text { Description }\end{array}$ & New Retail Store & Existing Retail Store \\
\hline Windows ${ }^{a}$ & $\begin{array}{l}\text { Insulating glass } \\
{\left[1.3 \mathrm{~cm}\left(1 / 2^{*}\right) \text { air space }\right]} \\
\mathrm{R}=\left(.36 \mathrm{~m}^{2} \cdot \mathrm{K}\right) / \mathrm{W}(2.04)\end{array}$ & $\begin{array}{l}0.6 \mathrm{~cm}\left(1 / 4^{\prime \prime}\right) \text { single pane glass } \\
\mathrm{R}=\left(.15 \mathrm{~m}^{2} \cdot \mathrm{K}\right) / \mathrm{W}(.88)\end{array}$ \\
\hline Exterior Doors ${ }^{a}$ & $\begin{array}{l}\text { Insulating glass } \\
{\left[1.3 \mathrm{~cm}\left(1 / 2^{*}\right) \text { air space }\right]} \\
\mathrm{R}=\left(.36 \mathrm{~m}^{2} \cdot \mathrm{K}\right) / \mathrm{W}(2.04)\end{array}$ & $\begin{array}{l}0.6 \mathrm{~cm}\left(1 / 4^{\prime \prime}\right) \text { single pane glass } \\
\mathrm{R}=\left(.15 \mathrm{~m}^{2} \cdot \mathrm{K}\right) / \mathrm{W}(.88)\end{array}$ \\
\hline Interior Walls & $\begin{array}{l}1.3 \mathrm{~cm}\left(1 / 2^{\circ}\right) \text { gypsum board } \\
10.2 \mathrm{~cm}\left(4^{\circ}\right) \text { metal frame } \\
1.3 \mathrm{~cm}\left(1 / 2^{\prime \prime}\right) \text { gypsum board } \\
\mathrm{R}=\left(.32 \mathrm{~m}^{2} \cdot \mathrm{K}\right) / \mathrm{W}(1.83)\end{array}$ & $\begin{array}{l}1.3 \mathrm{~cm}\left(1 / 2^{\circ}\right) \text { gypsum board } \\
10.2 \mathrm{~cm}\left(4^{\prime \prime}\right) \text { metal frame } \\
1.3 \mathrm{~cm}\left(1 / 2^{\prime \prime}\right) \text { gypsum board } \\
\mathrm{R}=(.32 \mathrm{~m} 2 . \mathrm{K} / \mathrm{W}(1.83)\end{array}$ \\
\hline Exterior Walls & $\begin{array}{l}5.1 \mathrm{~cm}\left(2^{\prime \prime}\right) \text { metal curtain wall } \\
10.2 \mathrm{~cm}\left(4^{\circ}\right) \text { metal frame } \\
2.5 \mathrm{~cm}(1 ") \text { rigid insulation } \\
1.3 \mathrm{~cm}\left(1 / 2^{\prime \prime}\right) \text { gypsum board } \\
\mathrm{R}=\left(1.14 \mathrm{~m}^{2} \mathrm{~K}\right) / \mathrm{W}(6.45)\end{array}$ & $\begin{array}{l}5.1 \mathrm{~cm}\left(2^{\prime \prime}\right) \text { metal curtain wall } \\
10.2 \mathrm{~cm}\left(4^{\prime \prime}\right) \text { metal frame } \\
\text { No insulation } \\
\mathrm{R}=\left(.35 \mathrm{~m}^{2} \cdot \mathrm{K}\right) / \mathrm{W}(2.00)\end{array}$ \\
\hline Roof (Flat) & $\begin{array}{l}1.0 \mathrm{~cm}\left(3 / 8^{\prime \prime}\right) \text { built-up roofing } \\
5.1 \mathrm{~cm}\left(2^{\prime \prime}\right) \text { roof insulation } \\
\text { Metal deck } \\
0.8 \mathrm{~m}\left(2.5^{\prime}\right) \text { air space } \\
\mathrm{R}=\left(1.20 \mathrm{~m}^{2} \cdot \mathrm{K}\right) / \mathrm{W}(6.82)\end{array}$ & $\begin{array}{l}1.0 \mathrm{~cm}\left(3 / 8^{\prime \prime}\right) \text { built-up roofing } \\
\text { No insulation } \\
\text { Metal deck } \\
0.8 \mathrm{~m}\left(2.5^{\prime}\right) \text { air space } \\
\mathrm{R}=\left(.22 \mathrm{~m}^{2} \cdot \mathrm{K}\right) / \mathrm{W}(1.26)\end{array}$ \\
\hline Celling & $\begin{array}{l}1.3 \mathrm{~cm}\left(1 / 2^{\prime \prime}\right) \text { false ceiling } \\
\mathrm{R}=\left(.22 \mathrm{~m}^{2} \cdot \mathrm{K}\right) / \mathrm{W}(1.25)\end{array}$ & $\begin{array}{l}1.3 \mathrm{~cm}\left(1 / 2^{\prime \prime}\right) \text { false ceiling } \\
\mathrm{R}=\left(.22 \mathrm{~m}^{2} \cdot \mathrm{K}\right) / \mathrm{W}(1.25)\end{array}$ \\
\hline Main Floor & $\begin{array}{l}10.2 \mathrm{~cm}\left(4^{\prime \prime}\right) \text { concrete slab } \\
\text { No insulation } \\
\left.\mathrm{R}=.08 \mathrm{~m}^{2} \cdot \mathrm{K}\right) / \mathrm{W}(.48)\end{array}$ & $\begin{array}{l}10.2 \mathrm{~cm}\left(4^{\prime \prime}\right) \text { concrete slab } \\
\text { No insulation } \\
\mathrm{R}=\left(.08 \mathrm{~m}^{2} \cdot \mathrm{K}\right) / \mathrm{W}(.48)\end{array}$ \\
\hline
\end{tabular}

Source: Honeywe11, Inc., Energy Resources Center [36].

a $\mathrm{R}$-values include surface resistances. 


\section{Figure 3.3 Schemata of Retail Stores}
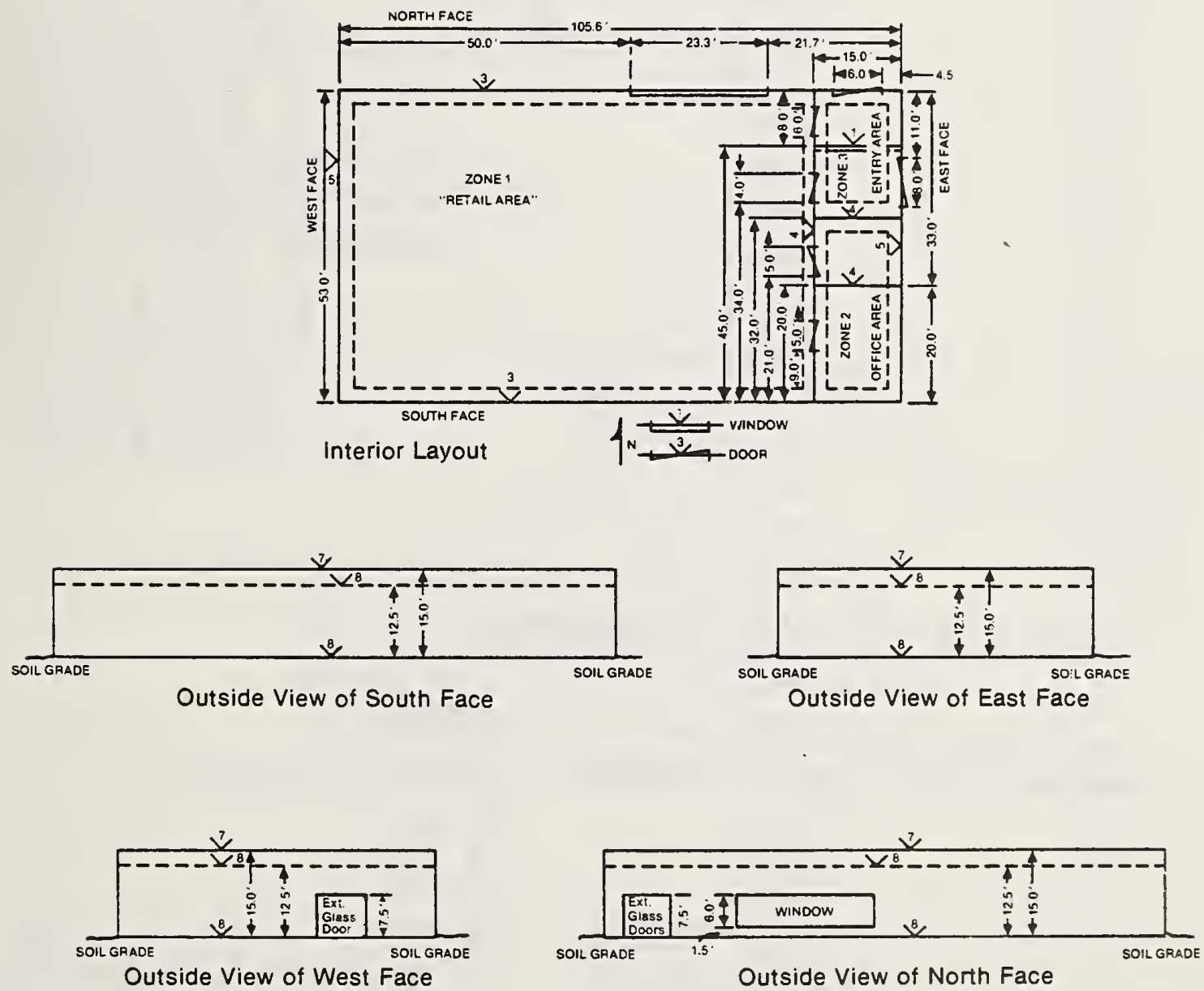

Source: Honeywell, Inc., Energy Resources Center [36]. 


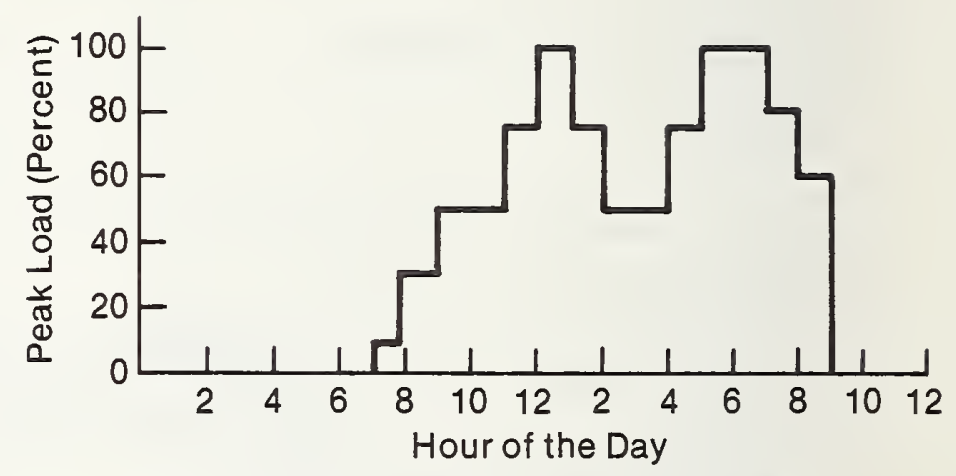

Office Building People Load Schedule [Average Number of People During Peak Hours of Operation $=100$ ]

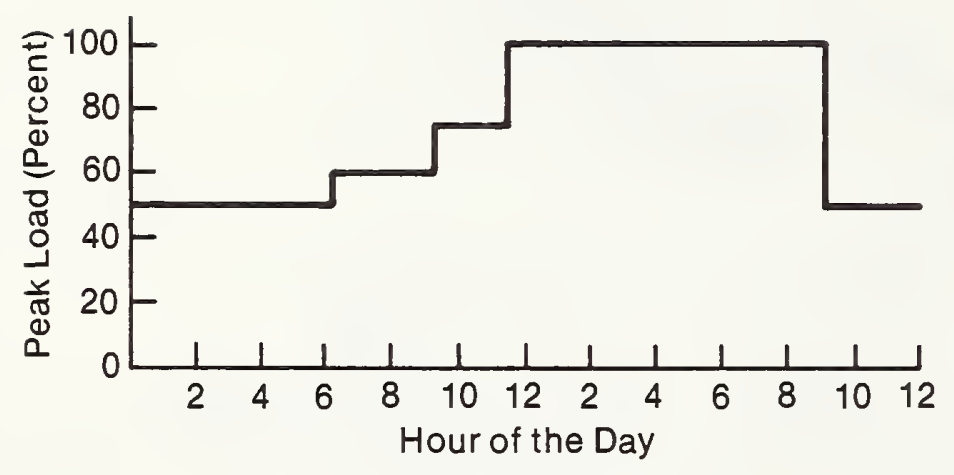

Retail Building Light Use Schedule [Maximum Lights $\left.=32.3 \mathrm{~W} / \mathrm{m}^{2}\left(3.0 \mathrm{~W} / \mathrm{ft}^{2}\right)\right]$

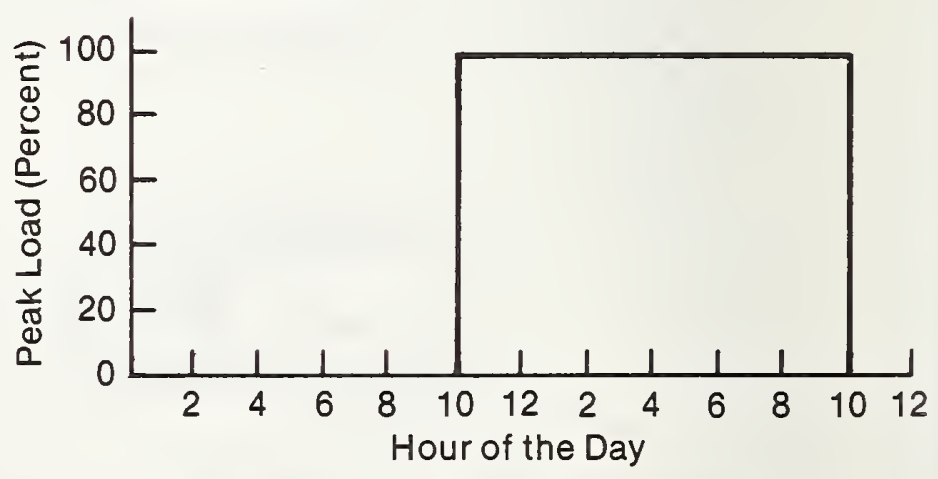

Retail Building Hot Water Schedule [ Maximum Hot Water Demand $=6.11 \mathrm{l} / \mathrm{hr}$ or $\left.\left.1.698 \times 10^{-6} \mathrm{~m}^{3} / \mathrm{s}\right)(1.615 \mathrm{gal} / \mathrm{hr})\right]$

Source: Honeywe11, Inc., Energy Resources Center [36]. 


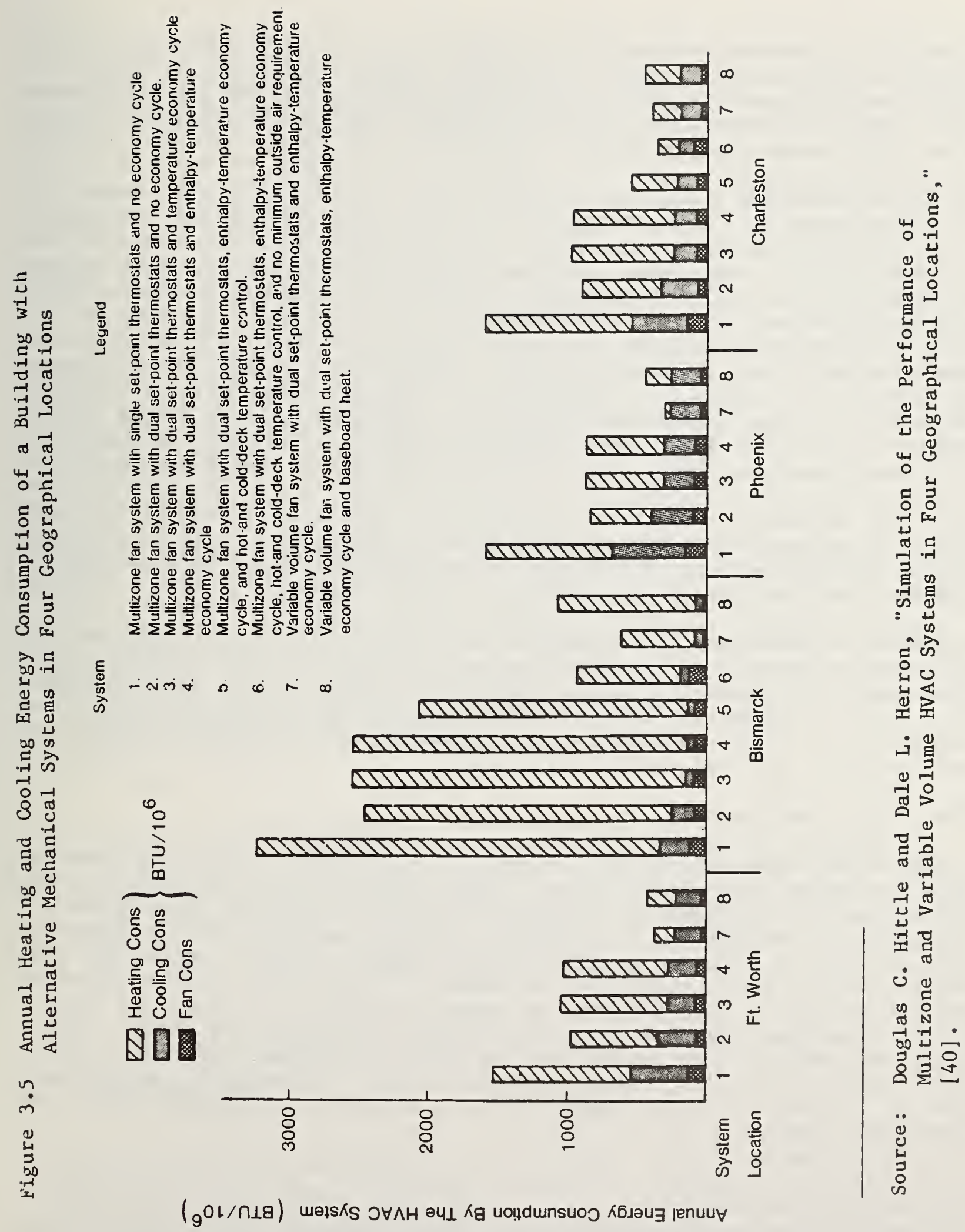


The mechanical systems were specified in detall for the four bulldings used for the case studies in this report.l In keeping with current trends in system design, energy-conserving variable air volume (VAV) systems (of the single-duct reheat type) were assumed for the new buildings; less energy efficient constant volume ( $\mathrm{CV}$ ) systems were assumed for the existing buildings.

Constant and variable volume air systems differ considerably in the energy loads they impose upon a building. Typically, in both systems, central supply air is cooled to the estimated lowest required temperature over the year. (A $15.6^{\circ} \mathrm{C}\left(60^{\circ} \mathrm{F}\right)$ ) cold deck temperature was assumed in this report). Once the air is cooled, the air distribution system regulates heat delivery to the building so that the desired temperature is maintained. The CV system does this by changing the supply air temperature, while keeping the same air flow rate. The VAV system maintains a constant heating or cooling coil temperature but changes the supply air flow rate. A VAV box at the entrance to each building zone limits the air being reheated and supplied to the building space to the minimum required at any given time. The VAV system considerably reduces the total energy requirement for heating and cooling as compared to the CV system.

Night-time temperature setbacks and reduction in operation of fans at night were assumed for all buildings because these simple measures for energy conservation are now widely undertaken in both new and existing buildings. An economizer cycle was specified for all but the existing retail store.

An economizer cycle used in conjunction with either a VAV or CV system controls the inflow of outside air to the air system. Outside air mixed with recirculated return air is supplied to the preheat and cooling coils. By increasing the inflow of outside air during in-between seasons and cold seasons, and reducing it in hot or humid months, the economizer cycle serves to reduce, or even eliminate, the load on the cooling coil.

\subsubsection{Office Buildings}

Two VAV systems were assumed for the new office building: one for the interior zones and one for the exterior zones. System capacities were specified for each building and location based on an analysis of the sensible and latent loads estimated for each building and location. (System capacities were established using the loads portion of the BLAST loads analyzer program -- see section 4.1.) For the interior zones, the supply air capacity is set to meet the annual zonepeak latent cooling load, with the VAV system supplying its minimum air fraction of 10 percent. For exterior zones, supply air capacity is set for the annual zone-peak sensible cooling load, with the VAV system supplying its maximum or capacity air flow. During operating hours, a minimum of 5 percent outside air, or one outside air change per hour, whichever was greater, was assumed to be maintained.

1 The selection of mechanical systems and specification of their characteristics were tasks assisted by Honeywell, Inc., Energy Resources Center, under contract to NBS [36]. 
The capacity of an air system is generally sized to meet peak-load conditions (temperature and humidity) whether or not these conditions occur simultaneously in all zones. The annual zone-peak sensible cooling load, 1.e., the energy required to maintain a desired temperature during the non-heating season, usually dictates the capacity of the system. (For buildings with a large percentage of exterior walls and roofs relative to interior space, sensible energy gains through the building envelope and from people and lights generate the major portion of the energy load.) However, in the interfor zones of a multi-story building, the sensible loads tend to be smaller than the latent cooling loads (caused by the humidity from human breathing). A VAV system sized for peak sensible loads may not be sufficient to meet this load. Furthermore, because the VAV system is controlled on the basis of dry-bulb temperature, 1.e., sensible loads only, the control system may dictate a low supply air fraction when sensible loads are low but latent loads are high. Thus in establishing a capacity of the system, it is necessary to consider the latent loads being generated while the VAV system is operating at a low supply air fraction as well as at capacity. In the test runs, it was established that the capacity would be based on the latent load at the VAV minimum. (A CV system sized for the peak sensible load supplies sufficient air to satisfy the latent load.)

Two CV air systems were assumed for the existing office building, each with a preheat coil in the mixed air duct. The supply air volume for each zone was set to meet the annual zone-peak sensible cooling load. A minimum of 10 percent of the supply air was outside air, with a minimum of six air changes per hour. In both bulldings, heat was supplied to the building space by perimeter radiation units (exterior zones) and by terminal reheat coils (interior zones). An enthalpy controlled economizer cycle (which adjusts for humidity as well as for temperature conditions) was assumed for both office buildings.

\subsubsection{Retail Stores}

A single VAV system was assumed for the new retall store bullding. This system had a minimum supply air fraction of 20 percent of the system capacity, as compared with 10 percent in the new office bullding. Supply air capacities were set to meet the annual zone-peak sensible cooling loads with the VAV system operating at full capacicy. Outside air was set at a minimum of 5 percent of the supply air volume, or one air change per hour, whichever was greater. A temperature-only type economizer cycle was assumed for the new retail store.

The CV system for the existing retail store had no preheat coil and no economizer cycle. Ventilation outside air was 10 percent of the supply air volume.

\subsection{HEATING PLANTS}

The heating plants for the bulldings consisted of a solar energy system used in combination with a conventional hot water boiler, fired alternatively by electricity, natural gas, or distillate fuel oil. The gas or oil-fired boilers in both of the existing buildings were assumed to be 60 percent efficient, while the gas and ofl-fired boilers in the new buildings were assumed to meet the ASHRAE 90-75 standard of 75 percent efficiency. The electric resistance systems for all buildings were assumed to be 100 percent efficient. 
These assumed boiler efficiencies of 60 and 75 percent are considerably higher than would normally be reasonable to assume for the heating system in its entirety, including the distribution system. Efficiency ratings of the delivery system were not taken into account in evaluating the economic feasibility of the solar energy systems because it was assumed that the solar energy would be subject to the same inefficiencies in the delivery system as the conventional energy source, thus cancelling out that efficiency effect. Possible cost of modification to the mechanical system to accommodate solar energy, and the efficiency effects thereof, were not taken into account. Boiler or furnace efficiency is a critical factor to consider in evaluating solar energy because it is a key determinant of the quantity of conventional energy saved.

For both the new and existing buildings, it was assumed that without solar, a conventional system identical to the backup conventional system in type, size, operating efficiency, and maintenance and repair costs would be used alone. This assumption may be deficient in that it neglects possible effects of part loading on boiler efficiencies. Other things equal, the lower the efficiency of the conventional furnace, the higher the net benefits of a solar energy system. However, if the efficiency of the conventional furnace drops substantially in direct response to the displacement of conventional energy by solar energy, the lowered conventional boiler efficiency offsets part, or all of the solar benefits. Although there is little hard measurement of the part loading effects it would appear, a priori, that a substantial solar-induced decline in plant efficiency would tend to drive solar towards either end of the sizing extremes. It is expected, however, that the part loading effects will generally not be drastic, particularly in newer systems.

Temperature settings of the heating systems were specified to be $20^{\circ} \mathrm{C}\left(68^{\circ} \mathrm{F}\right)$ during occupied periods of the heating season, $26^{\circ} \mathrm{C}\left(78^{\circ} \mathrm{F}\right)$ during occupied periods of cooling season, and $17^{\circ} \mathrm{C}\left(62^{\circ} \mathrm{F}\right)$ at night during the heating season. The cooling systems were assumed to be set at $37^{\circ} \mathrm{F}\left(99^{\circ} \mathrm{F}\right)$ during unoccupled periods.

The solar energy equipment was assumed to include high quality, double-glazed flat-plate collectors with selective absorber coatings like that illustrated in figure 3.6. The systems were assumed to use liquid as the heat transfer storage medium. 1 An off-the-shelf solar energy system was assumed for the retail store's hot water system, and custom designed and engineered systems for all of the other applications.

Figures 3.7 and 3.8 show illustrative schematic diagrams of solar energy systems like those assumed for this study. Figure 3.7 shows a service hot water system only, and figure 3.8, a combined space heating/hot water system.

1 The solar energy systems were characterized by Honeywel1, Inc., Energy Resources Center, under contract to NBS [36]. The collector design is representative of those installed in commercial buildings under the Solar Heating and Cooling Commercial Demonstration Program. 


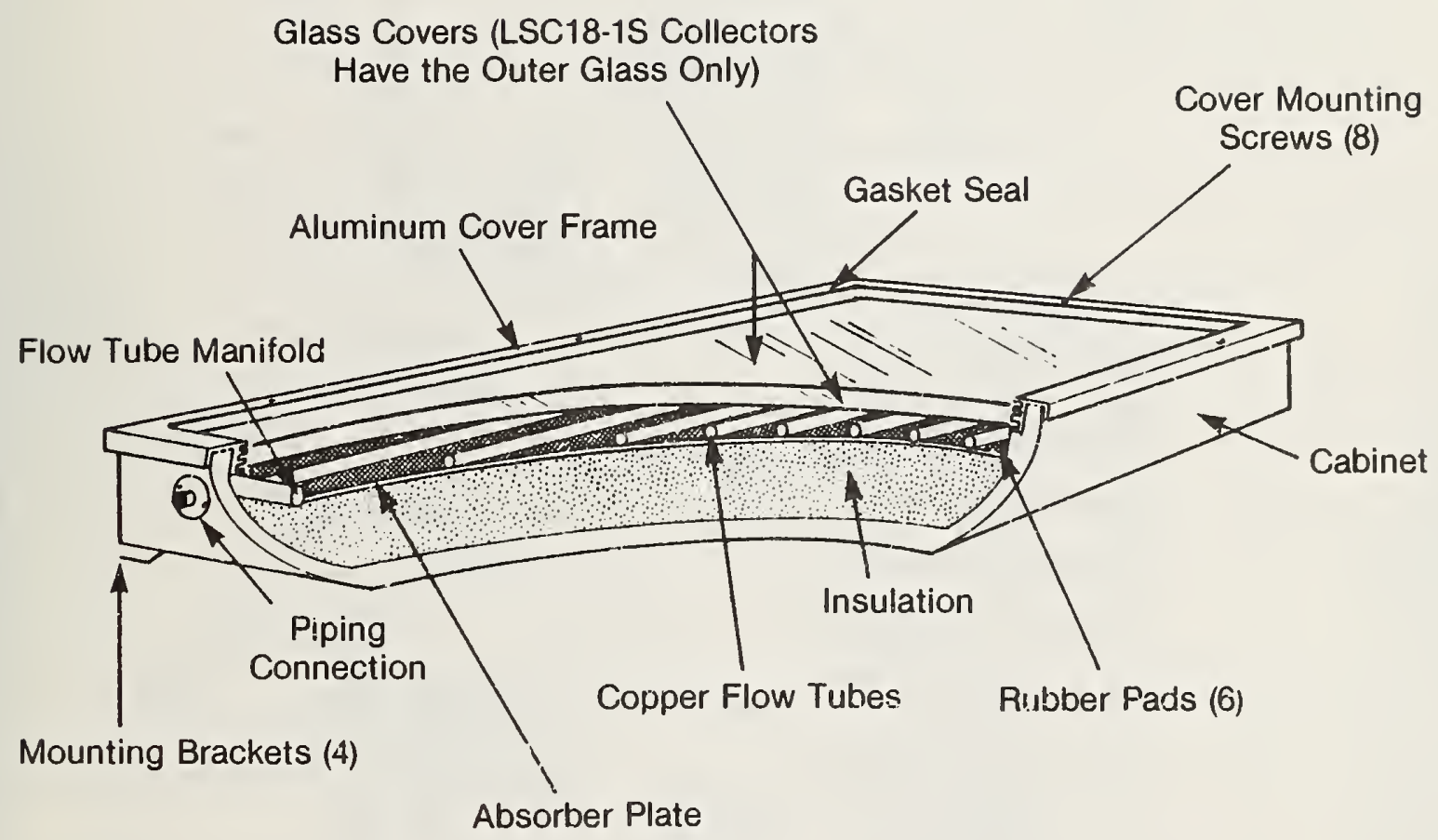

Source: Honeywell, Inc., Energy Resources Center [36].

a The collector covers illustrated are two sheets of .3 cm (1/8") tempered, antireflection low iron glass, with a gasket seal. The solar absorber is an assembly of parallel copper tubes bonded to a steel plate of black chrome on nickel. The collector has $8.9 \mathrm{~cm}\left(31 / 2^{\prime \prime}\right)$ of fiberglass insulation beneath the absorber plate and $2.5 \mathrm{~cm}$ ( $1^{\prime \prime)}$ around the sides of the collector enclosure. The enclosure is constructed of corrosion-resistant heavy gauge galvolume steel with a special electro-process paint finish. 

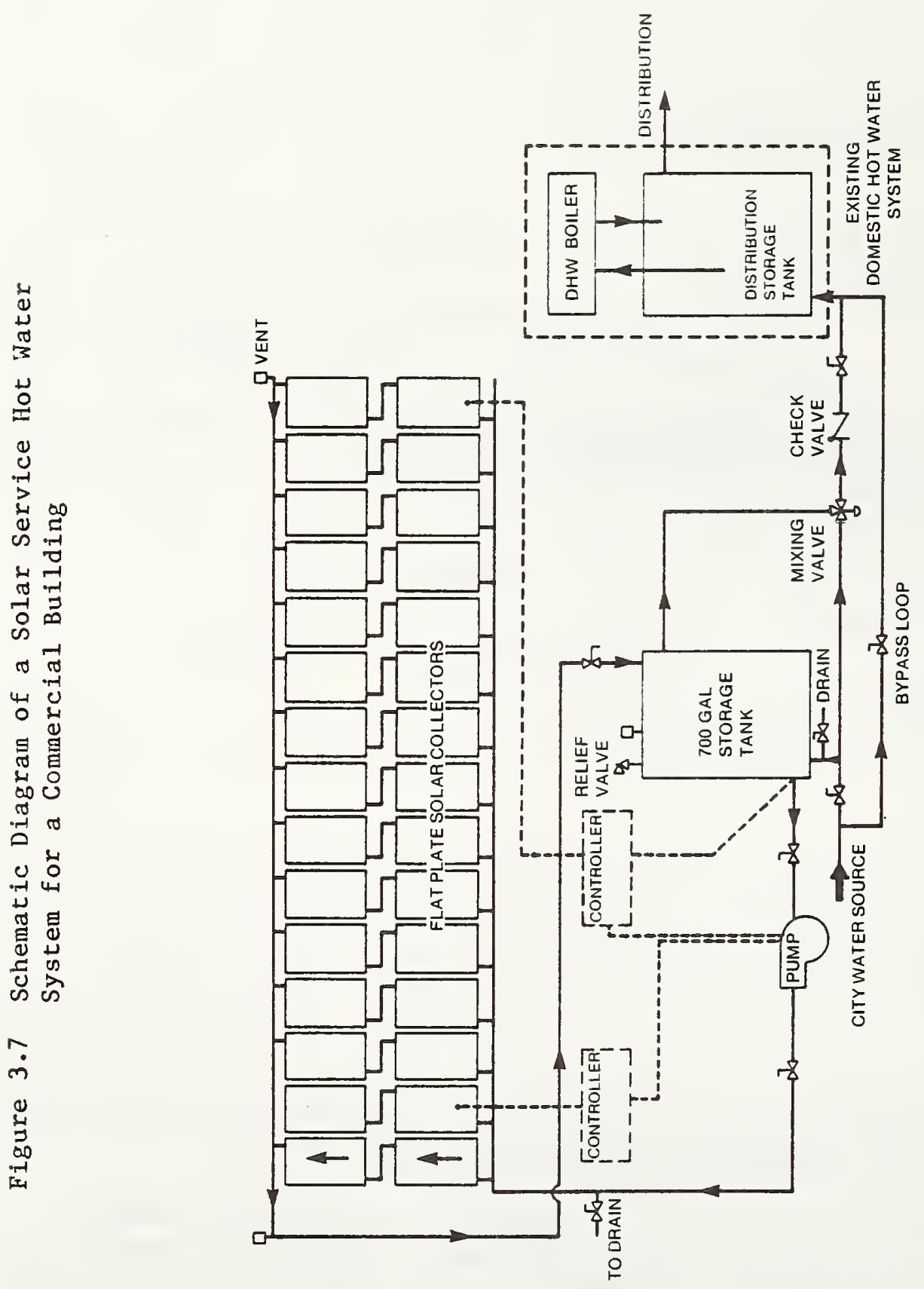

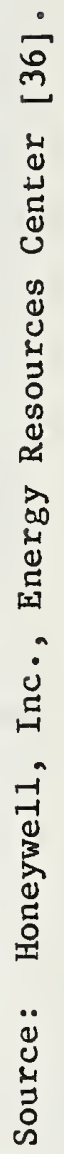




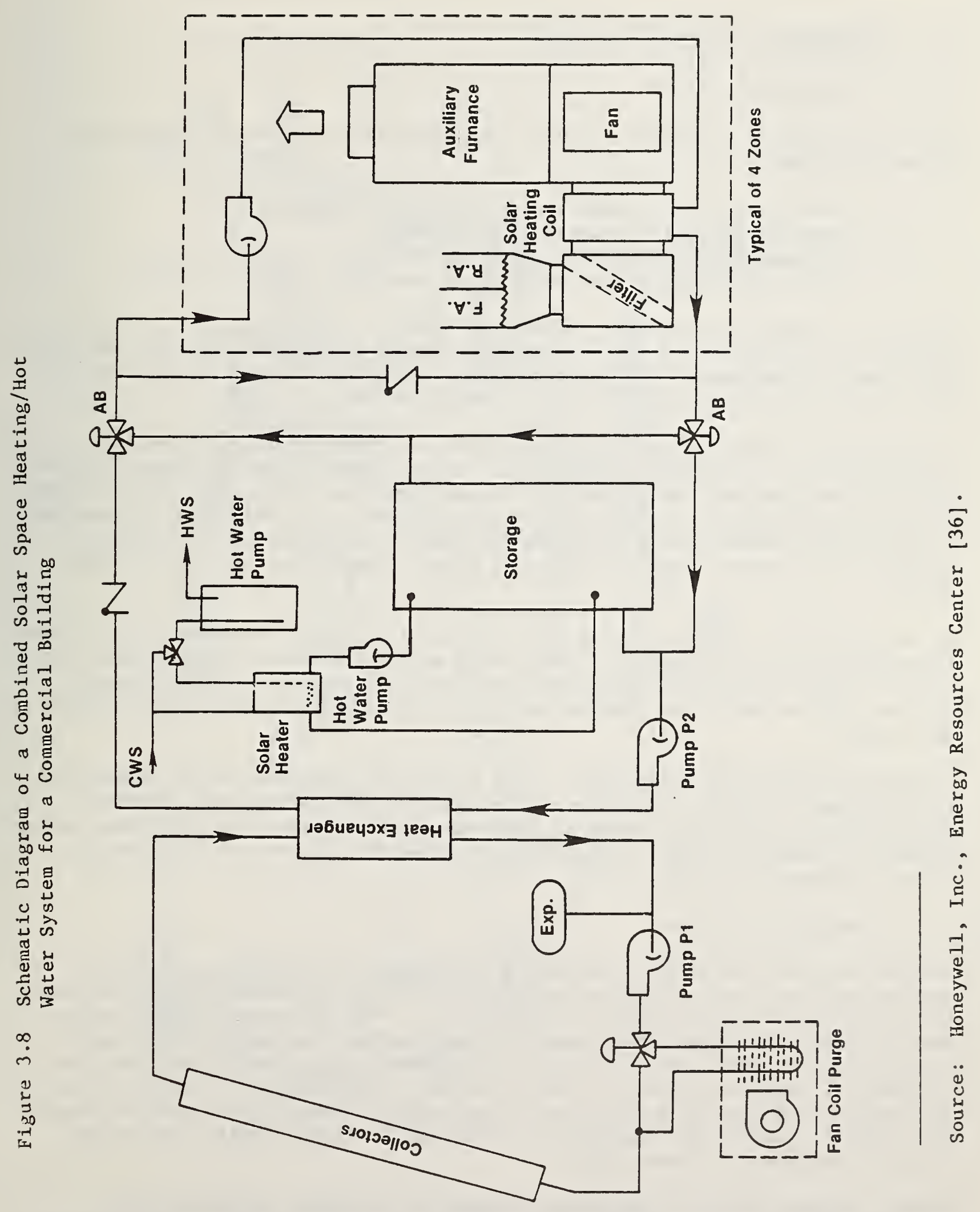




\subsection{GEOGRAPHICAL LOCATIONS AND DATA}

\subsubsection{Selection of Cities}

The following four selection criteria were applied to determine regions and cities for study:

1. Coverage of major climate zones in the continental U.S.;

2. Coverage of solar radiation variability;

3. Representation of major population centers;

4. Availability of hourly weather data and solar radiation data.

A survey was made of the major regions designated by other studies of solar energy, in particular the three "Phase 0" reports by General Electric [42], TRW [43], and Westinghouse [44]; two reports by the Mitre Corporation [45, 46]; and a report by the Intertechnology Corporation [47].

A comparison of these classifications with the Trewartha climate typology indicated that the twelve climatological regions identified by General Electric and later adopted by Intertechnology represented nine of the 11 climatic types designated by Trewartha. This is a broader climatic coverage than is provided by the other regional classifications examined. On the basis of its broad coverage, the General Electric regional classification was adopted for this study.

To select specific cities within each of the 12 regions, the total of 26 cities identified by the six reports listed above were located on a map divided into the 12 climate regions to determine their relative placements within each region. Cities were then checked against the availability of hourly weather data tapes.

Applying the selection criteria, it was determined that the cities identified by the General Electric study were also suitable for this study. However, Apalachicola, Florida was added to the sample to represent the Gulf Coast area. Figure 3.9 shows the final delineation of climatic regions and the specific cities selected for study.

\subsubsection{Geographical Data}

Weather data for evaluating the energy requirements of buildings in the 13 cities are from the Test Reference Year (TRY) series of weather tapes furnished by the National Climatic Center, Ashville, NC. The TRY tapes contain hourly data for dry-bulb temperature, wet-bulb temperature, dew-point temperature, wind direction, wind speed, barometric pressure at the station, weather (precipitation, fog, haze, dust), total sky cover, cloud amount ( 4 layers), type of cloud, and height of base of each cloud layer. (New Orleans weather tapes are used for the thermal analyses of buildings in Apalachicola, due to the lack of TRY tapes for that city.)

Monthly values for solar radiation incident on the solar collector were calculated using average daily radiation values reported by Liu and Jordan [48] 


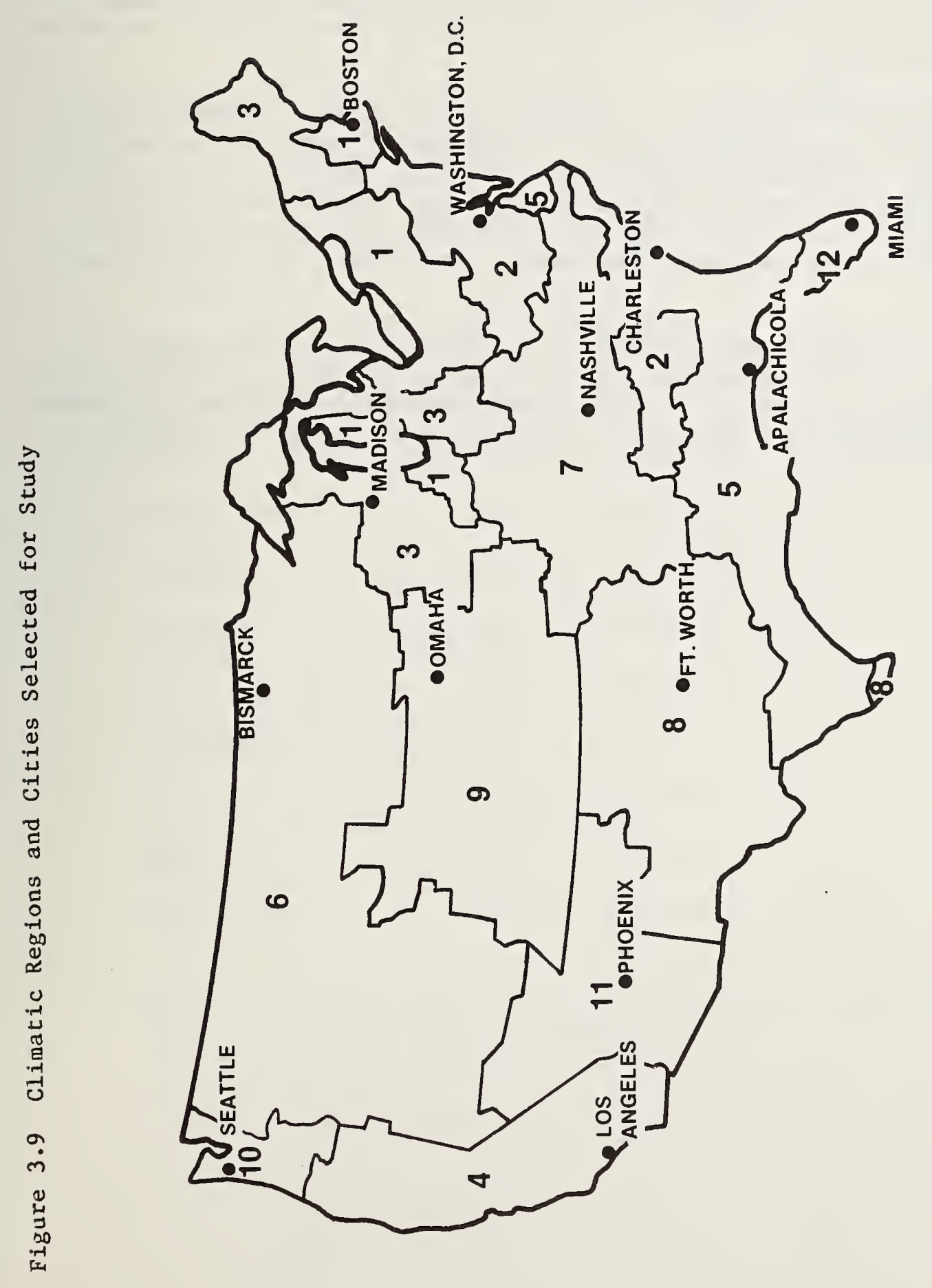


and procedures for adjusting for collector tilt developed by Klein [49]. (These procedures are incorporated within the economic optimization computer model in appendix $B_{.}$) Annual insolation values derived using these data and procedures are given in table 3.5 .

The analyses of energy requirements also required two measures of underground temperature: 1) the temperature of the water supplied through city mains for service use, and 2) the temperature of the earth around the building perimeter. Water supply temperatures were assumed to approximate deep-ground [1.2-3.7 m $\left(4^{\prime}-6^{\prime}\right)$ ] average soil temperatures reported by Kusuda [50]. (Kusuda reports data for 60 cities. Data for the cities nearest those selected for study were used.)

Arens and Carroll have published procedures for correcting the deep-soil temperatures to reflect temperatures $15 \mathrm{~cm}\left(6^{\prime \prime}\right)$ below the ground surface. Semiannual data corrected according to these procedures were used to measure thermal losses through the buflding floors [51]. These data are shown in tables 3.6 and 3.7 , respectively. 
Table 3.5 Annual Insolation Values for Selected Cities ${ }^{a}$

\begin{tabular}{|c|c|c|c|c|}
\hline \multirow[b]{3}{*}{ Boston } & \multicolumn{2}{|c|}{$\begin{array}{l}\text { Hot Water } \\
\text { Systems }\end{array}$} & \multicolumn{2}{|c|}{$\begin{array}{l}\text { Space \& Water } \\
\text { Heating Systems }\end{array}$} \\
\hline & $\mathrm{MJ} / \mathrm{m}^{2}$ & $\mathrm{Btu} / \mathrm{ft}^{2}$ & $\mathrm{MJ} / \mathrm{m}^{2}$ & $\mathrm{Btu} / \mathrm{ft}^{2}$ \\
\hline & $5,458.1$ & $480,614 \cdot 1$ & $5,238.9$ & $461,308.2$ \\
\hline Washington, D.C. & $6,148 \cdot 3$ & $541,392.2$ & $5,924.6$ & $521,688.9$ \\
\hline Nashville & $6,599.4$ & $581,108.6$ & $6,324 \cdot 1$ & $556,871.1$ \\
\hline Charleston & $6,917 \cdot 5$ & $609,119.9$ & $6,717 \cdot 3$ & $591,490.5$ \\
\hline Miami & $7,485.7$ & $659,151.4$ & $7,295.9$ & $642,441.0$ \\
\hline Apalachicola & $7,531.9$ & $663,222.6$ & $7,317.0$ & $644,302.3$ \\
\hline Bismarck & $6,101 \cdot 6$ & $537,275 \cdot 3$ & $5,872.4$ & $517,092.7$ \\
\hline Madison & $7,198.4$ & $633,858.6$ & $6,942 \cdot 4$ & $612,196.0$ \\
\hline Omaha & $6,740.8$ & $593,560.1$ & $6,526.0$ & $574,647.4$ \\
\hline Fort Worth & $7,629 \cdot 6$ & $671,812.5$ & $7,385.6$ & $650,347.5$ \\
\hline Phoenix & 9.164 .0 & $806,936.7$ & $8,897.6$ & $783,480.4$ \\
\hline Seattle & $4,623.7$ & $407,136.6$ & $4,380.5$ & $385,728.0$ \\
\hline Los Angeles & $7,769.5$ & $684,144.0$ & $7,522.9$ & $662,432.5$ \\
\hline
\end{tabular}

Source of radiation data: B.Y.H. Liu and R. C. Jordan, "A Rational Procedure for Predicting the Long-Term Average Performance of FlatPlate Sular Energy Collectors" [48].

a Corrected for collector tilt. 
Table 3.6 Water Supply Temperatures Used in Analysis of Service Hot Water Requirements

\begin{tabular}{|c|c|c|c|c|c|}
\hline \multirow{2}{*}{$\begin{array}{l}\text { City Selected } \\
\text { for Study }\end{array}$} & \multirow{2}{*}{$\begin{array}{l}\text { Nearest City } \\
\text { for which } \\
\text { Data is Available }\end{array}$} & \multicolumn{4}{|c|}{$\begin{array}{l}\text { Water Supply Temperature } \\
\text { grees Centigrade (Fahrenheit) }\end{array}$} \\
\hline & & Jan.-Mar. & April-June & July-Sep. & Oct.-Dec. \\
\hline Boston & Ithaca, NY & $5 \quad(41)$ & $5 \quad(41)$ & $14 \quad(58)$ & $12 \quad(54)$ \\
\hline Washington, D.C. & Upper Mar1boro, MD & $7 \quad(44)$ & $9 \quad(49)$ & $19 \quad(66)$ & $18 \quad(64)$ \\
\hline Nashville & Jackson, TN & $10 \quad(50)$ & $13 \quad(55)$ & $21 \quad(69)$ & $18 \quad(64)$ \\
\hline Charleston & Calhoun, SC & $11 \quad(52)$ & $14 \quad(57)$ & $23(73)$ & $21 \quad(70)$ \\
\hline Miami & Gainesville, FL & $16 \quad(61)$ & $22 \quad(71)$ & $26 \quad(79)$ & $26 \quad(78)$ \\
\hline Apalachicola & Athens, GA & $13 \quad(55)$ & $16 \quad(60)$ & $24 \quad(75)$ & $23 \quad(73)$ \\
\hline Madison & East Lansing, MI & $5 \quad(41)$ & $5 \quad(41)$ & $16 \quad(61)$ & $14 \quad(58)$ \\
\hline Bismarck & Madison, SD & $2 \quad(36)$ & $3 \quad(38)$ & $15 \quad(59)$ & $13 \quad(55)$ \\
\hline Omaha & Lincoln, NE & $4 \quad(40)$ & $7 \quad(44)$ & $18 \quad(65)$ & $16 \quad(61)$ \\
\hline Fort Worth & Temple, TX & $16 \quad(61)$ & $18 \quad(65)$ & $27 \quad(81)$ & $25 \quad(77)$ \\
\hline Phoenix & Tempe, AZ & $14 \quad(58)$ & $17 \quad(63)$ & $25 \quad(77)$ & $23 \quad(74)$ \\
\hline Seattle & Seattle, WA & $8 \quad(46)$ & $10 \quad(50)$ & $15 \quad(59)$ & $13 \quad(56)$ \\
\hline Los Angeles & Brawley, CA & $19 \quad(66)$ & $23 \quad(73)$ & $31 \quad(87)$ & $29 \quad(85)$ \\
\hline
\end{tabular}

Source: T. Kusuda, NBSLD, The Computer Program for Heating and Cooling Loads in Buildings $[50]$. 
Table 3.7 Ground Temperatures Used in Analyses of Space Heating Requirements ${ }^{a}$

\begin{tabular}{|c|c|c|}
\hline \multirow[b]{2}{*}{ Location } & \multicolumn{2}{|c|}{ Degrees Fahrenheit (Centigrade) } \\
\hline & October-May & June-September \\
\hline Boston & $14 \quad(57)$ & $18 \quad(64)$ \\
\hline Washington, D.C. & $16 \quad(60)$ & $20 \quad(68)$ \\
\hline Nashville & $17 \quad(62)$ & $21 \quad(69)$ \\
\hline Charleston & $17 \quad(63)$ & $22 \quad(72)$ \\
\hline Miami & $20 \quad(68)$ & $24 \quad(75)$ \\
\hline Apalachicola & $19 \quad(67)$ & $24 \quad(75)$ \\
\hline Bismarck & $13 \quad(56)$ & $18 \quad(65)$ \\
\hline Madison & $13 \quad(55)$ & $18 \quad(64)$ \\
\hline Omaha & $14 \quad(58)$ & $19 \quad(66)$ \\
\hline Fort Worth & $19 \quad(67)$ & $24 \quad(75)$ \\
\hline Phoenix & $19 \quad(67)$ & $23 \quad(73)$ \\
\hline Seattle & $16 \quad(60)$ & $18 \quad(64)$ \\
\hline Los Angeles & $20 \quad(68)$ & $24 \quad(75)$ \\
\hline
\end{tabular}

Source: Edward A. Arens and William L. Carro1l, Geographical Variation in the Heating and Cooling Requirements of a Typical Single Family House, and Correlation of These Requirements to Degree Days [51].

a The data were determined from averages of the winter and spring values and summer and fall values reported by Kusuda [50]. These averages were in turn averaged with the indoor-air average temperature. The actual cities for which the data were prepared are shown in the second column of table 3.6 . 


\subsection{HEATING AND HOT WATER REQUIREMENTS}

4.1.1 BLAST Transient Load Model

The BLAST (Building Loads Analyses and System Thermodynamics) transient load model was used to perform the analyses of heating requirements for the selected buildings in the designated locations.1 The BLAST model accounts for 1) hourly variations in solar loading on the building envelope, 2) transmission loads due to the building construction R-value characteristics, 3) internal loads from people, lights, and distribution equipment, including multizone variable air volume systems, 4) infiltration loads, and 5) the thermal capacity of the building. It has the advantages of a relatively fast running time. Data from the building loads and distribution systems subprograms are suitable for use with the solar load ratio performance model (section 4.2 ) and with the NBS economic analysis model (section 2.3 ).

Modifications to the BLAST program were required before using it to analyze the energy requirements of the prototypical building designs and systems in the 13 different citles. First, it was necessary to develop a methodology for using BLAST to size the air handling systems specified for the four buildings and locations and to validate the system control assumptions for each building. The new BLAST subprogram prepared for these purposes was used to calculate peak latent and sensible loads for each building and geographical location and to establish the sensible and latent load combinations at different points in time. This was done by performing full-year simulation runs to utilize extreme weather days. Very large system capacities were assumed for these runs to maintain zone temperatures at their inner limits (upper limit for heating, lower for cooling). Data obtained from running this subprogram were used to determine the system capacities for each bullding and location.

Additional modifications in the BLAST simulation included the following:

1) A masonry wall located diagonally across the space was simulated for the retail store zones, because the interior furnishings of the retail store sales area were assumed to have greater thermal storage effects than allowed for in BLAST.

2) Since only five- and seven-day operation schedules were provided for in BLAST, the program was modified for the retail stores to allow a six-day schedule. This modification was done by performing design day runs for five- and seven-day schedules, and adjusting the weekend schedule to make results close to the average of five- and seven-day results. Essentially, this entalled having the store operate half days on both Saturday and Sunday. Although this method may have altered start-up loads slightly over loads for a six-day week, the resulting monthly heating requirements appeared to be a good model of a six-day week.

1 For a description of the BLAST computer program, see [52] and [53]. The version of BLAST used in this study is designated BLAST-1.2. 
3) To facilitate operation of BLAST, the number of zones in the office building was reduced. Since the first and second story zones of the office building have nearly the same geometry and loads, it was possible to combine them in the computer simulation to form 10 thermal zones from the initial 15 zones. Trial runs showed differences of less than two percent in monthly loads with either the CV or VAV systems as a result of combining subjacent zones.

4) Because the computer responds more quickly in the BLAST simulation to a control action than would an actual building, control schedules were adjusted so that control actions occur an hour later than in a real building. The control schedules were set to coincide with the occupancy schedules shown in figures 3.2 and 3.4 .

The weather files used in the BLAST simulation were prepared using the March 1 , 1979 version of WIFE, the weather file encoding program developed by the Construction Engineering Research Laboratory (CERL) of the U.S. Department of the Army.

\subsubsection{Results of BLAST Analyses -- Space Heating}

With the above modifications, hourly heating and cooling loads for each zone were calculated with the BLAST Loads subprogram, using the system capacities generated in the design runs, hourly data from the TRY weather file, and the building descriptions and operating schedules described in sections 3.1 and 3.2 . The BLAST Loads subprogram accounts for a) transmission loads through walls, roofs, floors, and windows, b) solar gains through windows, walls, and roofs, c) internal loads from people, lights, and building equipment, and d)

infiltration loads.

Results from the BLAST Loads subprogram, together with the detailed specifications of the mechanical distribution system (including ventilation air requirements, equipment operating schedules, flow rates, fan pressures and motor efficiencies, heating coil capacities, dry and wet bulb temperatures, water supply temperatures, water velocity and flow rates, reheat capacities, and supply air volune) were entered into the systems simulation subprogram in BLAST. This final production phase of the BLAST program produced monthly requirements for thermal energy, broken down into space heating and cooling components. Table 4.1 shows the estimated annual space heating requirements of the new and existing office buildings and retail stores for each city aggregated from the monthly space heating requirements. These are the annual loads to be met by the solar energy auxiliary system or its alternative.1

1 Only the loads and nonsolar simulation portions of the BLAST program were used in this study. The economics portion of BLAST was not used because of its linited capability. It does not provide a tax or financing analysis, allow the input of multiple rates of fuel price escalation, nor calculate net savings in present value dollars [54]. 
Table 4.1 Estimated Annual Space Heating Requirements of the Selected Buildings ${ }^{a}$

\begin{tabular}{|c|c|c|c|c|c|c|c|c|}
\hline \multirow[b]{3}{*}{ Location } & \multicolumn{4}{|c|}{ Office Building } & \multicolumn{4}{|c|}{ Retail Stores } \\
\hline & \multicolumn{2}{|c|}{ New } & \multicolumn{2}{|c|}{ Existing } & \multicolumn{2}{|c|}{ New } & \multicolumn{2}{|c|}{ Existing } \\
\hline & $\mathrm{GJ}$ & $10^{6} \mathrm{Btu}$ & $\overline{\mathrm{GJ}}$ & $10^{6} \mathrm{Btu}$ & $\mathrm{GJ}$ & $10^{6} \mathrm{Btu}$ & GJ & $10^{6} \mathrm{Btu}$ \\
\hline Apalachicola & 200 & 190 & 3,431 & 3,252 & 93 & 88 & 818 & 775 \\
\hline Bismarck & 1,249 & 1,184 & 6,312 & 5,983 & 478 & 453 & 1,612 & 1,528 \\
\hline Boston & 658 & 624 & 4,840 & 4,588 & 268 & 254 & 1,139 & 1,080 \\
\hline Charleston & 233 & 221 & 3,491 & 3,309 & 116 & 110 & 903 & 856 \\
\hline Ft. Worth & 268 & 254 & 3,996 & 3,788 & 130 & 123 & 1,083 & 1,027 \\
\hline Los Angeles & 138 & 131 & 3,825 & 3,626 & 51 & 48 & 779 & 738 \\
\hline Madison & 896 & 849 & 5,623 & 5,330 & 350 & 332 & 1,354 & 1,283 \\
\hline Miami & 66 & 63 & 2,348 & 2,226 & 26 & 25 & 705 & 668 \\
\hline Nashville & 388 & 368 & 4,005 & 3,796 & 171 & 162 & 1,014 & 961 \\
\hline Omaha & 753 & 714 & 5,314 & 5,037 & 312 & 296 & 1,379 & 1,307 \\
\hline Phoenix & 226 & 214 & 4,416 & 4,186 & 117 & 111 & 1,175 & 1,114 \\
\hline Seattle & 593 & 562 & 5,375 & 5,095 & 247 & 234 & 1,175 & 1,114 \\
\hline Washington, D.C. & 462 & 438 & 4,466 & 4,233 & 208 & 197 & 1,174 & 1,113 \\
\hline
\end{tabular}

a These requirements were calculated by applying the BLAST computer program to the energy analysis of the selected buildings and mechanical systems and by aggregating the monthly data. Heating requirements are shown before adjustments for boiler efficiencies were made. 
Table 4.1 shows considerable variation in the estimated annual heating requirements between the new and the existing buildings, between the offices and the retail stores, and among the cities. The differences in estimated energy requirements between the new and existing buildings appear particularly great.

\subsubsection{Building Loads Model--Service Hot Water}

The energy requirements for service hot water were estimated separately from the space heating requirements. Service hot water loads were estimated to be 3.155 $\times 10^{-5} \mathrm{~m}^{3} / \mathrm{s}(0.5 \mathrm{gal} / \mathrm{min})$ for the office building, based on an average of 300 people during 10 operating hours, and $0.095 \times 10^{-5} \mathrm{~m} / \mathrm{s}(0.015 \mathrm{gal} / \mathrm{min})$ for the retail store, based on an average of 100 people during 12 operating hours. These estimated rates of hot water usage were assumed to represent the average hot water demand for these buildings. The approach to the development of these estimates is as following: Honeywe11, Inc., under contract to NBS, recommended a maximum hot water demand of $1.577 \times 10^{-4} \mathrm{~m}^{3} / \mathrm{s}(150 \mathrm{gal} / \mathrm{hr})$ for the office building and $1.698 \times 10^{-6} \mathrm{~m}^{3} / \mathrm{s}(1.615 \mathrm{gal} / \mathrm{hr})$ for the retail store. These maximum rates were compared with data published by ASHRAE for office buildings of $1.514 \times 10^{-3} \mathrm{~m}^{3} /$ person (.4 gal/person) for a maximum hour; $7.570 \times 10^{-3} \mathrm{~m}^{3} /$ person $(2.0 \mathrm{gal} /$ person) for a maximum day; and 3.785 $\times 10^{-3} \mathrm{~m}^{3} /$ person ( $1.0 \mathrm{gal} /$ person) for an average day. The ASHRAE average day rate per person was used directly for the office buildings analyses, resulting in an estimate of $3.155 \times 10^{-5} \mathrm{~m} / \mathrm{s}$ ( $30 \mathrm{gal} / \mathrm{hr}$ or $0.5 \mathrm{gal} / \mathrm{minute}$ ) for the building (based on 300 person occupancy over a 10-hour day).

Comparable average usage data were not available for retail stores. Half the maximum demand of $1.698 \times 10^{-6} \mathrm{~m} / \mathrm{s}(1.615 \mathrm{gal} / \mathrm{hr})$ recommended by Honeywell was taken as an estimate of the average rate. From this figure a usage rate was calculated which was rounded to $0.946 \times 10^{-6} \mathrm{~m} / \mathrm{s}(.015 \mathrm{gal} / \mathrm{min})$.

Using these water usage rates and the deep ground supply temperatures given in table 3.6 , energy requirements for service water heating are calculated with the standard static energy balance equation:

$$
\mathrm{Q}_{\mathrm{L}}=\mathrm{DWC}_{\mathrm{p}}\left(\mathrm{T}_{\text {out }}-\mathrm{T}_{\text {in }}\right) \text {, }
$$

where,

$$
\begin{aligned}
\mathrm{Q}_{\mathrm{L}} & =\text { energy requirements for hot water, } \mathrm{J}(\mathrm{Btu}) \\
\mathrm{D} & =\text { quantity of hot water demanded, } \mathrm{m}^{3}(\mathrm{gal}) \\
\mathrm{W} & =\text { density of water, } 100 \mathrm{~kg} / \mathrm{m}^{3}(8.34 \mathrm{1} / \mathrm{bal}) \\
\mathrm{C}_{\mathrm{p}} & =\text { specific heat of water, } 4.190 \times 10^{3} \mathrm{~J} /(\mathrm{kg} \cdot \mathrm{K})\left(1 \mathrm{Btu} / 1 \mathrm{~b} /{ }^{\circ} \mathrm{F}\right) \\
\mathrm{T}_{\mathrm{Out}} & =\text { hot water supply temperature }{ }^{\circ} \mathrm{C}\left({ }^{\circ} \mathrm{F}\right) \\
\mathrm{T}_{\text {In }} & =\text { supply water temperature, }{ }^{\circ} \mathrm{C}\left({ }^{\circ} \mathrm{F}\right)
\end{aligned}
$$

The resulting annual energy requirements for service hot water are shown in table 4.2. These estimates were used in the evaluation of the solar hot water systems in section 5.1. They were added to the space heating requirements in the analyses of combined solar space heating and hot water systems in section 5.2 . 
Table 4.2 Estimated Annual Hot Water Requirements the Selected Buildings ${ }^{a}$

\begin{tabular}{|l|c|c|c|c|}
\hline \multirow{2}{*}{ Location } & \multicolumn{2}{c|}{ Office Building } & \multicolumn{2}{c}{ Retail Stores } \\
\cline { 2 - 5 } Apalachicola & GJ & $10^{6}$ Btu & GJ & $10^{6}$ Btu \\
\hline Bismarck & 45.3 & 42.9 & 2.0 & 1.9 \\
\hline Boston & 58.4 & 55.4 & 2.5 & 2.4 \\
\hline Charleston & 57.4 & 54.4 & 2.4 & 2.3 \\
\hline Ft. Worth & 47.2 & 44.7 & 2.0 & 1.9 \\
\hline Los Angeles & 41.6 & 39.4 & 1.8 & 1.7 \\
\hline Madison & 36.7 & 34.8 & 1.6 & 1.5 \\
\hline Miami & 56.1 & 53.2 & 2.4 & 2.3 \\
\hline Nashville & 40.6 & 38.5 & 1.8 & 1.7 \\
\hline Omaha & 49.6 & 47.0 & 2.1 & 2.0 \\
\hline Phoenix & 54.5 & 51.7 & 2.3 & 2.2 \\
\hline Seattle & 43.7 & 41.4 & 1.9 & 1.8 \\
\hline Washington, D.C. & 52.2 & 49.5 & 2.2 & 2.1 \\
\hline
\end{tabular}

a See text for estimation procedures. 


\subsection{SOLAR ENERGY SYSTEM PERFORMANCE}

The solar load ratio model for active systems, developed by the Los Alamos Scientific Laboratory (LASL) was used to estimate the performance of the solar energy systems $[32,55]$. Unlike most other models of solar energy system performance, the solar load ratio model has documented capability for simulating commercial building systems, a prime factor in its selection for the case studies.

The solar load ratio model describes the performance of solar energy systems using general design and sizing curves which represent the empirical results of hourly simulations of different types of systems in different locations based on weather data from the 1950-62 period. The curves used in this study are based on simulations of a "typical" three-story commercial office building modeled for eight U.S. cities: Bismarck, ND; Fresno, CA; Los Alamos, NM; Madison, WI; Medford, OR; Miami, FL; Nashville, TN; and New York, NY. Note that four of these eight cities are among the 13 selected for case study.

"Universal" design and sizing curves have been developed by LASL for both combined space heating/hot water systems and for hot water systems. The universal curves express the fraction of the monthly thermal energy load met by solar as a function of collector area, monthly energy load of the building, and monthly solar radiation incident on the collector surface. Families of curves are available for three generic types of flat-plate collector and for various design water temperatures and heating coil supply temperatures. 1

The curves used for the case studies are based on a system of double-glazed, non-selective, flat plate collectors, a hot water setting of $54^{\circ} \mathrm{C}\left(130^{\circ} \mathrm{F}\right)$ for water heating only systems, a heating coil inlet temperature of $54^{\circ} \mathrm{C}\left(130^{\circ} \mathrm{F}\right)$ for combined space heating and hot water systems, and water storage sized for $73 \mathrm{~kg} / \mathrm{m}^{2}$ (15 1bs/ft${ }^{2}$ ) of collector. The design characteristics of the solar energy components specified for this study are either equal or superior to the design characteristics upon which the universal curves are based. Universal curves were not available for double-glazed collectors with selective coatings - the collectors specified for the case studies. However, the performance differences are not expected to be large. Adding a selective coating to the absorber surface of double-glazed collectors should improve performance only slight 1y.

Of the family of solar universal performance curves for combined space heating and hot water systems shown in figure 4.1, curve " $d$ " is the one used for the feasibility study, and of the family of curves for service hot water systems shown in figure 4.2, curve "b" is the one used.

1 LASL has since revised the universal design curves used in this study, such that they now predict somewhat lower performance for service hot water systems. The revisions are contained in an updated edition of the DOE Facilities Solar Design Handbook [32]. 
The computer code developed to apply the economic evaluation model incorporates the solar load ratio performance model within the economic model. The mathematical equations for the universal curves (shown in box inserts to figures 4.1 and 4.2 ) are linked with the economic model of section 2.3 .

\subsection{PURCHASE AND INSTALLATION COSTS OF THE SOLAR ENERGY SYSTEM}

\subsubsection{Estimating Fixed and Variable System Costs}

The costs for purchasing and installing a solar energy system are often quoted to a buyer either as (1) the total dollar cost of a particular system of given size, possibly broken down into labor, materials, and overhead (including profit), or (2) the average total system cost per unit of collector area, based also on a system of given size.

While either of these types of cost quotations will provide sufficient information about acquisition costs to determine if a given system is cost effective, neither gives adequate information to determine the economically optimal size of the system ( $1 . e .$, the size that will provide the largest net dollar savings).

To identify the economically optimal size of a solar energy system, it is necessary to know the relationship between system size and system costs. For active solar energy systems there is often a substantial "fixed" element of acquisition costs that is independent of the size of the system over a range of system sizes. There are additional "variable" costs that change as the size of the system changes. It should be recognized, however, that estimates of fixed and variable costs may not hold over all sizes of a system to be considered, due to possible discontinuities in the relationship between collector size (and costs) and the size (and costs) of other system components as collector size is expanded. The presence of significant discontinuities in size relationships may make it necessary to estimate fixed and variable costs for specific collector size intervals. Unfortunately, however, it is often difficult to distinguish the fixed from the variable costs and to develop the necessary functional costs relationships for appropriate intervals of system size.

To estimate fixed and variable system costs for the case studies of this report, NBS worked with a private contractor experienced in the commercial building/solar energy market, Honeywell, Inc., to develop acquisition cost estimating equations for the solar energy systems characterized in section 3.3 [36]. Fixed and variable costs were estimated for both the solar service hot water system and the combined solar space heating/hot water system described in section 3.3, as applied to the buildings described in section 3.1. Estimates were based on the contractor's experience with selling and installing systems of varying sizes, supported by internal records and professional judgement. The resulting cost estimating equations are shown in table 4.3.

The first term in each equation is the estimated fixed component of system costs, and the second term, the coefficient on collector area, is the variable component. There are separate equations in table 4.3 for new and existing buildings, for labor and materials costs, and for the service hot water and the combined space heating/hot water systems. 


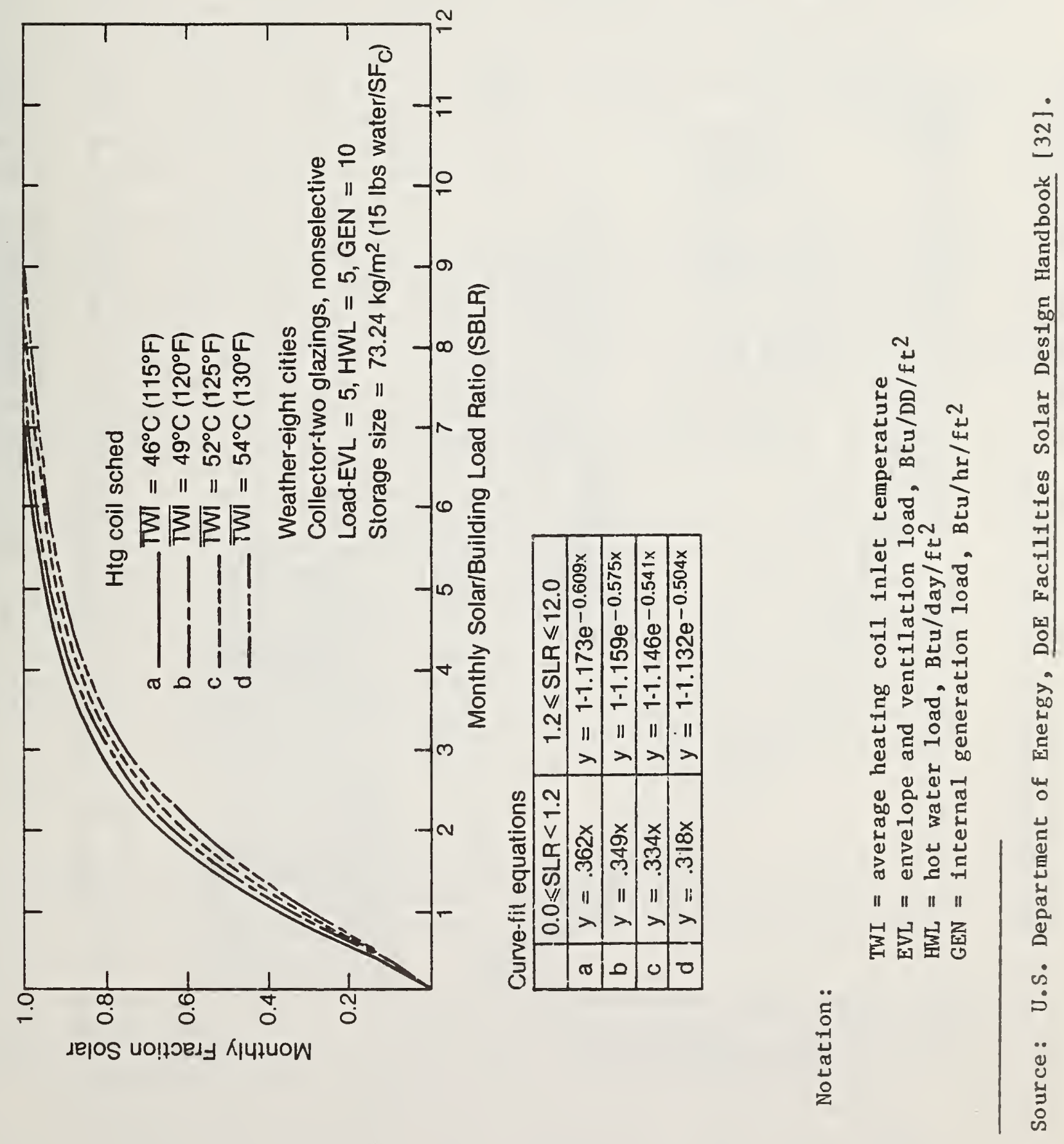




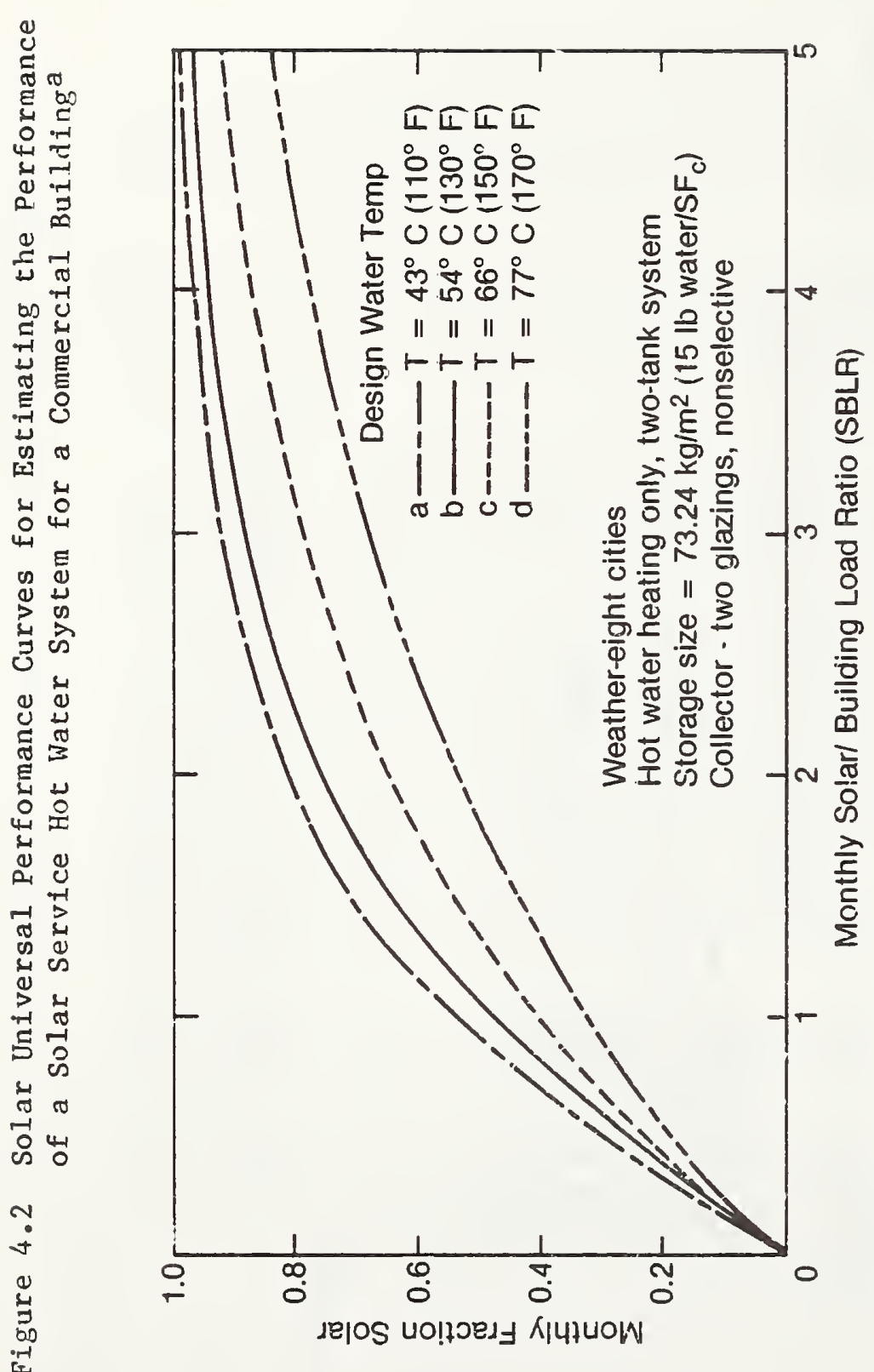

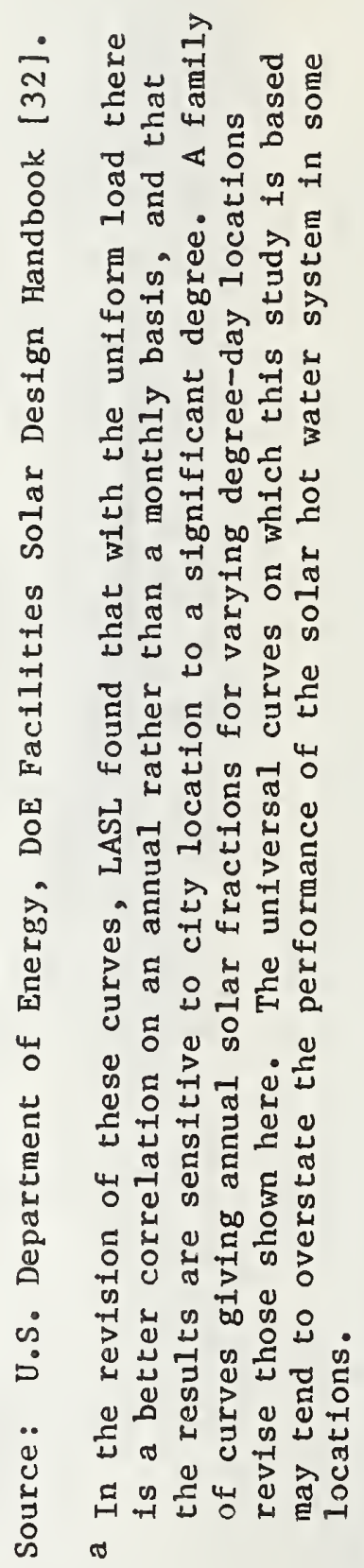


Although materials costs were assumed approximately uniform across the 13 cities, labor costs were assumed to vary by city. The breakout of labor and materials in the cost equations facilitated the conversion of these basic equations into region-specific equations for use in the case studies. To account for this locational variation, the regional labor cost adjustment factors shown in table 4.4 were applied to the fixed and variable components of the system labor cost equations given in table 4.3. Both the labor and materials equations were further adjusted to fit the analysis for each of the 13 citfes, by applying the appropriate sales tax rate (the city tax rates are given in table 4.11 ) to materials and/or labor costs. (The resulting 13 sets of cost estimating equations for the case studies are not shown here, but are included in the data files of the companion computer program of appendix $B_{.}$)

Each of the cost equations in table 4.3 describes a solar energy system with the same basic type of liquid storage and flat plate collectors described in section 3.3. Differences in the dollar values of the equations reflect primarily differences in the assumed size of the solar energy system and the associated complexity of the building application. In the case of the solar service hot water system for the retail stores, the cost functions describe a small, off-the-shelf system in the size range of $3 \mathrm{~m}^{2}$ to $8 \mathrm{~m}^{2}$ (about $30 \mathrm{ft}^{2}$ to $85 \mathrm{ft}^{2}$ ) of collector area, a system requiring little specialized design or engineering. For the office building's solar service hot water system, the cost functions apply to a system in the size range of $8 \mathrm{~m}^{2}$ to $50 \mathrm{~m}^{2}$ (about $85 \mathrm{ft}^{2}$ to $540 \mathrm{ft}^{2}$ ) of collector area, with some site-specific design and engineering required. The cost functions for the combined solar space heating/hot water system for both types of buildings are based on systems with collector arrays over about $50 \mathrm{~m}^{2}$ (over about $540 \mathrm{ft}^{2}$ ) which are assumed to entail considerably more custom design and engineering than the service hot water only systems. These higher assumed costs are reflected mainly in the fixed cost components of the cost estimating equations for the combined systems. A further source of the estimated difference between the costs of solar service hot water systems and of combined space heating/hot water systems is the year's dollars in which they are denominated. The equations for solar service hot water are based on end-of-year 1978 dollars, and the equations for the combined systems, on mid-1980 dollars.

\subsubsection{Reviewing the Cost Estimates}

Having assigned estimated values to system acquisition costs, let us now consider (1) the significance of the values assigned, (2) their probable accuracy, and (3) the selection of alternative values for performing sensitivity analysis.

The values assigned to fixed and variabie system acquisition costs are critical in two ways to the results of an economic optimization analysis: First, their total comprises the major item of costs against which present value savings are compared in determining the cost effectiveness of a solar energy system. Second, the unit vartable cost determines the system size that will either maximize net savings or minimize net losses from solar. (Fixed costs, being by definition independent of system size, do not determine the economically optimal size of a system, apart from possibly driving the optimal size to zero.) 
Table 4.3 Solar Energy System Cost Equationsa

\begin{tabular}{|c|c|c|}
\hline \multicolumn{3}{|c|}{ Fixed and Variable Acquisitions } \\
\hline Type of System & $\begin{array}{l}\text { Existing Buildings } \\
\text { Retrofit Cost }\end{array}$ & $\begin{array}{c}\text { New Construction } \\
\text { Initial Purchase Cost } \\
\end{array}$ \\
\hline \multicolumn{3}{|c|}{$\begin{array}{l}\text { Combined Heating and } \\
\text { Hot Water Systems, } 1980 \$ \mathrm{~b}\end{array}$} \\
\hline Materials & $\left(\begin{array}{c}\$ 40,824+\$ 270.51 / \mathrm{m}^{2} \cdot \text { Area }\left(\mathrm{m}^{2}\right) \\
\left(\$ 40,824+\$ 25.13 / \mathrm{ft}^{2} \cdot \text { Area }\left(\mathrm{ft}^{2}\right)\right)\end{array}\right.$ & $\begin{array}{c}\$ 37,045+\$ 240.80 / \mathrm{m}^{2} \cdot \text { Area }\left(\mathrm{m}^{2}\right) \\
\left(\$ 37,045+\$ 22.37 / \mathrm{ft}^{2} \cdot \text { Area }\left(\mathrm{ft}^{2}\right)\right)\end{array}$ \\
\hline Labor & $\left(\begin{array}{c}\$ 28,951+\$ 110.12 / \mathrm{m}^{2} \cdot \text { Area }\left(\mathrm{m}^{2}\right) \\
\left(\$ 28,951+\$ 10.23 / \mathrm{ft}^{2} \cdot \text { Area }\left(\mathrm{m}^{2}\right)\right)\end{array}\right.$ & $\begin{array}{l}\$ 24,532+\$ 35.85 / \mathrm{m}^{2} \cdot \text { Area }\left(\mathrm{m}^{2}\right) \\
\left(\$ 24,532+3.33 / \mathrm{ft}^{2} \cdot \text { Area }\left(\mathrm{ft}^{2}\right)\right)\end{array}$ \\
\hline \multicolumn{3}{|c|}{ Service Hot Water Systems } \\
\hline \multicolumn{3}{|l|}{ Office, $1978 \$$} \\
\hline Materials & $\left(\begin{array}{c}\$ 6,060+\$ 190.85 / \mathrm{m}^{2} \cdot \text { Area }\left(\mathrm{m}^{2}\right) \\
\left(\$ 6,060+\$ 17.73 / \mathrm{ft}^{2} \cdot \text { Area }\left(\mathrm{ft}^{2}\right)\right)\end{array}\right.$ & $\begin{array}{c}\$ 5,759+\$ 166.52 / \mathrm{m}^{2} \cdot \text { Area }\left(\mathrm{m}^{2}\right) \\
\left(\$ 5,759+\$ 15.47 /\left(\mathrm{ft}^{2} \cdot \text { Area }\left(\mathrm{ft}^{2}\right)\right)\right.\end{array}$ \\
\hline Labor & $\begin{array}{c}\$ 4,253+\$ 68.89 / \mathrm{m}^{2} \cdot \text { Area }\left(\mathrm{m}^{2}\right) \\
\left(\$ 4,253+\$ 6.40 / \mathrm{ft}^{2} \cdot \text { Area }\left(\mathrm{ft}^{2}\right)\right) \\
\end{array}$ & $\begin{array}{r}\$ 3,644+\$ 8.07 / \mathrm{m}^{2} \cdot \text { Area }\left(\mathrm{m}^{2}\right) \\
\left(\$ 3,644+\$ .75 / \mathrm{ft}^{2} \cdot \text { Area }\left(\mathrm{ft}^{2}\right)\right) \\
\end{array}$ \\
\hline \multicolumn{3}{|l|}{ Retail Store, $1978 \$$} \\
\hline Materials & $\begin{array}{c}\$ 1,600+\$ 179.44 / \mathrm{m}^{2} \cdot \text { Area }\left(\mathrm{m}^{2}\right) \\
\left(\$ 1,600+\$ 16.87 / \mathrm{ft}^{2} \cdot \text { Area }\left(\mathrm{ft}^{2}\right)\right)\end{array}$ & $\begin{array}{l}\$ 1,500+\$ 179.44 / \mathrm{m}^{2} \cdot \text { Area }\left(\mathrm{m}^{2}\right) \\
\left(\$ 1,500+\$ 16.67 / \mathrm{ft}^{2} \cdot \text { Area }\left(\mathrm{ft}^{2}\right)\right)\end{array}$ \\
\hline Labor & $\begin{array}{c}\$ 450+\$ 29.92 / \mathrm{m}^{2} \cdot \text { Area }\left(\mathrm{m}^{2}\right) \\
\left(\$ 450+\$ 2.78 / \mathrm{ft}^{2} \cdot \text { Area }\left(\mathrm{ft}^{2}\right)\right)\end{array}$ & $\begin{array}{r}\$ 310+\$ 23.90 / \mathrm{m}^{2} \cdot \text { Area }\left(\mathrm{m}^{2}\right) \\
\left(\$ 310+\$ 2.22 / \mathrm{ft} \mathrm{t}^{2} \cdot \text { Area }\left(\mathrm{ft}^{2}\right)\right) \\
\end{array}$ \\
\hline
\end{tabular}

a These cost equations were developed by Honeywell, Inc., under contract to NBS. The cost functions for the service hot water system for the retail stores were assumed to apply to an off-the-shelf system in the size range of about 3 to $8 \mathrm{~m}^{2}$ (about 30 to $85 \mathrm{ft}^{2}$ ) of collector area. The cost functions for the service hot water system for the office building reflect the assumption of higher design and engineering requirements for systems in the size range of about $8 \mathrm{~m}^{2}$ to $50 \mathrm{~m}^{2}$ (about 85 to $540 \mathrm{ft}^{2}$ ) of collector area. The cost functions for combined systems were assumed to apply to systems larger than $50 \mathrm{~m}^{2}\left(540 \mathrm{ft}^{2}\right)$.

b The costs for combined space heating/hot water systems were adjusted from end-of-year 1978 prices to mid-year 1980 prices based on the change in the Producer Price Index from end of 1978 to mid-1980. 
Table 4.4 Average Labor Adjustment Factorsa

\begin{tabular}{|c|c|}
\hline City & Factor \\
\hline Boston, MA & 1.04 \\
\hline Washington, DC & .99 \\
\hline Nashville, TN & .73 \\
\hline Charleston, SC & .57 \\
\hline $\begin{array}{l}\text { Apalachicola, FL } \\
\text { (nearest city for which } \\
\text { data was available was } \\
\text { Orlando) }\end{array}$ & .77 \\
\hline Omaha, NE & .93 \\
\hline Madison, WI & .92 \\
\hline $\begin{array}{l}\text { Bismarck, ND } \\
\text { (nearest city for which } \\
\text { data was available was } \\
\text { Jamestown, ND) }\end{array}$ & .66 \\
\hline Miami, FL & .87 \\
\hline Fort Worth - Dallas, TX & .83 \\
\hline Phoenix, AZ & 1.00 \\
\hline Los Angeles, CA & 1.14 \\
\hline Seattle, WA & 1.08 \\
\hline
\end{tabular}

a These adjustment factors indicate average variation among 21 labor items widely required for the installation of solar energy systems in commercial buildings.

Source: Dodge Manual for Building Construction Pricing and Scheduling, Dodge Building Cost Services (New York: McGraw-Hil1, 1977) [56]. 
How accurate are the acquisition cost estimating equations for the intended applications? Empirical validation of the equations is difficult because experience with solar energy in the selected types of buildings is quite limited and the existing data base is small. Furthermore, the available data applies chiefly to government-funded demonstration projects, which may differ in costs from projects that are privately funded, as well as from projects that come after the demonstration phase and benefit from lowered "learning costs". At best, the available data provide only a rough empirical basis for verifying the cost equations.

With this qualification in mind, let us compare the estimated cost functions of table 4.3 against cost functions developed from sample project data drawn from the Solar Demonstration Program [57]. The demonstration project data that was examined identifies total project cost and collector size for 262 nonresidential solar projects for many different kinds of applications. Of these 262 projects, only a few closely matched the systems/buildings treated by this study. A reasonably close fit, however, was obtained by selecting a sample of demonstration project data for combined solar space heating/hot water systems and solar space heating only systems for office bulldings. The sample consisted of 43 projects for low-, mid-, and high-rise offlce bulldings, ranging in size from about $30 \mathrm{~m}^{2}$ to about $850 \mathrm{~m}^{2}$ (about $320 \mathrm{ft}^{2}$ to about $9,150 \mathrm{ft}^{2}$ ) of collector area, with a mean size of about $200 \mathrm{~m}^{2}$ (about 2,150 $\mathrm{ft}^{2}$ ). (The data base contained an insufficient number of service hot water only systems for office buildings, or systems of any type for retail stores like those treated here, to allow direct comparisons with each of the cost equations in table 4.3.)

Least squares regression analysis of the size and cost data for the 43 demonstration projects yielded the following equation for materials and labor costs combined:

$$
\begin{aligned}
& \$ 35,764+\$ 448.22 / \mathrm{m}^{2} \cdot \text { area }\left(\mathrm{m}^{2}\right) \\
& \left(\$ 35,764+\$ 41.64 / \mathrm{ft}^{2} \cdot \text { area }\left(\mathrm{ft}^{2}\right)\right)
\end{aligned}=\text { total purchase and installation costs }
$$

Separate functions for material and labor are derivable from equation 40 by attributing the same proportions of labor and materials costs to total costs as reflected in the equations in table 4.1 :

$$
\begin{aligned}
& \$ 21,516+\$ 390.10 / \mathrm{m}^{2} \cdot \text { area }\left(\mathrm{m}^{2}\right) \\
& \left(\$ 21,516+\$ 36.24 / \mathrm{ft}^{2} \cdot \text { area }\left(\mathrm{ft} \mathrm{t}^{2}\right)\right)=\text { materials costs } \\
& \$ 14,248+\$ 58.13 / \mathrm{m}^{2} \cdot \text { area }\left(\mathrm{m}^{2}\right) \\
& \left(\$ 14,248+\$ 5.40 / \mathrm{ft} \mathrm{t}^{2} \cdot \text { area }\left(\mathrm{ft}^{2}\right)\right)=1 \text { abor costs }
\end{aligned}
$$

Figure 4.3 plots and compares the NBS cost function for the combined space heating/hot water system for new construction, from table 4.1, with the regression-fitted cost function for the 43 demonstration projects. The NBS cost function (solid line) indicates higher fixed costs than the regression-fitted cost function (dashed line), and, hence, produces a larger cost estimate than the latter for smaller projects. The regression-fitted cost function, however, Indicates higher variable cost per unit of collector area, causing it to predict higher costs for larger projects. The NBS cost function, with its lower variable 
cost, will result in a larger optimized size than the regression-fitted curve. For a given location, the two cost functions will produce approximately the same estimate of acquisition costs for a system with about $150 \mathrm{~m}^{2}\left(1,600 \mathrm{ft}^{2}\right)$ of collectors -- the point of intersection of the two functions shown in Figure 4.3 .

Although the remaining demonstration projects were less descriptive of the systems/buildings treated here than those in the above sample, they were also evaluated for comparison. The application of least-squares regression analysis to a sample of demonstration projects comprising 63 solar service hot water systems for the diversity of nonresidential buildings produced estimates of fixed and variable costs lower than those based on the sample of 43 combined space heating/hot water and space heating only systems for office buildings: a fixed cost of $\$ 27,378$ versus $\$ 35,764$, and a variable cost of $\$ 347.15 / \mathrm{m}^{2}$ versus $\$ 448.22 / \mathrm{m}^{2}\left(\$ 32.25 / \mathrm{ft}^{2}\right.$ versus $\left.\$ 41.64 / \mathrm{ft}^{2}\right)$, respectively.

Applying least squares regression analysis to a sample of 104 combined solar space heating/hot water demonstration projects for the diversity of nonresidential buildings -- again a loose comparison with the designated systems -produced a significantly higher estimate of fixed cost than the office building data sample $(\$ 42,420$ versus $\$ 35,764)$ and an estimate of variable cost just slightly higher $\$ 460.71 / \mathrm{m}^{2}$ versus $\$ 448.22 / \mathrm{m}^{2}$ or $\left(\$ 42.80 / \mathrm{ft}^{2}\right.$ versus $\left.\$ 41.64 / \mathrm{ft}^{2}\right)$.

Performing the regression analysis for solar service hot water systems only for a sample of new versus existing buildings produced little difference in cost estimates between the new and the existing buildings. However, the same analysis for combined solar space heating/hot water systems resulted in a substantial difference in fixed costs between the new and the existing building applications. Based on 23 demonstration retrofit projects, the regression--fitted cost equation showed $\$ 58,224$ of fixed costs and $\$ 470.29 / \mathrm{m}^{2}\left(\$ 43.69 / \mathrm{ft}^{2}\right)$ of variable cost; for 30 new demonstration projects, the regression-fitted cost equation showed $\$ 24,323$ in fixed costs and $\$ 464.69 / \mathrm{m}^{2}\left(\$ 43.17 / \mathrm{ft}^{2}\right)$ in variable costs. This finding supports the distinction made in table 4.3 between the cost estimates for new versus existing building applications.

To provide further perspective on recent solar acquisition costs, table 4.5 shows a grouped frequency distribution, by total system cost per $\mathrm{m}^{2}$ ( $\mathrm{ft}^{2}$ ) of collector area, of the total of 262 solar demonstration projects installed on a wide diversity of new and existing nonresidential buildings during the past several years. This table reveals a wide range of solar acquisition costs. It shows an average system cost of $\$ 1,076$ or less per $\mathrm{m}^{2}\left(\$ 100\right.$ or less per $\mathrm{ft}^{2}$ ) of collector for 83 percent of the nonresidential demonstration systems.

Hence, although it is difficult to estimate solar acquisition costs for the systems under study with a high degree of confidence, estimates in the range of those shown in table 4.3 appear reasonable. However, in light of the uncertainty attached to the estimated values, the case study results were tested for sensitivity to lower and upper bound cost estimates equal to one-half and oneand-one-half, respectively, of the base-case estimates of table 4.3. Furthermore, for each of the case studies, the system acquisition costs necessary for solar to break even over the life cycle were calculated. 
든

चा के

巳

논

on

ऽ 00

0 .

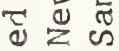

का

E)

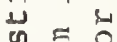

可战

कs in

है के

Q म

린

3

iा山

응오

यु

.

$\pi$

1

: क व

¿ 8

c 2 出

皮事

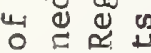

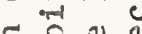

들 है

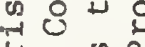

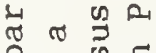

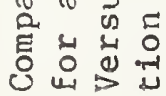

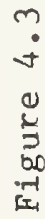

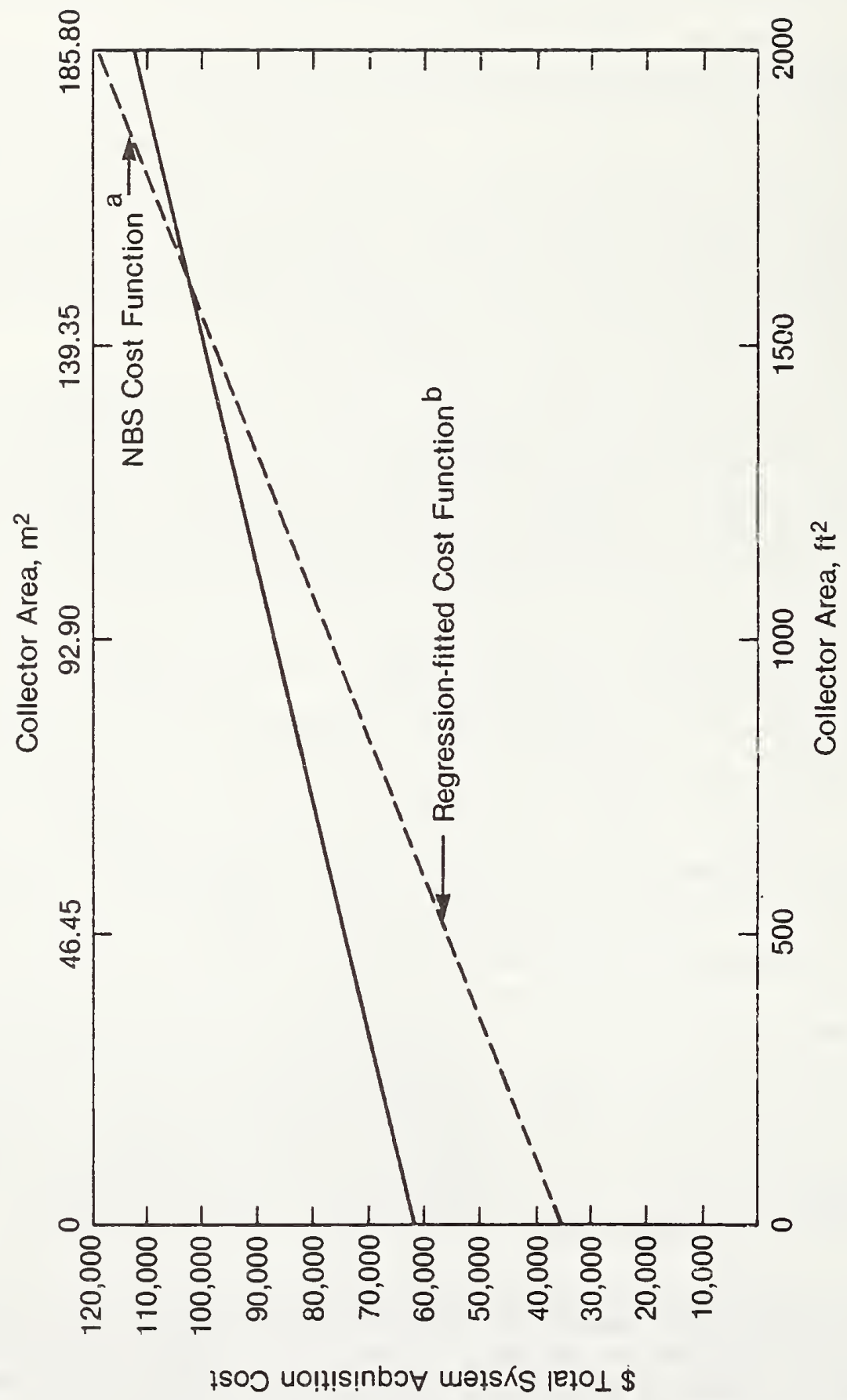

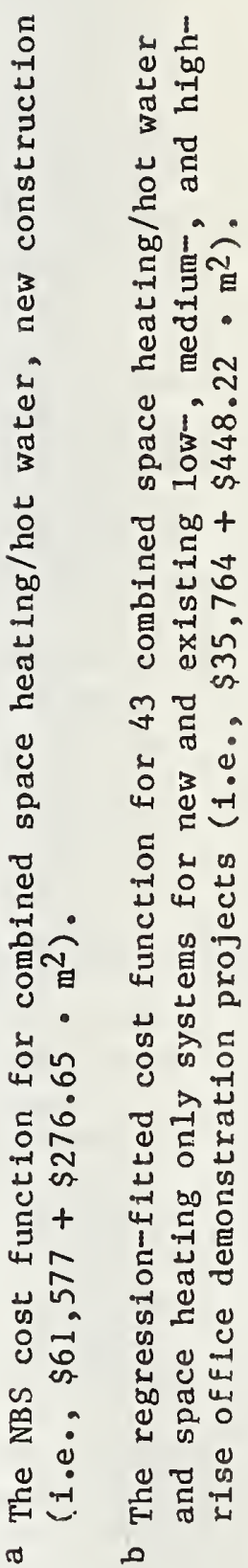




\subsection{ENERGY PRICES}

To estimate life-cycle energy savings, current and projected prices of energy were needed. The Energy Information Administration (EIA) of DoE provided a single source of reported and forecasted prices for the three types of energy considered in the case studies -- natural gas, distillate oil, and electricity.

The "base-year" prices used in the model were regional market prices.1 Future prices were incorporated into the model through the use of compound annual rates of change, derived by comparing base-year prices with EIA's projected benchmark prices for 1985, 1990, and 1995, and adjusting for an estimated rate of general price inflation. 2

The estimated annual rates of projected price escalation are uniform within each of the three time intervals: from the base-year to mid-1985, from mid1985 to mid-1990, and from mid-1990 to mid-1995 and beyond. The energy prices selected for use apply specifically to commercial buildings as distinct from the prices that would apply to residential and industrial uses.

EIA's price projections include ranges of possible future prices for each type of energy, based on different sets of assumptions about demand and supply conditions. For example, figure 4.4 illustrates the range of projected prices for oil as given in EIA's 1979 Annual Report to Congress [38]. The table insert to the graph indicates the nature of the demand/supply assumptions underlying each curve.

The selection of a future price scenario for the case studies was guided by DoE. This selection shifted during the course of the study from a "medium price" case early in the study to a "high price" case later in the study.

1 The EIA reports projected current market prices on a national basis in Short-Term Energy Outlook [58]. (Current regional price estimates, developed from the national data, are published periodically in the Federal Register [59] as part of the DoE Life Cycle Cost Rule.)

2 The benchmark regional energy prices projected by EIA's Mid-Term Energy Forecasting System (MEFS), an integrated computer model of the domestic energy system with explicit representation at the regional level of the projected supply and demand for energy sources, the costs of petroleum refining, electricity generation, and energy transportation, and the price elasticity of energy denand. These benchmark prices, given without inflation, are reported in an EIA Analysis Report entitled, Mid-Term Energy Supply and and Demand, 1985-1995 [60]. The benchmark prices and the derived real escalation rates are published periodically in the Federal Register [59] as part of the Life Cycle Cost Rule, and in the Life- Cycle Costing Manual for the Federal Energy Management Program [61]. For use in this study, the derived real escalation rates were converted to nominal rates by incorporating a 6 percent per annum assumed inflation rate. 
تृّ

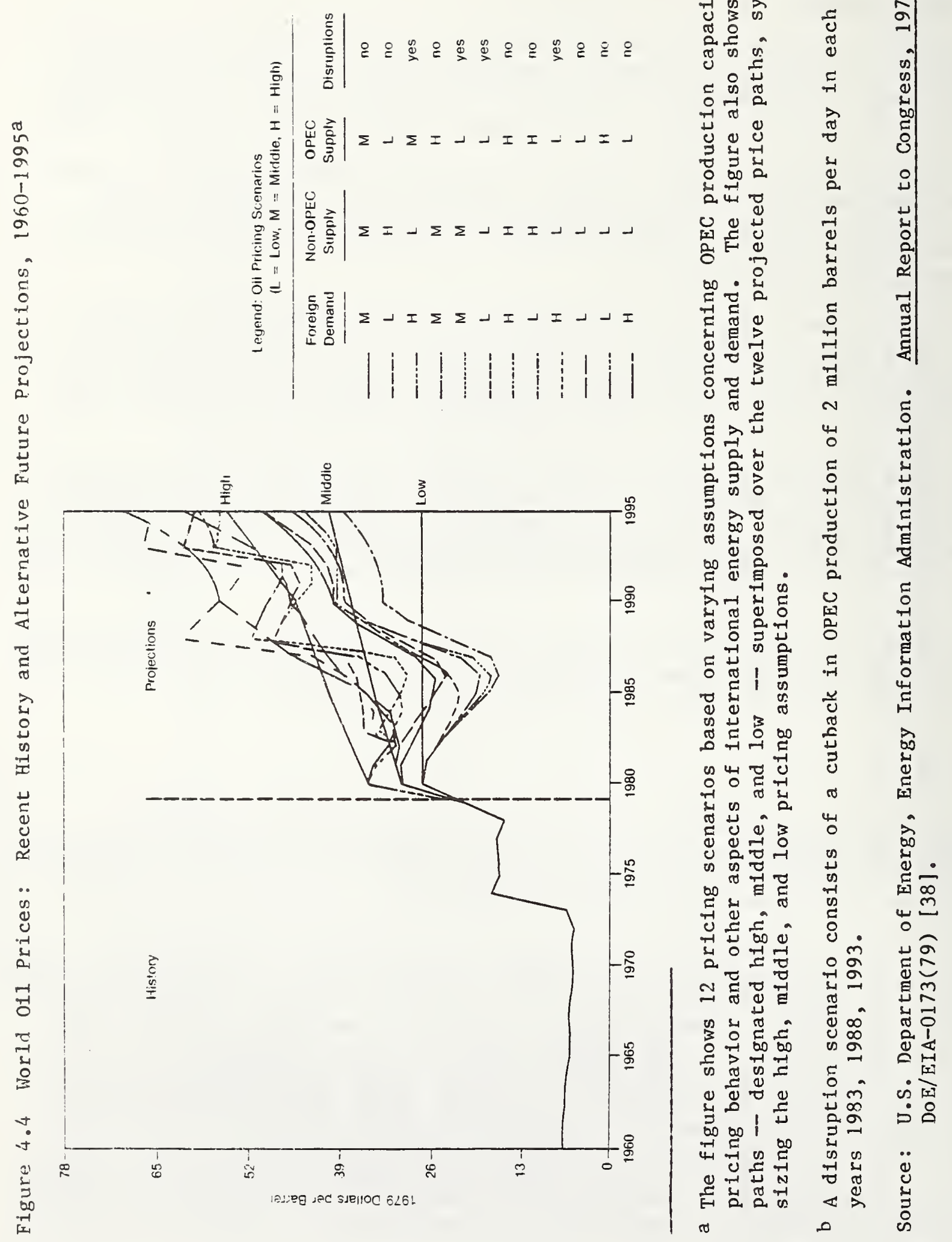




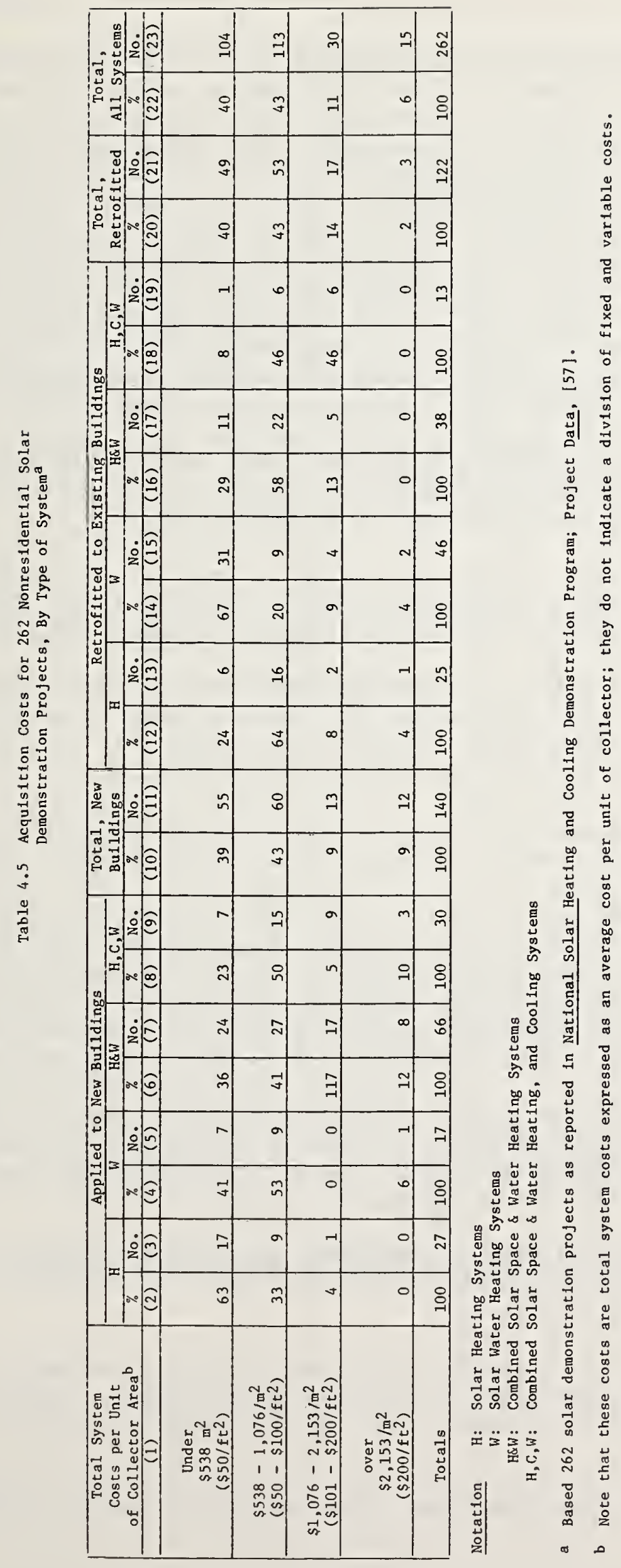

81 
Case studies were performed for three different sets of energy price data, reflecting ongoing price updates, revisions in demand and supply assumptions, and the above-mentioned change in the selection of a price scenario, all of which occurred during the course of the study. For the analysis of service hot water systems, energy prices and escalation rates as of December 1978 for the "medium price scenario" for the commercial sector were used. (They were paired with solar acquisition costs also in 1978 dollars for the solar hot water case studies.) These 1978 energy prices and escalation rates are shown in table 4.6. Since these data do not fully reflect the large actual increases in oil prices during 1979, the cost-effectiveness results for service hot water only systems (given in section 5.1) are likely low, particularly for the cases involving fuel oil. (The calculated break-even energy prices given in section 5.1, however, allow a comparison with current energy prices and projections.)

The case studies for the combined space heating/hot water systems were performed using DoE's early-1980 revised price projections and the "high price scenario." These 1980 prices and escalation rates are shown in table 4.7.

A comparison of the two sets of data in tables 4.6 and 4.7 , approximately one year apart in time, reveals a substantial upward revision in the base-year data, but, in most cases, comparable or lower projected long-term rates of escalation.

In mid-1980, EIA again revised the base-year energy prices and projected energy price escalation rates. The effects on the case study results were assessed and are reported in the sensitivity analysis of section 5.3. The energy price data used in the sensitivity analysis are given in table 4.8.1

The effect on life-cycle energy savings of these several data revisions is highlighted in table 4.9. Part A of table 4.9 shows for each of the three types of energy and for each region of the country, the total present value of 1 GJ ( 1 million Btu) purchased or saved each year over 20 years, based on the prices in table 4.6. Part B of table 4.9 shows the same information, based on the prices in table 4.8. Within either portion of the table, the substantial variation among regions and among energy types is indicative of a wide variation in solar economic feasibility dependent on the location and the avallability of alternative fuel sources. The most striking difference, however, is between parts $A$ and $B$, particularly for oil, whose 20 year present value more than doubled when based on the later price estimates. Thus, taking a long-run view of energy savings through the life-cycle costing format does not preclude substantial changes in estimated results, even in the very short run, due to rapid, unanticipated movements in price.

\subsection{FINANCIAL VARIABLES--DISCOUNT, BORROWING, AND INFLATION RATES}

\subsubsection{Discount Rate and Inflation}

The discount rate used by a corporate firm should reflect the rate of return required by the ultimate investors - stock and bond holders - for use of their money. The before-tax rate of return required by investors generally has at

1 The EIA energy price projections have since undergone further revision. [59]. 
Table 4.6 1978 Energy Prices and Projected Rates of Change ${ }^{a}$

(Base-Case Data for Service Hot Water System Analysis of Section 5.1)

Part A. Commercial Energy Prices in 1978 (1978 \$/Sales Unit)

\begin{tabular}{|c|c|c|c|c|c|c|c|c|c|c|}
\hline \multirow{2}{*}{$\begin{array}{l}\text { Fuel Type and } \\
\text { Unit Purchased }\end{array}$} & \multicolumn{10}{|c|}{ DoE Regions ${ }^{b}$} \\
\hline & 1 & 2 & 3 & 4 & 5 & 6 & 7 & 8 & $\overline{9}$ & 10 \\
\hline Electricity (kWH) & 0.050 & 0.061 & 0.043 & 0.036 & 0.041 & 0.034 & 0.037 & 0.029 & 0.038 & 0.018 \\
\hline Natural Gas $\left(\mathrm{ft}^{3}\right)$ & 0.004 & 0.003 & 0.002 & 0.002 & 0.002 & 0.002 & 0.002 & 0.002 & 0.002 & 0.002 \\
\hline Distillate (gal) & 0.429 & 0.430 & 0.413 & 0.406 & 0.410 & 0.404 & 0.409 & 0.417 & 0.412 & 0.412 \\
\hline Electricity (mJ) & 0.014 & 0.017 & 0.012 & 0.010 & 0.014 & 0.009 & 0.010 & 0.008 & 0.011 & 0.005 \\
\hline Natural Gas $\left(\mathrm{m}^{3}\right)$ & 0.131 & 0.097 & 0.082 & 0.061 & 0.068 & 0.056 & 0.054 & 0.054 & 0.069 & 0.086 \\
\hline Dist1llate (L) & 0.113 & 0.114 & 0.109 & 0.107 & 0.108 & 0.107 & 0.108 & 0.108 & 0.109 & 0.109 \\
\hline
\end{tabular}

Part B. Projected Rates of Change (Including Inflation Rate of $6 \%$ Per Annum) C

\begin{tabular}{|c|c|c|c|c|c|c|c|c|c|c|}
\hline Electricity & & & & & & & & & & \\
\hline $\begin{array}{r}1978-1985 \\
1985-1990 \\
1990-1998 \\
\end{array}$ & $\begin{array}{l}5.4 \\
7.2 \\
6.7\end{array}$ & $\begin{array}{l}3.8 \\
8.1 \\
6.7\end{array}$ & $\begin{array}{l}6.0 \\
6.6 \\
6.3\end{array}$ & $\begin{array}{l}8.0 \\
7.0 \\
6.6\end{array}$ & $\begin{array}{l}6.2 \\
6.8 \\
7.1\end{array}$ & $\begin{array}{l}9.4 \\
7.8 \\
6.5\end{array}$ & $\begin{array}{l}7.4 \\
7.0 \\
6.6\end{array}$ & $\begin{array}{l}8.0 \\
7.2 \\
6.8\end{array}$ & $\begin{array}{l}6.6 \\
6.8 \\
7.0 \\
\end{array}$ & $\begin{array}{l}9.6 \\
7.3 \\
7.1\end{array}$ \\
\hline \multicolumn{11}{|l|}{ Natural Gas } \\
\hline $1978-1985$ & 6.7 & 9.7 & 10.8 & 12.8 & 12.6 & 13.3 & 14.0 & 16.1 & 13.6 & 13.8 \\
\hline $1985-1990$ & 10.0 & 10.1 & 9.4 & 8.3 & 9.8 & 12.2 & 11.1 & 10.3 & 9.5 & 9.3 \\
\hline $1990-1988$ & 8.5 & 9.7 & 10.0 & 12.7 & 9.6 & 10.7 & 10.9 & 9.5 & 6.5 & 8.4 \\
\hline \multicolumn{11}{|c|}{ Distillate Fuel oil } \\
\hline $1978-1985$ & 9.1 & 9.3 & 10.1 & 10.4 & 9.3 & 10.0 & 9.0 & 9.2 & 8.1 & 8.1 \\
\hline $1985-1990$ & 10.4 & 10.3 & 10.3 & 10.3 & 10.5 & 10.4 & 10.7 & 10.5 & 10.8 & 10.8 \\
\hline $1990-1998$ & 10.7 & 10.7 & 10.7 & 10.6 & 10.8 & 10.7 & 10.9 & 10.7 & 8.0 & 7.7 \\
\hline
\end{tabular}

a Prices and rates were developed from prices for the period 1977 to 1995, estimated and projected by the Energy Information Administration (EIA) using its Mid-term Energy Forecasting Systems (MEFS), medium-price case, prices per million Btu.

b DoE Regions consist of the following states: DoE 1: ME, NH, VT, MA, CT, RI; DoE 2: NY, NJ, PR, VI; DoE 3: PA, MD, WV, VA, DC, DE; DoE 4: KY, TN, NC, SC, MS, AL, GA, FL, CZ; DoE 5: MN, WI, MI, IL, IN, OH; DoE 6: TX, NM, OK, AR, LA; DoE 7: KS, MO, IA, NE; DoE 8: MT, ND, SD, WY, UT, CO; DoE 9: $\mathrm{CA}, \mathrm{NV}, \mathrm{AZ}, \mathrm{HI}, \mathrm{TT}, \mathrm{AS}, \mathrm{GU} ; \mathrm{DOE} 10: \mathrm{WA}, \mathrm{OR}, \mathrm{ID}, \mathrm{AK}$.

C A $6 \%$ inflation rate, based on a sample of econometric forecasts of inflation for the $1978-90$ period ranging from $5 \%$ to $7 \%$, was added to the real rates of change derived from EIA energy prices. 
Table 4.7 Early 1980 Energy Prices and Projected Rates of Change ${ }^{a}$

(Base-Case Data for Combined Space Heating/Hot Water System Analysis of Section 5.2)

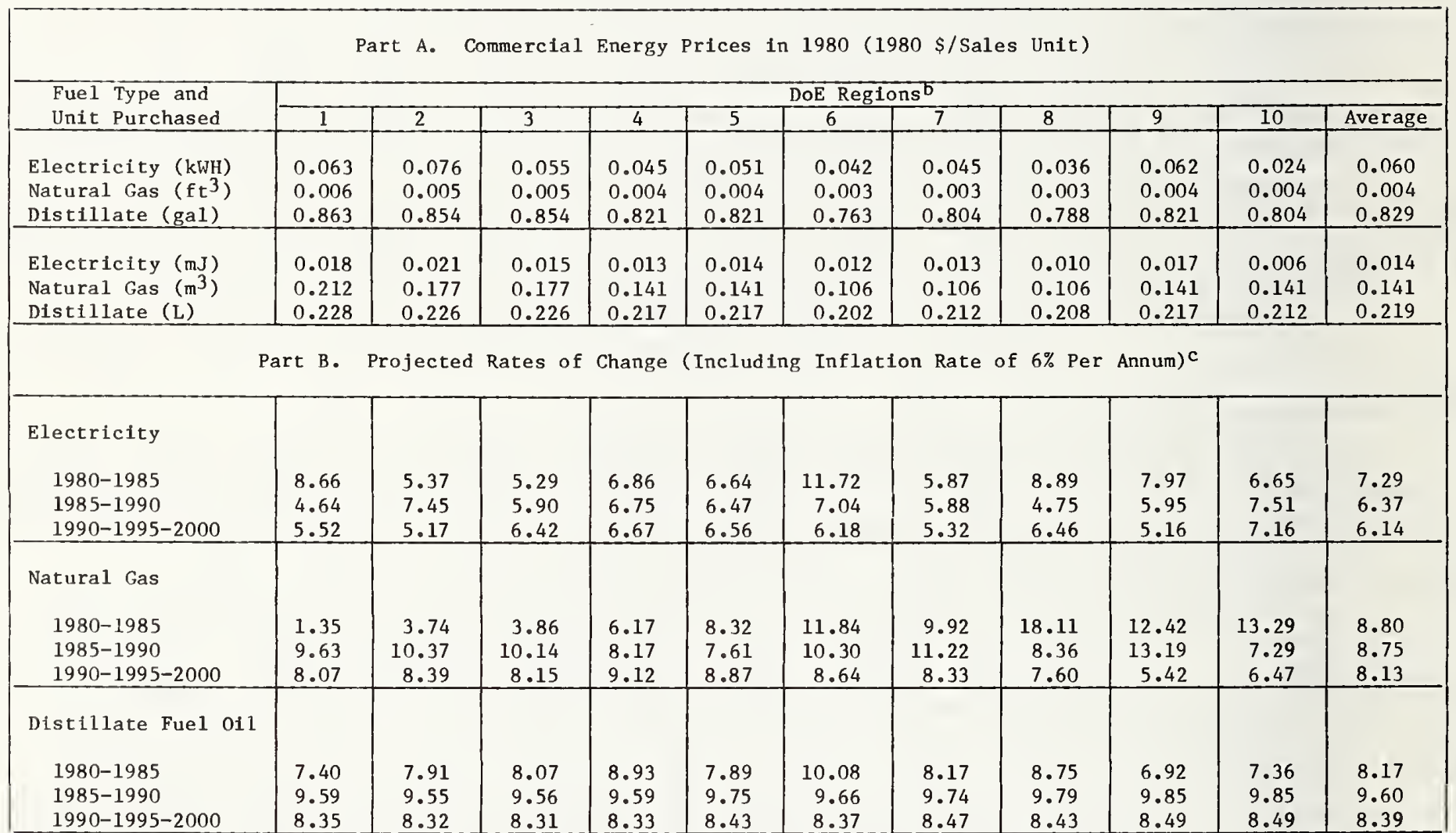

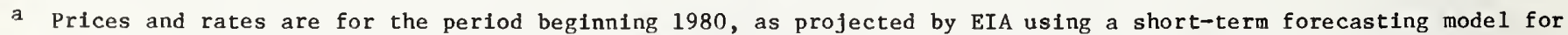
the 1980 prices and MEFS, high-price case, to project future prices. These prices were adopted by DoE for Federal

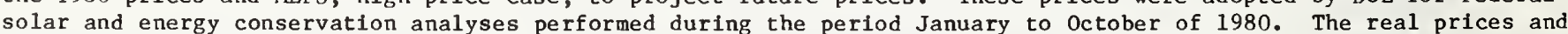
rates upon which those were based are reported in the Federal Register, January 23, 1980 [59].

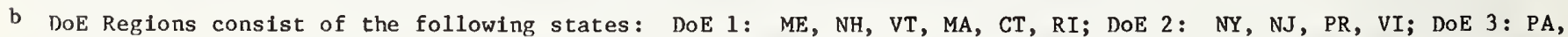
$\mathrm{MD}, \mathrm{WV}, \mathrm{VA}, \mathrm{DC}, \mathrm{DE}$; DoE 4: KY, TN, NC, SC, MS, AL, GA, FL, CZ; DoE 5: MN, WI, MI, IL, IN, OH; DoE 6: TX, NM, OK, AR, LA; DoE 7: KS, MO, IA, NE; DoE 8: MT, ND, SD, WY, UT, CO; DoE 9: CA, NV, AZ, HI, TT, AS, GU; DoE 10: $W A, O R, I D, A K$.

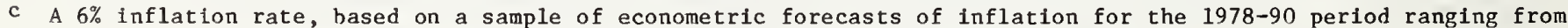
$5 \%$ to $7 \%$, was added to the real rates of change derived from EIA energy prices. 
Table 4.9 Total Present Value of 1 Million Btu ( 1 GJ) of Energy Purchased Each Year Over 20 Years

Part A. Present Value Based on 1978 Prices and Projected Escalationa

\begin{tabular}{c|c|c|c|c|c|c|}
\hline \multirow{2}{*}{ DoE Region } & \multicolumn{2}{|c|}{ Electricity } & \multicolumn{2}{c|}{ Natural Gas } & \multicolumn{2}{c}{ Oil } \\
& (PV\$/GJ) & (PV\$/MBtu) & (PV\$/GJ) & (PV\$/MBtu) & (PVS/GJ) & (PV\$/MBtu) \\
\hline & 162.70 & 154.21 & 49.21 & 46.64 & 48.03 & 45.52 \\
2 & 198.44 & 188.08 & 43.35 & 41.09 & 48.43 & 45.90 \\
3 & 147.38 & 139.69 & 38.58 & 36.57 & 48.52 & 45.99 \\
4 & 136.43 & 129.31 & 32.35 & 30.66 & 48.39 & 45.86 \\
5 & 144.04 & 136.52 & 35.20 & 33.36 & 46.33 & 43.91 \\
6 & 140.14 & 132.83 & 32.07 & 30.40 & 46.77 & 44.92 \\
7 & 135.63 & 128.55 & 31.68 & 30.03 & 45.82 & 43.48 \\
8 & 109.87 & 104.14 & 33.94 & 32.17 & 46.97 & 44.52 \\
9 & 134.40 & 127.39 & 35.53 & 33.68 & 42.65 & 40.42 \\
10 & 75.49 & 71.50 & 45.67 & 43.29 & 42.49 & 40.27
\end{tabular}

Part B. Present Value Based on Mid-1980 Prices and Projected Escalation ${ }^{b}$

\begin{tabular}{|c|c|c|c|c|c|c|}
\hline \multirow{2}{*}{ DoE Region } & \multicolumn{2}{|c|}{ Electricity } & \multicolumn{2}{c|}{ Natural Gas } & \multicolumn{2}{c|}{ Oil } \\
\hline & (PVS/GJ) & (PVS/MBtu) & (PVS/GJ) & (PVS/MBtu) & (PVS/GJ) & (PVS/MBtu) \\
\hline 1 & 283.74 & 268.95 & 59.05 & 55.97 & 107.92 & 102.29 \\
3 & 269.61 & 255.55 & 52.80 & 50.05 & 109.00 & 103.32 \\
4 & 215.60 & 204.36 & 48.40 & 45.88 & 109.55 & 103.84 \\
5 & 177.08 & 167.85 & 39.53 & 37.47 & 109.66 & 103.94 \\
6 & 198.69 & 188.33 & 43.69 & 41.41 & 106.01 & 100.48 \\
7 & 211.26 & 200.25 & 46.59 & 44.16 & 108.12 & 102.48 \\
8 & 201.57 & 191.06 & 42.93 & 40.69 & 105.37 & 99.88 \\
9 & 180.89 & 171.46 & 49.05 & 46.49 & 105.99 & 100.46 \\
10 & 238.66 & 226.22 & 48.97 & 46.42 & 102.84 & 97.48 \\
\hline
\end{tabular}

a Calculated from prices and rates of change given in table 4.6.

b Calculated from prices and rates of change given in table 4.8 . 
least four components: 1) compensation for postponing consumption now until a later time in order to purchase debt or equity shares in the firm; 2) compensation for risk; 3) compensation for the effects of inflation over the lifetime of the investment; and 4) compensation for the rate at which income is taxed. The required rate of return is influenced by the ratio of debt-to-equity financing of the firm, a factor which influences its level of risk. In actual practice, the discount rate varies widely among firms and investments.

The approach to selecting a discount rate for the case studies was based on the capital investment theory published by Modigliani and Miller in 1958 [62], and modified by these authors in 1963 [63]. Modigliani and Miller demonstrated that any project which raises the market value of the firm's debt and equity shares is worth undertaking. In order to increase the market value, the return on the project must be higher than the-weighted cost of capital to the firm. The return on debt and equity shares of the firm thus becomes the true cost of capital to the firm, i.e., it is the appropriate discount rate for that firm to use in making investment decisions. Modigliani and Miller show that this rate of return on debt and equity to the firm's stockholders would be the same for all firms in the same risk class in a perfectly functioning world with no corporate income taxes. Since current income tax laws allow the firm to deduct interest payments from taxable income, the cost of debt financing tends to be lower than the cost of equity financing; thus the discount rate used by a firm with a high debt-equity ratio tends to be lower than the discount rate used by a firm in the same risk class with a lower debt-equity ratio, other conditions remaining the same. At some point, of course, increased debt can be expected to increase the riskiness of the firm, and its risk class will change.

To select a discount rate according to this approach, historical trends in after-tax rates of return to investors over recent decades were investigated. Data published by Holland and Myers [64] describing real rates of return over all grades of nonfinancial common stocks and long-term corporate bonds were averaged over the different periods shown in table 4.10. The after-tax rate of 7 percent (rounded from 7.06 percent) covering the 1947-75 period was selected as representative of long-term returns. To this rate was added an estimate of long-term inflation of six percent per annum, the average of several econometric forecasts of inflation for the 1978-90 period.1 The resulting rate of 13 percent is intended to reflect an after-tax, after-inflation rate of return for a firm with an average debt-equity ratio in an average risk class. The nominal

1 At the time this analysis was made, the annual rate of inflation in the U.S. was considerably higher than 6 percent. However, a rate of 6 percent is intended to represent expectations of average long-term conditions, rather than what may be a short-term condition of double digit inflation. 
Table 4.10 Cost of Capital -- Average Returns on Debt and Equity in Nonfinancial Corporationsa

\begin{tabular}{|c|c|c|}
\hline Period & $\begin{array}{c}\text { Nominal Returns } \\
\text { (precent) }\end{array}$ & $\begin{array}{c}\text { Real Rates } \\
\text { (adjusted by CPI) } \\
\text { (percent) }\end{array}$ \\
\hline $1971-1975$ & 5.50 & -1.30 \\
\hline $1947-1975$ & 10.41 & 7.06 \\
\hline $1946-1975$ & 9.85 & 6.00 \\
\hline 1975 & 28.60 & 21.60 \\
\hline 1974 & -19.30 & -30.80 \\
\hline
\end{tabular}

a These averages are based on after-tax rates of return developed by Holland and Myers [64] from profit rate data published by Ibbotson and Sinquefield [65]. The average rate of return, $R_{t}$, to all bond and stockholders of nonfinancial corporations considered as a group is the following:

$$
R_{t}=R_{t}(D)\left(\frac{M V_{t}(D)}{M V_{t}}\right)+R_{t}(E)\left(\frac{M V_{t}(E)}{M V_{t}}\right)
$$

where

$$
\begin{aligned}
R_{t}(D)= & \text { after-tax rate of return earned in year } t \text { on a portfolio of } \\
& \text { all the net outstanding debt of nonfinancial corporations. } \\
& \text { It includes interest receipts and capital gains or losses. } \\
M_{t}(D)= & \text { market value of that debt at the start of year } t \text { (includes } \\
& \text { net interest paid). } \\
M V_{t}= & \text { total market value of all nonfinancial corporate securities } \\
& \text { at the start of year } t . \\
R_{t}(E)= & \text { after-tax rate of return earned in year } t \text { on all equity } \\
& \text { shares of nonfinancial corporations. It includes dividends } \\
& \text { and capital gains. } \\
M V_{t}(E)= & \text { market value of equity at the start of the year } t \text { (includes } \\
& \text { net dividend payments). }
\end{aligned}
$$

Holland and Myers determined real returns for each period by subtracting percentage changes in the consumer price index. Market value of debt, $M V_{t}(D)$, was found by capitalizing net interest paid using the Moody's Baa interest rate; market value of equity, $\mathrm{MV}_{t}(\mathrm{E})$, was found by capitalizing dividends using the dividend yield in the Standard and Poor's Compositee Stock Index. The combined rate of return, $R_{t}$, thus represents the average over all grades of nonfinancial corporate stocks and bonds, or the rate of return on a medium grade asset, or the expected rate of return on investment for a firm in an average risk class. 
13 percent rate, after-taxes, is equivalent to a nominal before-tax rate of approximately 26 percent. It is equivalent to a real after-tax rate of approximately 7 percent. 1

\subsubsection{Financing Terms}

For the purpose of the case studies, the latter approach -- that is, 1ncluding financing terms in the analysis - is taken. The effect of including financing terms and assuming deferred payment will generally improve the cost effectiveness of the investment if the after-tax cost of borrowing is less than the borrower's after-tax opportunity cost, as reflected in the discount rate, and will lessen the cost effectiveness if the after-tax cost of borrowing is higher.

Consistent with the prevailing lending practice, more favorable terms were assumed for new construction projects than for retrofit applications. Specif1cally, solar projects for new buildings were assumed to be financed as part of a 20-year mortgage at an interest rate of 9-1/4 percent. Solar projects for existing buildings were assumed financed with a five-year uncollateralized cominercial bank loan at an interest rate of 10-1/2 percent. The assumed downpayment for the combined solar space heating/hot water system was 25 percent; for the solar hot water systems, no initial downpayment was assumed. Since these loan rates were lower than the 13 percent discount rate used in the case studies, the financial assumptions improved somewhat the economic feasibility results.

In the benefit-cost analyses of investment decisions by large organizations that raise sizable amounts of debt and equity funds, project investment costs are generally evaluated as lump-sum initial cash outlays without regard to financing. 2 The assumption is that projects meeting the rate of return criterion (stated in terms of the weighted cost of capital) will be funded out of the firm's available supply of after-tax debt and equity funds, without distinction in the financing terms for individual projects of a given risk class. But for the smaller investor without stock and bond issue, financing often is specifically tied to individual projects, and, therefore, affects their comparative economic feasibility. In this case, it is appropriate to include financing terms in the benefit-cost analysis.

1 The relationship between a nominal rate of return (i.e., one that includes inflation) and a real rate (i.e., one that excludes inflation) may be expressed mathematically as $R=r+I+r I$, where $R=$ the nominal rate, $r=$ the real rate, and $I=$ the inflation rate. Applying this equation to the assumed real after-tax rate of return of 7 percent and the assumed inflation rate of 6 percent, one obtains a nominal rate of return of 13.42 percent (i.e., .07 $+.06+(.07)(.06)=.1342)$. For the purpose of this analysis, the nominal rate is rounded to 13 percent.

2 Note that the issue of including financing terms in benefit-cost analyses is different from the issue of the impact of cash flow scheduling on project feasibility. 
Financing terms are, of course, variable among commercial investors and across time. Keyed to the prime lending rate, a long-term mortgage loan rate can usually be expected to be roughly 1-to-2 percent lower than the prime rate, and an uncollateralized commercial bank loan, roughly 1-to-3 percent higher than the prine rate. Recently, most loan rates have been substantially higher than than those assumed here. The borrowing rates assumed for the base-case analysis are lower than the actual market rates prevailing in 1981, and were selected to be representative of rates which may prevail in the longer term. 1 The impacts of alternative assumptions about the borrowing rate and downpayment on solar economic feasibility are examined in section 5.3 .

\subsection{TAXES AND INCENTIVES}

Taxes may affect the economics of a solar investment through the routine operation of income tax laws, property taxes, and sales taxes, as well as through the use of taxes as mechanisms for providing special financial subsidies (incentives) for solar investment. Because tax law is the principal way through which solar incentives for businesses are currently provided, it is convenient to discuss assumptions regarding taxes and financial incentives jointly. Not all financial subsidies or incentives for investing are delivered through the tax system. For example, grants are not and preferential loan terms, if available, would not be. The primary solar incentives available generally to solar commercial investors, however, are related to taxes; they are income tax credits and deductions, accelerated depreciation allowances, and property and sales tax exemptions.

To determine the after-tax value of those energy-related expenses that are deductible from taxable income, the 46 percent maximum Federal corporate tax rate in effect at the time the case studies were performed was combined with the applicable state corporate income tax rate, and the combined rate was used as the marginal income tax rate in the economic evaluation model [67]. The calculation of the combined Federal/state income tax rates are based on the assumption that state income taxes are an allowed tax deduction at the Federal level, but Federal taxes are not deductible at the state level, i.e.,

$$
t=t_{s}+\left(1-t_{s}\right) t_{f}
$$

where

$$
\begin{aligned}
t & =\text { combined State and Federal corporate income tax rate, } \\
t_{s} & =\text { state corporate income tax rate (see table } 4.11 \text { for rates), and } \\
t_{f} & =\text { Federal corporate income tax rate ( } 46 \text { percent assumed). }
\end{aligned}
$$

The following expenses were assumed deductible from taxable income: fuel costs, other operating and maintenance costs, capital depreciation on energy-related

1 The Solar Energy and Energy Conservation Bank was authorized by Title $V$ of the Energy Security Act, the Solar Energy and Energy Conservation Act of 1980 to assist in the financing of residential and commercial solar energy systems; however, no special provisions for financing were available at the time of this study [66]. 
Table 4.11 Rates of Sales Tax, Property Tax, and State Income Tax by City ${ }^{a}$

\begin{tabular}{|c|c|c|c|}
\hline City & Sales Tax Rate $(\%)^{\mathrm{b}}$ & $\begin{array}{c}\text { Effective Property } \\
\text { Tax Rate }(\%) \\
\end{array}$ & $\begin{array}{l}\text { State Income } \\
\text { Tax Rate }(\%)\end{array}$ \\
\hline Phoenix & 5.0 (1abor only) & 0 (Full Exemption) & 10.5 \\
\hline Los Angeles & 6.0 (materials only) & 1.25 & 6.0 \\
\hline Miami & 4.0 (materials only) & 2.60 & 5.0 \\
\hline Apalachicola & 4.0 (materials on $1 y$ ) & 1.91 & 5.0 \\
\hline Boston & 5.0 (materials only) & $\begin{array}{l}0 \text { (10 year Solar Exemption)c } \\
12.6 \text { (After } 10 \text { years) }\end{array}$ & 9.5 \\
\hline Omaha & 4.5 (materials only) & 3.5 & 4.4 \\
\hline Bismarck & 3.0 (materials on $1 y$ ) & $\begin{array}{l}0 \text { (5 year Exemption) } \\
1.5 \text { (after } 5 \text { years) }\end{array}$ & 6.0 \\
\hline Charleston & 4.0 (materials only) & 1.5 & 6.0 \\
\hline Fort Worth & 0 (Fu11 Exemption) & 0 (Ful1 Exemption) & 4.0 \\
\hline Nashville & 4.5 & 0 (Full Exemption)e $^{e}$ & 6.0 \\
\hline Seattle & 5.4 & 0 (Full Exemption) & 0.46 \\
\hline Washington, D.C. & 5.0 (materials only) & 1.83 & 9.9 \\
\hline Madison & 4.0 (materials only) & $2.65^{f}$ & 7.9 \\
\hline
\end{tabular}

a Rates are based on a telephone survey of local taxing districts in early 1980, and are subject to change.

b Where the sales tax is applicable only to labor or only to materials, it is noted in parentheses.

c This exemption has now been extended to 20 years [68], but the extension is not reflected in the case studies for Boston.

d This rate of 12.6 percent, provided by the City of Boston Assessments Office, appears too high compared with the rate for Boston of 4.94 percent given by the "Taxable Property Values and Assessment Sales Price Ratios," 1977 Census of Governments [69]. The higher rate, provided directly by the Assessments office, is used in the Boston case studies. However, the cholce of rates for the Boston analysis makes little difference in the results because of the 10-year exemption of property taxes on solar energy systems and the discounting of those property taxes that are assumed to occur after the 10-year period.

e This provision has been recently revised and an expiration date of 1988 is now given [70]. This limitation on the exemption is not reflected in the Nashville case studies.

F The State of Wisconsin has since enacted a law [71] to exempt active solar energy systems from the property tax, a change which is not reflected in the Madison case studies. 
equipment, interest payments on the loan principal outstanding, and property and sales taxes. The combined income tax rate was used to calculate tax adjusted values of the above expenses.

Sales tax rates, property tax rates, and state income tax rates specific to the 13 local taxing districts covered by the study were compiled. These are shown in table 4.11 .

The effective property tax rates shown in table 4.11 were derived from quoted "nominal" property tax rates by multiplying the nominal rates by the quoted property assessment levels, stated as a percentage of market value.1 To estimate the solar property values to which the effective property tax rates were applied, it was assumed that the solar energy system would increase the value of the building in the year of purchase (the base year of the 1ife-cycle cost evaluation) by an amount equal to the system acquisition cost. A decay factor was applied to the solar property values to cause a decline in value over the 20-year study period, leaving a residual market value in the 20th year of 10 percent of the original acquisition costs.

As may be seen in table 4.11 , the sales tax and/or the property tax are exempted in part or in full in some of the cities. These exemptions constitute regional investment incentives by reducing the effective cost of solar energy in the locations where they apply.

Depreciation of solar capital costs was based on an allowable system tax life of 15 years and on a depreciation base of approximately 96 percent of the original system acquisition cost. This depreciation base was derived by assuming a 10 percent nominal net salvage value (including inflation and net of disposal costs) at the end of 15 years, and adjusting the nominal net value to a real dollar basis to reflect the assumed annual inflation rate of 6 percent. To compute depreciation according to the straight-line method, the net salvage value was subtracted initially to obtain the depreciation base; whereas, using a declining balance depreciation method, the initial depreciation base included net salvage value, but depreciation ceased when the net salvage value was reached. Solar energy systems applied in new construction were depreciated by the 150 percent declining balance method applicable at the time the case studies were performed. (According to conventional practice, a switchover to the straight-line method was provided for at the point that the straight-line method yielded a higher yearly depreciation allowance than the declining balance method.) Systems retrofitted to existing buildings were depreciated by the straight-1ine method.2

1 Nominal tax rates and assessment levels were obtained from each of the local property tax authorities through telephone interview.

2 These assumptions comply with the rules for depreciation specified in section 167 of the Internal Revenue Code of 1954 [29], and were based in part on the advice of IRS staff concerning component depreciation and allowable tax lives for conmercial building heat systems. 
Several of the c1t1es selected for study were in states which provided economic incentives for commerclal use of solar energy through the allowance of shortened depreclation periods. States providing this type of incentive were Arlzona, with a 36-month amortization period for solar equipment [72]; Texas, with a 60-month period [73]; and Massachusetts and W1sconsin, with 1mmediate deduction of depreciable costs from gross income in the tax year in which they occur [74, 75]. (These state provisions were In effect as of mid-1980 and are reflected in the analyses; subsequent state depreclation legislation is not taken into account.)

The difference between the small undepreclated system cost and the somewhat higher actual residual value assumed to remaln at the end of 20 years $1 \mathrm{~s}$ subject to capital gains tax. To evaluate the capital gains tax, a combined Federal and state cap1tal gains tax rate was used, based on a Federal corporate capital gains rate of 28 percent and the state income tax rates shown in table 4.11. (The capital gains tax rates for states vary, but are widely set at the ordinary income tax rate.) The combined rate was derived as follows:

$$
\mathrm{T}_{\mathrm{cg}}=\mathrm{t}_{\mathrm{s}}+.28\left(1-\mathrm{t}_{\mathrm{s}}\right)
$$

where

$\begin{aligned} t_{c g} & =\text { combined Federal and state capital gains tax rate, and } \\ t_{s} & =\text { state ordinary income tax rate for corporations. }\end{aligned}$

Income tax credits are allowed by the Federal government and by several state governments to purchasers of solar energy systems. By providing a direct reduction in income taxes by the amount of the allowable credit, the income tax credit is a much more potent incentive than an income tax deduction of equal percentage value.

Inder the National Energy Tax Act of 1978 [76], purchasers of solar energy systems were allowed a one-time reduction in their taxes equal to 10 percent of the purchase and installation costs of solar energy, energy conservation, or wind energy systems acquired after September 30,1978, for heating and/or cooling commercial bulldings. Qualified investment for the 10 percent energy tax credit was defined in section 48 (1)(4) of the Act. The energy tax credit was subsequently raised to 15 percent, the effect of which is examined in the sensitivity analysis of section 5.3. Solar and wind energy property considered under existing law to be a structural component of a building does not qualify additionally for the regular 10 percent investment tax credit. However, property qualifying both as regular investment credit property under existing laws and as solar and wind energy property (e.g., solar industrial process heat equipment) would generally be eligible for both tax credits, for a total of 25 percent of the system acquisition cost.

Several of the cities were in states which allowed tax credits against state tax liability. The allowances in California was a 55 percent tax credit for system costs less than $\$ 12,000$, up to a $\$ 3,000$ maximum (1ess Federal tax credits), and a 25 percent tax credit (less Federal tax credits) for systen costs of $\$ 12,000$ and above. The tax credit was in lieu of a state depreciation 
allowance [77]. North Dakota allowed a tax credit of 5 percent of system costs for two years [78].1

It should be noted that a tax credit at the state level is not effectively equivalent to a Federal tax credit of the sane stated percentage. Because state taxes are an allowable deduction from taxable income at the Federal level, a credit against the state tax liability is effectively reduced by a percentage equal to the Federal tax rate. For example, given a one-time tax credit of 10 percent of system cost at the state level, a system cost of $\$ 5,000$, and a Federal corporate income tax rate of 46 percent, the tax savings would equal $\$ 270(.10 \times \$ 5,000 \times(1-.46)=\$ 270)$, as compared with a tax savings of $\$ 500$ from a Federal tax credit of 10 percent.

In order to reduce the number of variables in the economic evaluation model without sacrificing analytical detal1 or accuracy, the parameters for two types of state tax incentives -- income tax credit and rapid depreciation writeoff -were converted to their equivalents in terms of an annual Federal tax credit. To convert a state tax credit to an equivalent annual Federal tax credit, the following equation can be used:

$$
s_{c}\left(1-t_{f}\right)=F_{C}
$$

where

$$
\begin{aligned}
& \mathrm{S}_{\mathrm{C}}=\text { state tax credit (a percent of system cost), } \\
& \mathrm{t}_{\mathrm{F}}=\text { Federal corporate income tax rate, and } \\
& \mathrm{F}_{\mathrm{C}}=\text { Federal tax credit (a percent of system cost). }
\end{aligned}
$$

To convert an annual depreciation deduction allowable only at the state level to an equivalent annual Federal tax credit, the following equation was used:

$$
F_{e}=\frac{\frac{C}{L} t_{s}\left(1-t_{F}\right)}{C}
$$

where

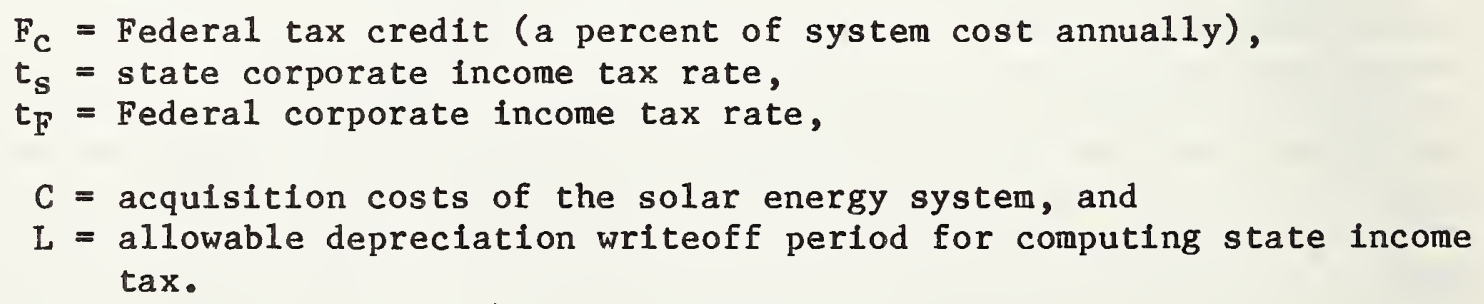

1 Arizona subsequently enacted a solar tax credit--not reflected in the case studies for Phoenix--equal to 35 percent of defined eligible costs of a solar energy device for commercial or industrial purposes through 1983, to be decreased each year thereafter. This tax credit was in lieu of the rapid depreciation writeoff [79]. 


\subsection{OTHER DATA AND ASSUMPTIONS}

\subsubsection{Operation, Maintenance, and Repair Costs}

There is little historical data available upon which to base estimates of long-run operation, maintenance, and repair costs for solar energy systems. Of ten these are somewhat arbitrarily assumed to be equal to one percent of the initial contract cost, plus inflation, an assumption adopted for the case studies. The estimate was assumed to cover insurance premiums less reimbursables, uninsured damage to collectors or other components of the solar system, periodic cleaning of collector surfaces, routine replacement of parts, and electricity required to operate the system. Electrical energy costs to run the pumps, fans, and other motors of the active solar energy system were in this study lumped with nonfuel operation, maintenance, and repair costs, and were assumed to escalate at the rate of general price inflation.

\subsubsection{Solar Energy System Life and Salvage Value}

For the case studies, it was assumed that the solar energy system, whether retrofitted to an existing building or incorporated into new construction, would have an economic life of 20 years. It was further assumed that building ownership would not change over that period.

A nominal resale value of 10 percent of the initial system cost was assumed to remain at the end of the 20-year period. This was considered to be a conservative estimate, since the copper tubing would likely have a significant salvage value. Furthermore, it is possible that some of the system components would have remaining service life at the end of 20 years. However, there is little or no data upon which to base the estimate.

\subsection{SUMMARY OF ECONOMIC PARAMETERS COMMON TO ALL CITIES}

Table 4.12 summarizes the economic parameters that are uniform for all of the case studies. The table gives the values for those parameters used both for the service hot water analyses and for the combined space heating/hot water analyses. The data in table 4.12 are paired with the city-specific data in the case studies which follow. 
Table 4.12 Economic Parameters Common to All Cities: Base Case

\section{Economic Parameter}

Solar Energy System Materials Cost

Discount Rate (Nominal)

General Rate of Inflation

Loan Interest Rate

New Buildings

Existing Buildings

Down Payment

Service Hot Water Systems

Combined Space Heating/Hot Water Systems

Years Financed

New Buildings

Existing Buildings

Depreciation Method

New Buildings

Existing Buildings

Depreciation Period

Recurring Cost Rate

Resale Value (Nominal)

Federal Tax Credit

Economic Life
Assigned Value

See Materials Component, table 4.3

$13 \%$

$6 \%$

$9.25 \%$

$10.5 \%$

0

$25 \%$

20 Years

5 Years

150\% Declining Balance

Straight Line

15 Years

$1 \%$ of Init1al System Cost plus annual Inflation

$10 \%$ of Initial System Cost

$10 \%$ of Initial System Cost

20 Years 


\section{CASE STUDY RESULTS}

This part of the report presents the results obtained from the case studies of solar economic feasibility. The case studies were based on the buildings, bullding systems, solar energy systems, and geographical locations described in section 3, and the parametric values designated in section 4 . The case study evaluations were performed using a computer program (1isted in appendix B) representing the economic model described in section 2. Note that the results for the solar service hot water system were based on 1978 estimates of base-year and future energy prices which understate the increase in oil prices that occurred between 1978 and 1980, and the combined heating/hot water systems are based on 1980 price data.

First, the case studies for the service hot water systems are given. A summary overview is provided with comparisons among the case studies. This overview is followed by detailed results for selected cases.

Second, the case studies for the combined space heating/service water heating systems are given. Results are presented for selected case studies under initial assumptions, revised assumptions, and alternative sensitivity assumptions. Thus, a more comprehensive and current evaluation is provided for the combined systems than for the service hot water systems.

\subsection{CASE STUDY RESULTS FOR SOLAR SERVICE HOT WATER HEATING SYSTEMS UNDER BASE-CASE ASSUMPTIONS}

5.1.1 Summary Overview and Comparisons

Tables 5.1 and 5.2 summarize the base-case results of the economic analyses of solar service hot water systems for the new office building and new retail store, respectively, for each of the 13 city case studies. Only the net present value savings are shown; the payback period is not shown because the estimated net savings were less than zero for all of the cities, based on 1978 data.

For each of the 13 cities listed in column 1 of the two tables, there are two rows of data. The first row, labeled "Base Case" gives the results for the 1978 data and base-case assumptions, including the assumed hot water usage rates. The second row gives the break-even results, including the calculated break-even hot water usage rate. The optimal solar fraction given in column 4 is identical in the two rows because the optimal collector area changes at approximately the same rate as the hot water load changes, thereby yielding a constant optimal solar fraction for a given set of values for technical, economic, and climatological parameters (see section 2.5). The optimal solar collector area (column 5) is higher for the break-even analysis than for the base case due to the larger hot water load to be met.

Note that the tables show results only for solar as an alternative to electric resistance heating of service hot water for the new office and new retail store. The results for the existing buildings and the other fuel sources are not shown because the hreak-even collector area for these other cases generally exceeded the upper size limit on the collector area of about $50 \mathrm{~m}^{2}\left(540 \mathrm{ft}^{2}\right)$ for office 
Table 5.1 Economic Analyses of Solar Hot Water for a New Office Building with an Electric Resistance Backup System: Case Study Results for 13 Citiesa (Based on 1978 Energy Prices and System Costs and on Base-Case Assumptions)

\begin{tabular}{|c|c|c|c|c|c|c|}
\hline City/Case & $\begin{array}{l}\quad(2) \\
\text { Hot Water } \\
\text { Usage Rate } \\
\text { (gal/min) }\end{array}$ & $\begin{array}{c}\text { (3) } \\
\text { Thermal } \\
\text { Load } \\
\left(10^{7} \text { Btu) }\right.\end{array}$ & $\begin{array}{c}\text { (4) } \\
\text { Optimal } \\
\text { Solar } \\
\text { Fraction } \\
(\%) \\
\end{array}$ & $\begin{array}{l}\text { (5) } \\
\text { Optimal } \\
\text { Collector } \\
\text { Area }\left(\mathrm{ft}^{2}\right)\end{array}$ & $\begin{array}{c}\text { (6) } \\
\text { PV } \\
\text { Energy } \\
\text { Savings } \\
(\$)\end{array}$ & $\begin{array}{l}\quad(7) \\
\text { Net PV Solar } \\
\text { Energy Savings } \\
\text { minus Solar } \\
\text { Costs }(\$) \\
\end{array}$ \\
\hline \multicolumn{7}{|l|}{ Phoenix } \\
\hline Base Case & .53 & 4.1 & 89 & 167 & 2,385 & -469 \\
\hline Break-even Case & .63 & 5.2 & 89 & 212 & 3,027 & 0 \\
\hline \multicolumn{7}{|l|}{ Boston } \\
\hline Base Case & .50 & 5.4 & 81 & 289 & 3,416 & -556 \\
\hline Break-even Case & .62 & 6.8 & 81 & 359 & 4,248 & 0 \\
\hline \multicolumn{7}{|l|}{ Bismarck } \\
\hline Base Case & .50 & 5.5 & 82 & 223 & 2,406 & -601 \\
\hline Break-even Case & .70 & 7.8 & 82 & 313 & 3,374 & 0 \\
\hline \multicolumn{7}{|l|}{ Nashville } \\
\hline Base Case & .50 & 4.7 & 81 & 213 & 2,604 & -787 \\
\hline Break-even Case & .74 & 7.0 & 81 & 316 & 3,862 & 0 \\
\hline \multicolumn{7}{|l|}{ Charleston } \\
\hline Base Case & .50 & 4.5 & 81 & 180 & 2,479 & $-1,174$ \\
\hline Break-even Case & .89 & 8.0 & 81 & 321 & 4,422 & 0 \\
\hline \multicolumn{7}{|l|}{ Forth Worth } \\
\hline Base Case & .50 & 3.9 & 84 & 161 & 2,360 & $-1,221$ \\
\hline Break-even Case & .90 & 7.0 & 84 & 289 & 4,230 & 0 \\
\hline \multicolumn{7}{|l|}{ Madison } \\
\hline Base Case & .50 & 5.3 & 78 & 227 & 2,770 & $-1,364$ \\
\hline Break-even Case & .93 & 9.9 & 78 & 422 & 5,157 & 0 \\
\hline \multicolumn{7}{|l|}{ Wash., D.C. } \\
\hline Base Case & .50 & 4.9 & 79 & 216 & 2,802 & $-1,446$ \\
\hline Break-even Case & .94 & 9.3 & 79 & 406 & 5,267 & 0 \\
\hline \multicolumn{7}{|l|}{ Los Angeles } \\
\hline Base Case & .50 & 3.5 & 85 & 143 & 1,908 & $-1,470$ \\
\hline Break-even Case & 1.08 & 7.5 & 85 & 318 & 4,129 & 0 \\
\hline \multicolumn{7}{|l|}{ Apalachicola } \\
\hline Base Case & .50 & 4.3 & 82 & 161 & 2,422 & $-1,634$ \\
\hline Break-even Case & 1.05 & 9.0 & 82 & 338 & 5,096 & 0 \\
\hline \multicolumn{7}{|l|}{ Miami } \\
\hline Base Case & .50 & 3.9 & 81 & 139 & 2,145 & $-2,209$ \\
\hline Break-even Case & 1.37 & 10.6 & 81 & 381 & 5,883 & 0 \\
\hline \multicolumn{7}{|l|}{ Omaha } \\
\hline Base Case & .50 & 5.2 & 74 & 178 & 2,583 & $-2,570$ \\
\hline Break-even Case & 1.46 & 15.1 & 74 & 518 & 7.520 & 0 \\
\hline \multicolumn{7}{|l|}{ Seattle } \\
\hline Base Case & .50 & 5.2 & 47 & 135 & 988 & $-2,816$ \\
\hline Break-even Case & n.a. & n.a. & n.a. & n.a. & n.a. & n.a. \\
\hline
\end{tabular}

a Based on the buildings and building systems described in section ${ }^{3}$ and the data and assumptions given in section 4 , and calculated by the model described in section 2 . Results are shown for solar energy as an alternative to electric resistance heating of service hot water. The comparison is made on the basis of identical electric systems as backup to the solar energy system and as the nonsolar alternative to it. The case results for solar as an alternative to distillate oil and natural gas were in all cases less favorable than those shown here for electricity. The break-even loads for the other cases are depicted in figure 5.1 .

b n.a. means not applicable. (For Seattle, the break-even collector area exceeded significantly the size limit for which the cost estimating function was assumed to apply.)

Note: For simplicity, the hot water usage rate, the thermal 1oad, and the collector area are given in English units. Metric equivalents $(X)$ can be found as follows: (X) $\mathrm{m}^{3} / \mathrm{s}=\mathrm{gal} / \mathrm{mln} \cdot 0.0379 / 60.0$; $(\mathrm{X}) \mathrm{GJ}=\mathrm{Btu} \cdot 1055.87 / 10^{9} ;(\mathrm{X}) \mathrm{m}^{2}=\mathrm{ft}^{2} \cdot 0.0929$. 
Table 5.2 Economic Analyses of Solar Hot Water for a New Retall Store with an Electric Resistance Backup System: Case Study Results for 13 Citiesa

(Based on 1978 Energy Prices and System Costs and on Base-Case Assumptions)

\begin{tabular}{|c|c|c|c|c|c|c|}
\hline City/Case & $\begin{array}{l}\text { (2) } \\
\text { Hot Water } \\
\text { Usage Rate } \\
\text { (gal/min) }\end{array}$ & $\begin{array}{c}\text { (3) } \\
\text { Thermal } \\
\text { Load } \\
\left(10^{7} \text { Btu) }\right.\end{array}$ & $\begin{array}{c}(4) \\
\text { Optimal } \\
\text { Solar } \\
\text { Fraction } \\
(\%)\end{array}$ & $\begin{array}{c}\text { (5) } \\
\text { Optima1 } \\
\text { Collector } \\
\left.\text { Area (ft }{ }^{2}\right)\end{array}$ & $\begin{array}{c}\text { (6) } \\
\text { PV } \\
\text { Energy } \\
\text { Savings } \\
(\$) \\
\end{array}$ & $\begin{array}{l}\quad(7) \\
\text { Net PV Solar } \\
\text { Energy Savings } \\
\text { minus Solar } \\
\text { Costs }(\$)\end{array}$ \\
\hline \multicolumn{7}{|l|}{ Los Angeles } \\
\hline Base Case & .015 & .15 & 91 & 8 & 88 & -186 \\
\hline Break-even Case & .057 & .57 & 91 & 30 & 334 & 0 \\
\hline \multicolumn{7}{|l|}{ Phoenix } \\
\hline Base Case & .015 & .18 & 88 & 7 & 102 & -363 \\
\hline Break-even Case & .092 & 1.09 & 88 & 45 & 618 & 0 \\
\hline \multicolumn{7}{|l|}{ Bismarck } \\
\hline Base Case & .015 & .24 & 80 & 9 & 101 & -383 \\
\hline Break-even Case & .110 & 1.78 & 80 & 61 & 753 & 0 \\
\hline \multicolumn{7}{|l|}{ Boston } \\
\hline Base Case & .015 & .25 & 77 & 11 & 140 & -429 \\
\hline Break-even Case & .093 & 1.46 & 78 & 70 & 881 & 0 \\
\hline \multicolumn{7}{|l|}{ Nashville } \\
\hline Base Case & .015 & .20 & 76 & 8 & 106 & -438 \\
\hline Break-even Case & .120 & 1.58 & 78 & 69 & 846 & 0 \\
\hline \multicolumn{7}{|l|}{ Forth Worth } \\
\hline Base Case & .015 & .17 & 79 & 6 & 96 & -500 \\
\hline Break-even Case & .140 & 1.55 & 82 & 57 & 904 & 0 \\
\hline \multicolumn{7}{|l|}{ Charleston } \\
\hline Base Case & .015 & .19 & 78 & 7 & 102 & -520 \\
\hline Break-even Case & .150 & 1.88 & 78 & 75 & 1,013 & 0 \\
\hline \multicolumn{7}{|l|}{ Madison ${ }^{5}$} \\
\hline Base Case & .015 & .23 & 75 & 9 & 115 & -526 \\
\hline Break-even Case & .150 & 2.22 & 75 & 82 & 1,108 & 0 \\
\hline \multicolumn{7}{|l|}{ Wash., D.C. } \\
\hline Base Case & .015 & .21 & 74 & 8 & 113 & -544 \\
\hline Break-even Case & .140 & 2.05 & 76 & 78 & 1,115 & 0 \\
\hline \multicolumn{7}{|l|}{ Apalachicola } \\
\hline Base Case & .015 & .19 & 77 & 6 & 98 & -652 \\
\hline Break-even Case & .165 & 2.04 & 79 & 70 & 1,116 & 0 \\
\hline \multicolumn{7}{|l|}{ Seattlec } \\
\hline Base Case & .015 & .22 & 42 & 5 & 38 & -590 \\
\hline Break-even Case & n.a. & n.a. & n.a. & $\mathrm{n} \cdot \mathrm{a}$. & $\mathrm{n} . \mathrm{a}^{\circ}$ & n.a. \\
\hline \multicolumn{7}{|l|}{ Miami } \\
\hline Base Case & .015 & .17 & 81 & 6 & 93 & -652 \\
\hline Break-even Case & .210 & 2.37 & 78 & 78 & 1,272 & 0 \\
\hline \multicolumn{7}{|l|}{ Omaha } \\
\hline Base Case & .015 & .22 & 71 & 7 & 107 & -730 \\
\hline Break-even Case & n.a. & $\mathrm{n} \cdot \mathrm{a}$. & n.a. & n.a. & n.a. & n.a. \\
\hline
\end{tabular}

a Based on the buildings and building systems described in section 3 and the data and assumptions given in section 4, and calculated by the model described in section 2. Results are shown for solar energy as an alternative to electric resistance heating of service hot water. The comparison is made on the basis of the identical electric systems as backup to the solar energy system and as the nonsolar alternative to 1t. The case results for solar as an alternative to distillate oil and natural gas were in a11 cases less favorable than those shown here for electricity. The break-even loads for the other cases are depicted in figure 5.1 .

b These break-even results are shown although they exceed somewhat the size limit imposed on the size of the collector for which the cost estimating function was assumed to apply.

c n.a. means not applicable. (For Seattle and Omaha, the break-even collector area exceeds significantly the size limit for which the cost estimating function was assumed to apply.)

Note: For simplicity, the hot water usage rate, the thermal load, and the collector area are given in English units. Metric equivalents $(X)$ can be found as follows: $(X) \mathrm{m}^{3} / \mathrm{s}=\mathrm{gal} / \mathrm{min} \cdot 0.0379 / 60.0$; $(\mathrm{X}) \mathrm{GJ}=\mathrm{Btu} \cdot 1055.87 / 10^{9} ;(\mathrm{X}) \mathrm{m}^{2}=\mathrm{ft}^{2} \cdot 0.0929$. 
building systems and about $8 \mathrm{~m}^{2}\left(85 \mathrm{ft}^{2}\right.$ ) for retail store systems for which the cost estimating functions were assumed to apply. The economic feasibility results for solar in these other cases were less favorable than those for the electric resistance alternative in new buildings.

Figure 5.1, part A, summarizes the break-even hot water usage rates for the new office buildings in each city based on each of the three energy alternatives and on the 1978 data and base-case assumptions. Part B of the figure shows the break-even rates for the new retail store based on electricity only. The other break-even results for the retail store are not shown because the collector size requirements necessary to meet the loads imposed by the break-even rates generally exceeded the allowable limits.

of the cases evaluated under the 1978 data and base-case assumptions, the estimated ininimum hot water loads necessary for cost effectiveness exceeded those designated as representative for the selected buildings, and net present value losses were estimated (see column 7 of tables 5.1 and 5.2 , base-case row for each city). However, by comparing the estimated hot water usage rates for the base case with the rates for the break-even case--both in column 2 of tables 5.1 and 5.2--it can be seen that the solar service hot water system was relatively close to cost effectiveness in some of the cities even based on the lower 1978 energy prices. With only a slightly larger hot water load than that assumed for the base case, a break-even outcome was estimated. For example, the solar energy system was estimated to break even relative to the electric resistance heating system in the Boston office building at a hot water usage rate of $0.62 \mathrm{gal} / \mathrm{min}\left(3.916 \times 10^{-5} \mathrm{~m} / \mathrm{s}\right)$ versus the assumed base case rate of $0.50 \mathrm{gal} / \mathrm{min}\left(3.55 \times 10^{-5} \mathrm{~m}^{3} / \mathrm{s}\right)$.

In those cases where the estimated break-even hot water usage rate was ciose to the base case rate, cost-effective estimates would 1ikely have resulted if the bullding had been slightly larger, if occupancy rate had been larger, or if the building's functional use had dictated higher hot water requirements than those assumed typical of the case study bulldings. The estimated breakeven hot water usage rates for solar energy as an alternative to oll would be lower than those shown if they reflected the higher-than-projected rise in the ofl prices from 1978 to 1980.

New Versus Existing Buildings. The case study evaluations of solar service hot watex systems for both commerclal office buildings and retail stores estimated the new buildings to be much more favorable to the use of solar energy systems than the existing buildings; in fact, the minimum hot water loads necessary for system cost effectiveness in the existing retall store generally exceeded the collector size limits imposed on the extrapolation of the system cost estimating equations of table 4.3. The poorer estimated economic performance of the systems for the existing buildings reflected three key assumptions: (1) Higher cost functions were developed to estimate the costs of the systems for existing buildings. (2) Less favorable depreciation allowances were assumed for existing building systems (see section 4). (3) Less favorable loan terms were assumed for exlsting building systems. 


\section{A. New office Bulldings b}

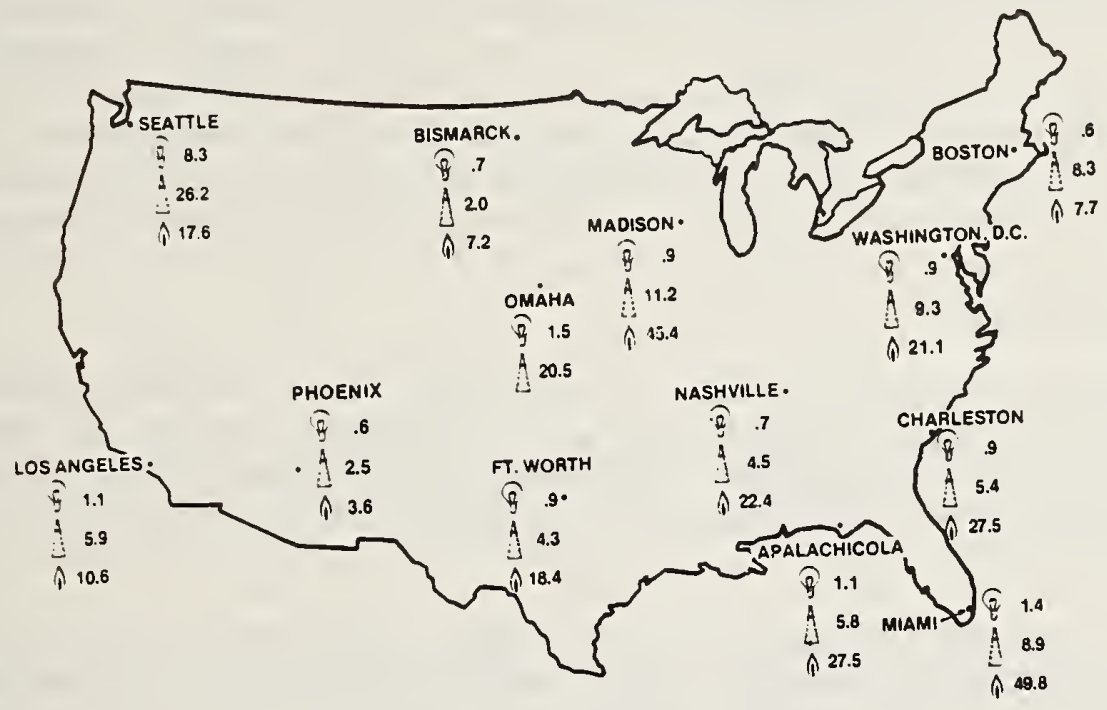

B. New Retail Stores ${ }^{c}$

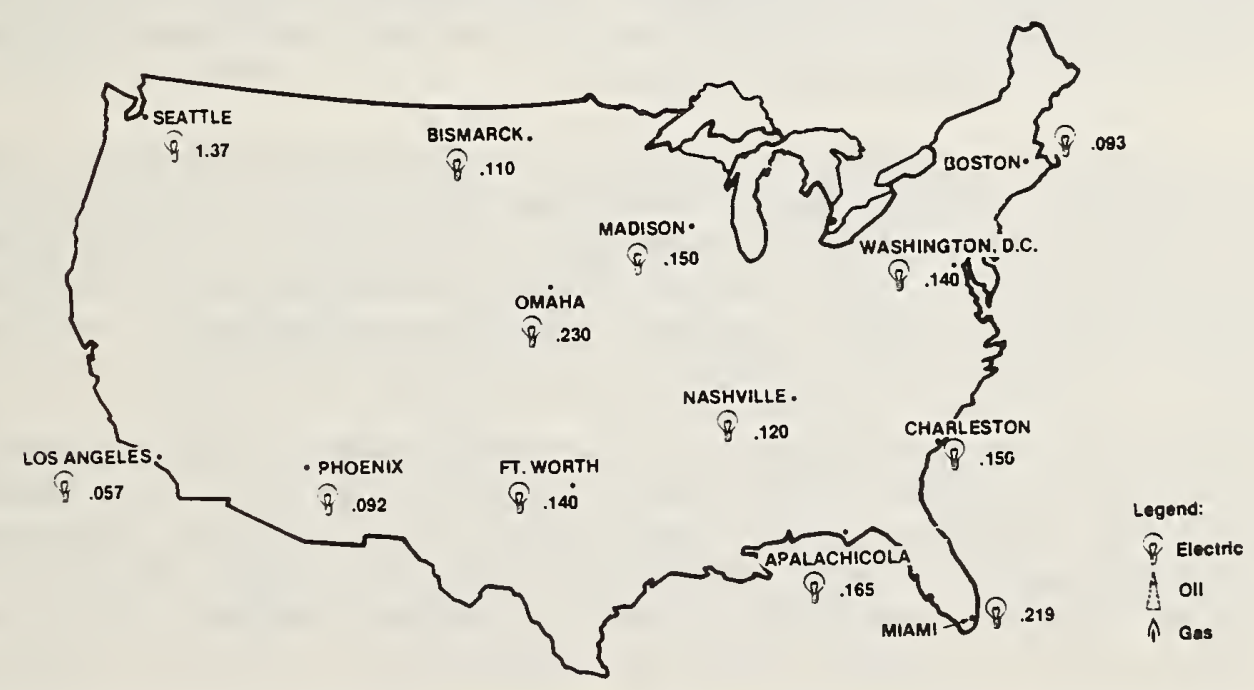

a Minimum hot water usage rates are based on three alternative fuel types for the nonsolar alternative energy system with which solar energy is compared. For usage rates lower than those indicated, solar energy is not estimated to be cost effective; for higher usage rates, net present value savings are estimated.

b Average hot water usage rates in the representative 3-story office building occupled five days a week by 300 people was assumed to be .5 gallons per minute ( 30 gallons per hour or $3.155 \times 10^{-5} \mathrm{~m}^{3} / \mathrm{s}$ ).

c Average hot water usage rates in the representative 1-story retail store occupied six days per week by 100 people was estimated at .015 gallons per minute $\left(0.9\right.$ gallons per hour or $\left.0.095 \times 10^{-5} \mathrm{~m}^{3} / \mathrm{s}\right)$. Results are not shown for oll and gas for retall stores because the collector size necessary to meet the breakeven load exceeded the allowable size limit imposed by the system cost-estimating equations given in table 4.3.

Note: Metric equivalent hot water usage rates $(X)$ can be found as follows: $(\mathrm{X}) \mathrm{m}^{3} / \mathrm{s}=\mathrm{gal} / \mathrm{min} \cdot 0.0379 / 60.0$. 
Office Bulldings Versus Retail stores. By comparing column 6 of tables 5.1 and 5.2 , it further can be seen that estimated total energy savings were much larger for the office buildings than for the retail stores. However, a comparison between the two tables of columns 2 and 5 also shows show much larger break-even loads and collector areas for the office buildings than for the retail stores. Additionally, the collector cost per unit area was assumed higher for the office buildings than the retail stores. As a result, higher net dollar losses were estimated (column 7) for the office buildings than for the retail stores.

City Comparisons. Tables 5.1 and 5.2 array the cities in descending order of the estimated cost effectiveness of the solar energy systems as compared with electric systems. For the office building case studies, Phoenix, Boston, and Bismarck were estimated to be the three most favorable locations for solar energy.

The favorable outcome for Phoenix, (for solar energy versus electricity) owed to its high annual solar radiation and relatively high tax incentives. Phoenix offered no particular locational advantage to the use of solar in terms of other parameters, such as labor costs to install the systems and the price of electricity $(1978 \mathrm{price}$ of $\$ .038 / \mathrm{kWh})$. A locational disadvantage was the relatively high water pipeline temperatures that effectively lower the energy load associated with given water usage rates.

Boston's relatively favorable outcome can be attributed primarily to the high cost of electricity ( 1978 price of $.050 / \mathrm{kWh}$--approximately twice as high as in most of the rest of the U.S.). Other factors favorable to solar energy were the relatively high tax incentives in Massachusetts and the relatively large energy loads resulting from a low water pipeline temperature. A locational disadvantage was the relatively high cost of labor in Boston.

Bismarck's locational advantages were its relatively low labor costs for solar installation, its relatively high solar radiation, its low water pipeline temperatures which increased the hot water loads, and its solar energy incentives. Despite its northerly latitude, its daily radiation values compared favorably with those of many of the other cities. The major disadvantage for solar energy versus electricity in Bismarck was the comparatively low cost of electricity.

The least favorable locations were estimated to be Seattle, Omaha, and, perhaps surprisingly (given its early lead in the use of solar hot water systems), Miami.1 of the thirteen locations examined, Seattle was found to be the least favorable to solar energy because of three main factors: substantially lower electricity prices than in the other locations, relatively high labor costs, and relatively low radiation values.

1 Note, however, the high optimal solar fraction for Miami (81 percent). Economic feasibility results might be considerably more favorable for a solar energy system with lower cost/lower efficiency characteristics than that used for this analysis. 
Omaha was found to be a relatively unfavorable city for solar energy. Causal factors were the lack of solar financial incentives, comparatively higher labor costs, comparatively high water pipeline temperatures, and comparatively low solar radiation values.

Miami's advantage of high insolation values throughout the year did not offset the locational drawbacks: a lack of special incentives, high water pipeline temperatures, and relatively low energy prices.

The break-even hot water usage rates (i.e., the minimum rates necessary for solar cost effectiveness), shown in the upper map of figure 5.1, illustrate the variation in solar locational feasibility as a function of the nonsolar fuel alternative and its price in a given city. For example, with oil as the alternative fuel, Bismarck was estimated to be more favorable for solar cost effectiveness than either Phoenix or Boston, the two most favorable cities for solar energy with electricity as the alternative. Furthermore, with oil as the alternative fuel, Ft. Worth, Charleston, Apalachicola, and Los Angeles were all more favorable locations for solar energy than Boston, because the very large price disparity between Boston and these other cities for electricity did not exist for oil. As another example, Nashville, a relatively favorable location for solar energy relative to an electric resistance system was a relatively unfavorable location with natural gas as the alternative. This is because natural gas prices were lower than average in Nashville, while electricity prices were about average.

It can be seen by comparing columns 1 of tables 5.1 and 5.2 that the solar-favorable ranking of the cities for the retall stores is quite similar to that for the office buildings, with a striking exception: Los Angeles. The solar service hot water system in the Los Angeles retail store ranked first among the retail store locations, both in terms of life-cycle cost effectiveness and in terms of having the smallest break-even load. In contrast, the Los Angeles location ranked ninth among the office building locations. Los Angeles was estimated to be a favorable location for the solar service water system in the retail store because of the higher percentage tax credit in California for smaller, lower cost systems. 1 For the larger, higher cost systems for the office buildings, the relatively low electricity costs and high water pipeline temperatures in Los Angeles prevented the location from being particularly favorable to solar.

Climatic conditions are often emphasized as the prime factors determining locational advantages and disadvantages for solar use. However, the locational variations depicted in tables 5.1 and 5.2 and figure 5.1 reflect the importance of at least four additional factors that are locationally dependent: (1) energy prices, (2) labor costs, (3) state and local taxes, and (4) state and local governmental incentives.

1 As explained in section 4.6, the effect of the California tax credit in effect at the time of this analysis was to provide a credit equal to 55 percent of initial costs for systems costing less than $\$ 12,000$, up to a $\$ 3,000$ maximum tax credit (less Federal tax credits), and a credit of 25 percent for system. costing $\$ 12,000$ or more. 


\subsubsection{Detailed Results for Selected Case Studies}

For illustrative purposes, two of the case studies are presented in more detail below. For the Boston and Phoenix case studies city-specific input data and results of the break-even analysis are sumnarized in tabular form, and graphs showing the economic optimization paths are given.

Boston Solar Hot Water Case Studies. Table 5.3 summarizes the city-specific input data for Boston. The electricity and natural gas prices shown in the table are approximately 50 percent higher than the corresponding average for the country. The tax incentives are also relatively high. The water supply temperature is relatively low. Labor costs are relatively high. To perform the case studies of solar service hot water for Boston, the city-specific data in table 5.3 were paired with the set of non-location-specific economic paraneters summarized in table 4.12 .

Based on the 1978 data and base-case assumptions, solar energy service hot water was found to be uneconomical for the selected buildings and systems in Boston. The break-even analysis estimated that the system would become cost effective in comparison with electric resistance heating for the new office building with only a small increase in the hot water usage rate, $.62 \mathrm{gal} / \mathrm{min}$ versus the assumed $.50 \mathrm{gal} / \mathrm{min}\left(3.916 \times 10^{-5} \mathrm{~m}^{3} / \mathrm{s} \mathrm{vs} .3 .55 \times 10^{-5} \mathrm{~m}^{2} / \mathrm{s}\right)$. Substantially larger increases in hot water consumption were estimated to be necessary to achieve solar cost effectiveness in comparison with oil or natural gas.

The break-even results, based on the 1978 data and base case assumptions, are shown in table 5.4. The first column gives the estimated break-even hot water usage rates and as the corresponding thermal energy loads. Column 2 gives the life-cycle energy cost of supplying the break-even hot water load using the designated conventional fuel. For example, the cost of meeting the break-even load solely by electricity was estimated at $\$ 5,215$ in present values dollars. Column 3 gives the present value cost of meeting the residual break-even hot water load with a conventional auxiliary energy system when part of the load is met by solar energy. For example, the table shows that it was estimated to cost $\$ 966$ to meet the break-even load with an auxiliary electric resistance system. Column 4 gives the estimated present value of the energy savings from having the break-even solar energy system; column 5, the estimated solar fraction; and column 6 , the estimated collector area necessary to achieve the break-even position. For example, it was estimated for the new office building that a system with $359 \mathrm{ft}^{2}\left(33 \mathrm{~m}^{2}\right)$ of collector area would provide 81 percent of the load, with a resulting energy savings of $\$ 4,248--j u s t$ sufficient to offset the after-tax present value of related investment costs over the life cycle. Hence, the discounted payback period given in column 7 is equal to 20 years, the assumed life of the system. (For comparison, footnote c to table 5.4 gives the optimization results for the base-case data and assumptions.)

Figure 5.2 depicts the economic optimization paths, derived according to the model described in section 2.5. In the upper part of the figure the estimated linear relationship between the optimally sized collector area (measured on the horizontal axis) and the hot water load (measured on the upper vertical axis) 
Table 5.3 Economic Parameters Specific to Bostona

\section{Economic Parameter}

Labor Cost Adjustment Factor

Current Price Per Unit of Fuel

Electricity

Distillate Fuel 011

Natural Gas

Sales Tax on Solar Energy System

Materials and/or Labor

Sales Tax on Fuel

or Special Fuel Tax

Fuel Price Escalation Rates, Nominal

Property Tax Rate

and/or Exemption Period

Combined Federal and State Tax Rate

Effective State Tax Credit

(see table 4.11)

Number of Years for Which Credit Applied

Combined Tax Credit

\section{Assigned Value}

1.04

$\$ 0.050 / \mathrm{kWh}(\$ 0.014 \mathrm{~mJ})$

$\$ 0.43 / \mathrm{gal}(\$ 0.113 \ell)$

$\$ 3.70 / 1,000 \mathrm{ft}^{3}\left(0.131 \mathrm{~m}^{3}\right)$

$5 \%$

Materials Only

0

0

See tables 4.6, DoE Region 1

$12.6 \%$

10 yrs.

$51.3 \%$

$5.1 \%$

1

$15.1 \%$

a Summarized from section 4 


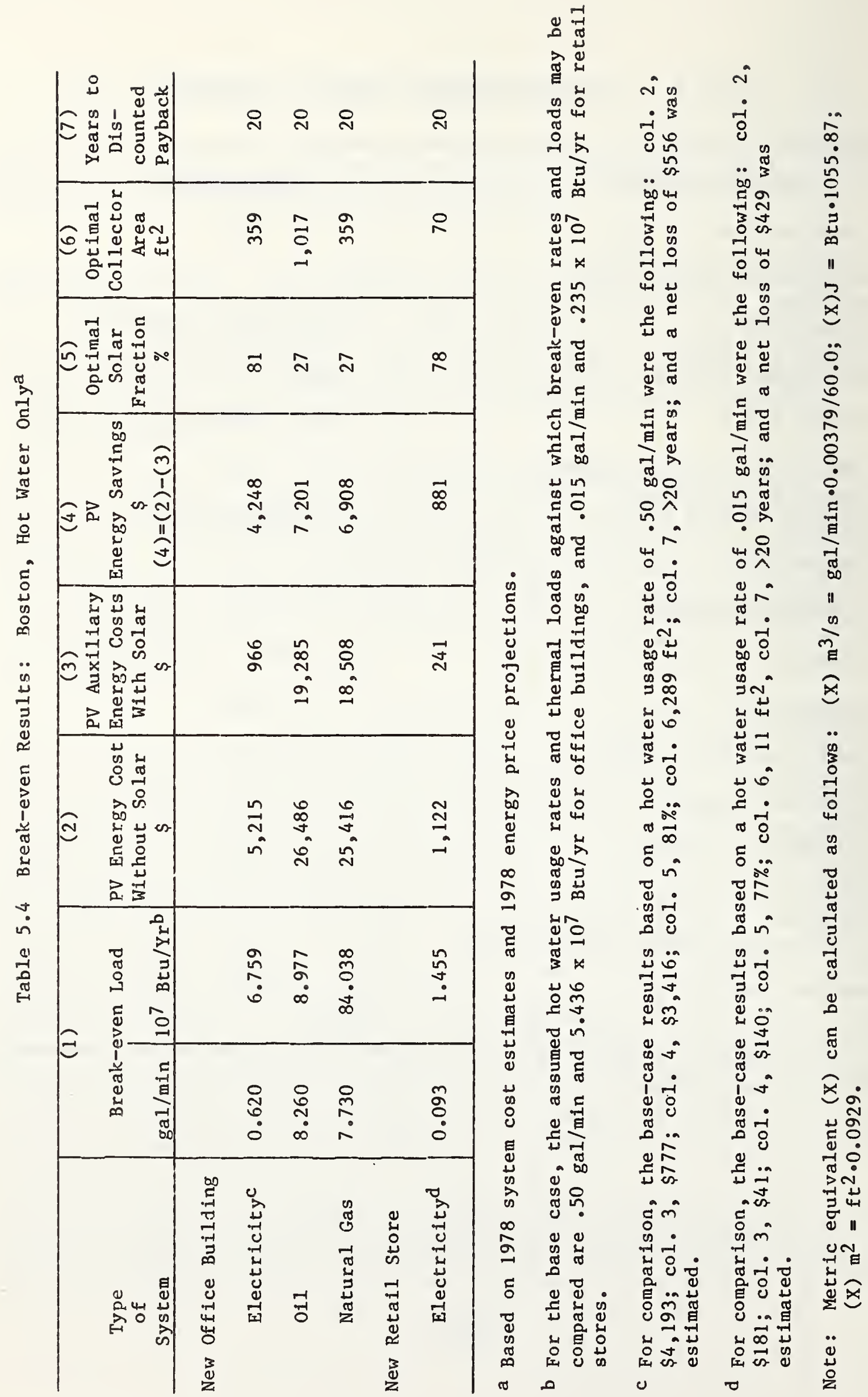


is shown for the new office building and the new retail store, based on electricity as the alternative energy source. The optimal solar fraction was estimated to be constant at 79 percent for the retail store and 81 percent for the new office building. (Note from section 2.5 that the constant relationship between collector area and hot water load is dependent on the cost functions and other assumptions holding for the higher and lower hot water loads indicated. For the purpose of illustration, these economic optimization paths are shown extended beyond the collector size limits assumed for the cost functions.) The lower left end of each of the two lines in the upper part of the figure designates the break-even hot water loads and the economically eff1cient collector sizes to meet these break-even loads.

Net savings lines in the lower part of figure 5.2 correspond to the economic optimization paths. They intersect the horizontal axis at the point of the break-even load, indicating a zero net savings, and extend from that point downward to the right, indicating increasing net savings associated with increasing hot water loads.

Phoenix Solar Hot Water Case Studies. Table 5.5 summarizes the data for Phoenix. Tax incentives included sales and property tax exemptions and a deduction from taxable income over three years of the acquisition costs of the solar energy system. Estimated conventional energy costs in Phoenix were moderate relative to those in the other locations. Solar-related labor costs, on the other hand, were higher than in most of the other locations. Water pipeline temperatures were also high. Annual solar radiation values exceeded substantially those in any of the other cities considered.

Table 5.6 gives the estimated break-even results for solar hot water in Phoenix. The solar energy systems were estimated to be very nearly cost competitive against electricity for the new office building, based on the 1978 data and assumptions. The estimated minimum hot water usage rate was $.63 \mathrm{gal} / \mathrm{min}$ $\left(3.98 \times 10^{-5} \mathrm{~m}^{3} / \mathrm{s}\right)$ versus the $.50 \mathrm{gal} / \mathrm{min}\left(3.15 \times 10^{-5} \mathrm{~m}^{2} / \mathrm{s}\right)$ of the base-case. Break-even hot water usage rates based on natural gas or ofl for the office building and electricity for the retall store as the conventional fuels were 5 to 7 times the base-case assumed rates.

Figure 5.3 shows the economic optimization paths for Phoenix. In this case, the projected expansion paths based on electricity, natural gas, and oil as the auxiliary fuels are shown for the new office bullding. The path based on electricity is shown for the new retail store. 
ECONOMIC OPTIMIZATION PATHS

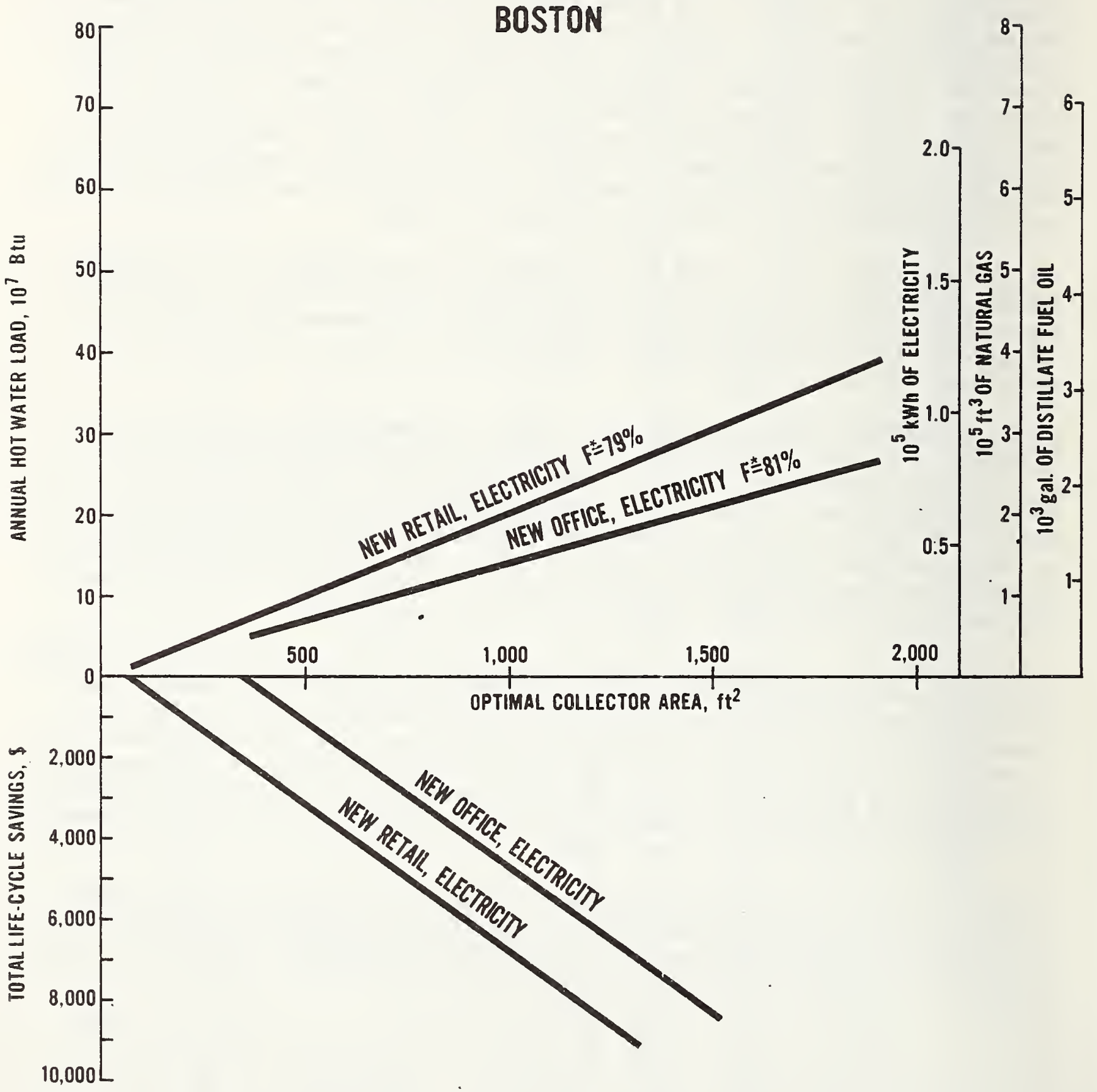

$F=$ Fraction of annual hot water load provided by solar

Figure 5.2 Economic Optimization Paths: Boston 
Table 5.5 Economic Parameters Specific to Phoenix ${ }^{a}$

Economic Parameter

Labor Cost Adjustment Factor

Current Price Per Unit of Fuel

Electricity

Distillate Fuel $0 i 1$

Natural Gas

Sales Tax on Solar Energy System

Materials and/or Labor

Sales Tax on Fue1

or Special Fuel Tax

Fuel Price Escalation Rates, Nominal

Property Tax Rate

and/or Exemption Period

Combined Federal and State Tax Rate

Effective State Tax Credit

(see table 4.11)

Number of Years for Which Credit Applied

Combined Tax Credit
Assigned Value

1.00

$\$ 0.038 / \mathrm{kWh}(\$ 0.011 \mathrm{~mJ})$

$\$ 0.412 / g a 1(\$ 0.109 \ell)$

$\$ 0.194 / 1,000 \mathrm{ft}^{3}\left(\$ 0.069 \mathrm{~m}^{3}\right)$

$5 \%$

Labor Only

$5 \%$

0

See tables 4.6, DoE Region 9

0

$51.7 \%$

$1.9 \%$

3

$11.9 \%$

a Summarized from section 4 


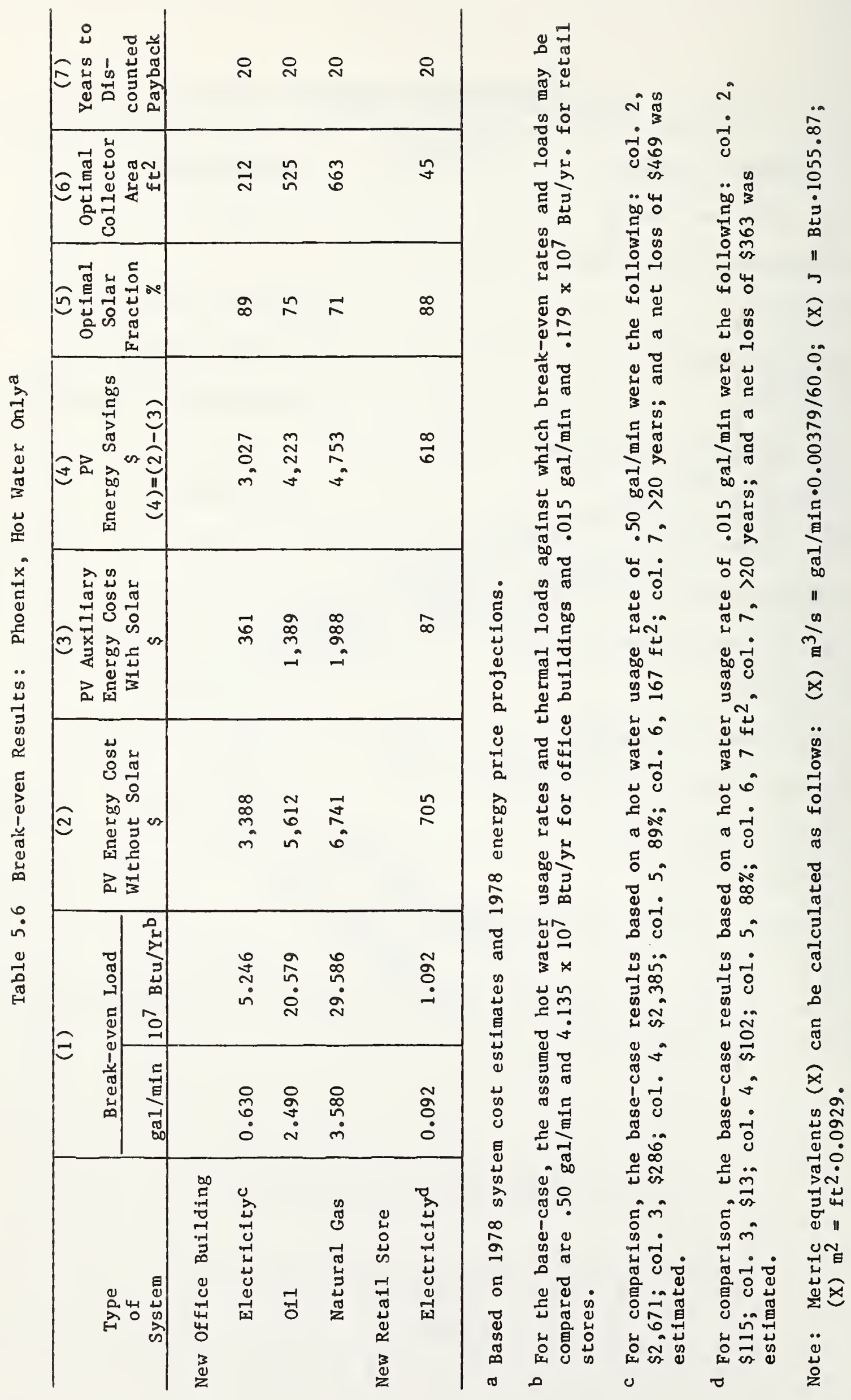




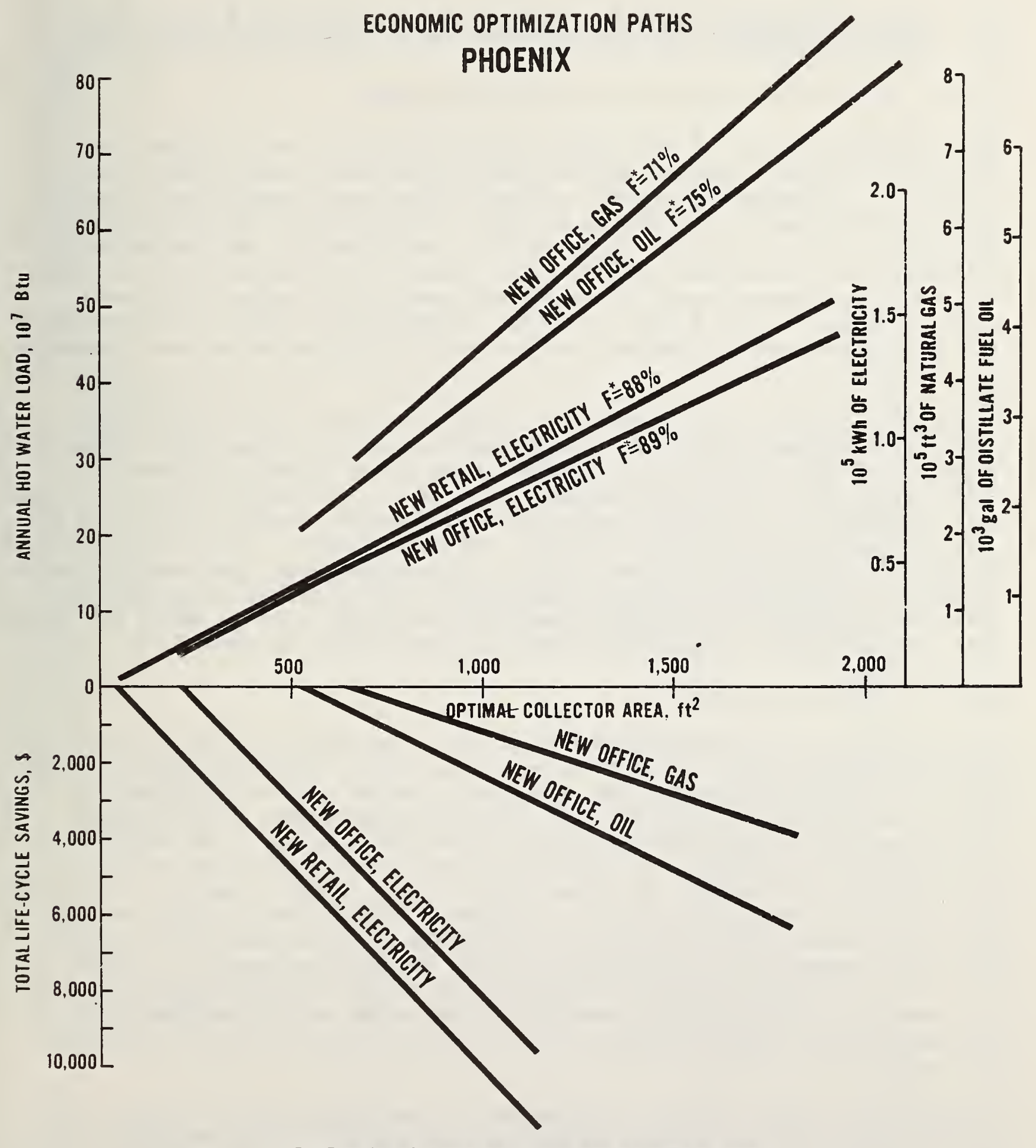

$F=$ Fraction of annual hot water load provided by solar

Figure 5.3 Economic Optimization Paths for Phoenix 


\subsection{CASE STUDY RESULTS FOR SOLAR COMBINED SPACE HEATING AND SERVICE WATER HEATING SYSTEMS}

\subsubsection{Results Compared for Two Sets of Assumptions}

The economic analyses of the combined space heating/hot water systems were initially performed based on energy price projections of early-1980, given in table 4.7. A substantial upward revision in base-year energy prices, particularly for oil, was made by DoE in mid-1980, reflecting the faster-than-projected short-run escalation in oil prices in 1980. Additionally, the Federal energy investment tax credit was raised from 10 percent to 15 percent. Selected case studies were repeated based on the revised energy price estimates given in table 4.8, and on the 15 percent Federal investment tax credit. Comparisons of the two sets of results demonstrates the volatility of solar economic feasibility over time.

Table 5.7 summarizes key measures of economic performance for four cities (col. 1) and three conventional energy sources (co1.2). The results shown in columns 3-5 are based on the early-1980 energy price projections (table 4.7) and the 10 percent Federal investment tax credit. The results shown in columns 6-8 are based on the mid-1980 energy price projections (table 4.8) and the 15 percent Federal investment tax credit. The estimated net losses over the life cycle were considerably reduced by use of the revised data, and near break-even outcomes were estimated for the combined solar energy system in Bismarck and Phoenix as compared with electric resistance heating. (The estimated net losses for the other case studies were larger than those given in table 5.7).

\subsubsection{Break-even Analysis}

Tables 5.8 and 5.9 summarize the results of a break-even analysis performed for initial energy prices, energy price escalation rates, and solar energy systems costs, holding other assumptions at base-case values. Table 5.8 gives the estimated break-even prices per unit of the nonsolar fuels. These are the initial prices of the fuels necessary to cause solar energy to be minimally cost effective, assuming that the initial prices will escalate at the rates forecasted in early 1980. It shows in col. 2, for example, that oil would have to cost $\$ 1.55$ per gallon $(\$ 0.41 / \ell)$ in Bismarck in the base year (as compared with the assumed price of $\$ 0.788$ per gallon $(\$ 0.21 / \ell)$ in early 1980 ) in order for solar energy to be cost effective, other things being equal. It shows in col. 3, for example, that the estimated price of oil in early 1980 would have to escalate 1.82 times faster over the 20 year study period than was projected in early 1980 in order for solar energy to become cost effective in Bismarck in comparison with oil.

Table 5.9 indicates in col. 4 the estimated break-even value for solar energy system costs, given the other assumptions of early 1980. The break-even values are indicated as a percentage of the base-case system costs calculated according to the equations in table 4.3. For example, for the solar energy system to break even relative to an oil-fired systern in Bismarck, the optimally sized solar energy system could cost no more than about half the amount estimated by table 4.3 cost equations. Relative to electric resistance heating (lower part 


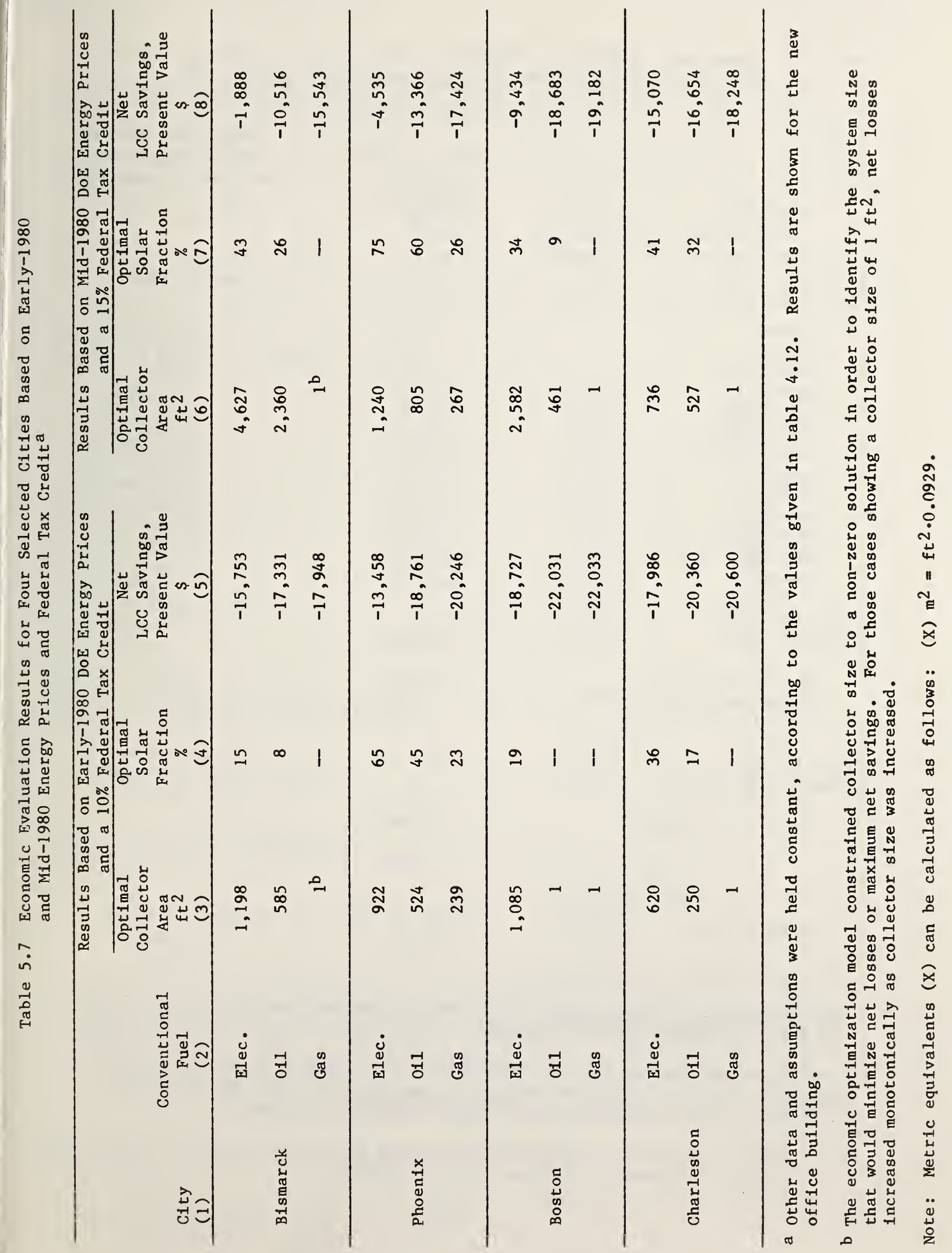


Table 5.8 Break-even Analysis of Base-Year Fuel Prices and Fuel Escalation Rates for Selected Cases Based on Ear1y-1980 Assumptions

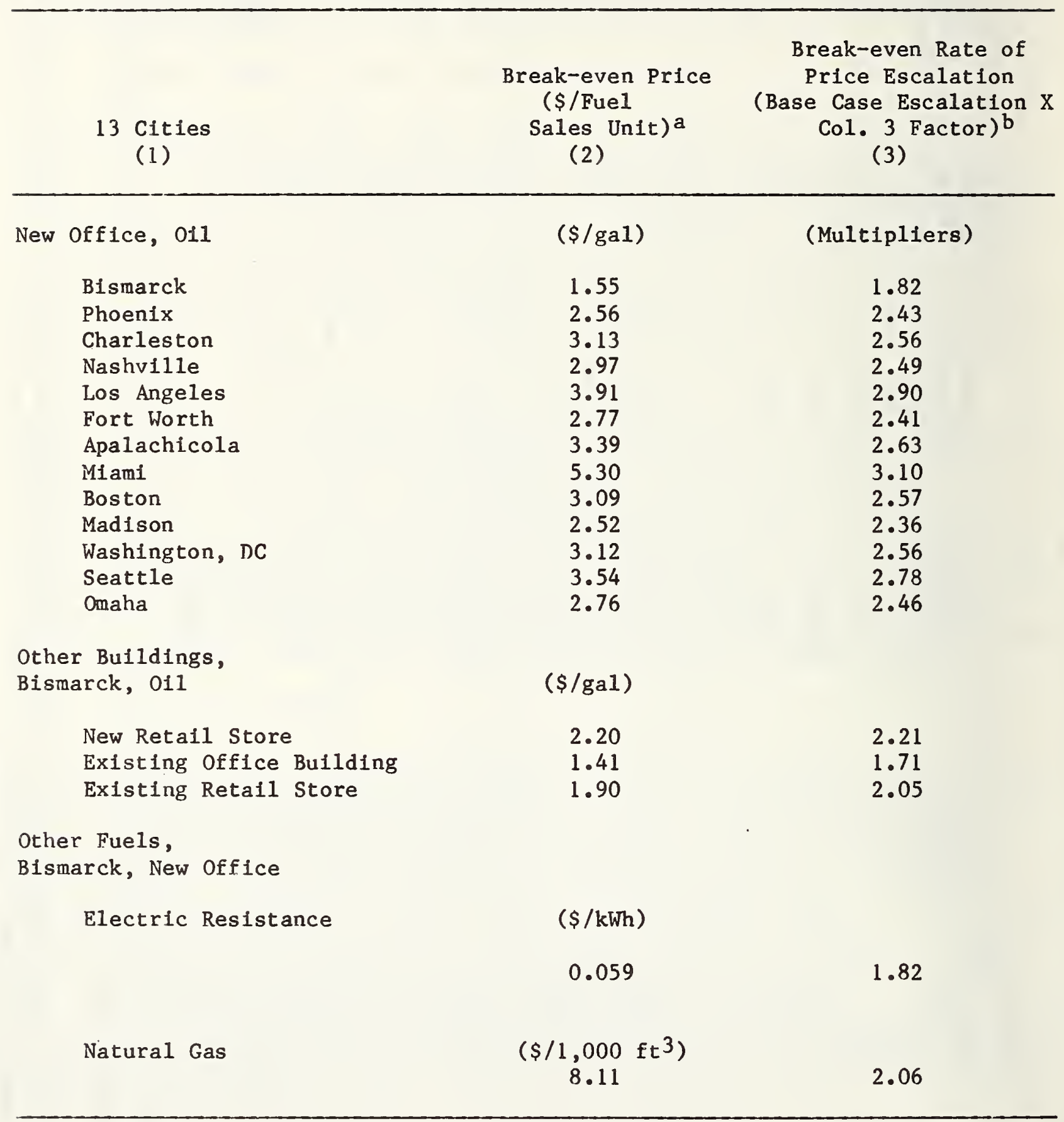

a Fuel prices in 1980 that would yield break-even outcomes if escalated over 20 years at the DoE rates forecasted in early 1980.

b Fuel price escalation rate multipliers that if applied to the DoE rates forecasted in early 1980 and used in conjunction with the DoE base-year fuel prices for early 1980 would yield break-even outcomes.

Note: Metric equivalents $(X)$ may be calculated as follows: $(\$ X) / \ell=\$ / g a l \div 3.785$; $\$(X) / \mathrm{mJ}=\$ / \mathrm{kWh} \div 3.6 ; \$(X) / \mathrm{m}^{3}=\$ / \mathrm{ft}^{3} \div 0.02832$. 
Table 5.9 Break-even Analysis of System Cost for Selected Cases Based on Early-1980 Data and Assumptions

\begin{tabular}{cccc} 
& Optimal & Optimal & \\
& Solar & Collector & Break-even \\
& Fraction & Area, & System Cost \\
13 C1ties & $\%$ & ft $^{2}$ & $\%$ \\
$(1)$ & $(2)$ & $(3)$ & $(4)$ \\
\hline
\end{tabular}

New Office, 011

System as Solar Alternative

$\begin{array}{ll}\text { Bismarck } & 45 \\ \text { Phoenix } & 78 \\ \text { Charleston } & 68 \\ \text { Nashille } & 54 \\ \text { Los Angeles } & 82 \\ \text { Fort Worth } & 68 \\ \text { Apalachicola } & 71 \\ \text { Miami } & 90 \\ \text { Boston } & 47 \\ \text { Madison } & 46 \\ \text { Washington, DC } & 54 \\ \text { Seattle } & 39 \\ \text { Onaha } & 50\end{array}$

$4,893 \quad 51$

$78 \quad 1,392 \quad 32$

$68 \quad 1,792 \quad 27$

$54 \quad 2,777 \quad 28$

$82 \quad 1,203 \quad 21$

$\begin{array}{lll}68 & 1,866 & 27\end{array}$

$71 \quad 1,534 \quad 24$

$90 \quad 804 \quad 16$

$47 \quad 4,174 \quad 28$

$46 \quad 4,465$

$54 \quad 3,029 \quad 27$

$39 \quad 3,315 \quad 23$

$\begin{array}{lll}50 & 3,785 & 29\end{array}$

Other Bulldings, Bismarck,

011 System as Solar Alternative

New Retall Store

Existing Office Buflding

Existing Retall Store
62

35

49
2,886

11,816

4,696
36

56

41

Other Alternative Energy

Systems, Bismarck, New Office

Bullding

Electric Resistance Natural Gas

a The maximum percentage of fixed and variable system costs, as estimated by the equations in table 4.3, for which the optimally sized systems would be cost effective, other factors held constant.

Note: Metric equivalent $(X)$ may be calculated as follows: $(X) m^{2}=f t^{2} \cdot 0.929$. 
of col. 4), the solar energy system could cost as much as 61 percent of the estimated base-case amount and still break even. (Note that in each of the above cases, factors other than the value of the parameter specified are held constant, but the size of the solar energy system is reoptimized for the new value of the specified parameter).

\subsubsection{Effects of Financing, Taxes, Incentives, and Discounting}

Figure 5.4 breaks down the changes in estimated solar energy costs and savings caused by financing, taxes, incentives, and discounting for a selected case study. The illustration is for a new office building in Phoenix with oil as the alternative energy system. The illustration, based on early-1980 data and assumptions, shows three vertical bars: the first shows adjustments to the costs of the solar energy system; the second, adjustments to the energy savings; and the third, net savings resulting from combining adjusted system costs and adjusted energy savings.

The first vertical bar, labeled "Costs of the Solar Energy System," shows a reduction in the initial contract cost of the system (purchase and installation costs, plus sales taxes) from $\$ 76,358$ to $\$ 63,303$ by taking into account the assumed long-term financing of the investment and by discounting the loan payments to their present value. (This reduction reflects the fact that the assumed interest rate on borrowed funds was lower than the firm's assumed opportunity cost of capital as expressed by the value of the discount rate.) Costs are further reduced from $\$ 63,303$ to $\$ 20,560$ by deductions from taxable income for interest payments, depreciation, and sales taxes, together with tax credits at the state and Federal levels, and a credit for salvage value expected at the end of the system life. Taking into account future nonfuel operation and maintenance cost (allowing for the associated tax deduction), plus capital gains taxes, raises long-term solar costs from $\$ 20,560$ to $\$ 24,717$, as indicated by the upward pointing arrows next to the shaded portion of the bar.

The second vertical bar, labeled "Energy Savings of the Solar Energy System," shows that the dollar fuel savings are effectively reduced from $\$ 12,331$ to $\$ 5,956$ by taking into account that fuel costs are a tax deductible business expense. Hence, after adjustment, \$5,956 of estimated energy savings are paired with $\$ 24,717$ of estimated solar energy cost, as shown in the third vertical bar labeled "Net Savings on the Solar Energy System." The outcome is $\$ 18,761$ in estimated net losses.

\subsection{SENSIVITITY ANALYSIS}

\subsubsection{Sensitivity of Solar Cost Effectiveness to System Size}

To examine the sensitivity of life-cycle costs to the size of the solar energy system, net dollar savings (losses) were calculated for solar fractions ranging from 10 to 99 percent, in increments of 10 percent, for the new office building, with oil as the alternative energy system. This analysis was based on early1980 data and assumptions. Two of the resulting curves, showing net losses, are plotted in figures 5.5 and 5.6 for Phoenix and Bismarck. 

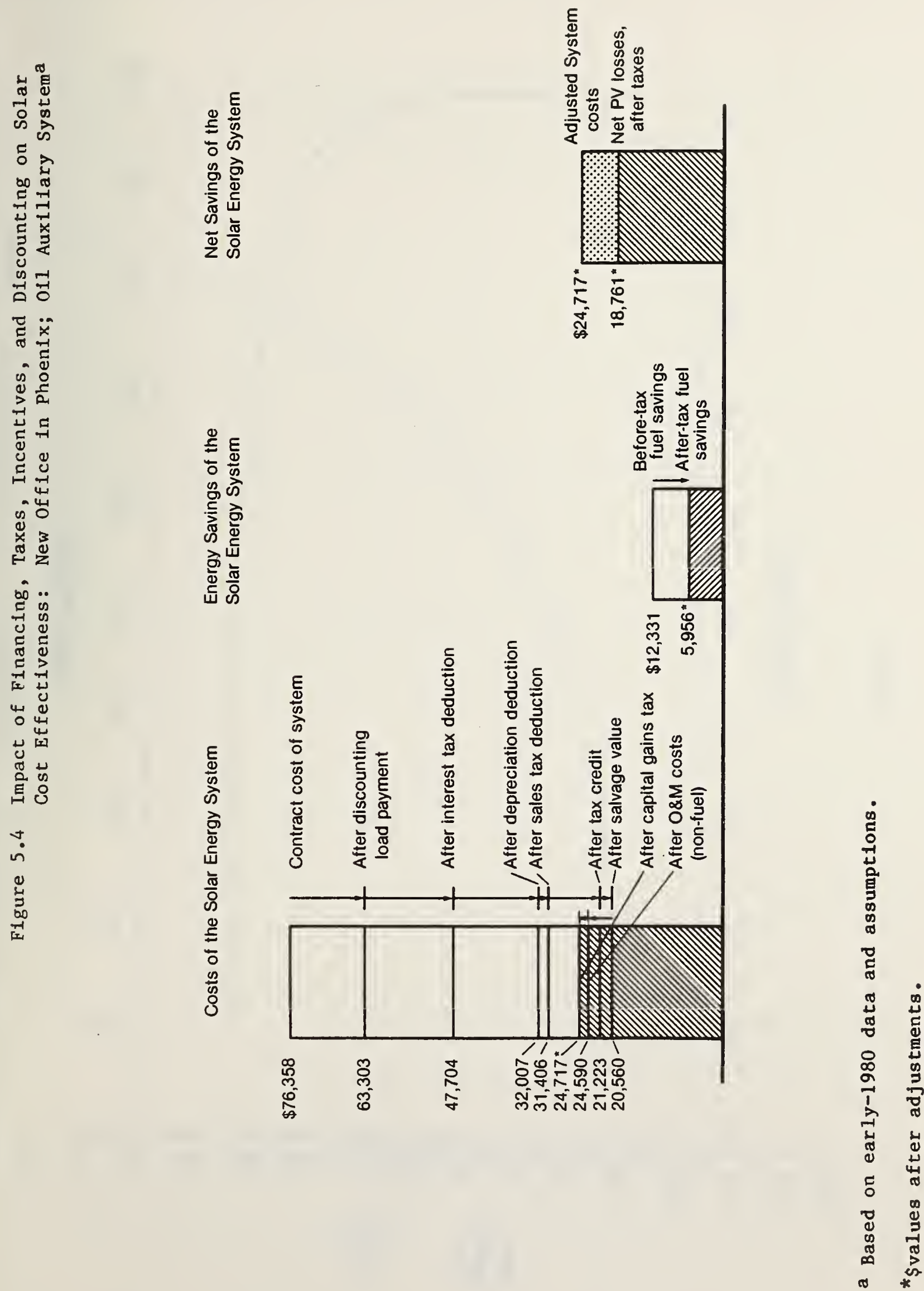


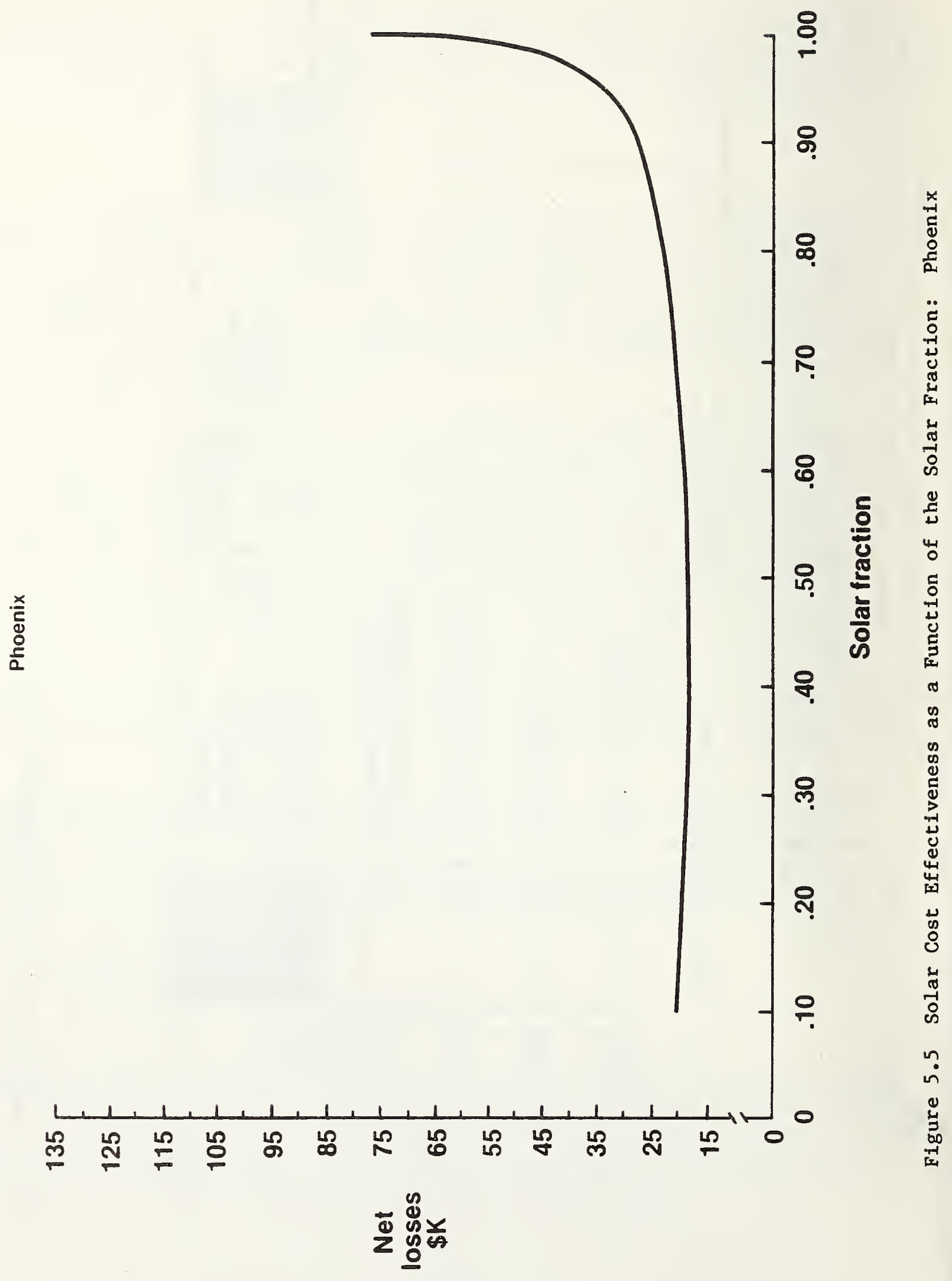




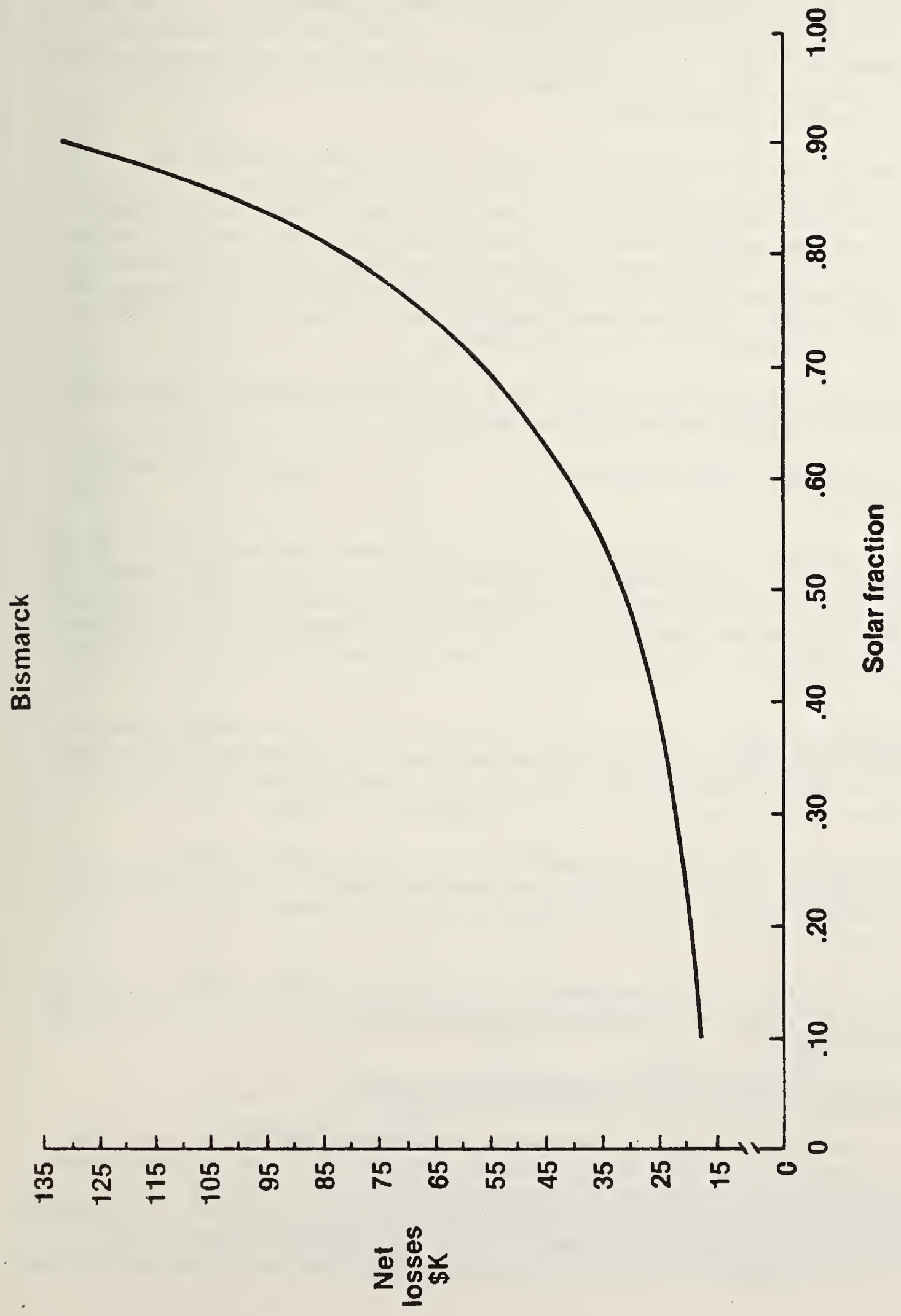

Uै

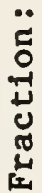

लำ

㟧

芩

$\infty$

告

है

ต

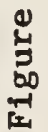


In Phoenix (figure 5.5), estimated net losses, though lowest for a system meeting 40 to 50 percent of the load, were relatively insensitive to the solar fraction up to a fraction of about 75 percent. In contrast, estimated net losses for Bismarck (figure 5.6) increased rapidly over the whole range as the solar fraction was raised. (In both cases, the optimization analysis was constrained to nonzero system sizes.)

An examination of similar curves for the other cases showed substantial variability in the sensitivity of net losses to the solar fraction. In the cities with high insolation values, for example, Phoenix, Charleston, Miami, Apalachicola, and Los Angeles, the curves were virtually flat over a wide portion, indicating that for the given data and assumptions the solar fraction could be varied substantially with little estimated change in net savings or losses. In other cities, the estimated dolar penalty from deviating substantially from the optimized size was considerable.

5.3.2 Sensitivity of Solar Life Cycle Costs to Selected Economic Assumptions: Phoenix Case Study for New office Bulldings

(Note that the results of this section (5.3.2) are all based on mid-1980 data and assumptions.)

Down payment. Figure 5.7 illustrates for one case study the sensitivity of the total life-cycle cost to the size of the down payment. Other things remaining the same, the lower the downpayment, the lower the 11 fe-cycle cost of the solar energy system, and, hence, the greater its cost effectiveness to the purchaser. This relationship would be expected only if the discount rate is higher than the assumed loan rate.

Federal Energy Tax Credit. Figure 5.8 illustrates for a given case study the relationship between solar life-cycle cost and the size of the Federal energy tax credit. As would be expected, the life-cycle cost of the solar energy system declines proportionately with an increasing tax credit.

Depreciation Period. Figure 5.9 illustrates for a given case study the relationship between solar life-cycle cost and the length of the depreciation period. The faster the write-off of system costs, the lower the 11fe-cycle cost of the system.

System Costs. Figure 5.10 illustrates for a given case study how the total Iife-cycle cost of using solar declines with decreasing cost of purchasing and Installing the system.

\subsection{THE CHANGING STATUS OF SOLAR ECONOMIC FEASIBILITY}

During the course of this study, there were several changes in key data that dramatically affected the case study results. Furthermore, the outcomes were found to be sensitive to a number of assumptions that could change in the future. Table 5.10 compares for several cities the results based on alternative values for projected energy prices and the size of the Federal tax credit. Additionally, the impact of a lower percentage downpayment as might result from 
Figure 5.7 Life-Cycle costs of the Solar Energy System as a Function of the Size of the Down Payment ${ }^{a}$

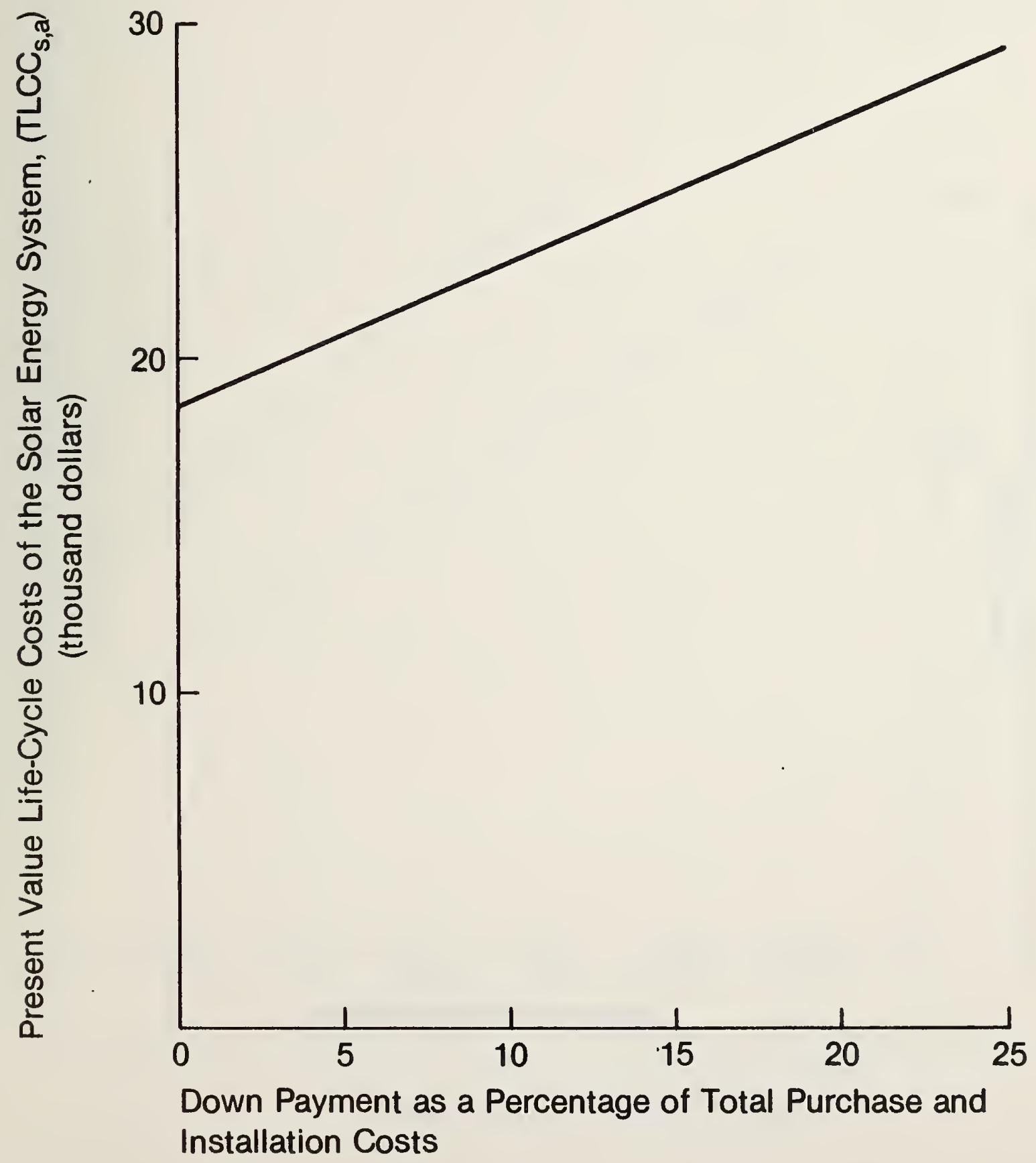

a Based on mid-1980 data and assumptions, including a 15 percent Federal tax credit. The results reflect a solar energy system size reoptimized for each down payment percentage. 
Figure 5.8 Life-Cycle costs of the Solar Energy System as a Function of the Energy Tax Credit ${ }^{a}$

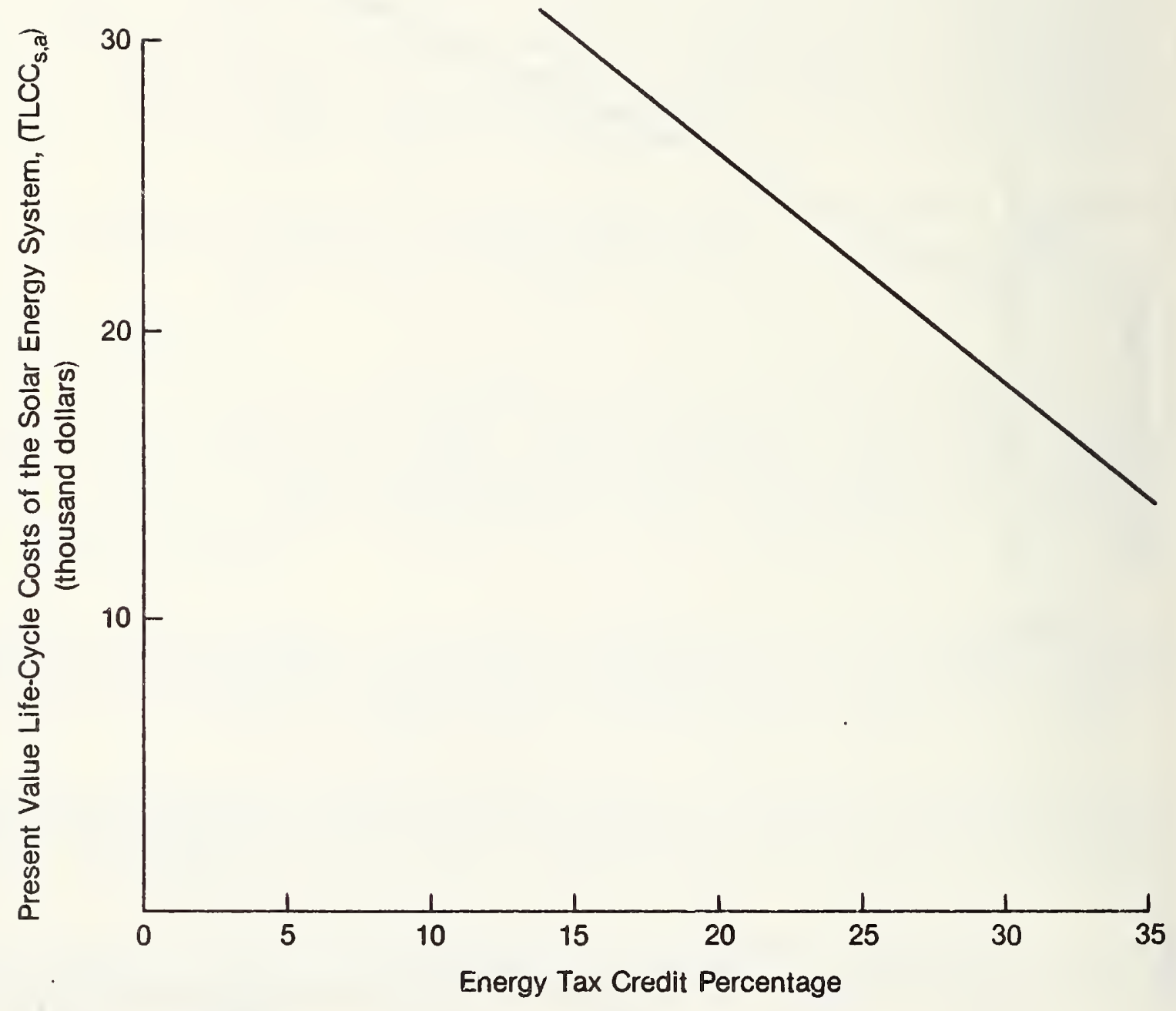

a Based on mid-1980 data and assumptions, including a 15 percent Federal tax credit. The results reflect a solar energy system size reoptimized for each energy tax credit. 
Figure 5.9 Life-Cycle Costs of the Solar Energy System as a Function of the Length of the Depreclation Perloda

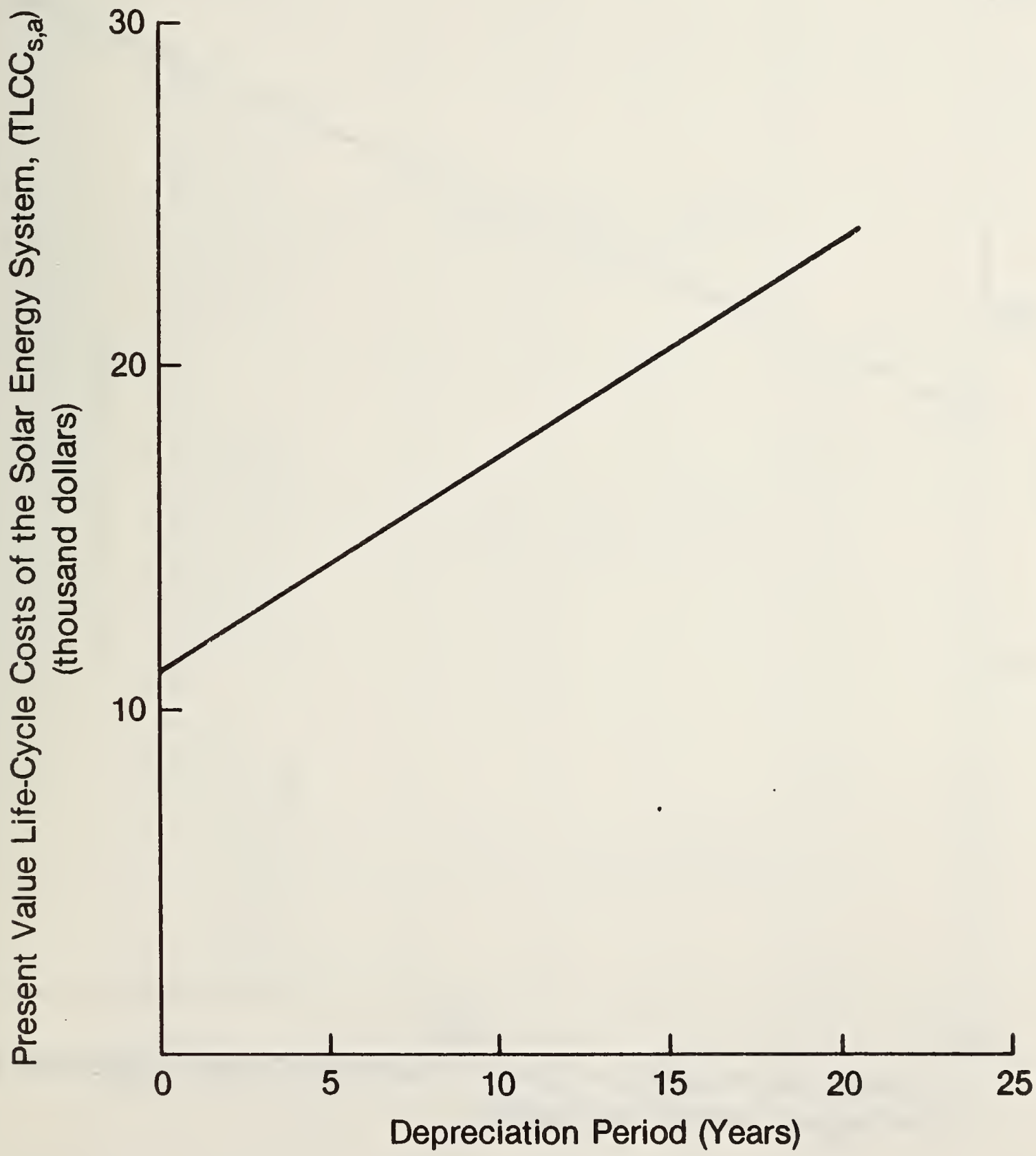

a Based on mid-1980 data and assumptions, including a 15 percent Federal tax credit. The results reflect a solar energy system size reoptimized for each depreciation period. 
Figure 5.10 Life-Cycle Costs of the Solar Energy System as a Function of the of the Purchase and Installation Costa

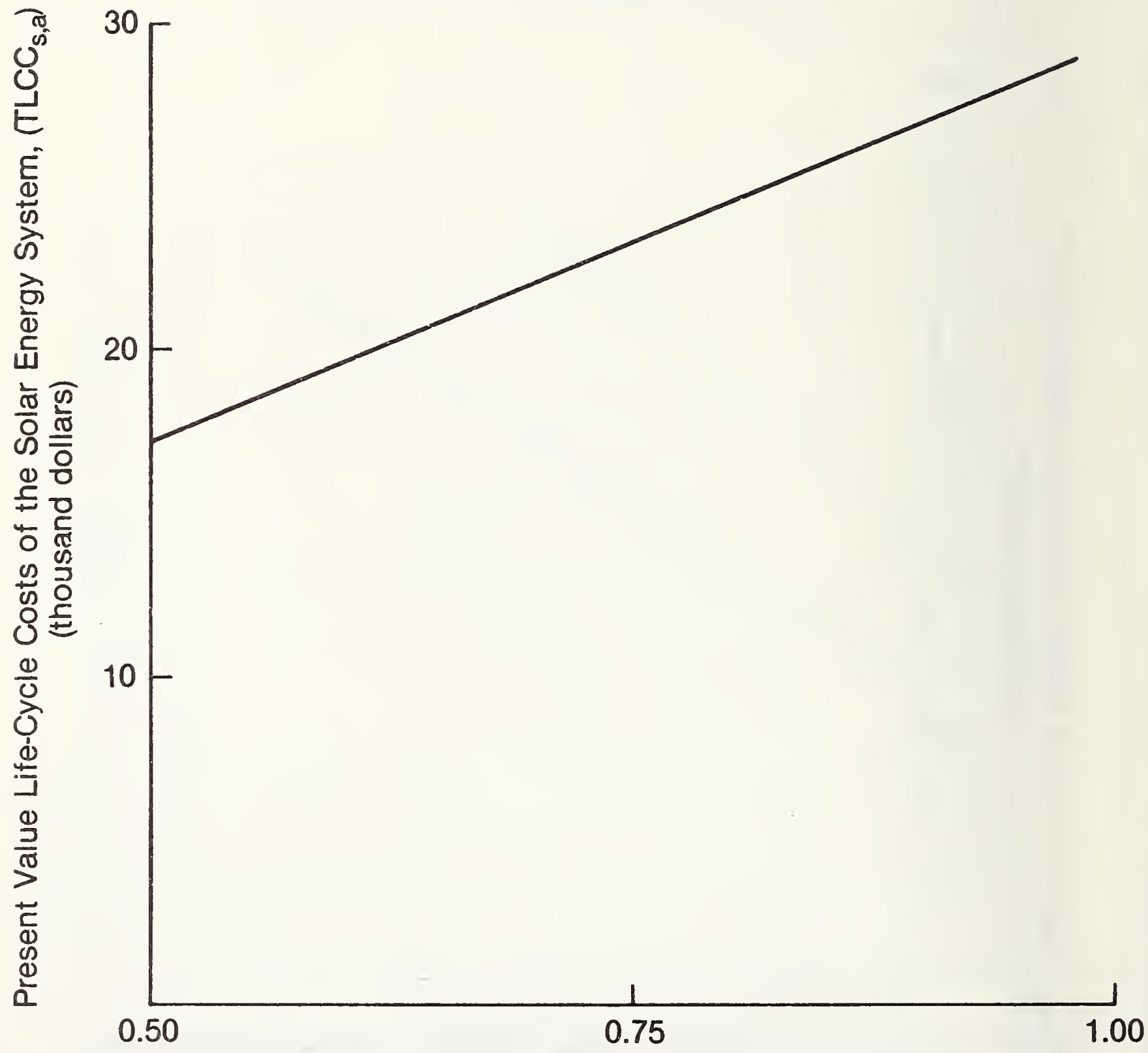

Purchase and Installation Costs of the Solar Energy System as a Percentage of Base-Case Values

a Based on mid-1980 data and assumptions, including a 15 percent Federal tax credit. The results reflect a solar energy system size reoptimized for each purchase and installation cost.

b Base-case values are those calculated according to the cost-estimating equations in table 4.3 . 


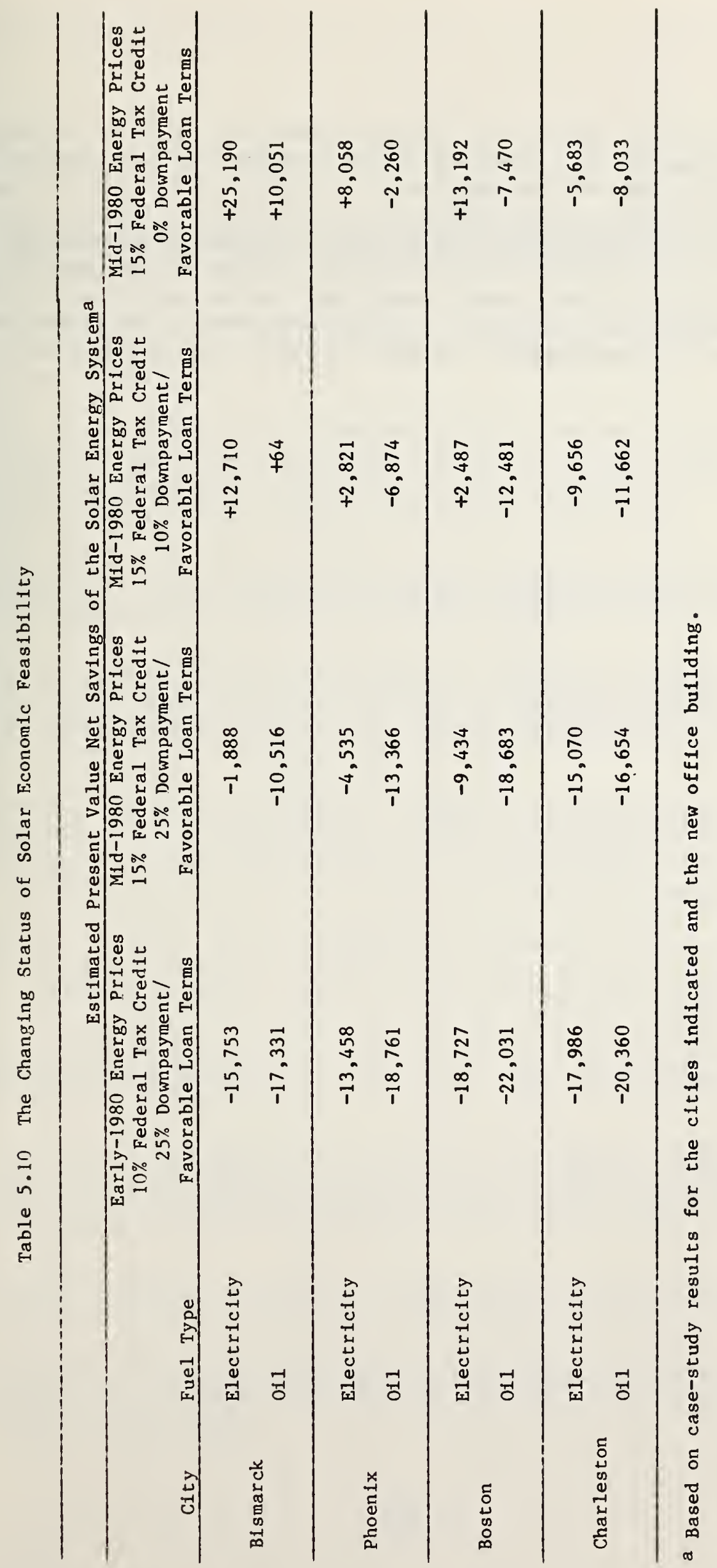


establishment of the Solar Energy and Energy Conservation Bank is illustrated. The table shows in some cases a change from net savings to the investor in response to changes in data and assumptions.

These case studies have demonstrated the economic evaluation methodology and the estimated cost-effectiveness of solar energy in selected applications. They also have demonstrated in quantitative terms that the economic feasibility of solar energy is variable with respect to the nature of the application, time, and events. Periodic reassessments are necessary for a valid appraisal of its current status. 


\section{REFERENCES}

1. Ruegg, Rosalie T. "Economic Feasibility of Solar Applications to office Buildings and Retail Stores," Proceedings of the Solar Energy Market Analysis and Evaluation Contractors' Review Meeting (Sponsored by the U.S. Department of Energy), Apri1 1980.

2. Sav, G. Thomas. "Universal Economic Optimization Paths for Solar Hot Water Systems in Commercial Buildings," Energy, Vol. 4, Summer 1978, pp. 415-427.

3. Ruegg, Rosalie T.; Sav, G. Thomas; Powel1, Jeanne W.; and Pierce, E. Thomas. "Comparative Economic Feasibility of Solar Heating for New and Existing Commercial Buildings." (A paper presented at the 1979 Western Economic Association Annual Conference), June 1979.

4. Ruegg, Rosalie T. "Determining the Economic Performance of a Commercially Used Solar Energy System." (A paper presented at the Operations Research Society of America Annual Meeting), November 1977.

5. Sav, G. Thomas. "Economic Optimization of Solar Energy and Energy Conservation in Commercial Buildings," Conference on System Simulation and Economic Analysis for Solar Heating and Cooling (Sponsored by the U.S. Department of Energy), June 1978.

6. McGarity, Arthur E. and Revelle, Charles S. "Mathematical Modeling and Optimization in the Design and Economic Analysis of Solar Heating Systems." (Unpublished contractor's report prepared at the Johns Hopkins University for the National Bureau of Standards), December 1977.

7. Francis, Richard. "Solar Properties of the Solar Energy Linear Program of McGarity and Revelle." (Innublished paper prepared in the National Bureau of Standards in the Center of Applied Mathematics), January 1978.

8. Ruegg, Rosalie T. and Sav, G. Thomas. "The Microeconomics of Solar Energy," Solar Energy Handbook. New York, New York: McGraw-Hill Book Company, 1981 .

9. Schurr, Sam H.; Darmstadter, Joel; et al. Energy in America's Future, The Cholces Before Us. National Energy Strategies Project conducted by Resources for the Future Baltimore: (The Johns Hopkins University Press, July 1979).

10. Oak Ridge National Laboratory. Energy Use Data Book, Report No. OR-NL-5552, December 1979.

11. National Solar Heating and Cooling Information Center, Rockville, Maryland (Telephone interview wi.th Ms. Molly Sayvetz, Installation Data Base Manager, June 1980). 
12. U.S. Department of Energy, Energy Information Administration. Solar Collector Manufacturing Activity, July-December 1978 (Information obtained by telephone interview with Mr. John Dale, National Solar Heating and Cooling Information Center, Rockville, Maryland, June 1980).

13. Löf, G. O. G. and Tybout, R. A. "Cost of House Heating with Solar Energy." Solar Energy, Vo1. 14, 1973, pp. 253-278.

14. Shaws, A. and Fichtenbaum R. "The Feasibility of Solar House Heating: A Study in Applied Economics." Sharing the Sun (Proceedings of Joint Solar Conference), August 15, 1976, pp. 32-50.

15. Reid, R. L.; Lumsdaine, E.; and Albrecht, L. "Economics of Solar Heating with Homeowner Type Financing," Solar Energy, Vol. 19, 1977, pp. 513-517.

16. Petersen, H. Craig. "Simulation of the Impact of Financial Incentives on Solar Energy Utilization for Space Conditioning and Water Heating: 1985," Energy and Buildings, Vol. 2, 1979, pp. 77-84.

17. Earley, Ronald F.; Mohtadi, Malek M., et al. Macroeconomic and Sector Implications of Installing 2.2 Million Residential Solar Units. U.S. Department of Energy, Energy Information Administration Report, DoE/EIA 0102/51, Apri1 1979.

18. Bezdek, Roger. An Analysis of the Current Economic Feasibility of Solar Water and Space Heating, U.S. Development of Energy Report, DoE/CS-0023, January 1978.

19. Khan, A. M. and Simon, H. A. "Solar Retrofit in a Large Institutional Building: An Economic Analysis." ASHRAE Journal, February 1977, pp. $32-37$.

20. Daystar Corporation. Solar Energy in High-Rise Buildings (A report prepared for the Energy Research and Development Administration, now the Department of Energy, under Contract EA-77-X01-1963) October 1977.

21. Mishan, E. J. Cost Benefit Analysis; An Introduction. New and Expanded Edition. New York: Praeger Publishers, 1976).

22. Grant, Eugene L.; Ireson, W. Grant; and Leavenworth, Richard S. Principles of Engineering Economy, 6th Edition. New York: The Ronald Press Co., 1976.

23. Marshall, Harold E. and Ruegg, Rosalie T. Simplified Energy Design Economics. National Bureau of Standards Special Publication 544, Washington, D.C.: U.S. Government Printing Office, 1980.

24. Ruegg, Rosalie T. and Sav G. Thomas. "The Microeconomics of Solar Energy." Solar Energy Handbook, ch. 28. Edited by Jan F. Krelder and Frank Kreith. New York: McGraw-Hill Publishing Company, 1981. 
25. Marsha11, Harold E. and Ruegg, Rosalle T. Energy Conservation in Bu1ldings: An Economics Guidebook for Investment Decisions. National Bureau of Standards Handbook 132. Washington, D.C.: U.S. Government Printing office, 1980.

26. Löf, G. 0. G. and Tybout, R. A. "Solar House Heating." Natural Resources Journal, Vol. 23, No. 2, Apri1 1970, pp. 268-325.

27. Kle1n, S. A.; Beckman, W. A.; and Duffie, J. A. "A Design Procedure for Solar Heating Systems." Solar Energy, Vo1. 18, pp. 113-127.

28. Powell, Jeanne W. and Rodgers, Richard C., Jr. FEDSOL: Program User's Manual and Economic Optimization Guide for Solar Federal Buildings Projects, National Bureau of Standards NBSIR 81-2342, August 1981 .

29. Internal Revenue Code (as of June 23, 1980). Chicago, Illinois: Commerce Clearing House, Inc., 1980.

30. Economic Recovery Tax Act of 1981 (PL 97-34); Law and Explanation. Chicago, Illinois: Commerce Clearing House, Inc., August 1981.

31. Sav, G. Thomas. "Universal Economic Optimization Paths for Solar Hot Water Systems in Commercial Buildings." Energy, The International Journal, Vol. 4, 1979, pp. 415-427.

32. U.S. Department of Energy. DoE Facilities Solar Design Handbook, DoE/AD$0006 / 1,1978$.

33. Sav, G. Thomas. "Economic Optimization of Solar Energy and Energy Conservation in Commercial Buildings." Systems Simulation and Economic Analysis for Solar Heating and Cooling. Proceedings of the U.S. Department of Energy Conference. San Diego, California, June 27-29, 1978, pp. 88-90.

34. The American Appraisal Company. Boeckh Building Valuation Manual, Vol. II, Commercial. Milwaukee, Wisconsin: Boeckh Division, The American Appraisal Company, 1973.

35. U.S. Department of Energy, Energy Information Administration. Annual Report to Congress, 1977, Vol. 2, DoE/EIA-0036/Z. Washington, D.C.: U.S. Goverminent Printing office, 1978.

36. Honeywe11, Inc., Energy Resources Center, Minneapolis, Minnesota. (Unpublished contractor's reports prepared under the leadership of Mr. Dean Finn-Carlson for The National Bureau of Standards, 1978).

37. Jackson, J. R. and Johnson, W. S. Commercial Energy Use: A Disaggregation by Fuel, Building Type, and End Use. Oak Ridge National Laboratory Report, ORNL/CON-14, February 1978. 
38. U.S. Department of Energy, Energy Information Administration. Annual Report to Congress, 1979, Vo1. 3, DoE/EIA-0173(79)/3 Washington, D.C.: U.S. Government Printing office, 1980 .

39. American Society of Heating, Refrigerating and Air Conditioning Engineers, Inc. ASHRAE Standard 90-75: Energy Conservation in New Building Design. New York, New York: ASHRAE, 1975.

40. Hittle, Douglas C. and Herron, Dale L. "Simulation of the Performance of Multizone and Variable Volume HVAC Systems in Four Geographical Locations". ASHRAE Transactions 1977, Vol. 83, Part 1.

41. American Society of Heating, Refrigerating, and Air Conditioning Engineers. ASHRAE Handbook and Product Directory, 1976 Systems Volume, Chapter 37. New York, New York: ASHRAE, Inc., 1976.

42. General Electric Company. Solar Heating and Cooling of Builldings, Phase 0 Feasibility and Planning Study, Vo1. 2, NSF/RA/N-74-021B, May 1974.

43. TRW Systems Group. Solar Heating and Cooling of Buildings, Phase 0, NSF/ $\mathrm{RA} / \mathrm{N}-74-022 \mathrm{C}$, May 31, 1974.

44. Westinghouse Electric Corporation. Solar Heating and Cooling of Buildings, Phase 0, NSF/RA/N-74-023D, May 1974 .

45. Mitre Corporation. An Economic Analysis of Solar Water and Space Heating, prepared for Energy Research and Development Administration, ERDA/140901, November 1976.

46. Mitre Corporation. A System for Projecting the Utilization of Renewable Resources, SPURR Methodology, prepared for U.S. Dept. of Energy, (ERDA/ 140300 , September 1977.

47. Intertechnology Corporation. Intertechnology Corporation Proposed Systems Level Plan for Solar Heating and Cooling Commercial Buildings, National Solar Demonstration Program, Vol. 3, Energy Research and Development Adminstration, No. C00-2688-76-6, May 1976.

48. Liu, B. Y. H. and Jordan, R. C. "A Rational Procedure for Predicting the Long-Tern Average Performance of Flat-Plate Solar Energy Collectors." Solar Energy, Vol. 7, No. 2, 1963, pp. 53-71.

49. Klein, S. A. "Calculation on Monthly Average Insolation on Tilted Surfaces." Solar Energy, Vol. 19, 1977, pp. 325-329.

50. Kusuda, T. NBSLD, The Computer Program for Heating and Cooling Loads in Buildings. National Bureau of Standards Building Science Series 69. Washington, D.C., 1976. 
51. Arens, Edward A. and Carrol, William L. Geographical Variation in the Heating and Cooling Requirements of a Typical Single Family House, and Correlation of These Requirements to Degree Days. National Bureau of Standards Building Science Series 116. Washington D.C., 1978.

52. U.S. Department of the Army, Construction Engineering Research Laboratory. Building Loads Analysis and System Thermodynamics (BLAST) Program: User's Manual, 1977.

53. U.S. Department of the Army, Construction Engineering Research Laboratory. Building Loads Analysis and System Thermodynamics (BLAST) Program: Reference Manual, 1977.

54. Powel1, Jeanne $W$. and Barnes, Kimberly A. Com parative Analysis of Economic Models in Selected Solar Energy Computer Programs. National Bureau of Standards NBSIR 81-2379, January 1982.

55. Solar Energy Research Institute. Solar Design Workbook. Edited by G. Franta, et al., SERI/SP-62-308, January 1981 .

56. Dodge Manual for Building Construction Pricing and Scheduling. Dodge Building Cost Services. New York, New York: McGraw-Hi11, 1977.

57. U.S. Department of Energy. National Solar Heating and Cooling Demonstration Program; Project Data (Report prepared by the PRC Energy Analysis Company), July 1979.

58. U.S. Department of Energy, Energy Information Administration. Short-Term Energy Outlook, DoE/EIA-0202/2.

59. Federal Register. "Federal Energy Management and Planning Programs; Methodology and Procedures for Life Cycle Cost Analysis," Vol. 45, No. 16, January 23, 1980; Vo1. 45, No. 196, October 7, 1980 (amended October 24, 1980); and Vol. 46, No. 222, November 18, 1981.

60. U.S. Department of Energy, Energy Information Administration. Mid-Term Energy Supply and Demand, 1985-1995, AR/EIA/80-17.

61. Ruegg, Rosalie T. Life Cycle Costing Manual for the Federal Energy Management Program. National Bureau of Standards Handbook 135. Prepared for the U.S. Department of Energy Washington, D.C.: U.S. Government Printing Office, December 1980.

62. Modigliani, Franco and Miller, Merton H. "The Cost of Capital, Corporate Finance and the Theory of Investment." American Economic Review, Vol. 48, June 1958, pp 261-297.

63. Modigliani, Franco and Miller, Merton H. "Taxes and the Cost of Capital: A Correction." American Economic Review, Vol. 53, June 1963, pp. 433443. 
64. Holland, Daniel M. and Myers, Stewart C. Trends in Corporate Profitability and Capital Costs, WP 937-77, Alfred P. Sloan School of Management. Cambridge, Mass.: Massachusetts Institute of Technology, 1977.

65. Ibbotson, Roger G. and Singuefield, Rex A. "Stocks, Bonds, Bills, and Inflation: Year-by-Year Historical Returns (1926-74)." Journal of Business, Vol. 49, January 1976, pp. 11-47.

66. Federal Register. Solar Energy and Energy Conservation Bank, 24 CFR Parts 1800-1899, Bylaws; Codification, Vo1. 45, No. 181, September 16, 1980 .

67. U.S. Congress. Revenue Act of 1978. Pub. L. 95-600, 95th Cong., 1978, 92 Stat. 2820, Sec. 301.

68. Massachusetts. State Code, Chapter 59, Sec. 5, Paragraph 90-482. (As added by Chapter 734, Acts 1975; as amended by Chapter 388, Acts 1978).

69. U.S. Bureau of the Census, "Taxable Property Values and Assessment Sales Price Ratios." 1977 Census of Government, Vo1. 2, 1978.

70. Tennessee. Code, Annotated, Section 67-511 (Amended by Public Chapter 837, HB329).

71. Wisconsin. State Statutes, Section 2, 70.111(18), Chapter 349, Laws of 1979.

72. Arizona. Revised Statutes, Chapter 39, paragraph 43-1031(A).

73. Texas. Franchise Tax Exemption Statute, Texas Rev. Civ. Ann. Art. $12.01(6)$.

74. Massachusetts. General Laws, Chapter 63, Section 38H, paragraph 91-322.

75. Wisconsin. State Statutes Relating to Tax Credits and Deductions, Section 4, 71.09 .

76. U.S. Congress. National Energy Tax Act of 1978, Pub. L. 95-618, 95th Cong., 1978, 92 stat. 3194.

77. California. AB 3623, Chapter 1159, Section 1, 1978.

78. North Dakota. HB 1479, Chapter 537, 1977.

79. Arizona. Revised Statutes, Chapter 39, HB 2184, Section 9, paragraph 43-1162. 


\section{APPENDIX A. MATHEMATICAL PROGRAMMING AND STOCHASTIC MODELING: EXPLORATORY}

RESEARCH

An exploratory effort was undertaken to assess the feasibility of using mathematical programming and stochastic modeling as the principal tools for solar optimization analysis. A mathematical programming approach offers the potential for optimizing the solar energy system for multiple design parameters at low computational costs. This capability would obviate the need in the optimization analysis for the simplifying approach that optimizes the system only with respect to collector area. A stochastic modeling approach is of interest because it casts the measures of solar performance in probabilistic terms, providing critical information for certain types of solar application. This exploratory investigation of mathematical programming and stochastic modeling was conducted by the NBS Applied Economics Group as a cooperative efffort with the Johns Hopkins University and the NBS Center for Applied Mathematics. 1

This appendix discusses the importance of multivariate optimization in solar analysis in light of recent research. It gives a classification framework for solar design variables, developed by the Johns Hopkins University research team. The mathematical modeling performed by the same team is described, together with supporting work performed by the NBS Center for Applied Mathematics. Sample results from the Johns Hopkins Model are compared with results from a simulation model.

\section{A.1 THE IMPORTANCE OF MULTIVARIATE ANALYSIS IN SOLAR DESIGN}

In section 2.2, several studies are cited in support of using a single variate optimization procedure, with collector area as the key design variable. These studies, however, considered a limited range of bullding loads. Subsequent research has suggested that optimal economic results may be significantly sensitive to storage volume under certain conditions.

A report of work performed by the Department of Mechanical Engineering of the University of Toronto for the U.S. Department of Energy, entitled "Solar Space Heating Using Annual Heat Storage" [1-A] indicates that the minimum life-cycle cost of a solar energy system is quite sensitive to storage volume if extreme values of solar fraction or extreme prices for storage are involved. The sensitivity occurs for solar fractions greater than 70 percent or for storage costs significantly higher than those generally assumed. In addition, this work finds that, based on typical storage costs, short-term storage in the range of 10-30 lbs/ $\mathrm{ft}^{2}$ of collector area minimizes solar costs for solar

1 Dr. Arthur E. McGarity and Dr. Charles S. Revelle, of the Department of Geography and Environmental Engineering, were co-principal investigators of the research work performed at the Johns Hopkins University for the National Bureau of Standards [2-A]. Dr. Richard L. Francis, of the Department of Systems and Industrial Engineering at the University of Florida, and a participant in the NBS "Visiting Mathematical Scientist Program," also contributed to this effort [3-A]. 
fractions below 50 percent, while annual storage minimizes solar costs for solar fractions greater than 50 percent. Costs are found by the University of Toronto study to be insensitive to the storage/collector ratio in the 50 percent range of solar fraction. 1

Figure A.1, taken from the University of Toronto study, shows the relationship between system acquisition costs and the ratio of storage volume to collector area for systems supplying an energy fraction ranging from 45 to 100 percent. Over a wide range of storage volume/collector area ratios, the cost curves are steeper the higher the solar fraction. The minimum cost region for solar fractions above 50 percent occurs at a tank volume/collector area ratio or 65-85 $1 \mathrm{bs} / \mathrm{ft}^{2}$. This range is characteristic of annual storage systems. The minimum cost region for smaller solar fractions, of 50 percent and below, occurs at 10-20 1bsift ${ }^{2}$.. This range is characteristic of the short-term storage systems, suggested by Löf and Tybout [4-A] as well as Klein, Beckman, and Duffle [5-A], which generally provide for a storage perlod of from one to three days, depending on climate factors. In the 45 to 60 percent solar fraction range, costs appear falrly insensitive to storage/collector area ratios.

Figure A.12 shows that if the costs of solar storage were three to four times greater than those assumed in figure $A_{0} 11, e_{.} ., K_{1}=\$ 4.15 / 1 b^{2 / 3}$, the shape of the solar cost curves would change markedly, with the curves everywhere sensitive to the storage volume/collector area ratio. With the higher solar storage costs, the minimum cost points are shown to occur in the $10-20 \mathrm{lbs} / \mathrm{ft}^{2}$ region for solar fractions of 60 percent and below, and in the 65-85 lbs/ft ${ }^{2}$ range for solar fractions above 80 percent. The minimum cost for systems providing a solar fraction in the range from 60 to 80 percent may occur at either region.2

The University of Toronto study indicated that long-term storage systems may be economically more favorable than short-term storage in the situations indicated. If long-term storage is used, performance of a system in one month will depend on performance in previous months.

These findings suggest the need under certain conditions for solar evaluation methodologies that allow a more flexible and comprehensive economic optimization across multiple design variables (see also [6-A] and [7-A]. Ideally, it would be unnecessary to assume that relationships among design variables optimized for one collector area, cost structure, and time frame hold for all other situations.

1 Annual storage systems can be distinguished from short-term storage systems by the characteristic that annual storage systems reach maximum and minimum temperatures once a year while short-term systems have temperature cycles from one to thirty days in length (most typically 1-2 days), depending on the actual storage-collector sizing configuration and climatological factors.

2 F.C. Hooper et al., Solar Space Heating Systems Using Annual Heat Storage $[1-\mathrm{A}]$. 
Figure A.l Sensitivity of Solar Acquisition Cost to Storage Volume/Collector Area Ratio for Given Solar Fractions and "Typical" Storage Cost

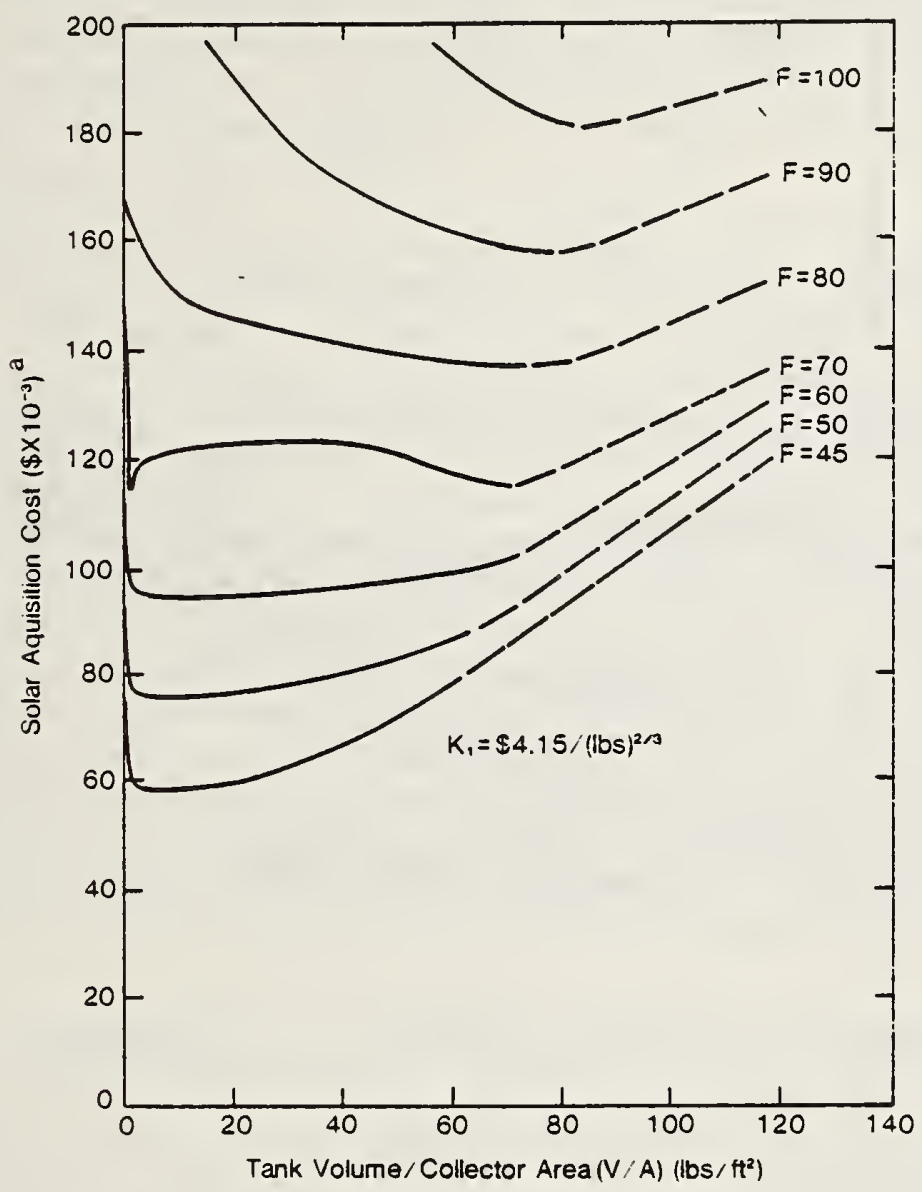

Notation: $F$ refers to solar fraction; $K_{1}$ refers to the sum of all solar energy system costs divided by the sum of the surface area of the floor, walls, and top of the storage tank $\left(\$ 1.15 / 1 b^{2 / 3}\right)$.

a Solar acquisition costs are described by the function

$$
\mathrm{C}_{\mathrm{SAQ}}=\mathrm{K}_{0} \mathrm{~V}+\mathrm{K}_{1} \mathrm{~V}^{2 / 3}+\mathrm{K}_{2} \mathrm{~A}+\mathrm{K}_{3} \text {, where }
$$

$\mathrm{K}_{0}, \mathrm{~K}_{2}$, and $\mathrm{K}_{3}$ are defined as $\$ 2.70 \times 10^{-3} / 1 \mathrm{~b}, \$ 35 / \mathrm{ft}^{2}$, and $\$ 3,000$, respectively. (See F.C. Hooper, et al., [1-A], figure 2.1, page 15, for performance data on which the graphs are based.)

Source: F. C. Hooper, et al., Solar Space Heating Systems Using Annual Heat Storage [1-A, pp. 36 and 38]. 
Figure A.2 Sensitivity of Solar Acquisition Cost to Storage Volume/Collector Area Ratio for Given Solar Fractions and High Storage Cost

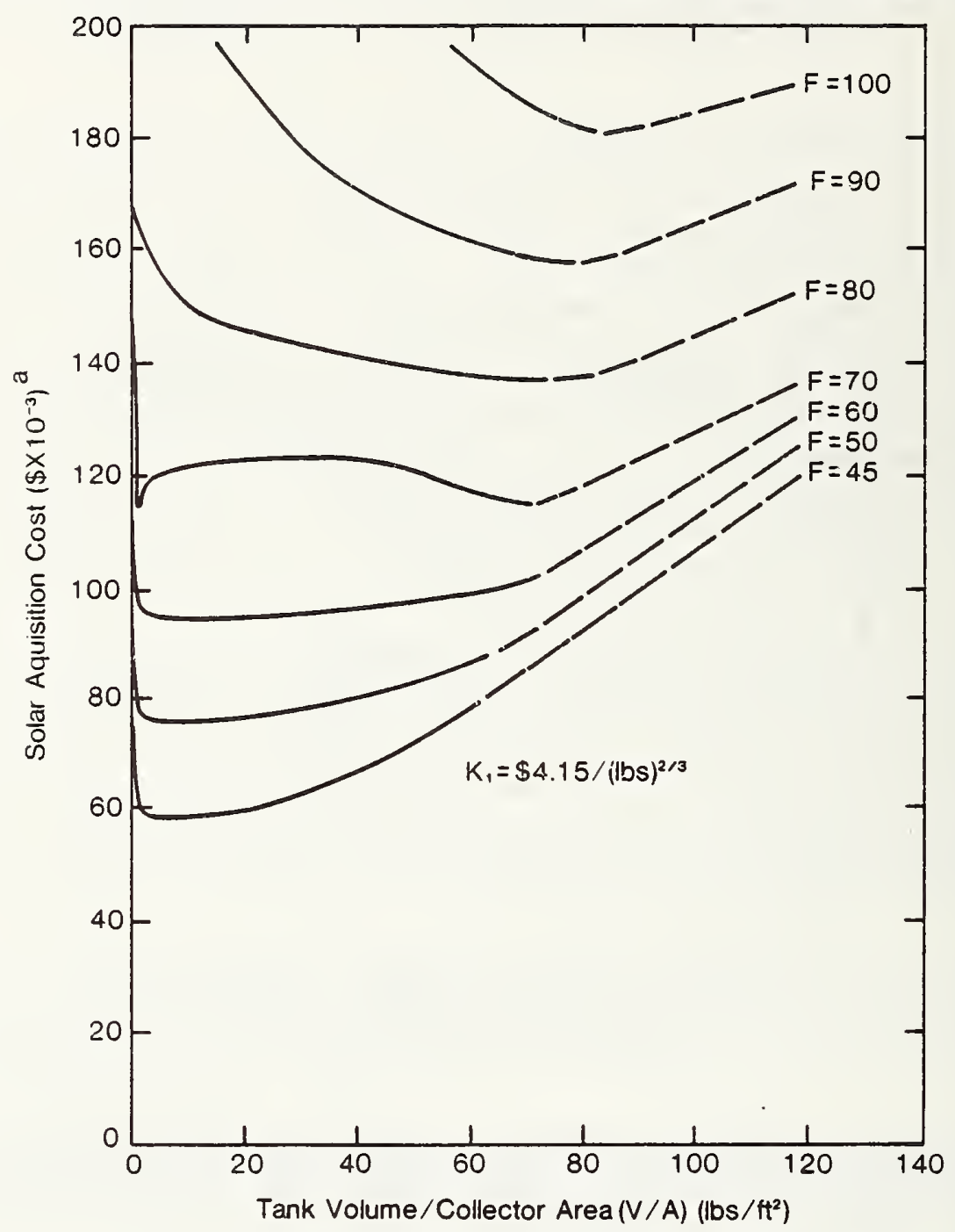

Notation: F refers to solar fraction; $\mathrm{K}_{1}$ refers to the sum of all solar energy system costs divided by the sum of the surface area of the floor, walls, and top of the storage tank $\left(\$ 4.15 / 1 b^{2 / 3}\right)$.

a Solar acquisition costs are described by the function

$$
\mathrm{C}_{\mathrm{SAQ}}=\mathrm{K}_{0} \mathrm{~V}+\mathrm{K}_{1} \mathrm{~V}^{2 / 3}+\mathrm{K}_{2} \mathrm{~A}+\mathrm{K}_{3} \text {, where }
$$

$K_{0}, K_{2}$ and $K_{3}$ are defined as $\$ 2.70 \times 10^{-3} / 1 \mathrm{~b}, \$ 35 / \mathrm{ft}^{2}$, and $\$ 3,000$, respectively. See F. C. Hooper et al., [1-A], figure 2.1, page 15 for performance data on which the graphs are based.)

Source: F.C. Hooper et al., Solar Space Heating Systems Using Annual Heat Storage $[1-\mathrm{A}, \mathrm{pp}, 36$ and 38]. 


\section{A.2 CLASSIFICATION FRAMEWORK FOR SOLAR DESIGN VARIABLES}

As a first step towards establishing a more flexible methodological framework, the Johns Hopkins research team classified solar design varlables on the basts of (1) the degree of influence that each variable has on economic objectives and on performance requirements, and (2) the nature of the relationships that each variable bears to other variables.

The first classification designates variables as either "primary" or "secondary;" the second designates them as "independent," "dependent," or "Interdependent." For example, collector area is designated a primary design variable, interdependent with other variables; and storage insulation thickness is designated a secondary design variable, independent of other variables at a given site. The overall classification of solar design variables is shown in table A.1. Note in the table that collector area, storage volume, and bullding load reduction (achieved through energy conservation alterations to the building envelope) are all designated interdependent variables. The optimal values of these variables depend on cost and performance of other variables in the group. These interdependent variables can be "traded off" unt1l the lowest cost combination in conjunction with nonsolar energy use is found. The variables classified by McGarity and Revelle as "primary" and "interdependent" are called "decision variables," since their determinations are the most significant decisions in the design process. The existence of three decision variables -- collector area, storage volume, and bullding load reduction -- supports the use of a multivariate optimization technique for solving the optimal solar design problem.

\section{A.3 MATHEMATICAL PROGRAMMING AS A POTENTIAL TOOL FOR SOLAR ANALYSIS}

Mathematical programming is a technique that is particularly sulted for finding numerical values for a number of variables which in combination optimize an objective function subject to the constraints imposed by required resource relationships. This technique potentially enables one to find the cost minimizing (or net-savings maximizing) combination of several primary interdependent solar decision variables, while allowing restrictions to be placed on the values these variables can take to reflect the operating characteristics of the components of the solar energy system. Mathematical programming is the recommended approach in multivariate optimization when inequality constraints prohibit, or make it difficult to use, traditional economic optimization methods employing the Lagrange Multiplier.

If the objective function and the constraints can be expressed as 1 inear functions of the design variables to be optimized, the equations can be solved efficiently by linear programming methods, at low computational cost, with widely available computer programs. Both economic and physical performance relationships can be built into the mathematical program. Unlike the simulation method, mathematical programming does not require the value of one design variable to be specified in order to determine the optimal value of another design variable. 
Table A.1 Classification of Solar Design and Load Variablesa

\begin{tabular}{|c|c|c|c|c|c|}
\hline \multicolumn{6}{|c|}{ Classification of Solar Design Variables } \\
\hline \multirow[b]{2}{*}{ Variable } & \multicolumn{2}{|c|}{ Degree of Influence } & \multicolumn{3}{|c|}{ Relationship to Other Variables } \\
\hline & Primary & Secondary & Independent & Dependent & Interdependent \\
\hline Collector Area & $\sqrt{d}$ & & & & $\checkmark$ \\
\hline Storage Volume & $\sqrt{ }$ & & & & $\sqrt{ }$ \\
\hline $\begin{array}{l}\text { Storage Insula- } \\
\text { tion Thickness }\end{array}$ & & $d$ & $\checkmark$ & & \\
\hline $\begin{array}{c}\text { Fluid Flow } \\
\text { Rates }\end{array}$ & & $\checkmark$ & & $\checkmark$ & \\
\hline \multicolumn{6}{|c|}{ Classification of Variables Affecting Load } \\
\hline \multirow[b]{2}{*}{ Variable } & \multicolumn{2}{|c|}{ Degree of Influence } & \multicolumn{3}{|c|}{ Relationship to other Variables } \\
\hline & Primary & Secondary & Independent & Dependent & Interdependent \\
\hline $\begin{array}{l}\text { Building Load } \\
\text { Reduction }\end{array}$ & $\checkmark$ & & & & $\sqrt{ }$ \\
\hline $\begin{array}{l}\text { Rates of } \\
\text { Thermal } \\
\text { Resistance of } \\
\text { Building } \\
\end{array}$ & $\checkmark$ & & 1 & & \\
\hline $\begin{array}{l}\text { Design } \\
\text { Temperatures }\end{array}$ & 1 & & $\checkmark$ & & \\
\hline $\begin{array}{l}\text { Weather } \\
\text { Variables }\end{array}$ & $\checkmark$ & & $\checkmark$ & & \\
\hline Thermal Loads & $\sqrt{ }$ & & & $\sqrt{ }$ & \\
\hline
\end{tabular}

a Classification according to McGarity and Revelle [2-A]. 
The TRNSYS (an acronym for "transient simulation program") solution to an optimization problem with 3 design variables of 10 intervals each, using 15 minute time steps, would require 35 million computer iterations [2-A]. Each of more than 35,000 time steps would require 1,000 iterations of the simulation. Fifteen minute, half-hourly, or hourly time steps are generally used with the simulation methods. With a time step as large as one day, it is 11kely that an iterative approach will take too long to converge--if it converges at al1-at each time step, because of the sequential nature of the simulation solution process. In comparison, a mathematical programming solution to an optimization problem should require just one run for each of 365 daily time steps.

\section{A.4 THE MCGARITY-REVELLE SOLAR PERFORMANCE MODEL 1}

McGarity and Revelle initially perceived the problem of optimizing solar energy system design within the format of a cost-minimizing linear program and proceeded to investigate the possibilities of this approach. 2 However, due to nonlinearities in the functional relationships, they were unsuccessful in using a linear program to solve for minimum cost values of collector area, storage volume, and performance. McGarity and Revelle, however, succeeded in developing a set of simultaneous equations for predicting the thermal performance of a solar energy system with a specifled collector area and storage volume. Furthermore, they found the computational cost of their approach lower than that of alternative methods of predicting solar energy system performance, because longer time steps could be used without a significant sacrifice in accuracy.

This linear programming of solar performance represents an important step and an essential component of a mathematical programming model for determining the economically optimal system design. This section describes the linear program formulation, solution properties of the program, and test results for two sample design problems.

It should be stressed that the linear program described here is a model for predicting solar performance for a system of a given collector area and storage volume. Since collector area and storage volume are prespecified, this program does not find the values of system parameters which minimize cost. Instead it minimizes the weighted sum of all undesirable flows of energy. It can be used to find solution values for the following nine variables at optimal system performance, given the specifled collector area and storage volume:

$\mathrm{T}_{t-1}=$ the temperature of storage at the end of the period which precedes period $t$;

1 This sectinn is based on the unpublished report prepared by Arthur McGarity and Charles Revelle, of the Johns Hopkins University, under the sponsorship of NBS [2-A], supplemented by supporting notes and oral presentations.

2 For a discussion of the application of linear programming to economic problems, see a mathematical economics text such as Fundamental Methods of Mathematical Economics [8-A]. 
$T_{t}=$ the temperature of storage at the end of period $t$;

$Q_{t}=$ the energy supplied to storage during period $t$;

$Y_{t}=$ the energy that would be lost if energy collection is attempted during periods with insufficient solar radiation;

$X_{t-1}=$ the temperature of the preheat tank at the end of the period which precedes period $t$;

$X_{t}=$ the temperature of the preheat tank at the end of period $t$;

$W_{t}=$ the energy which cannot be collected during periods for which the storage temperature equals the boiling point of water;

$F_{t}=$ the auxiliary energy supplied for space heating during period $t ;$

$M_{t}=$ the auxiliary energy supplied for water heating during period $t$.

The minimized energy flows in the objective function include (1) energy that would be lost if energy collection is attempted during periods of insufficient solar radiation, $\mathrm{Y}_{t} ;$ (2) energy which cannot be collected during periods for which the storage temperature equals the bolling point of water (energy in storage is already equal to storage capacity), $\mathrm{W}_{t} ;$ (3) auxiliary conventional energy supplied for space heating during the period, $F_{t}$; and (4) auxiliary conventional energy supplied for water heating during the period, $M_{t}$. The latter two energy flows are given greater weights in the objective function because the control actions of the actual heating system which they reflect have priority in the solar heating system. To establish this priority, the first two energy flows are given fractional weights in the Iinear program objective function.

The objective function is subject to a set of equality constraints and a set of inequality constraints that describe thermal performance of the solar heating system of the bullding. The relationships are expressed for every time period " $t$ ". Fixed values are used for collector area and storage volume to enable the constraints to be expressed as linear functions of the nine design variables listed above and, thus, to enable the system of equations to be solved as a linear program.

A schematic diagram of the solar space and water heating system is shown in figure A.3. For each time period, a constraint is required for each component of the system that is designated by a circled letter in the diagram, 1.e., the collector, storage system, preheat tank, hot water auxiliary system, and the space heating distribution system. Each constraint represents an energy balance relationship or a control action required to describe the performance of the systen. The objective function establishes the operational control strategy of the solar energy system. It minimizes undesirable energy flows, e.g., it prevents use of auxiliary energy when the solar energy supplied is sufficient. 


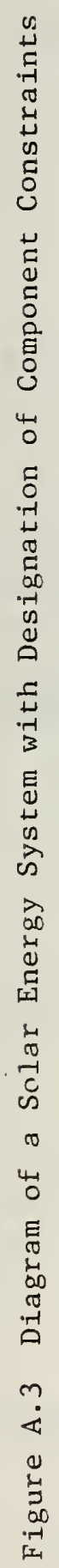
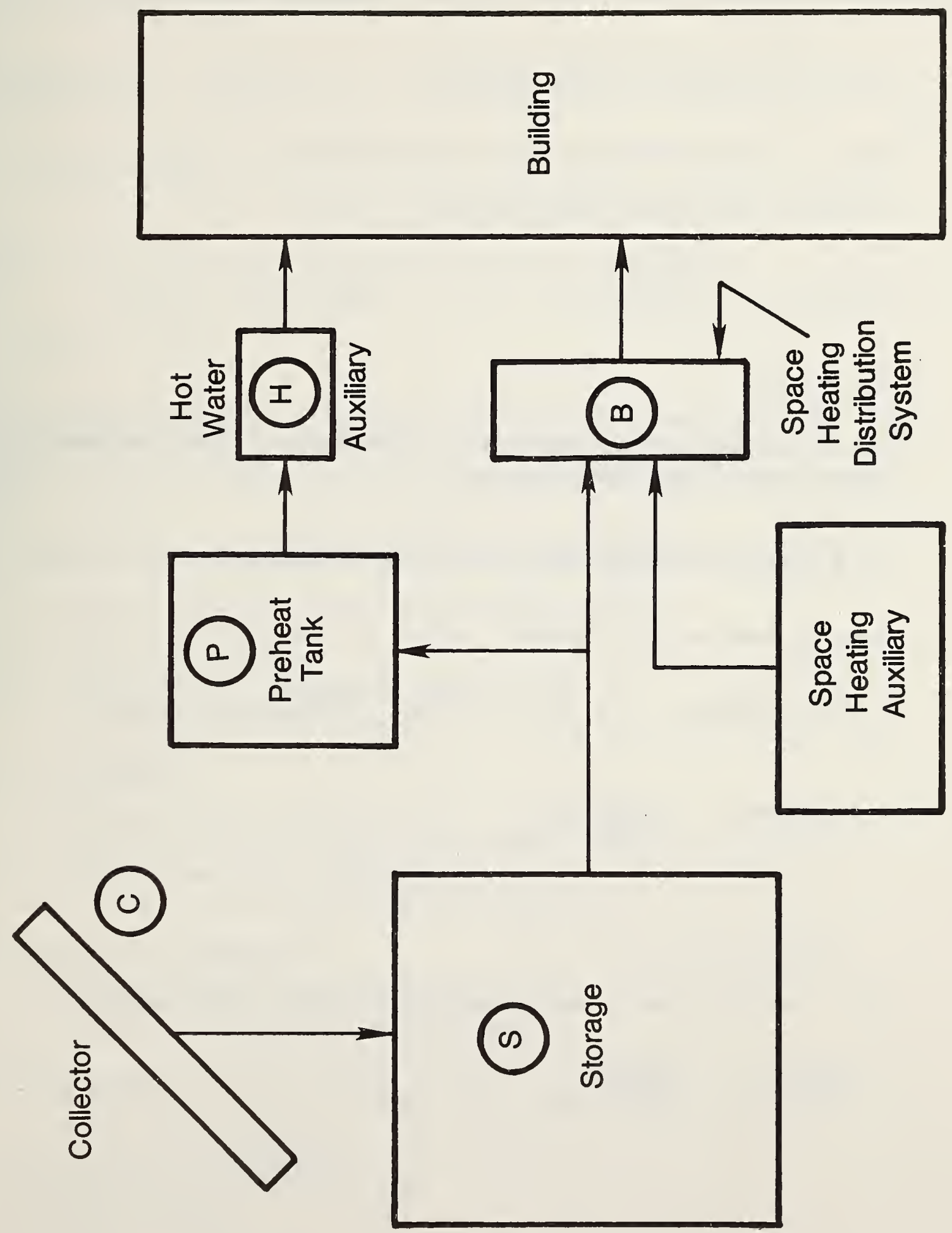
In algebraic notation, the linear program is formulated as follows:1

$$
\operatorname{Minimize} \sum_{t=1}^{N} a Y_{t}+b W_{t}+F_{t}+M_{t}
$$

subject to the following constraining conditions for $t=1, \ldots, N$ :

(collector performance relationship)

$$
\begin{aligned}
& \left(\frac{\mathrm{F}_{\mathrm{R}}^{\prime} A U_{L} \Delta t}{2}\right) \mathrm{T}_{\mathrm{t}}+\left(\frac{\mathrm{F}_{\mathrm{R}}^{\prime} \mathrm{AU}_{\mathrm{L}}^{\Delta t}}{2}\right) \mathrm{T}_{\mathrm{t}-1}+\mathrm{Q}_{\mathrm{t}}-\mathrm{Y}_{\mathrm{t}}=\mathrm{F}_{\mathrm{R}}^{\prime} \mathrm{A}\left[\left(n_{\alpha}\right) \mathrm{E}_{\mathrm{t}}+\mathrm{U}_{\mathrm{L}} \Delta \mathrm{t} \bar{\theta}_{\mathrm{t}}\right] \\
& \mathrm{t}=1, \ldots, \mathrm{N}
\end{aligned}
$$

(space heating load relationship -- performance of heat exchanger in space heating distribution system)

$$
\left(\frac{\varepsilon_{B} \dot{\dot{m}}_{B} C_{P} \Delta t}{2}\right) T_{t}+\left(\frac{\varepsilon_{B} \stackrel{\circ}{m}_{B} C_{P} \Delta t}{2}\right) T_{t-1}+F_{t}>B_{t}+\varepsilon_{B} \dot{m}_{B} C_{P} \Delta t T_{B} ; t=1, \ldots, N
$$

(storage tank energy balance)

$$
\begin{aligned}
& {\left[\left(\frac{U_{s} A_{s}+\varepsilon_{p} \dot{m}_{p} C_{P}}{2}\right) \Delta t+\rho C_{p} V\right] T_{t}+\left[\left(\frac{U_{s} A_{s}+\varepsilon_{p} \dot{m}_{p} C_{p}}{2}\right) \Delta t+\rho C_{p} V\right] T_{t-1}} \\
& -\left(\frac{\varepsilon_{p} \dot{m}_{p} C_{p} \Delta t}{2}\right) X_{t}-\left(\frac{\varepsilon_{p} \dot{m}_{p} C_{p} \Delta t}{2}\right) X_{t-1}-Q_{t}-F_{t}+W_{t}=. \\
& U_{s} A_{s} \Delta t T_{B}-B_{t} ; t=1, \ldots, N
\end{aligned}
$$

(water heating load -- performance of auxiliary water heater)

$$
\left(\frac{\dot{\mathrm{m}}_{w} \mathrm{C}_{\mathrm{p}} \Delta t}{2}\right) \mathrm{X}_{\mathrm{t}}+\left(\frac{\dot{\mathrm{m}}_{\mathrm{w}} \mathrm{C}_{\mathrm{p}} \Delta \mathrm{t}}{2}\right) \mathrm{X}_{\mathrm{t}-1}+\mathrm{M}_{\mathrm{t}} \geq \dot{\mathrm{m}}_{\mathrm{w}} \mathrm{C}_{\mathrm{p}} \Delta t \mathrm{~T}_{s} ; \mathrm{t}=1, \ldots, N
$$

1 See section A.6 for component performance formulas used in the development of the linear program format, together with a list of the mathematical notation. 


$$
\begin{aligned}
& \text { (pre-heat tank energy balance) } \\
& \left(\frac{\varepsilon_{p} \dot{m}_{p} C_{p}{ }_{t}}{2}\right) T_{t}-\left(\frac{\varepsilon_{p} \dot{m}_{p} C_{p} \Delta t}{2}\right) T_{t-1}+\left[\left(\frac{\varepsilon_{p} \dot{m}_{p} C_{p}+U_{p} A_{p}}{2}\right) \Delta t+\rho C_{p} V_{p}\right] X_{t} \\
& +\left[\left(\frac{\varepsilon_{p} \dot{m}_{p} C_{p}+U_{p} A_{p}}{2}\right) \Delta t+\rho C_{p} V_{p}\right] x_{t-1}-M_{t}=U_{p} A_{p} \Delta t T_{B}-V_{w} ; t=1, \ldots, N \\
& \left\{\mathrm{~T}_{\min } \leq \mathrm{T}_{\mathrm{t}} \leq \mathrm{T}_{\max } ; \mathrm{Q}_{\mathrm{t}} \geq 0 ; \mathrm{Y}_{\mathrm{t}} \geq 0 ; \mathrm{F}_{\mathrm{t}} \geq 0 ; \mathrm{M}_{\mathrm{t}} \geq 0 ; \mathrm{W}_{\mathrm{t}} \geq 0 ;\right. \\
& t=1, \ldots, N\} \text {, }
\end{aligned}
$$

where the variables, $T_{t-1}, T_{t}, O_{t}, Y_{t}, X_{t-1}, X_{t}, W_{t}, F_{t}$ and $M_{t}$ are the nine design variables previously defined; $a=$ the weight of the $Y$ vartables and $b=$ the weight of the $\mathrm{W}$ variables; and all other terms are constant parameters defined as follows:

Energy flows and temperatures during each time period indexed by " $t$ " --

$$
\begin{aligned}
& E_{t}=\text { Solar radiation per unit of area during period } t, \\
& B_{t}=\text { Space heating load during period } t, \\
& V_{W}=\text { water heating load, } \\
& \theta_{t}=\text { average outdoor temperature during period } t, \\
& T_{B}=\text { building temperature. }
\end{aligned}
$$

\section{Collector parameters --}

$$
\begin{aligned}
A & =\text { collector area, } \\
F_{R}^{\prime} & =\text { dimensionless heat transfer efficiency factor, } \\
U_{L} & =\text { collector heat loss coefficient, } \\
\left(n_{\alpha}\right) & =\text { collector transmittance-absorptance product. }
\end{aligned}
$$

Space heating load parameters --

$\dot{\mathrm{m}}_{\mathrm{B}}=$ mass flow rate in space heat exchanger,

$\varepsilon_{B}=$ effectiveness of space heat exchanger.

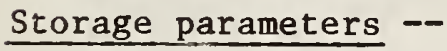

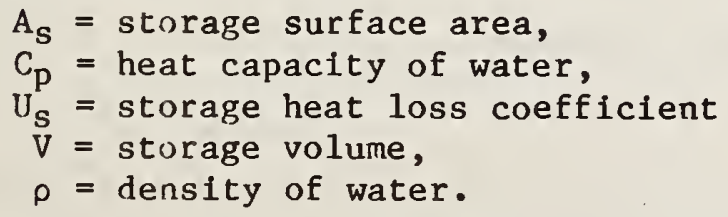




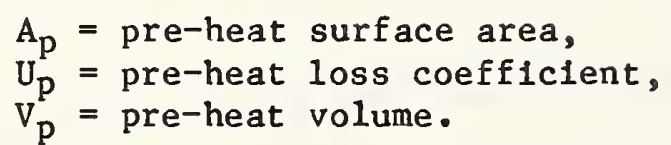

\section{Intertank heat exchange parameters}

$\dot{\mathrm{m}}_{\mathrm{p}}=$ mass flow rate in intertank heat exchanger,

$\varepsilon_{\mathrm{p}}^{\mathrm{p}}=$ effectiveness of intertank heat exchanger.

\section{Water heating load parameters --}

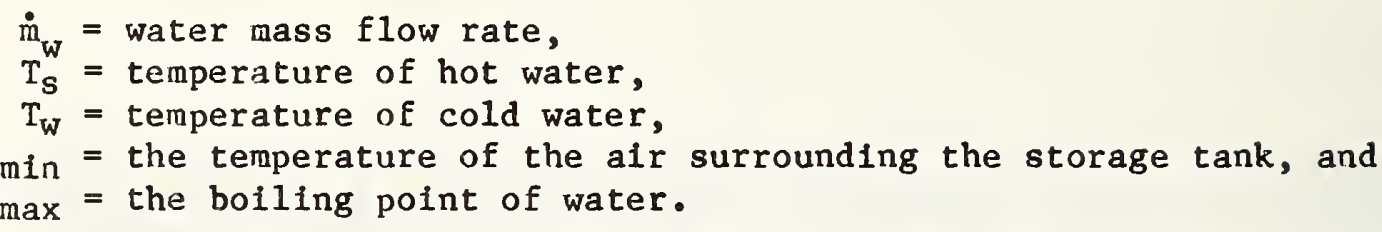

Coefficients on the design variables $T_{t-1}, T_{t}, Q_{t}, Y_{t}, X_{t-1}, X_{t}, W_{t}, F_{t}$, and $M_{t}$, in equations $(A .3)-(A .6)$ can be summarized as:

$$
\begin{aligned}
& \mathrm{f}_{C 1}=\frac{F_{R}^{\prime} U_{L} \Delta t}{2} \\
& f_{C 2}=\frac{F_{R}^{\prime} A U_{L} \Delta t}{2} \\
& \left(f_{C R}\right)_{t}=F_{R}^{\prime} A\left[\left(n_{\alpha}\right) E_{t}+U_{L} \Delta t \bar{\theta}_{t}\right] ; t=1, \ldots, N \\
& f_{B 1}=\frac{\varepsilon_{B} \dot{m}_{B} C \Delta t}{2} \\
& f_{B 2}=\frac{\varepsilon_{B} \dot{m}_{B} C_{P} \Delta t}{2} \\
& \left(f_{B R}\right)_{t}=B_{t}+\varepsilon_{B} \dot{m}_{B} C_{p} \Delta t T_{B} ; t=1, \ldots, N \\
& f_{S 1}=\left(\frac{U_{s}^{A} A_{S}+\varepsilon_{p} \dot{m}_{p} C_{p}}{2}\right) \Delta t+\rho C_{p} V \\
& f_{S 2}=\left(\frac{U_{s} A_{s}+\varepsilon_{p} m_{p} C_{p}}{2}\right) \Delta t+\rho C_{p} V
\end{aligned}
$$




$$
\begin{aligned}
& f_{S 3}=\frac{\varepsilon_{p} m_{p} C_{p} \Delta t}{2} \\
& f_{S 4}=\frac{\varepsilon_{p} \dot{m}_{p} C_{p} \Delta t}{2} \\
& \left(f_{S R}\right)_{t}=U_{S} A_{S} \Delta t T_{B}-B_{t} ; t=1, \ldots, N \\
& \mathrm{f}_{\mathrm{Hl}}=\frac{\dot{\mathrm{m}}_{\mathrm{w}} \mathrm{C}_{\mathrm{p}} \Delta t}{2} \\
& f_{H 2}=\frac{\dot{\mathrm{m}}_{\mathrm{w}} \mathrm{C}_{\mathrm{p}} \Delta t}{2} \\
& \mathrm{E}_{H R}=\dot{\mathrm{m}}_{\mathrm{W}} \mathrm{C}_{\mathrm{p}} \Delta t \mathrm{~T}_{s} ; t=1, \ldots, \mathrm{N} \\
& f_{P 1}=\frac{\varepsilon_{p} \dot{m}_{p} C_{p} \Delta t}{2} \\
& \mathrm{f}_{\mathrm{P} 2}=\frac{\varepsilon_{\mathrm{p}} \dot{\mathrm{m}}_{\mathrm{p}} \mathrm{C}_{\mathrm{p}} \Delta t}{2} \\
& f_{P 3}=\left(\frac{\varepsilon_{p} m_{p} C_{p}+U_{p} A_{p}}{2}\right) \Delta t-\rho C_{p} v_{p} \\
& f_{p 4}=\left(\frac{\varepsilon_{p} \dot{m}_{p} C_{p}+U_{p} A_{p}}{2}\right) \Delta t+\rho C_{p} V_{p} \\
& f_{P R}=U_{p} A_{P} \Delta t T_{B}-V_{W} ; t=1, \ldots, N
\end{aligned}
$$

Using the summary form for coeffictents of the design varlables, the matrix form of the linear program is the following:

$$
\text { Minimize } \sum_{t=1}^{N} a Y_{t}+b W_{t}+F_{t}+M_{t} \text {, }
$$

subject to the following constraining conditions:

For $t=1,2, \ldots, N$ 


$\left[\begin{array}{ccccccccc}\mathrm{f}_{\mathrm{C} 1} & \mathrm{f}_{\mathrm{C} 2} & 1 & -1 & 0 & 0 & 0 & 0 & 0 \\ \mathrm{f}_{\mathrm{S} 1} & \mathrm{f}_{\mathrm{S} 2} & -1 & 0 & -\mathrm{f}_{\mathrm{S} 3} & -\mathrm{f}_{\mathrm{S} 4} & 1 & -1 & 0 \\ -\mathrm{f}_{\mathrm{P} 1} & -\mathrm{f}_{\mathrm{P} 2} & 0 & 0 & \mathrm{f}_{\mathrm{P} 3} & \mathrm{f}_{\mathrm{P} 4} & 0 & 0 & -1 \\ \mathrm{f}_{\mathrm{B} 1} & \mathrm{f}_{\mathrm{B} 2} & 0 & 0 & 0 & 0 & 0 & 0 & 0 \\ 0 & 0 & 0 & 0 & \mathrm{f}_{\mathrm{H} 1} & \mathrm{f}_{\mathrm{H} 2} & 0 & 0 & 1 \\ 0 & 1 & 0 & 0 & 0 & 0 & 0 & 0 & 0 \\ 0 & 1 & 0 & 0 & 0 & 0 & 0 & 0 & 0\end{array}|=| \begin{array}{l}\mathrm{T}_{\mathrm{t}-1} \\ \mathrm{~T}_{\mathrm{t}} \\ \mathrm{Q}_{\mathrm{t}} \\ \mathrm{Y}_{\mathrm{t}} \\ \mathrm{x}_{\mathrm{t}-1} \\ \mathrm{x}_{\mathrm{t}} \\ \mathrm{w}_{\mathrm{t}} \\ \mathrm{F}_{\mathrm{t}} \\ \mathrm{M}_{\mathrm{t}}\end{array} \mid \begin{array}{l}\left.\mathrm{f}_{\mathrm{SR}}\right)_{\mathrm{t}} \\ \mathrm{f}_{\mathrm{PR}} \\ \left(\mathrm{f}_{\mathrm{BR}}\right)_{\mathrm{t}} \\ \mathrm{f}_{\mathrm{HR}} \\ \mathrm{T}_{\mathrm{m} 1 \mathrm{n}} \\ \mathrm{T}_{\max }\end{array}\right.$

The system of equations can be solved using the Iinear program described above in matrix notation, assuming in addition the following relationships to hold:

$$
\begin{aligned}
& Q_{t} Y_{t}=0, \\
& F_{t} G_{t}=0, \\
& M_{t} N_{t}=0, \\
& W_{t}=\begin{array}{l}
Q_{t}-Z_{t}-R_{t}-L_{t}, \text { if } \bar{T}_{t}=T_{\max } \\
0, \text { if } T_{t}<T_{\max },
\end{array}
\end{aligned}
$$

where

$Y_{t}, G_{t}$ and $N_{t}=$ surplus variables which convert equations (A.2), (A.3), and (A.5) to equalities,

$\mathrm{Z}_{\mathrm{t}}=$ energy delivered from storage to space heating during period $t$,

$R_{t}=$ energy delivered from storage to pre-heat during period $t$,

$\mathrm{L}_{t}=$ energy lost from storage during period $t ;$

$\overline{\mathrm{T}}_{\mathrm{t}}=$ average storage tank temperature in time period $t$, and other terms are as defined previously.

Equations (A.28) - (A.31) are nonlinear and cannot be entered directly into the linear program, but they represent important physical properties of the real operation of the combined system. Control actions in the actual combined solar auxiliary system are intended to cause these conditions to hold. The control actions are reflected in the linear program through the operation of the objective function in the solution process of minimizing all undesired energy flows.

Variable $Y_{t}$ is entered directly into the linear program so the collector relationship is an equality. $G_{t}$ and $N_{t}$ appear only indirectly in the surplus variable form. The surplus variables, in combination with the conditions expressed in equations (A.28) - (A.31), represent switching functions in the

$$
\text { A-14 }
$$


operation of the controls of the actual solar/auxillary system that turn off undesired energy flows not needed to meet the thermal load requirements of the bullding. The switching functions represent relationships of the types

$$
x^{+}=\begin{aligned}
& x \text { for } x>0 \\
& 0 \text { for } x \leq 0
\end{aligned}
$$

for collector performance, heat exchanger performance, and auxiltary hot water heater performance. These components of the system are labeled $S$, $H$, and $B$ in figure 3.A. Equations (A.28) - (A.31), which can be called "orthogonality conditions," can be interpreted as follows: " $\mathrm{Q}_{t} \mathrm{Y}_{t}=0$ " says that energy will not be supplied to storage when solar radiation is insufficient for collection (either $Q_{t}$ or $Y_{t}=0$ for every time period), 1.e., the control system should shut off the collector system during periods of insufficient radiation; " $F_{t} G_{t}=$ 0 " says auxiliary energy will not be supplied for space heating at the same time that solar energy supplied to meet the space heating load exceeds the space heating load (either $F_{t}$ or $G_{t}=0$ for every time period), $1 . e$. , the controls in the actual system should shut off auxiliary energy supply for space heating when it is not required; " $\mathrm{M}_{\mathrm{t}} \mathrm{N}_{\mathrm{t}}=0$ " says auxiliary energy w1ll not be delivered from the auxiliary water heater to meet water heating requirements if the solar energy supplied for water heating exceeds the water heating load (either $M_{t}$ or $\mathrm{N}_{\mathrm{t}}=0$ for every time period), $1 . e$. , the controls in the actual system should shut off auxiliary energy supply for water heating when it is not required.

Within the linear program, the objective function dictates that these control operations reflected in the orthogonality conditions shall occur by minimizing undesired energy flows. The variables $Y_{t}, F_{t}$, and $M_{t}$ will have zero values if the energy flows they represent are not required. If energy cannot be collected because radiation is insufficient, then $Y_{t}=0$, i.e., energy collection will not be attempted. If energy supplied to the building for space heating from solar collection equals or exceeds the space heating load, then $F_{t}=0$, i.e., auxiliary energy will not be used for space heating. If the temperature of water in the preheat tank equals or is greater than the desired water temperature, then $M_{t}=0$, $1 . e$. , no auxillary energy will be used to heat water further. The $W_{t}$ condition is similar: if storage is not full, then energy will be delivered to storage, and energy will not be wasted so $W_{t}=0$. However, if storage is full, energy will be wasted by the amount $Q_{t}-Z_{t}-R_{t}-L_{t}$.

Since these orthogonality conditions are not imposed explicitly in the constraint equations of the linear program, the question arises whether they will always hold mathematically, as they are assumed to do, in the operation of actual solar/auxiliary systems. Are there situations under which the objective function will not cause these conditions to hold mathematically in every time period? If so, the linear program cannot be used to predict solar performance under these situations. 


\section{A. 5 SOLUTION PROPERTIES OF THE MCGARITY-REVELLE LINEAR PROGRAM 1}

The characteristics of solutions to the McGarity-Revelle solar energy 1inear program was investigated by Francis [3-A] to establish the conditions under which the orthogonality conditions described above will automatically hold without being imposed explicitly in the program.

Francis considered using a more general objective function that includes economic costs of the energy flows. This more general objective function is expressed as follows:

$$
Z=\sum_{t=1}^{N}\left[a_{t} F_{t}+b_{t} N_{t}+c_{t} M_{t}+d_{t} G_{t}+e_{t} Q_{t}+f_{t} W_{t}+g_{t} Y_{t}\right]
$$

where $F_{t}, M_{t}, N_{t}, Q_{t}, W_{t}$, and $G_{t}$ are as defined previously, and $a_{t}, b_{t}, c_{t}$, $d_{t}, e_{t}, f_{t}$, and $g_{t}$ are appropriate cost coefficients (i.e., the costs of corresponding energy flows). The surplus variables $N_{t}$ and $G_{t}$ which, like the other elements in the objective function, are undesirable energy flows, are entered into this more general objective function, and, like the other energy flows, are given cost coefficients. Any cost coefficient which is not of interest, or which may be meaningless for a specific context, can be deleted by setting it equal to zero.

This formulation retains the desirable properties of the McGarity-Revelle linear program, and factlitates a rigorous evaluation of the mathematical properties of solutions to the program.

In the four observations which follow, Francis described the situations under which the "orthogonality" conditions $\left(O_{t} Y_{t}=0\right.$, and $\left.F_{t} G_{t}=0\right)$ will automatically hold without being imposed explicitly; the conditions under which they will not hold; and the effect which relative values of space heating costs, storage costs, and collector costs have upon optimum solutions to the linear program. (The underlying logic in support of the observations is given in section $\mathrm{A.7.)}$

Observation 1

(a) If

$$
a_{t}+d_{t}<e_{t}+g_{t}
$$

then, in any optimum feasible solution to the linear program, at least one of the variables $Q_{t}$ and $Y_{t}$ will be zero. That is, energy will not be supplied to storage at the same time that energy is lost due to attempted energy collection when there is insufficient solar radiation.

(b) If

$$
a_{t}+d_{t}=e_{t}+g_{t}
$$

1 This discussion of solution properties of the linear programming model is based on an unpublished paper prepared by Dr. Francis for the NBS Applied Economics Group [3-A]. 
and if there exists an optimum feasible solution to the linear program, then there exists an optimum feasible solution for which at least one of the variables $Q_{t}$ and $Y_{t}$ is zero.

Note that to have at least one of the variables $Q_{t}$ or $Y_{t}$ equal to zero is equivalent to having $Q_{t} Y_{t}=0$. Observation 1 provides conditions for which the nonlinear mathematical constraint is redundant and thus may be ignored. The condition will automatically hold without being imposed and thus disrupting the linearity of the program.1

Observation ?

(a) If

$$
a_{t}+d_{t}>e_{t}+g_{t}
$$

then, in any optimum feasible solution to the linear program, at least one of the variables $F_{t}$ and $G_{t}$ will be zero. That is, auxiliary energy will not be supplied for space heating at the same time that solar energy supplied to meet the space heating load exceeds the space heating load. (Note that the sufficient condition in observation 1 (a) cannot hold simultaneously with the sufficient condition in observation 2 (a).)

(b) If

$$
a_{t}+d_{t}=e_{t}+g_{t}
$$

and if there exists an optimum feasible solution to the linear program, then there exists an optimum feasible solution for which at least one of the variables $F_{t}$ and $G_{t}$ is zero.

Observations 1 and 2 imply that the relative values of $a_{t}+d_{t}$ and $e_{t}+g_{t}$ have a significant effect upon the optimal feasible solutions to the linear program. With knowledge of their relative values, conclusions may be drawn as to when auxiliary energy supplied for space heating, and energy supplied to storage, may be zero. Note that $a_{t}$ and $d_{t}$ both involve space heating costs, while $e_{t}$ and $g_{t}$ involve storage and collection costs. Observations 1 and 2 thus imply that the relative values of space heating costs and storage and collection costs have an important effect upon optimum answers to the linear program. It is intuitively obvious that an actual solar heating system would exhibit such effects, and so their prediction by the model serves to corroborate the modeling approach. Observations 1 and 2 precisely state this implication.

\section{Observation 3}
(a) If
$a_{t}+d_{t}+f_{t}>0$

then in any optimum feasible solution to the linear program, at least one of the variables $F_{t}, F_{t}$, and $W_{t}$ will be zero. That is, it will never be the case that all three of the following events occur simultaneously: auxiliary energy

1 The conclusion of observation 1 was conjectured by McGarity and Revelle, but without proof or specification of conditions under which the conclusion would hold. 
is supplied for space heating; the solar energy supplied to meet the space heating load exceeds the space heating load; solar energy cannot be collected due to the fact that storage temperature is at the boiling point of water.

\section{(b) If}

$$
a_{t}+d_{t}+f_{t}=0 \text {, }
$$

and if there exists an optimum feasible solution to the linear program, then there exists an optimum feasible solution for which at least one of the variables $F_{t}, G_{t}$, and $W_{t}$ is zero.

In effect, observation 3 says that if the storage temperature is at the boiling point of water ( $1 . e$. , more than enough solar energy is avallable to keep storage at its maximum temperature), then auxiliary energy will not be needed for space heating at the same time that solar energy is supplied for space heating in excess of the space heating demand. This is, again, a reassuring conclusion.

\section{Observation 4}

$$
e_{t}+f_{t}+g_{t}<0,
$$

then the linear program does not have any optimum feasible solution: the objective function value may be made arbitrarily small. Observation 4 is a minor observation, but it is possibly valuable in checking for a badly formulated problem. A comparison of $e_{t}+f_{t}+g_{t}$ with zero avoids trying to find an optimum feasible solution when none exists. Further, observation 4 identifies a situation for which $Y_{t}$ and $Q_{t}$ could be positive, and indicates that such a situation would result from a poorly formulated problem. Table A.2 summarizes the four above observations, plus two additional observations. Justifications for the observations are given in section A.7.

\section{A.6 MATHEMATICAL RELATIONSHIPS EMPLOYED IN THE SOLAR ENERGY LINEAR PROGRAM AND A LISTING OF MATHEMATICAL NOTATIONS}

\section{A.6.1 Component Performance Relationships}

Collector Performance: A difference equation form of the collector performance equation developed by Hottel in 1942 and modified by deWinter in 1975 is used:

$$
Q_{t}=F_{R}^{\prime} A\left[\left(n_{\alpha}\right) E_{T}-U_{L} \Delta t\left(\bar{T}_{t}-\bar{\theta}_{t}\right)\right]^{+}
$$

Space Heating Load:

$$
F_{t}=\left[B_{t}-\varepsilon_{B} \dot{m}_{B} C_{p} \Delta t\left(T_{t}-T_{B}\right)\right]^{+}, Z_{t}=B_{t}-F_{t}
$$

1 The material given in this appendix is taken from unpublished notes provided to NBS by Arthur McGarity pertaining to the mathematical programming work which he performed at the Johns Hopkins University, under the sponsorship of NBS. 
Table A.2 Summary of Observations on the Solution Properties of the McGarity-Revelle Linear Programa

\begin{tabular}{|c|c|c|}
\hline $\begin{array}{l}\text { Observation } \\
\text { Number }\end{array}$ & $\begin{array}{l}\text { Condition on } \\
\text { Cost Coefficients }\end{array}$ & $\begin{array}{l}\text { Conclusions About } \\
\text { Optimum Solution }\left(0 . S_{.}\right)\end{array}$ \\
\hline (1) & $a_{t}+d_{t}<e_{t}+g_{t}$ & $Y_{t}$ or $Q_{t}=0$ \\
\hline (2) & $a_{t}+d_{t}>e_{t}+g_{t}$ & $F_{t}$ or $G_{t}=0$ \\
\hline (3) & $a_{t}+d_{t}+f_{t}>0$ & $F_{t}$ or $G_{t}$ or $W_{t}=0$ \\
\hline (4) & $e_{t}+f_{t}+g_{t}<0$ & $\begin{array}{l}\text { no } 0 . S \text {. exists: } Q_{t}, W_{t} \text {, and } Y_{t} \\
\text { can be made arbitrarily large }\end{array}$ \\
\hline (5) & $e_{t}+f_{t}+g_{t}>0$ & $Q_{t}$ or $W_{t}$ or $Y_{t}=0$ \\
\hline (6) & $a_{t}+d_{t}+f_{t}<0$ & $\begin{array}{l}\text { no } 0 . S \text { exists: } F_{t}, G_{t} \text {, and } \\
W_{t} \text { can be made arbitrarily large }\end{array}$ \\
\hline
\end{tabular}

a In the appendix we also conclude that if

$$
\begin{array}{ll} 
& \beta_{t}+\delta_{t} \geq 0 \\
\text { and/or } & \alpha_{t}+\beta_{t}+\delta_{t} \geq 0, \\
\text { and if } & \beta_{t} \geq 0 \\
\text { and/or } & \alpha_{t}+\beta_{t} \geq 0
\end{array}
$$

then it will never be the case that both $Q_{t}$ and $Y_{t}$ are positive in an optimum basic feasible solution. The terms $\alpha_{t}, \beta_{t}$, and $\delta_{t}$ are defined, with reference to equations (A.8) - (A.25), as follows:

$$
\begin{aligned}
& \alpha_{t}=\left(f_{C R}\right)_{t}-\left(f_{C 1}\right) T_{t-1}-\left(f_{C 2}\right) T_{t} \\
& \beta_{t}=\left(f_{S R}\right)_{t}-\left(f_{S 1}\right) T_{t-1}-\left(f_{S 2}\right) T_{t}+\left(f_{S 3}\right) X_{t-1}+\left(f_{S 4}\right) X_{t} \\
& \delta_{t}-\left(f_{B R}\right)_{t}-\left(f_{B 1}\right) T_{t-1}-\left(f_{B 2}\right) T_{t} .
\end{aligned}
$$

(Here $\mathrm{T}_{\mathrm{t}}$ and $\mathrm{X}_{\mathrm{t}}$ are the storage and preheat tank temperatures, respectively, at the end of period $t_{.}$)

Source: Taken from an unpublished paper prepared by Richard Francis, NBS Center for Applied Mathematics, for the NBS Applied Economics Group [3-A]. 
Intertank Heat Exchange:

$$
R_{t}=\varepsilon_{p} \dot{m}_{p} C_{p} \Delta t\left(\bar{T}_{t}-\bar{X}_{t}\right)
$$

Storage Losses:

$$
L_{t}=U_{s} A_{s} \Delta t\left(T_{t}-T_{B}\right)
$$

Storage Tank Energy Balance:

$$
\rho C_{p} V\left(T_{t}-T_{t-1}\right)=Q_{t}-Z_{t}-R_{t}-L_{t}-W_{t}
$$

Wasted Energy:

$$
W_{t}=\left\{\begin{array}{l}
Q_{t}-Z_{t}-R_{t}-L_{t} \text { if } \bar{T}_{t}=T_{\max } \\
0 \text { if } \bar{T}_{t}<T_{\max }
\end{array}\right.
$$

Water Heating Load:

$$
M_{t}=\dot{m}_{w} C_{p} \Delta t\left[T_{s}-\bar{x}_{t}\right]^{+}, U_{t}=V_{m}-M_{t}
$$

Preheat Thermal Loss:

$$
P_{t}=U_{p} A_{p} \Delta t\left(X_{t}-T_{B}\right)
$$

Preheat Tank Energy Balance:

$$
\rho C_{p} V_{p}\left(X_{t}-X_{t-1}\right)=R_{t}-U_{t}-P_{t}
$$

\section{A.6.2 Combination of Performance Formulas for Linear Program Format}

The following relationships among the average tank temperatures $\left(\vec{T}_{t}\right.$ and $\vec{X}_{t}$ ) and the tank temperatures at the end of the current and preceding periods ( $T_{t}$, $\mathrm{T}_{\mathrm{t}-1}$, and $\mathrm{x}_{\mathrm{t}}, \mathrm{x}_{\mathrm{t}-1}$ ) are assumed:

$$
T_{t}=\frac{1}{2}\left(T_{t}+T_{t-1}\right)
$$

and

$$
x_{t}=\frac{1}{2}\left(x_{t}+x_{t-1}\right)
$$

\section{Collector Performance:}

A new variable $Y_{t}$ is introduced:

$$
Q_{t}-Y_{t}+F_{R}^{\prime} A\left[(\tau \alpha) E_{t}-U_{L} \Delta t\left(\bar{T}_{t}-\bar{\theta}_{t}\right)\right], Q_{t} Y_{t}=0
$$


Applying the assumption above, the following is obtained:

$$
\begin{aligned}
& \left(\frac{F_{R}^{\prime} A U_{L} \Delta t}{2}\right) T_{t}+\left(\frac{F_{R}^{\prime} A U_{L} \Delta t}{2}\right) T_{t-1}-Q_{t}-Y_{t}=F_{R}^{\prime} A\left[\left(n_{\alpha}\right) E_{t}+U_{L} \Delta t \bar{\theta}_{t}\right] \\
& Q_{t} Y_{t}=0
\end{aligned}
$$

\section{Space Heating Load:}

A new variable $G_{t}$ is introduced:

$$
F_{t}-G_{t}=B_{t}-\varepsilon_{B} \dot{m}_{B} C_{p} \Delta t\left(\bar{T}_{t}-T_{B}\right), F_{t} G_{t}=0
$$

or

$$
\begin{aligned}
& \left(\varepsilon_{B} \dot{m}_{B} C_{p} \Delta t\right)_{t}+\frac{\left(\varepsilon_{B} \dot{m}_{B} C_{p} \Delta t\right)}{2} T_{t-1}+F_{t}-G_{t}=B_{t}+\varepsilon_{B} \dot{m}_{B} C_{p} \Delta t T_{B} \\
& F_{t} G_{t}=0
\end{aligned}
$$

\section{Storage Tank Energy Balance:}

Using the assumption concerning tank temperatures and the formulas for intertank heat exchange and storage losses, the following is obtained:

$$
\begin{aligned}
& {\left[\left(\frac{U_{s} A_{s}+\varepsilon_{p}{ }^{m} C_{p}}{2}\right) \Delta t+\rho C_{p V}\right] T_{t}+\left[\left(\frac{U_{s} A_{s}+\varepsilon_{p}{ }_{p} C_{p}}{2}\right) \Delta t-\rho C_{p} V\right] T_{t-1}} \\
& -\left({ }^{\varepsilon_{p}{ }^{m}{ }^{C} p^{\Delta t}}\right) X_{t}-\left(\frac{\varepsilon_{p}{ }^{m} C_{p} \Delta t}{2}\right) X_{t-1}-Q_{t}-F_{t}+W_{t}=U_{s} A_{s} \Delta t T_{B}-B_{t}
\end{aligned}
$$

\section{Water Heating Load:}

The new variable $\mathrm{N}_{\mathrm{t}}$ is introduced:

$$
M_{t}-N_{t}=\dot{m}_{w} C_{p} \Delta t\left[T_{s}-\bar{x}_{t}\right], M_{t} N_{t}=0
$$

or

$$
\left(\frac{\dot{\mathrm{m}}_{\mathrm{w}} \mathrm{C}_{\mathrm{p}} \Delta t}{2}\right) \mathrm{x}_{t}+\left(\frac{\dot{\mathrm{m}}_{\mathrm{w}} \mathrm{C}_{\mathrm{p}} \Delta t}{2}\right) \mathrm{x}_{\mathrm{t}-1}+\mathrm{M}_{t}-\mathrm{N}_{\mathrm{t}}=\dot{\mathrm{m}}_{\mathrm{w}} \mathrm{C}_{\mathrm{p}} \Delta t \mathrm{~T}_{\mathrm{s}}, \mathrm{M}_{\mathrm{t}} \mathrm{N}_{\mathrm{t}}=0
$$

Preheat Tank Energy Balance

Using the assumption concerning tank temperatures and the formulas for intertank heat exchange and preheat tank losses, the following is obtained. 


$$
\begin{aligned}
& \left.\left.-\frac{\left(\varepsilon_{p} \dot{m}_{p} C_{p} \Delta t\right.}{2}\right)_{t}-\frac{\left(\varepsilon_{p} \dot{m}_{p} C_{p} \Delta t\right.}{2}\right) T_{t-1}+\frac{\left[\left(\varepsilon_{p} \dot{m}_{p} C_{p} p_{p} A_{p}\right)\right.}{2} \Delta t \\
& \left.+\rho C_{p} V_{p}\right] X_{t}+\left[\left(\frac{\varepsilon_{p}{ }_{p} C_{p}+U}{2}{ }_{p}^{A} p\right) \Delta t-\rho C_{p} V_{p}\right] X_{t-1}-M_{t}=U_{p} A_{p} \Delta t T_{B}-V_{W}
\end{aligned}
$$

\section{A.6.3 Mathematical Notation}

Energy flows and temperatures during each time period indexed by " $t$ ":

$$
\begin{aligned}
& E_{t}=\text { solar radiation per unit of area during period } t \\
& Q_{t}=\text { solar energy delivered to storage during period } t \\
& L_{t}=\text { energy lost from storage during period } t \\
& W_{t}=\text { energy wasted if storage is full during period } t \\
& Z_{t}=\text { energy delivered from storage for space heating during period } t \\
& R_{t}=\text { energy delivered from storage to pre-heat during period } t \\
& F_{t}=\text { auxiliary energy for space heating during period } t \\
& M_{t}=\text { auxiliary energy for water heating during period } t \\
& P_{t}=\text { energy lost from preheat during period } t \\
& B_{t}=\text { space heating load during period } t \\
& V_{W}=\text { water heating load } \\
& U_{t}=\text { energy delivered from preheat to water heating during period } t \\
& \bar{\theta}_{t}=\text { average outdoor temperature during period } t \\
& T_{t}=\text { storage temperature at the end of period } t \\
& X_{t}=\text { preheat temperature at the end of period } t \\
& T_{B}=\text { building temperature }
\end{aligned}
$$

(The diagram of the solar energy system shown in Figure A.4 is labeled according to the above notation to indicate the physical location of each parameter.)

Other notation used in the appendix:

\section{(1) Collector parameters}

$A=$ collector area

$\mathrm{F}_{\mathrm{R}}^{\prime}=\mathrm{a}$ dinensionless heat transfer efficiency factor 


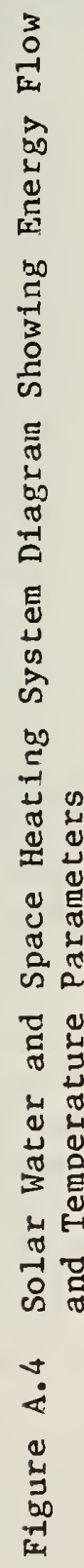

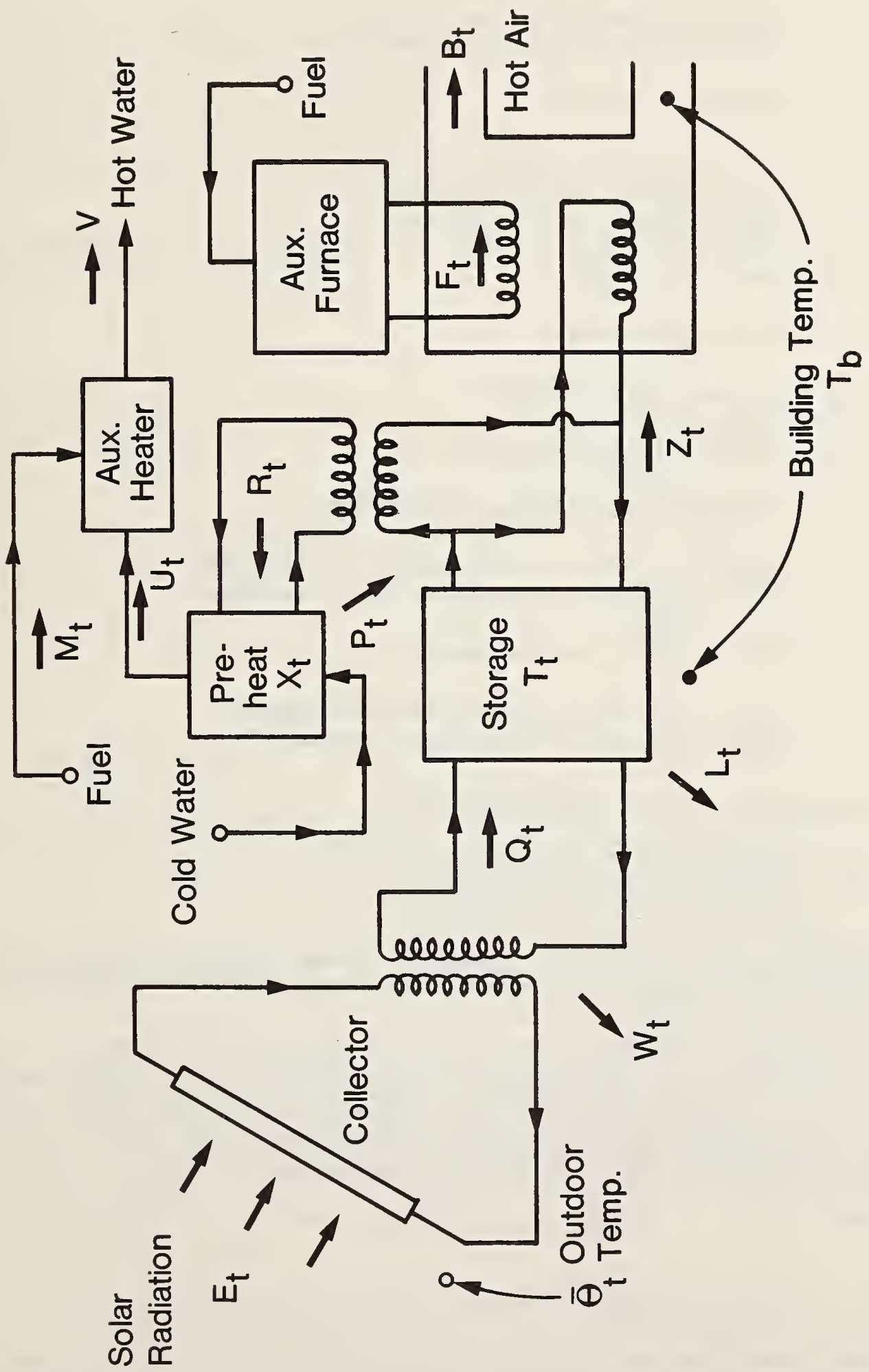


$\mathrm{U}_{\mathrm{L}}=$ collector heat loss coefficient

$\left(n_{\alpha}\right)=$ collector transmittance-absorptance product

(2) Storage parameters

$A_{S}=$ storage surface area

$\mathrm{C}_{\mathrm{p}}=$ heat capacity of water

$\mathrm{U}_{\mathrm{S}}=$ storage heat loss coefficient

$V=$ storage volume

$\rho=$ density of water

(3) Pre-heat parameters

$A_{p}=$ preheat surface area

$\mathrm{V}_{\mathrm{p}}=$ preheat volume

$U_{p}^{p}=$ preheat loss coefficient

(4) Intertank heat exchange parameters

$\dot{\mathrm{m}}_{\mathrm{p}}=$ mass flow rate in intertank heat exchanger

$\varepsilon_{p}=$ effectiveness of intertank heat exchanger

(5) Space heating load parameters

$\dot{\mathrm{m}}_{\mathrm{B}}=$ mass flow rate in space heat exchanger

$\varepsilon_{B}=$ effectiveness of space heat exchanger

(6) Water heating load parameters

$\dot{\mathrm{m}}_{\mathrm{w}}=$ water mass flow rate

$\mathrm{T}_{\mathrm{S}}=$ temperature of hot water

$\mathrm{T}_{\mathrm{W}}=$ temperature of cold water

A.7 DERIVATIONS OF SOLUTION PROPERTIES OF THE MCGARITY-REVELLE LINEAR PROGRAMMING MODEL 1

After temperature variables T's and X's, (which have no effect upon the analysis) are incorporated into the terms on the right side, upper and lower bounds on temperatures (which likewise have no effect) are deleted, and surplus variables $\mathrm{N}_{t}$ and $\mathrm{L}_{t}$ are introduced to convert inequalities into equations, the McGarityRevelle constraints for time period $t$ appear as follows:

$$
\begin{aligned}
Q_{t} & -Y_{t} & =\alpha_{t} \\
-F_{t} & -Q_{t}+W_{t} & =\beta_{t}
\end{aligned}
$$

1 Taken from an unpublished paper prepared by Dr. Richard Francis, Visiting Mathematician in the NBS Center for Applied Mathematics, for the NBS Applied Econornics Group [3.A]. 


$$
\begin{aligned}
& -\mathrm{M}_{\mathrm{t}} \quad=\gamma \\
& F_{t} \quad-G_{t} \quad=\delta_{t} \\
& -\mathrm{N}_{\mathrm{t}}+\mathrm{M}_{\mathrm{t}} \quad=\varepsilon
\end{aligned}
$$

where all variables displayed are nonnegative.

Network Interpretation The constraints (1) through (5) above may be depicted as a network flow problem as follows :
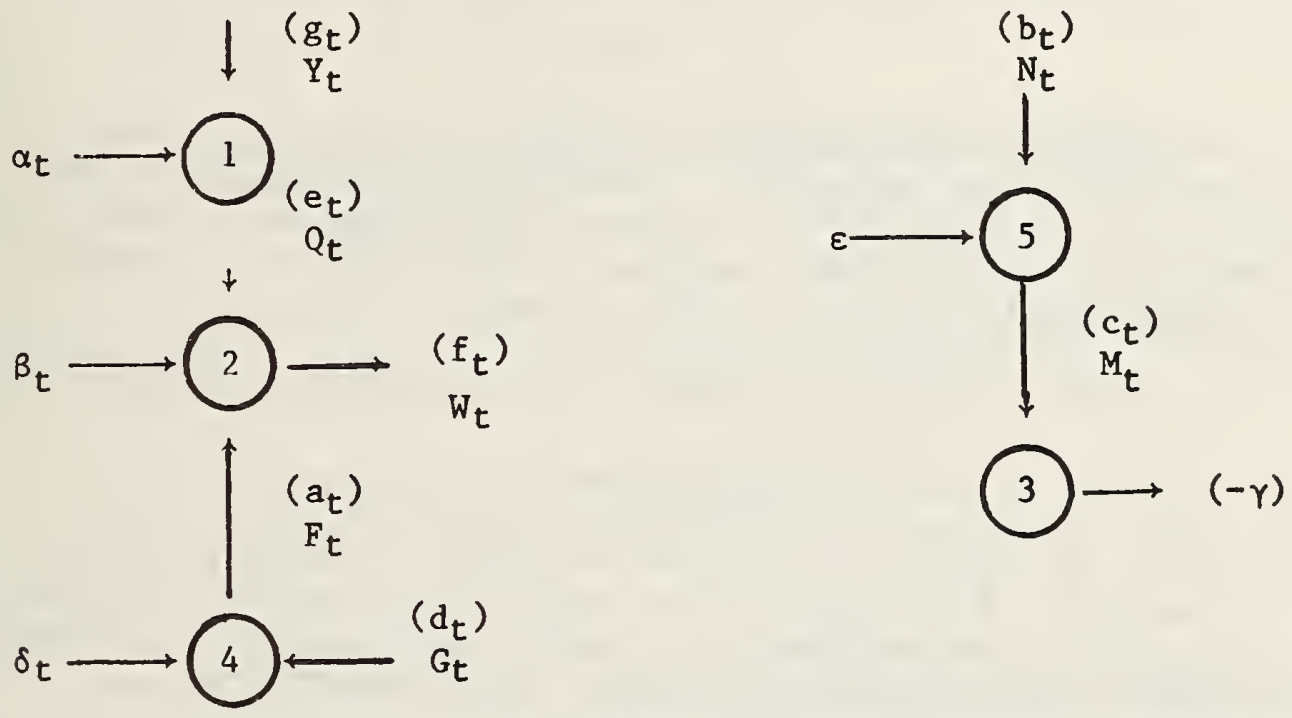

This network representation can be useful in providing insight regarding the nature of the constraints. Each numbered node 1 through 5 corresponds to the constraint having the same number, and the condition that the input "flow" equals the output "flow" is the constraint itself; e.g., for constraint (1), $\alpha_{t}+Y_{t}=Q_{t}$, where $\alpha_{t}+Y_{t}$ and $Q_{t}$ are the total input and output flows respectively for node 1. The "input equals output" conditions for the other nodes represent the other corresponding constraints. To have nonnegative "flows" means that the variables are nonnegative. Unit costs are shown in parentheses above the variables. To illustrate the use of the flow interpretations, suppose $Y_{t}$ and $Q_{t}$ are positive, and let $\Delta t=\min \left(Y_{t}, Q_{t}\right)>0$. If we decrease the value of $Y_{t}$ and $Q_{t}$ by $\Delta t$, we maintain the input-output condition for node 1 . Now the flow into node 2 from node $l$ is reduced by $\Delta t$, so we must increase the flow into node 2 from node 4 by $\Delta t$ to compensate. Likewise we must increase the flow into node 4 by $\Delta t$, to compensate. Thus we reduce $Y_{t}$ and $Q_{t}$ by $\Delta t$, and increase $F_{t}$ and $G_{t}$ by the same amount in order to compensate: in effect, a new feasible solution has been constructed.

The foregoing illustrates much of the justification for observation 1 . Dther observations may be justified similarly. In what follows, algebraic justifications (complementary to these "flow" arguments) are given in some detail.

As a parting speculative remark, it seems possible that this "partial" network structure of the linear program (L.P.) (temperature variables prevent having a 
complete network structure) might be of use in developing a more efficient algorithm to solve the L.P.

For convenience, the abbreviations F.S. and O.F.S. stand for feasible solution and optimal feasible solution respectively. The underlying logic needed to justify the observations is much the same for all the observations. Thus only the justification for observation 1 is given in substantial detail.

Justification for Observation 1 Given a feasible solution (F.S.) to the L.P. for which

$$
\Delta t \equiv \min \left(Q_{t}, Y_{t}\right)>0
$$

construct new variable values $Q_{t}^{\prime}=Q_{t}-\Delta t, Y_{t}^{\prime}=Y_{t}-\Delta t, F_{t}^{\prime}=F_{t}+\Delta t, G_{t}^{\prime}=G_{t}+\Delta t$, leaving remaining variable values unchanged. Since $Q_{t}-Y_{t}=Q_{t}-Y_{t}=\alpha_{t},-F_{t}-Q_{t}+W_{t}=$ $-F_{t}-Q_{t}+W_{t}=\beta_{t}$, and $F_{t}-G_{t}=F_{t}-G_{t}=\delta_{t}$, the new variable values provide a $F . S$. Further, certainly $\min \left(Q_{t}, Y_{t}\right)=0$. Letting $z$ and $z^{\prime}$ denote the initial and new objective function values respectively, we have

$$
\begin{aligned}
z-z^{\prime} & =a_{t} F_{t}+d_{t} G_{t}+e_{t} Q_{t}+g_{t} Y_{t}-\left(a_{t} F_{t}^{\prime}+d_{t} G_{t}^{\prime}+e_{t} Q_{t}^{\prime}+g_{t} Y_{t}^{\prime}\right) \\
& =-a_{t} \Delta t-d_{t} \Delta t+e_{t} \Delta t+g_{t} \Delta t=\left(e_{t}+g_{t}-a_{t}-d_{t}\right) \Delta t .
\end{aligned}
$$

(a) Since $\Delta t>0$, if $\left(e_{t}+g_{t}-a_{t}-d_{t}\right)>0$ then $\left(e_{t}+g_{t}-a_{t}-d_{t}\right) \Delta t>0$ so $z-z^{\prime}>0$, i.e., z>z'. Thus the given F.S. could not be an optimal feasible solution ( $\mathrm{z}^{\prime}$.F.S.) Hence for any O.F.S., the minimum of $Q_{t}$ and $Y_{t}$ must be zero, as otherwise a new F.S. with smaller objective function value can be constructed.

(b) If $\left(e_{t}+g_{t}-a_{t}-d_{t}\right)=0$ then $z=z^{\prime}$, so if the initial F.S. is an O.F.S., then the new F.S. is an O.F.S., and one for which the minimum of the new values of $Q_{t}$ and $Y_{t}$ is zero.

Justification for Observation 2 Given a F.S. to the L.P. for which

$$
\Delta t \equiv \min \left(F_{t}, G_{t}\right)>0 \text {, }
$$

construct new variable values by decreasing $F_{t}$ and $G_{t}$ by $\Delta t$, increasing $Q_{t}$ and $Y_{t}$ by $\Delta t$, and leaving other variable values unchanged. It is direct to verify that the new values provide a F.S., and one for which the minimum of the new values of $F_{t}$ and $G_{t}$ is zero. Further, if $z$ and $z^{\prime}$ are the initial and new objective function values respectively, then

$$
\begin{aligned}
z-z^{\prime}= & a_{t} F_{t}+d_{t} G_{t}+e_{t} Q_{t}+g_{t} Y_{t}- \\
& {\left[a_{t}\left(F_{t}-\Delta t\right)+d_{t}\left(G_{t}-\Delta t\right)+e_{t}\left(Q_{t}+\Delta t\right)+g_{t}\left(Y_{t}+\Delta t\right)\right] } \\
= & \left(a_{t}+d_{t}-e_{t}-g_{t}\right) \Delta t .
\end{aligned}
$$

(a) Since $\Delta t>0$, if $\left(a_{t}+d_{t}-e_{t}-g_{t}\right)>0$, then $z>z^{\prime}$ and so the initial given F.S. could not be an O.F.S. Thus for any O.F.S., the minimum of $F_{t}$ and $G_{t}$ would have to be zero. 
(b) If $\left(a_{t}+d_{t}-e_{t}-g_{t}\right)=0$ then $z=z^{\prime}$, so if the Initial F.S. Is an O.F.S. then the new F.S. Is also an O.F.S., and has the minimum of the new values of $F_{t}$ and $G_{t}$ equal to zero.

Justification for Observation 3 Given a F.S. to the L.P. for which

$$
\Delta t \equiv \min \left(F_{t}, G_{t}, W_{t}\right)>0 \text {, }
$$

construct new variable values by decreasing $F_{t}, G_{t}$, and $W_{t}$ by $\Delta t$, and leaving other variable values unchanged. It is direct to verify that the new variables provide a F.S. for which the minimum of the new values of $F_{t}, G_{t}$, and $W_{t}$ is zero. Further, if $z$ and $z^{\prime}$ are the initial and new objective function values respectively, then

$$
\begin{aligned}
z-z^{\prime} & =a_{t} F_{t}+d_{t} G_{t}+f_{t} W_{t}-a_{t}\left(F_{t}-\Delta t\right)-d_{t}\left(G_{t}-\Delta t\right)-f_{t}\left(W_{t}-\Delta t\right) \\
& =\left(a_{t}+d_{t}+f_{t}\right) \Delta t .
\end{aligned}
$$

(a) Since $\Delta_{t}>0$, if $\left(a_{t}+d_{t}+f_{t}\right)>0$, then $z>z^{\prime}$ and so the initial given $F . S$. could not be an 0.F.S. Thus for any O.F.S. the minimum of $F_{t}, G_{t}$, and $W_{t}$ would have to be zero.

(b) If $\left(a_{t}+d_{t}+f_{t}\right)=0$ then $z=z^{\prime}$, so if the initial F.S. is an O.F.S. then the new F.S. is also an O.F.S., and one for which the minimum of the new values of $F_{t}, G_{t}$, and $W_{t}$ are zero.

Justification for Observation 4 Given a F.S. to the L.P., add any positive term $\Delta t$ to $Q_{t}, W_{t}$, and $Y_{t}$ to obtain new variable values, while leaving other variable values unchanged. It is direct to verify that the new variables provide a F.S. Further, if $z$ and $z^{\prime}$ denote the initial and new objective function values respectively, then

$$
\begin{aligned}
z-z^{\prime} & =e_{t} Q_{t}+f_{t} W_{t}+g_{t} Y_{t}-\left[e_{t}\left(Q_{t}+\Delta t\right)+f_{t}\left(W_{t}+\Delta t\right)+g_{t}\left(Y_{t}+\Delta t\right)\right] \\
& =-\left(e_{t}+f_{t}+g_{t}\right) \Delta t .
\end{aligned}
$$

Since $\Delta t>0$, if $\left(e_{t}+f_{t}+g_{t}\right)<0$ then $z>z^{\prime}$. Further, $\Delta t$ can be made arbitrarily large, implying that $z^{\prime}$, the new objective function value, can be made arbitrarily small, and hence no O.F.S. to the L.P. exists.

Observation 5 (a) If

$$
e_{t}+f_{t}+g_{t}>0
$$

then, in any optinum feasible solution to the L.P., at least one of the variables $Q_{t}, Y_{t}$, and $W_{t}$ will be zero. That is, it will never be the case that all three of the following events occur simultaneously: energy is supplied to storage; energy is wasted because the storage temperature is at the boiling point of water; energy is lost because energy collection is attempted when there is insufficient radiation. 
(b) If

$$
e_{t}+f_{t}+g_{t}=0
$$

and if there exists an optimum feasible solution to the L.P., then there exists an optimum feasible solution for which at least one of the variables $Q_{t}, Y_{t}$, and $W_{t}$ is zero.

Observation 6 If

$$
a_{t}+d_{t}+f_{t}<0
$$

then the L.P. does not have any optimum feasible solution: the objective function value may be made arbitrarily small.

Observations 5 and 6 are quite similar to Observations 3 and 4 respectively; their justifications are also similar, and so they are omitted.

As a final remark, all these observations are related to finding flow-augmenting paths in network flow optimization problems.

Conclusions from the L.P. Tableau The main conclusion of this section is as follows. If

$$
\beta_{t}+\delta_{t} \geq 0
$$

and/or

$$
\alpha_{t}+\beta_{t}+\delta_{t} \geq 0
$$

and if

$$
\beta_{t} \geq 0
$$

and/or

$$
\alpha_{t}+\beta_{t} \geq 0
$$

then it will never be the case that both $O_{t}$ and $Y_{t}$ are positive in an optimum basic feasible solution. Also, some conclusions are drawn about what the L.P. tableau will look like if both $O_{t}$ and $Y_{t}$ are basic variables in any basic feasible solution, including an optimal basic feasible solution.

Consider the L.P. constraints (1) through (5) for the case when both $D_{t}$ and $Y_{t}$ are in the basis. Note that (3) and (5) completely specify $N_{t}$ and $M_{t}$, so that the constraints of interest reduce to

$$
\left(\begin{array}{rrrrr}
0 & 0 & 1 & 0 & -1 \\
-1 & 0 & -1 & 1 & 0 \\
1 & -1 & 0 & 0 & 0
\end{array}\right)\left(\begin{array}{l}
F_{t} \\
G_{t} \\
Q_{t} \\
W_{t} \\
Y_{t}
\end{array}\right)=\left(\begin{array}{l}
\alpha_{t} \\
\beta_{t} \\
\delta_{t}
\end{array}\right)
$$


We first observe, if $Q_{t}$ and $Y_{t}$ are in the basis, that $W_{t}$ is nonbasic, since

$$
\left(\begin{array}{l}
0 \\
1 \\
0
\end{array}\right)=(-1)\left(\begin{array}{r}
1 \\
-1 \\
0
\end{array}\right)+(-1)\left(\begin{array}{r}
-1 \\
0 \\
0
\end{array}\right)
$$

That is, $Q_{t}, Y_{t}$ and $W_{t}$ are linearly dependent. Thus if $Q_{t}$ and $Y_{t}$ are in the basis, and another variable for time period $t$ is in the basis, it must be either $F_{t}$ or $G_{t}$.

If $F_{t}, Q_{t}$, and $Y_{t}$ are in the basis, the basis matrix and its inverse appear as follows :

$$
B=\left(\begin{array}{rrr}
0 & 1 & -1 \\
-1 & -1 & 0 \\
1 & 0 & 0
\end{array}\right) \& \quad B^{-1} \quad=\left(\begin{array}{rrr}
0 & 0 & 1 \\
0 & -1 & -1 \\
-1 & -1 & -1
\end{array}\right)
$$

(which verifies linear independence). That part of the tableau which is of interest appears as follows:

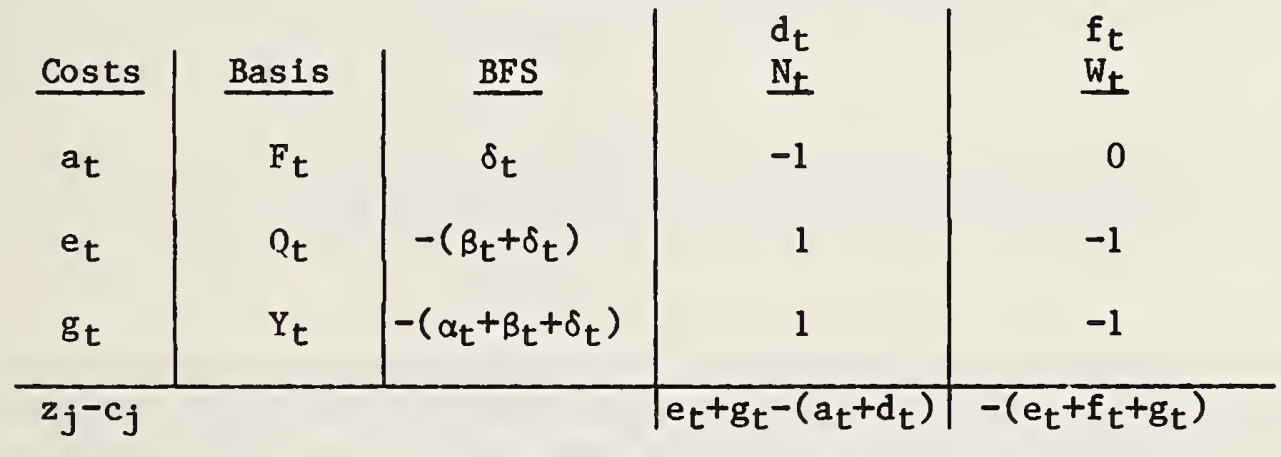

Tableau I

If $G_{t}, Q_{t}$, and $Y_{t}$ are in the basis, we have

$$
B=\begin{array}{rrr}
0 & 1 & -1 \\
0 & -1 & 0 \\
-1 & 0 & 0
\end{array} \quad \& \quad B^{-1} \quad \begin{array}{rlrr}
0 & 0 & -1 \\
0 & -1 & 0 \\
-1 & -1 & 0
\end{array}
$$

(which verifies linear independence). That part of the tableau which is of interest appears as follows:

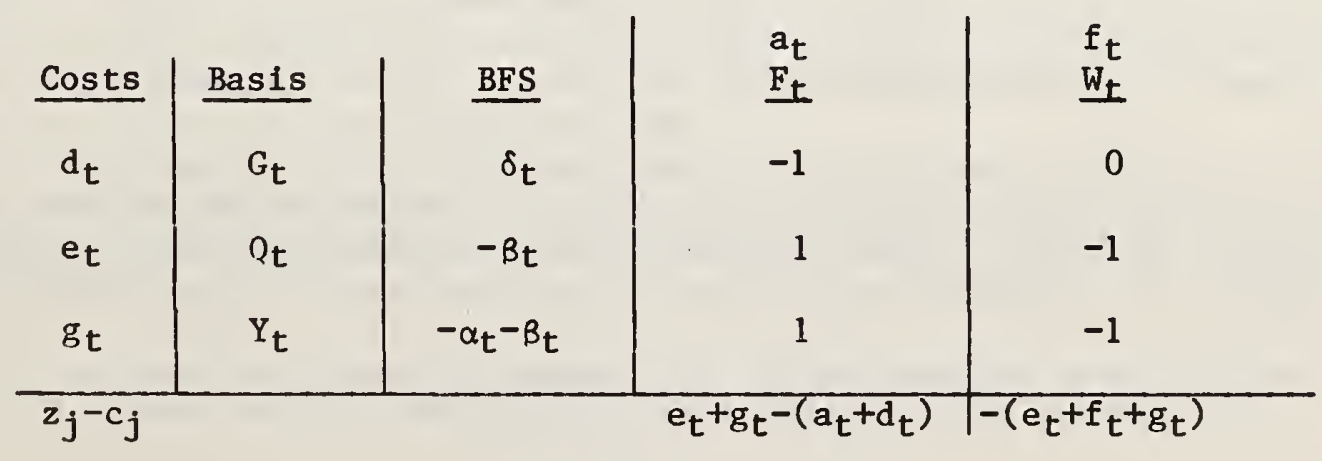


In order for either tableau to specify an optimum basic feasible solution, the reduced costs (the $z_{j}-c_{j}$ ) would have to be nonpositive and the basic variables would have to be nonnegative. Thus, if $F_{t}, O_{t}$, and $Y_{t}$ appear in an optimum basic feasible solution and $Q_{t}$ and $Y_{t}$ are positive, then (from Tableau $I$ ) $\delta_{t} \geq 0$,

$$
\begin{aligned}
& \beta_{t}+\delta_{t}<0 \\
& \alpha_{t}+\beta_{t}+\delta_{t}<0 \\
& e_{t}+g_{t} \leq a_{t}+d_{t} \\
& e_{t}+f_{t}+g_{t} \geq 0 .
\end{aligned}
$$

Likewise, if $G_{t}, Q_{t}$, and $Y_{t}$ appear in an optimum basic feasible solution and $Q_{t}$ and $Y_{t}$ are positive, then (from Tableau II) $\delta_{t} \leq 0$,

$$
\begin{aligned}
& \beta_{t}<0 \\
& \alpha_{t}+\beta_{t}<0 \\
& e_{t}+g_{t} \leq a_{t}+d_{t} \\
& e_{t}+f_{t}+g_{t} \geq 0 .
\end{aligned}
$$

Note that conditions $(A .76)$ and (A.77) are identical to (A.80) and (A.81) respectively, and are in agreement with Observations 2 and 5 respectively. Further, either the conditions (A.74) and (A.75), or (A.78) and (A.79), may prove rather stringent, although avallable data was insufficient to permit checking these conditions.

When we consider the full L.P. (every time period), if $Q_{t}$ and $Y_{t}$ are both positive in an optimum basic feasible solution, and either $F_{t}$ or $G_{t}$ is in the basis, then the foregoing conclusions again apply. If neither $F_{t}$ nor $G_{t}$ is in the optimal basis (which could conceivably occur when more than one time period is considered) then the constraints involving $Q_{t}$ and $Y_{t}$ would reduce to

$$
\begin{aligned}
Q_{t}-Y_{t} & =\alpha_{t} \\
-Q_{t} & =\beta_{t}
\end{aligned}
$$

and thus (A.78) and (A.79) would still hold if both $Q_{t}$ and $Y_{t}$ are positive.

In conclusion, if both $Q_{t}$ and $Y_{t}$ are positive in an optimum basic feasible solution, then either $(A .74)$ and $(A .75)$, or (A.78) and (A.79) must hold. Thus if $(A .74)$ or $(A .75)$ is not true, and $(A .78)$ or $(A .79)$ is not true, then it will never be the case that both $Q_{t}$ and $Y_{t}$ are positive in an optimum basic feasible solution. 


\section{A.8 TEST RESULTS: THE LINEAR PROGRAM COMPARED WITH TRNSYS 1}

McGarity and Revelle used the linear program described in section A. 4 to solve problems in predicting solar heating system performance. In solving these problems, they encountered no situations for which the orthogonal conditions fail to hold. That is, in actual operation of the linear program in a large number of computer runs, the situations in which violations could occur, did not arise.

McGarity and Revelle compared the linear programming solution with results obtained from the simulation program TRNSY [9-A] in the following two problems:

The first problem in performance prediction is for a solar hot water system for a commercial building in Boulder, Colorado, for one week during the month of January. The solar energy system is assumed to have a collector area of $65 \mathrm{~m}^{2}\left(700 \mathrm{ft}^{2}\right)$ and a storage volume of $3,900 \mathrm{l}(1,030 \mathrm{gal}$.$) , and to provide hot$ water at a rate of 3,000l (393 gal.)/day, evenly distributed between the hours of $7: 00 \mathrm{a} . \mathrm{m}$. and $9: 00 \mathrm{p} . \mathrm{m}$. If the temperature in the storage tank falls below $60^{\circ} \mathrm{C}$, additional energy is to be added to the water flowing out of the tank to raise its temperature to $60^{\circ} \mathrm{C}$. The temperature of the storage unit at the beginning of the week is $60^{\circ} \mathrm{C}$.

McGarity and ReVelle solved the linear program in time steps of one hour using the commercially available software linear programing package MPS on an IBM360 computer. They solved the same performance problem with TRNSYS using time steps of one hour or less.

Solution results from the linear program and from TRNSYS for the temperature of storage at end of the day ( $T_{t}$ variable) appear in figure A.5. The two solutions are almost identical.

The second problem in performance prediction is for a solar space and water heating system in a single-family residence. The specified collector area of the system is $50 \mathrm{~m}^{2}\left(538 \mathrm{ft}^{2}\right)$ and the storage volume is $4005 \mathrm{l}(1,058 \mathrm{gal}$.). The space heating load during each hour and the hourly values of solar radiation and outdoor temperature are supplied on weather computer tapes. The linear program is solved with time steps of 24 hours using the software MPS package on an IBM-360 computer. The TRNSYS simulation is used to solve the same problem in time steps of 15 minutes. The linear programming solution for temperatures of storage at the end of a weekly period ( $T_{t}$ variable) is compared with the TRNSYS solution to the same problem in figure A.6. The solutions are for the most part quite similar, but there are small differences, possibly due to the different lengths of time steps used in the two methods -- 15 minutes for TRNSYS and 24 hours for the linear program.

The comparisons demonstrate the accuracy and efficiency of the linear programming method as a prediction tool for studying solar heating performance

1 This section is based on a report prepared by Arthur McGarity and Charles Revelle, of the Johns Hopkins University, under sponsorship of NBS [2-A]. 
characteristics. Dally temperature and insolation data seem adequate for use with the linear programing technique.

In contrast, dally time steps are not generally adequate for a simulation solution. The simulation approach depends on sequential calculations as compared to the simultaneous solutions of the linear program. With time steps as large as one day, it is quite possible that computer iterations of the simulation will take a long time to converge or will not converge at all at each time step to give a solution.

\section{A.9 SUBSEQUENT RESEARCH}

The solar mathematical programming approach has since been extended by McGarity, Revelle, and Cohen [6-A], [7-A]. By employing a hybrid basic descent method, they were able to generate "optimal area-volume paths" describing the cost minimizing combinations of collector area and storage volume for providing different fractions of the heating load.

This multivariate, mathematical programing optimization model, called the "Finite Difference Direct Calculation Method," produces estimates of thermal performance using one time step per day with weather and heating load data averaged over dafly intervals. It was developed through a combination of two other methods: 1) the Direct Calculation Method which solves the nonlinear differential equation associated with the storage energy balance and 2) the Simultaneous Solution Method which uses a modified form of the linear program described in section A.5 to solve descriptive difference equations for all time periods belng considered.

Preliminary results suggest that the optimal area-volume path is quite sensitive to solar equipment cost assumptions, and that it is often desirable to use substantially more storage volume than has been typically suggested in the literature. These preliminary results support the findings of Hooper et al. [1-A] discussed in section A.5. They also support the need for a multivariate optimization approach to solar energy design problems.1

\section{A.10 STOCHASTIC MODELING OF WEATHER VARIABLES 2}

Weather-related parameters are important determinants of a building's energy demand and of the performance of a solar energy heating system. These parameters represent energy flows and temperatures that have a random nature. The intensity of solar radiation, the outdoor temperature, and the windspeed are all subject to fluctuations independent of other performance factors. Their vartability results in variable performance of the solar energy system.

1 For additional work in this area, see $[10-\mathrm{A}],[11-\mathrm{A}],[12-\mathrm{A}]$.

2 The potential for using stochastic modeling of weather variables in conjunction with mathematical programming for solar energy analysis was Investigated by Arthur McGarlty and Charles Revelle of the Johns Hopkins University under sponsorship of the National Bureau of Standards [2-A], and expanded by McGarity and Quadir [13-A] . 
F1gure A.5 Comparison of Performance Test Results for a Commerclal Solar Water Heating System in Boulder, Colorado: Linear Program Versus TRNSYS ${ }^{a}$

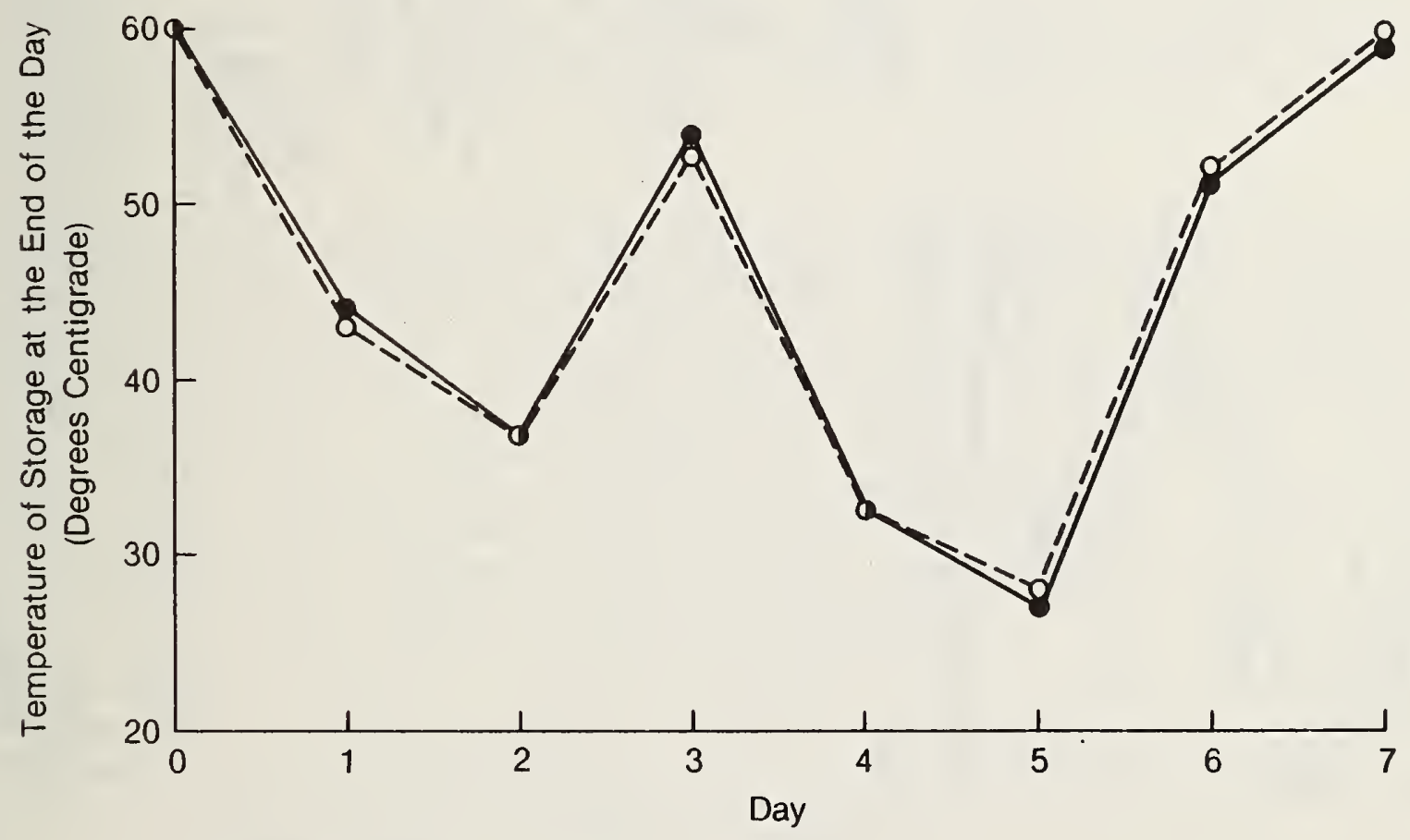

- Linear Program

O TRNSYS

a Linear program and TRNSYS both use hourly time steps in this sample coinparison.

Source: Arthur McGarity and Charles Revelle [2-A]. 
Figure A.6 Comparison of Performance Test Results for a Residential Solar Water and Space Heating System in Madison, Wisconsin: Linear Program Versus TRNSYS

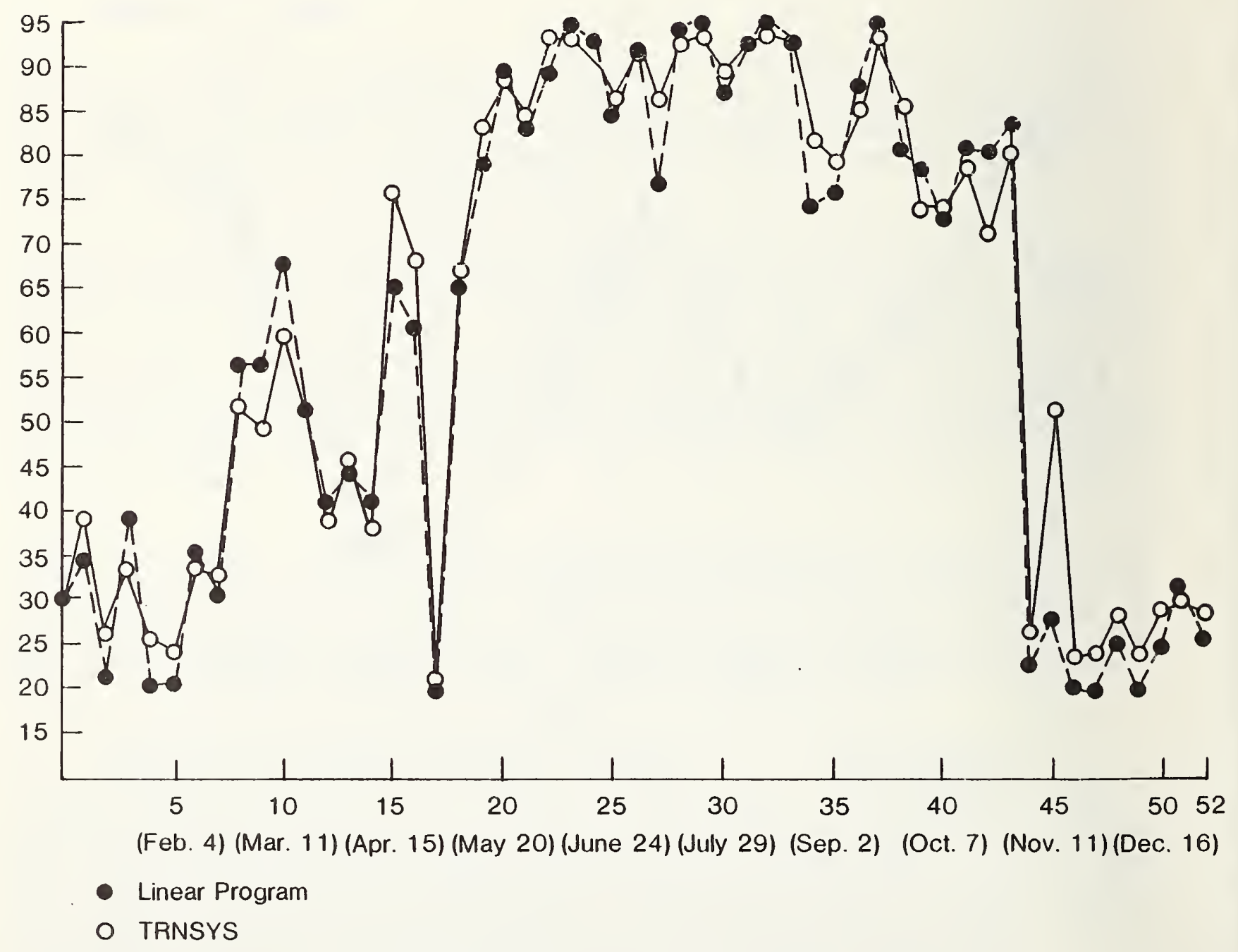

a Linear program uses daily time steps; TRNSYS uses 15-minute time steps. Source: Arthur McGarity and Charles Revelle [2-A]. 
Many of the methods developed for predicting solar performance have used radiation and temperature data that lead to reasonably accurate "average" expected performance figures over a several year period. Liu and Jordan developed general utilizability curves useful in predicting long-term performance of water heating systems utilizing flat plate collectors [14-A]. They used years of monthly meteorological data to construct their curves for predicting long-term average performance. Löf and Tybout used actual data for a single year [4-A], while Klein, Beckman, and Duffie constructed monthly data for an artificial year by choosing months from an 8-year period which reflected average monthly conditions [5-A].

A study of performance during a single year -- real or artificial -- however, provides no information about the year-to-year variability of a particular month's or week's performance. In addition, the data for an artificial year does not allow for serial correlation of weather conditions from one month to the next, a common feature of hydrologic systems that also depend on the weather $[15-\mathrm{A}]$.

These are limitations to using the more traditional weather data methods in predicting solar performance. How important they are depends on the circumstances and objectives of the building owner or system designer. The constructed average-year data seem capable of yielding acceptable average long-term performance predictions. For some building owners, year-to-year variability in monthly performance of a system may not be important if the "average" or "typical" year provides a reasonable estimate of system performance over a number of years. Also, in most cases, the serial correlation of weather values from month to month will likely be small. The serial correlation tends to be small because the performance of a system in one month will not be affected greatly by excess energy in storage at the end of the previous month if storage is sized for periods of only a few days -- and short-term storage is typical. For other building owners, however, it may be important to know how much variation can be expected in the amount of auxiliary fuel that will be required with a solar energy system. This information is likely to be particularly important to owners of commercial buildings who are given relatively low allocation priority if shortages of fuel oil or natural gas occur.

To estimate the probahility that the predicted performance of a solar energy system will occur and to estimate the year-to-year variability in monthly performance, stochastic models of meteorological data are needed. A stochastic model (a statistical model for treating random phenomena) can be developed by applying the methods of time series analysis to recorded observations. The statistical properties of actual meteorological data collected for a number of years can then be used to generate synthetic meteorological data which duplicate the statistical properties of the actual data. These synthetic data then become the weather parameters used in the solar performance model.

Weather data can be separated into two components. The first component is deterministic, representing the long-term characteristics of the weather variable, (i.e., radiation, temperature, or windspeed) in a given geographical region. The second component is stochastic, or unpredictable, reflecting the "dynamic behavior" of long-run weather phenomena resulting from random meteorological events. The first can be described by average values (or means) of 
observations of the same time period for different years. The second can be described by the variance of observations from the average values and by the correlation among sequential observations ("autocorrelation"). For any time period, the stochastic component, $x_{i}$ is given by:

$x_{i}=y_{i}-Y_{i}, i=1,2, \ldots, n$,

where $y_{i}$ is the value of the individual observation,

and $Y_{1}$ is the computed deterministic component.

Several stochastic models of solar radiation are reported in the literature. Goh, Tan, and Brinkworth describe models for long-term insolation forecasting using first-order autoregressive equations that pick up autocorrelation in radiation over two-day periods [16-A, 17-A]. (Autocorrelation over periods greater than two days has been shown to be insignificant.)

A stochastic model of insolation can be used to generate synthetic data for any number of years. However, it is of limited value for analyzing the expected performance of solar heating systems unless synthetic data for the other driving meteorological forces, such as outdoor temperature can also be generated. An important feature of a stochastic model for generating outdoor temperature data is that it must account for the correlation between daily insolation and average daily temperatures.

Additional work is necessary to develop a stochastic model for each of the forces affecting solar heating system performance and building load. Models are needed that incorporate any correlation which may exist among the different driving forces, such as the day-to-day correlation between solar insolation and outdoor temperature, as well as the cross-correlation between the insolation and temperature.

Once a complete stochastic model has been developed, it can be used with solar performance prediction models such as the linear program described above to derive a probability distribution of the thermal performance of a specified solar energy system. The linear programming solar performance model described in section A.4 is particularly suited to the use of stochastic models of solar insolation and temperature. Note that the insolation and outdoor temperature variables all appear on the right side of the constraint equations in the linear program (section A.4). Once an initial solution to the linear program has been obtained for one year of solar energy system operation, results for different years and different values of temperature and radiation data can be obtained with little additional computational effort because the matrices of coefficients from the constraint equations need not be adjusted again either in the hand calculations or computer operation of the simplex method. One can find an initial solution with the original data, modify the right side of the constraint equations, and proceed with the simplex method until a new solution is found.

In addition, the test results reported in section A. 6 show that daily time steps are sufficient when the linear programing method is used for performance 
prediction. This greatly facilitates use of either stochastic models or good average year data. Weather data is available on a dally basis for a large number of clties for several years, and the stochastic models reported in the literature thus far generate daily data.

In contrast, simulation models require the same amount of computation each time they are run and generally require runs for a minimum of hourly, preferably 15minute, time steps. This data is more difficult to obtain from historical files or to generate by a stochastic model.

\section{APPENDIX A - REFERENCES}

1-A Hooper, F. C., Attwater, C. R., et al. Solar Space Heating Systems Using Annual Heat Storage. (Progress Report prepared by the Department of Mechanical Engineering, University of Toronto for the U.S. Department of Energy) NTIS COO/2929-5. Washington, D.C., February 1978.

2-A McGarity, Arthur E. and Revelle, Charles S. "Mathematical Modeling and Optimization in the Design and Economic Analysis of Solar Heating Systems." (Unpublished contractor's report prepared at the Johns Hopkins University for the National Bureau of Standards), December 1977.

3-A Francis, Richard L. "Solar Properties of the solar Energy Linear Program of McGarity and Revelle." (Unpublished paper prepared at the National Bureau of Standards, Center of Applied Mathematics), January 1978.

4-A Löf, G.O.G. and Tybout, R. A.. "Solar House Heating." Natural Resources Journal, Vol. 23, No. 2, April 1970, pp. 268-325.

5-A Klein, S. A.; Beckman, W. A; and Duffie, J. A. "A Design Procedure for Solar Heating Systems." Solar Energy, Vol. 18, pp. 111-127.

6-A McGarity, A. E. "Solar Heating Simulation: Accuracy and Precision of a Model Using Daily Data." SUN II. Proceedings of the 1979 Congress of the International Solar Energy Society. Atlanta, Georgia, May 1979.

7-A McGarity, A. E.; Revelle, C. S.; and Cohen, J. L. "Solar Heating System Performance: Continuous and Finite Difference Solutions for Hourly and Daily Data." Proceedings of Solar Rising. Meeting of the American Section of International Solar Energy Society. Philadelphia, Pennsylvania, May 1981 .

8-A Chiang, Alpha C. Fundamental Methods of Mathematical Economics. 2nd ed. New York: McGraw-H111, Inc., 1974.

9-A TRNSYS - A Transient Simulation Program. Solar Energy Laboratory, Report 38. Madison, Wisconsin: University of Wisconsin, November 1976.

10-A McGarity, A. E. "Optimum Collector Storage Combinations Involving Annual Cycle Storage." Proceedings of the Solar Energy Storage Options Workshop, sponsored by the U.S. Department of Energy, San Antonio, Texas, March 1979. 
11-A McGarity, A. E. and Revelle, C. S. "Solar Energy Optimization: CostMinimizing Collector-Storage Combinations." Proceedings of the International Association of Sclence and Technology for Developinent Symposium on Modelling, Planning and Decision in Energy Systems. Montreux, Switzerland, June 1979.

12-A McGarity, A. E.; Revelle, C. S.; and Cohen, J. L. "Solar Heating Design with a Performance Requirement." Proceedings of Solar Rising. Meeting of the American Section of the International Solar Energy Society, Philadelphia, Pennsylvania, May 1981.

13-A McGarity, A. E., and Quadir, I. Z. "Modeling of Renewable Energy Systems: An Application of Time Series Analysis." Proceedings of the Twelfth Annual Pittsburgh Modeling and Simulation Conference. Pittsburgh, Pennsylvania: Iniversity of Pittsburgh, May 1981 .

14-A Liu, B. Y. H. and Jordan, R. C. "A Rational Procedure for Predicting the Long-Term Average Performance of Flat-Plate Solar Energy Collectors." Solar Energy, Vol. 7, No. 2, 1963, pp. 53-71.

15-A Fiering, M. B. and Jackson, B. B. Synthetic Steam-flows. American Geographical Union Monograph 1, 1971.

16-A Goh, T.N. and Tan, K. J. "Stochastic Modeling and Forecasting of Solar Radiation Data." Solar Energy, Vol . 19, No. 6, 1977, pp. 755-757.

17-A Brinkworth, B. J. "Autocorrelation and Stochastic Modeling of Insolation Sequences." Solar Energy, Vol. 18, 1977, pp. 343-347. 
APPENDIX B. COMPUTER PROGRAM USED TO APPLY THE ECONOMIC EVALUATION MODEL TO SELECTED CASE STUDIES FOR COMBINED SPACE HEATING AND HOT WATER ${ }^{1}$

The computer program, written in BASIC, is designed to analyze the technical and economic performance characterlstics of a specified solar energy system and to search for the size of that system which will minimize life-cycle costs. Environmental data, such as air temperature, ground temperature, and cloud cover, pertalning to the solar energy system's technical performance are incorporated in the computer program. The program calculates iffe-cycle costs with and without the optimally sized solar energy system, the resulting net savings or losses in present value dollars, and the discounted payback period if net savings are positive. If net savings are negative, 1.e., if net losses are estimated for the optimally sized system larger than zero, values of key parameters are calculated which will result in an economic equality between the solar and alternative conventional energy systems. The parameters for which break-even values are calculated (holding other varlables except system size constant in each case) are (1) the initial fuel price, (2) the future rate of escalation in fuel price, and (3) the purchase and installation cost of the solar energy system.

City Data Files. The city specific data used for the case studies are located In 13 individual files within the program. Each file contains for the designated city location the following data: (1) monthly average dally radiation on a horizontal surface, (2) cloudiness index, (3) quarterly ground temperatures, (4) monthly heating load data for each of the four buildings--the new office bullding, the existing office building, the new retall store, and the existing retall store, (5) early-1980 fuel prices, (6) fuel price escalation rates, (7) city-specific labor cost adjustment factor, (8) latitude, angle of collector tilt, and ground reflectance, (9) location-specific tax rates, including state income tax, sales tax, and property tax rates; fuel tax, if applicable; and any state income tax credits. 2

Engineering Data and Assumptions. The total combined energy load to be met is calculated by the program from (1) the space heating load input by the user and (2) the hot water load generated by the program based on user-specified rates of hot water usage, operating schedules, and climate data. The portion of the total load, or of elther of its two components, met by a solar energy system of given design is calculated for a range of system sizes by a subroutine of the

1 The computer programming code listed in this appendix was originally developed by G. Thomas Sav and modified by Joel Levy. It was designed to implement the solar economic evaluation model for combined space heating and service hot water systems presented in section 2.3. This brief description of the program is condensed from a preliminary draft report prepared by Joel Levy. A revised edition of the NBS computer code for evaluating solar energy systems for commercial buildings, and accompanying user's guide, is in preparation under the name "COMSOL."

2 Energy price data stored in the computer files are those given in table 4.7 of the text. 
program based on the LASL solar load ratio method as described in section 4.2 of this report. Monthly insolation values are calculated by the program according to a procedure equivalent to that given by S.A. Klein in his paper "Calculation of Monthly Average Insolation on Tilted Surfaces" [35]. The equipment efficiencies for the conventional and solar energy systems are data inputs.

Economic Data and Assumptions. Four sets of purchase and installation cost data for the solar energy system are contained in the program (1ines 1361013750). There is one for each building type, with each set comprised of fixed cost and variable cost elements for materials and labor.1 (Labor costs are adjusted in the program by the city-specific labor cost adjustment factor.) ${ }^{2}$ Financial parameters include the discount rate, inflation rate, loan rate, downpayment as a proportion of purchase and installation costs, loan life, Federal income tax rate, depreciation allowance, and capital gains tax rate. 3 Both the straight-line and declining balance depreciation methods are programmed. Annually recurring cost is input as a fixed percentage of the initial system cost, and is increased annually at the rate of general price inflation.

Optimization Algorithm. The solar energy system is optimized with respect to the size of the collector area that will minimize total life-cycle costs. The size selection algorithm applies not only when variable costs are linear but also when these costs are any convex function of collector area. 4

1 Cost data for purchasing and installing the solar energy system contained in this program are those given in table 4.3 of the text.

2 Labor cost adjustment factors stored in the city data files are those given in table 4.4 of the text.

3 Data contained in the program for these financial parameters are consistent with that given in section 4.5 of the text.

4 It may be demonstrated as follows that the cost function used to assess solar energy system performance is convex in collector area: the initial purchase and installation cost of a solar energy system is assumed linear in collector area, $\mathrm{i} . e .$, can be expressed as $\mathrm{Kl}+\mathrm{K} 2 \cdot \mathrm{A}$, where $\mathrm{Kl}$ is total fixed cost and $\mathrm{K} 2$ is the coefficient of the variable cost taken as linear in collector area. Interest payments, maintenance costs, taxes and tax exemptions are all linear in the applicable cost base. Letting $F$ denote the fraction of the total heating load met by solar energy, the life-cycle cost of fuel for the conventional system equals (1-F) - (heating load) - K3, where $\mathrm{K} 3$ is a positive constant depending on energy type, prices, tax rates, etc., but not varying with collector area. Similarly the heating load does not depend on collector area and therefore, may be considered a positive constant for present purposes. It may then be shown as follows that $(1-F)$ is convex in collector area:

For each month, $J$, the fraction of the building load in that month met by solar energy, $\mathrm{Z}(\mathrm{J})$, is calculated in SUB2 of the computer program by lines 
5890 thru 5990. Line 5890 defines $L 1=A \cdot\left(\frac{I(J)}{L(J)}\right) \cdot A$, where the term 1 n brackets is a positive constant with respect to A.

If $\mathrm{Ll}<1.2$ then effectively, $Z(J)=A l \cdot \frac{I(J)}{\mathrm{L}(\mathrm{J})} \cdot A$, and so $1-\mathrm{Z}(\mathrm{J})$ is convex as a function of $A$ for $L 1>1.2$.

It remains to check the function $(1-\mathrm{Z}(\mathrm{J}))$ at the point A yielding $\mathrm{L} 1=1.2$.

For $\mathrm{Al}=.318, \mathrm{~A} 2=1.132$, and $\mathrm{A} 3=.504$, (values given in Ines $4191-4193$

of the main program), there is a limit of $1-Z(J)$ as A increases such that

L1 tends to 1.2 as $1-.318 * 1.2=.618$. For $A$ at $L 1=1.2$ there 1 s a 1 imit of $1-\mathrm{Z}(\mathrm{J})$ as $A$ increases such that $\mathrm{L} 1$ tends to 1.2 as $1-.318 * 1.2=.618$. For $A$ at $\mathrm{Ll}=1.2$,

$$
1-. \mathrm{Z}(\mathrm{J})=1.132 \cdot \mathrm{e}-.504 * 1.2=.618 \text {. }
$$

So $1-Z(J)$ is continuous.

The factor of the positive term $\frac{I(J)}{L(J)}$ in the slope of $1-Z(J)$ to the left of $A$ at $\mathrm{L} 1=1.2$ is -.318 . The factor of $\frac{\mathrm{I}(\mathrm{J})}{\mathrm{L}(\mathrm{J})}$ for the right hand derivative at at $\mathrm{A}$ corresponding to $\mathrm{Ll}=1.2$ is:

$$
-(1.132)(.504)^{-1.2 * .504=-.312,}
$$

1.e., at that point the slope of $1-Z(J)$ is greater to the right than it is to the left. Thus for $A>1$ the function $(1-Z(J))$ is convex.

Taking the sum of positive multiples of the convex functions discussed above we find that $11 f e-c y c l e$ cost is a convex function of $A$.

This result that total 1ife-cycle cost of the solar energy system is convex in the collector area is exploited to justify the algorithm used to minimize total life-cycle cost. 
A number of parameters of economic significance independent of collector area are calculated in the program. Using these parameters, the program calculates the total life-cycle cost of a solar energy system with a given collector area. The sequence of steps used in the optimization algorithm employs principles of search techniques to find an extremum of the unimodel function.

\section{Other Economic Evaluation Measures. The payback computation involves} considering initial investment cost, $C_{0}$, and anticipated net return in each subsequent year, $N_{j} j=1 \ldots, k$, where by definition $N_{j}=R_{j}-C_{j}$, and $R_{j}$ is revenue from the candidate investment in year $j$ and $C_{j}$ is the cost of operating the investment in year $j$.

The simple payback period is the first $k$ such that:

$$
\sum_{j=1}^{k} N_{j}-C_{0}>0 .
$$

The measure of discounted payback period formulated in the computer program is designed to overcome two problems: The first problem is that obtaining a positive 1ife-cycle value of an investment does not guarantee that in every year after the investment net return will be positive. Consequently there exists the possibility of a sequence of positive and negative values for the partial sums of discounted returns. The second problem is that the payback measure often does not adequately account for the use of borrowed funds.

To deal with the latter problem, the discounted payback measure used here does not treat future loan payments as an initial cost. Purchases made with borrowed funds are entered as costs at the time the indebtedness is eliminated. If financing terms allow the debt to run to year $t$, then for a year prior to $t$ to be a candidate for the payback year, it is necessary that the sum of discounted net returns be equal to or greater than the discounted value of the remaining unpaid principal on the debt.

Furthermore, if we denote by $U_{k}$ the unpaid balance at end of year $k$, by $D$ the discount rate, and use the simple payback notation above, then the payback year is constrained to the first year $t$ such that

$$
\sum_{j=1}^{k} \underset{(1+D)^{j}}{N_{j}}-\frac{U_{k}}{(1+D)^{k}}-C_{o}>0,
$$

for all $k-t, t+1, \ldots, L$.

If this condition is not met for any year prior to the end of system life, the program prints "cumulative savings first equals cost beyond system Iife." This is a euphemism to state that discounted 11 fe cycle savings do not cover cost of the solar energy system.

If the $11 \mathrm{fe}$-cycle analysis determines that the solar energy system is not cost effective based on input paraneter values, break-even analysis is then performed on the premise that if other variables are held fixed: 
a. for a sufficlently high fuel price in the base year the net life-cycle savings will be positive;

b. for a sufftciently high rate of future increase in fuel prices the net iffe-cycle savings will be positive; or

c. for a sufficiently low system cost the net 1tfe-cycle savings will be positive.

Elrst, the program calculates the minimum value of the base-year fuel price necessary for the system to equal the conventional system in economic performance based on a reoptimization of system size. Next it finds the break-even escalation rate of fuel in terms of how much faster than predicted w111 fuel prices have to rise in order that the solar energy system will just pay for itself, assuining other cost parameters as initially specifled, but again allowing the system size to be reoptimized. It then calculates the factor by which the initially assumed system cost must be multiplied in order for the system, based on a reoptimized size, to be equivalent economically to the conventional system. The break-even system cost factor is the multiplicative inverse of the break-even base-year fuel price factor and the fuel price escalation rate. The optimal collector area and solar fraction for the break-even system costs will be the same as that calculated for the break-even base-year fuel price and the fuel price escalation rate. 1

The computer program consists of a main part, three subroutines and 13 city files. The computer program code is listed below. This is followed by a sample printout of a city file (Boston) in table B-1. Table B-2 shows a sample output of the program, performed for a new office building in Washington, D.C.

Operating The Program. After the program and data files are loaded into the computer, the program is accessed. The user than specifies the city for which the economic efficlency of the solar energy system 1 s to be analyzed, the type of bullding for which the analysis is being conducted, and the conventional fuel that is to yield the energy requirements supplementary to that supplied by solar energy.

This is done by specifying three lines of instruction:

\section{(1) "30 Files ZNFL非"。}

For the last two symbols the relevant number of the city is entered. Numbers identify corresponding cities as follows:

Ø1. Boston, Massachusetts

Ф2. Washington, D.C.

Ø3. Nashville, Tennesseee

1 A variation of this computer program, not included in appendix $B$ was used to evaluate the case studies for hot water only. That version of the program additionally provides for the calculation of breakdown hot water loads. 


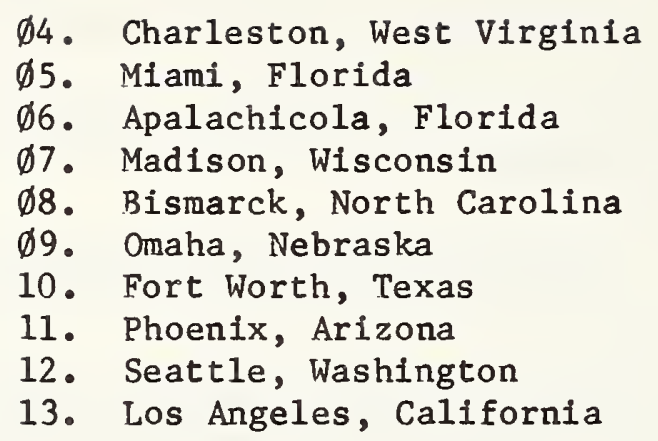

The name of the city for which the analysis has been run is the last item printed on the first line of output information. (Print instruction line 1810).

(2) $" 12404=$ = " .

This line specifies the type of fuel supplying the energy requirements supplemental to and complementary to solar energy for the analysis. The alternatives are:
1. Gas
2. 0 il
3. Electricity

The fuel type specified is reported in the program output in line twelve of the printed output. (Print instruction is line 2110).

(3) $12505=$ = "

The line selects the building type for which the analysis is conducted. Four alternatives can be chosen by setting 05 equal to 1 thru 4. The alternatives. are:

1. New office building

2. Existing office building

3. New retail building

4. Existing retail building.

The type of building for which the analysis has been run is reported in the program output on the first printed line just before the name of the city in which the building is located. (Print instruction line 1810). 


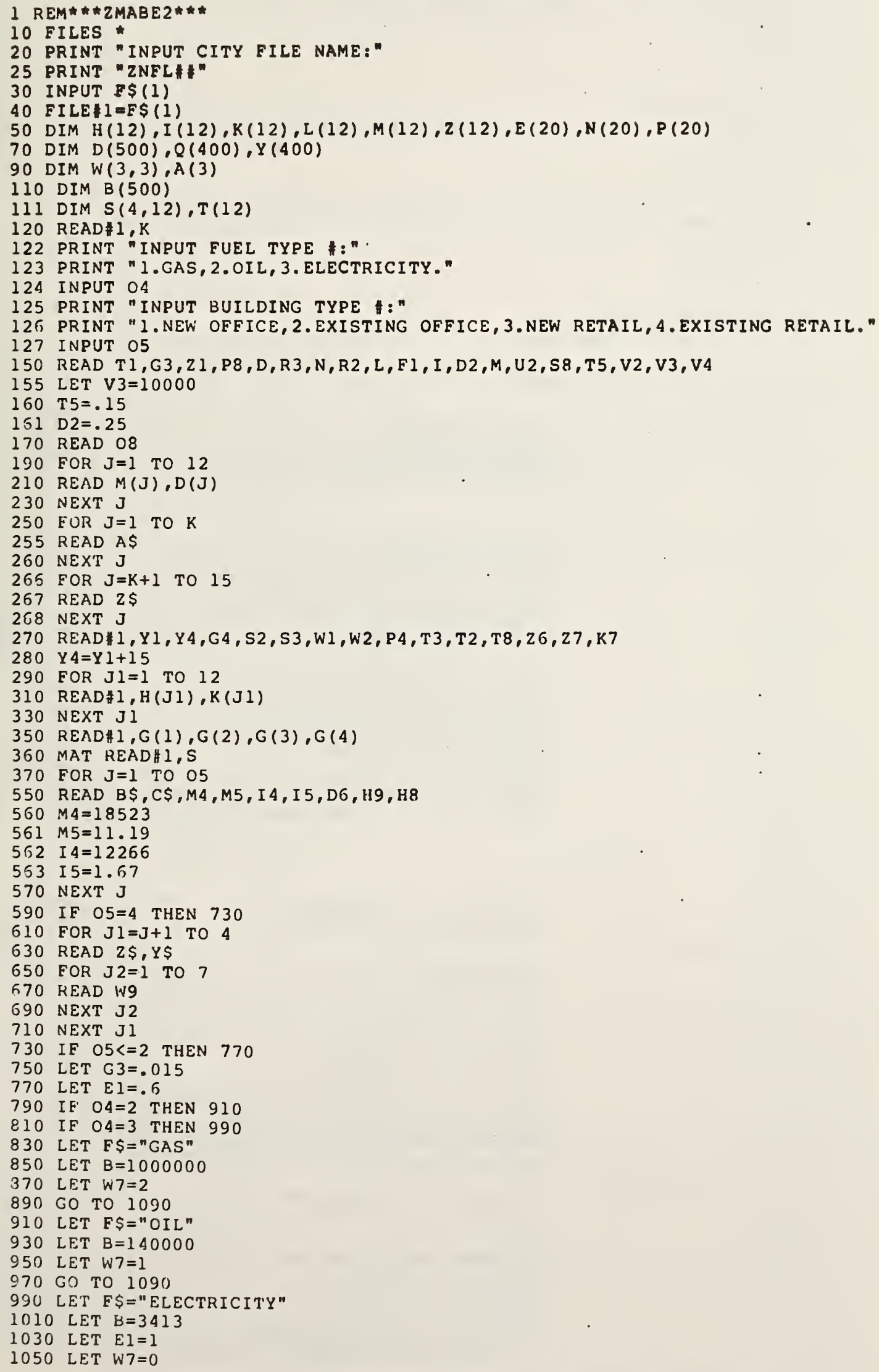


1070 GO TO 1150

1090 IF $B \$=" E X I S T I N G "$ THEN 1150

1130 LET El $=.75$

1150 READ P5

1170 FOR $J=1$ TO PS

$1190 \operatorname{READ} \mathrm{N}(\mathrm{J})$

1210 NEXT J

1230 MAT READ\#1,A

$1250 \mathrm{P} 9=\mathrm{A}(04)$

1370 MAT READH $1, W$

1390 FOR $J=1$ TO P5

$1410 \mathrm{E}(\mathrm{J})=W(04, \mathrm{~J})$

1430 NEXT $J$

$1450 \mathrm{Jl}=(1 / .54) *\left(.72 * \mathrm{l}^{\prime} 2-.18\right)$

1470 READ 1 , A9

1590 LET I $4=I 4 * A .9$

1610 LET I $5=I 5 * A 9$

1630 LET N9 $=1$

1650 LET HI=G3

1670 IFB $\$="$ EXISTING" THEN 1750

1710 LET $\mathrm{I}=.0925$

1810 PRINT "THE FOLLOWING ANALYSIS IS FOR A(N) "B\$,C\$" IN "A\$

1830 PRINT

1850 PRIN'T"

1870 PRINT"

1890 PRINT" "

1910 PRINT"

1930 PRINT

1950 PRINT

1970 PRINT"

1990 PRIN'T"

2010 PIRIN'"

2030 PRINT"

2050 PRINT"

2070 PRINT"

2090 PRINT

2110 PRINT"

2130 PRINT"

2.150 PRINT"

2170 PRINT "

2190 PRINT "

2210 PRINT"

2230 PRINT"

2250 PRINT "

2270 FUR $J=1$ TO P5

2290 PRINT."

2310 NEXT J

2330 PRINT

2350 PRINT"

2370 PRINT" "

2390 IF FI=0 THEN 2470

2410 PRINT"

2430 PRINT"

2450 PRINT"

2470 IE D6=1 THEN 2550

2490 PRINT"

2510 PRINT"

2530 GO TO 2570

2550 PRINT "

2570 PRINT"

2590 PRINT"

2610 PRINT"

2630 IE T' $3=1$ I'HEN 2670

2650 PRINT "

2670 PRINT "

2690 PRINT

2710 PKINT"

2730 PRINT"

2740 PRINT"

2750 PRINT"

2770 PRINT"

2790 PRI:NT"

2810 IF $Z 7=0$ TILEN 2850

2830 PRINT"

LAT ITUDE, DEGREES. ................. "YI

HOT WATER TEMP.,F................ T1

AVERAGE ANNUAL SUPPLY TEMP., F..........

GALLON/MINUTE USE................"G3

FIXED MATERIAL COST, $\ldots \ldots \ldots \ldots \ldots \ldots \ldots \ldots$ VARIABLE MATERIAL COST/SQ/FT/COLL......."M5 FIXED LABOR COST, \$................ IA VARIABLE LABOR COST/SQ/FT/COLL........."I5

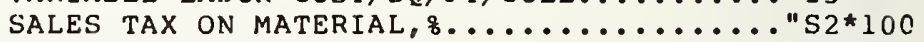

SALES TAX ON LABOR, $3 \ldots \ldots \ldots \ldots \ldots \ldots \ldots \ldots \ldots \ldots+\ldots \ldots$

FUEL TYPE IS "E\$

CONVENTIONAL EQUIP.EFF. ...................... 100 "q"

BTU CONTENT OF FUEL............... B

CURRENT (1978) PRICE PER UNIT, \$......... P9

SALES TAX ON FUEL, $8 \ldots \ldots \ldots \ldots \ldots \ldots \ldots \ldots \ldots \ldots$. W $1 * 100$

SPECIAL FUEL TAX, $8 \ldots \ldots \ldots \ldots \ldots \ldots \ldots \ldots \ldots \ldots$ W $2 * 100$

NUMBER OF FUEL ESICALATION PERIODS. ......." 5

EISCALATION RATES (NOMINAL) \&LENGTH OF PERIODS *

$$
\text { " } E(J), N(J)
$$

DISCOUN'T RATE (NOMINAL), $8 \ldots \ldots \ldots \ldots \ldots \ldots \ldots$......... 100

GENERAL RATE OF INFLATION, $8 \ldots \ldots \ldots \ldots \ldots \ldots$. P $8 * 100$

LOAN INTEREST RATE, $8 \ldots \ldots \ldots \ldots \ldots \ldots \ldots \ldots \ldots$ I* 100

DOWNPAYMENT, $8 \ldots \ldots \ldots \ldots \ldots \ldots \ldots \ldots \ldots \ldots \ldots \ldots \ldots{ }^{*} 2{ }^{\star} 100$

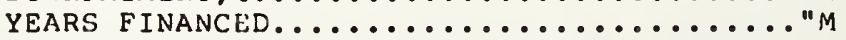

DEPRECIATION METHOD-- -

DECLINING BALANCE RATE, $8 \ldots \ldots \ldots \ldots \ldots \ldots \ldots$ R $3^{*} 100$

DEPRECIATION METHOD---------STRAIGHT LINE"

NUMBER OF DEPRECIATION YEARS.........."N

RECURRING COST RATE, $\%$ OF CONTRACT COST ..."R2*100

PROPERTY TAX RATE, 8 OF CONTRACT COST..... PA* 100

PROPLRTY TAX EXEMPT UNTIL YEAR........."T3

SALVAGE VALUE, 8 OF CONTRACT $\operatorname{cosT} \ldots \ldots \ldots \ldots \ldots$........ $88^{\star} 100$

COMBINED FEDERAL/STATE TAX RTE, $8 \ldots \ldots \ldots . .$. T2*100

FEDERAL TAX RATE, $8 \ldots \ldots \ldots \ldots \ldots \ldots \ldots \ldots \ldots \ldots$. . . $2 \star 100$

EFFECTIVE CAPITAL GAINS TAX RATE, $8 \ldots \ldots \ldots$...... J1*100

FEDERAL TAX CREDIT, $8 \ldots \ldots \ldots \ldots \ldots \ldots \ldots \ldots \ldots$............ $5 * 100$

EFFECTIVE STATE TAX CREDIT, $8 \ldots \ldots \ldots \ldots \ldots \ldots n$ T $8 * 100$

\# OF YEARS STATE CREDIT APPLIES.........

STATE CREDIT IN LIEU OF DEPRECIATION" 
2850 REM

2870 REM CALCULATE HOT WATER LOADS SOLAR RADIATION ON TILTED SURFACE

2890 LET $Q 1=0$

2910 LET L $2=0$

2930 LE' $Q=.017453293$

2970 FOR $J=1$ 'TO $1 ?$

2980 U $5=\operatorname{INT}((\mathrm{J}+2) / 3)$

$3150 \mathrm{~T}(\mathrm{~J})=\mathrm{G} 3 * 60 * \mathrm{H} 9 * \mathrm{H} 8 *(\mathrm{D}(\mathrm{J}) / 7) \star 8.34 *(\mathrm{~T} I-\mathrm{G}(\mathrm{U} 5))$

$3155 \mathrm{~L}(\mathrm{~J})=\mathrm{T}(\mathrm{J})+\mathrm{S}(05, \mathrm{~J}) * 10^{-} \mathrm{G}$

$3170 \operatorname{LET} B(\mathrm{~J})=\mathrm{L}(\mathrm{J})$

3190 LET $L 2=L($, S $)+L 2$

3210 LET $Y 2=23.45 * \operatorname{SIN}(2 * 350 / 365 *(284+M(\mathrm{~J})))$

3230 LET W3=ATN $\left(\operatorname{SQR}(1-(-\operatorname{TAN}(Q * Y 1) \star \operatorname{TAN}(Q * Y 2)) \wedge 2) /\left(-\operatorname{TAN}(Q * Y 1){ }^{*} \operatorname{TAN}((2 * Y 2))\right) / Q\right.$

3235 If $W 3>=0$ 'I'HEN 3250

3240 म $3=43+180$

3250 IF $Y 1 \ll Y 4$ THEN 3310

3270 LET $Y=90$

3290 GO 'I'O 3390

3310 LE' $Y 3=-\operatorname{TAN}(Q *(Y 1-Y 4))$ *TAN $(Q * Y 2)$

3330 LE'I $Y=A T N\left(\operatorname{SQR}\left(1-Y 3^{\wedge} 2\right) / Y 3\right) / Q$

3350 IF $Y>0$ THEN 3390

3370 LET $Y=Y+180$

3390 OY $=2 *$ MIN $(Y, W 3)$

$3430 Y 5=\operatorname{COS}(Q *(Y 1-Y 4)) * \operatorname{COS}(Q * Y 2) * \operatorname{SIN}(O S)+09 * \operatorname{SIN}(Q *(Y 1-Y 4)) * \operatorname{SIN}(Q * Y ?)$

3450 LE'I $Y G=Y 5 /(\operatorname{COS}(Q * Y 1) \star \operatorname{COS}(Q * Y 2) \star \operatorname{SIN}(Q * W 3)+Q * W 3 * \operatorname{SIN}(Q * Y 1) \star \operatorname{SIN}(Q * Y 2))$

3470 LET $Y 5=1.39-4.027 * K(J)+5.531 * K(J) \wedge 2-3.108 * K(J) \wedge 3$

$3490 \operatorname{LET} Y(J)=(1-Y 5) * Y 6+Y 5 *(1+\operatorname{COS}(Q * Y 4)) / 2+K 7 *(1-\operatorname{COS}(Q \star Y 4)) / 2$

$3510 \operatorname{LE} T$ S I $(\mathrm{J})=Y(\mathrm{~J}) * H(\mathrm{~J}) * \mathrm{D}(\mathrm{J})$

3530 NEXT J

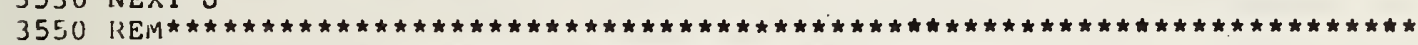

3570 HEM ECONOIIC PARAMETERS INDEPENDENT OF COLLECTOR AREA

3590 LE'T $P 1=((1+D) \wedge M-1) /\left(D^{*}(1+D)^{\wedge} M\right)$

3610 LET P $2=(1+P 8) /(D-P 8)^{\star}\left((1+D)^{\wedge} L-(1+P 8)^{\wedge} L\right) /(1+D)^{\wedge} L$

$3630 \mathrm{LET} R \mathrm{RS}=\mathrm{I} / 12 *(1+\mathrm{I} / 12) \wedge(12 * \mathrm{M}) /\left((1+\mathrm{I} / 12)^{\wedge}(12 * M)-1\right)$

$3650 M 2=(1+I / 12)^{\wedge} 12 *(1+D)^{\wedge} M-(1+I / 12)^{\wedge}(12 * M+12)$

$3670 M 2=112 /((1+D) * M *(1+D-(1+I / 12) \wedge 12))$

$3690 M I=l^{\prime} 2 *(1-D 2) *(12 * R 6 * P 1+(1-12 / I * R G) *(1-1 /(1+I / 12) \wedge 12) \star M 2)$

3710 LET $X=L^{\star}\left(1-S 8^{\wedge}(1 / L) /(1+P Q)\right)$

$3730 P G=(1-((L-X) *(1+P 8) /(L *(1+D))) \wedge(L+1-T 3)) * L *(1+D) /(X+X * P 8-P 8 * L+D * L)$

3750 LET $\mathrm{P} 6=\mathrm{P} 4 *(1-\mathrm{T} 2) *((\mathrm{~L}-\mathrm{X}) *(1+\mathrm{P} 8) /(\mathrm{L} *(1+\mathrm{D}))) \wedge \mathrm{T} 3 * \mathrm{P} 6$

3770 IF $D G=1$ THEN 3850

$3771 D(300)=S 8 /(1+P 8)^{-1} \mathrm{~L}$

$3773 \mathrm{D}(301)=1 /(1-\mathrm{R} 3 / \mathrm{N})$

$3774 \quad D(302)=N-N / R 3+1$

3775 J $2=I N T(N+2-N / R 3)$

3777 IF $\left(\mathrm{J} 2-\mathrm{N} / \mathrm{R} 3 * \mathrm{D}(300) \star \mathrm{D}(301)^{\wedge}(\mathrm{J} 2-1)\right)>=\mathrm{D}(302)$ THEN 3780

3778 J $2=\mathrm{J} 2+1$

3779 GO TO 3777

$3780 \mathrm{~N} 2=1 /(1+D)$

$3785 \mathrm{~N} 1=(1-\mathrm{R} 3 / \mathrm{N}) \star \mathrm{N} 2$

$3789 \mathrm{Dl}=\left(1-\mathrm{N} 1^{\wedge}(\mathrm{J} 2-1)\right) /(1-\mathrm{N} 1)$

$3792 \mathrm{Dl}=(\mathrm{R} 3 / \mathrm{N}) \star \mathrm{N} 2 * \mathrm{D} 1$

$3795 N 3=(D(301) \wedge(1-J 2)-D(300)) /(N+1-J 3)$

$3800 \mathrm{~N} 3=\mathrm{N} 3^{*}(\mathrm{~N} 2 \wedge \mathrm{J} 2) *(1-\mathrm{N} 2 \wedge(\mathrm{N}+1-\mathrm{J} 2)) /.(1-\mathrm{N} 2)$

$3810 \mathrm{Dl}=\mathrm{T} 2 *(\mathrm{D} 1+\mathrm{N} 3)$

3830 GO $T O 3890$

3850 LET DI $=\mathrm{T} 2 / \mathrm{N} *\left((1+D)^{\wedge} \mathrm{N}-1\right) /\left(D^{*}(1+D)^{\wedge} \mathrm{N}\right)$

$3870 \mathrm{Dl}=\mathrm{D} 1^{\star}\left(1-\mathrm{S} 8 /(1+\mathrm{P} 8)^{\wedge} \mathrm{L}\right)$

3890 LET $\times 2=\mathrm{D} 2+(1-\mathrm{D} 2) * 12 * \mathrm{R} 6 * \mathrm{P} 1$

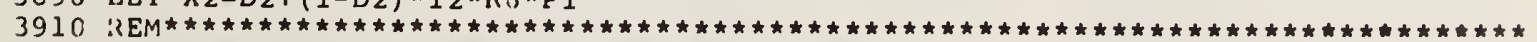

3930 REM PVFFOR P5 FUEL ESCALATION PERIODS IN L

3950 LET $Q 2=1$

3970 LET P3=0

$3 \operatorname{Sin}()$ FOR $J=1$ TO $P 5$

4010 [E E (J) $=$ D THEN 4070

4030 LET $P(J)=Q 2 *(1+E(J)) /(D-E(J)) *\left((1+D)^{\wedge} N(J)-(1+E(J))^{\wedge} N(J)\right) /(1+D)^{\wedge} N(J)$

4050 GO TO 4090

$4070 \quad \mathrm{P}(\mathrm{J})=02 \star \mathrm{N}(\mathrm{J})$

4090 LET $P 3=P(J)+P 3$

4110 LET $Q 2=Q 2 *((1+E(J)) /(1+D))^{\wedge} N(J)$ 
4130 NEXT J

4150 LET $X 1=P 3 * P 9 *(1+W 1) *(1+W 2) /(E 1 * B)$

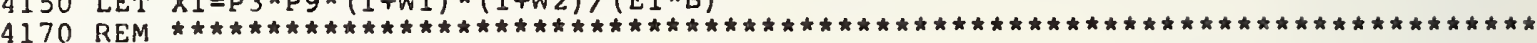

4190 REM SELECT PERFORMANCE PARAMETERS

4191 LET $A I=.318$

4192 LE'T A2 $=1.132$

4193 LET $A 3=.504$

4194 CO TO 4910

4210 ON Z1 GO TO $4250,47.10,4830$

4230 REM DIFE. TEMP. FOR 2 CLAZINGS, NONSECTIVE

4250 ON $(\mathrm{Tl}-1 \mathrm{l} 0) / 20+1$ CO TO $4290,4390,4490,4590$

4270 KEM TEMP $110 \mathrm{~F}$

4290 LET Al $=.508$

4310 LE'T A2 $=1.153$

4330 LET A $3=.933$

4350 GO TO 4910

4370 REM TEMP $130 \mathrm{~F}$

4390 LET $A 1=.499$

4410 LE' A2 $=1.08$

4430 LET $A 3=.729$

4450 CO TO 4910

1470 REM TEMP $150 \mathrm{~F}$

4490 ()E'T $A 1=.44$

4510 LET $\wedge 2=.978$

1530 LET $A 3=.514$

4550 CO TO 4910

1570 RE'N TEMP $=170 \mathrm{~F}$

4590 LET $A 1=.343$

4610 LET $A 2=. \subseteq 66$

4530 LET $A 3=.355$

4650 CO TO 4910

4570 REM DIFE. COLLECTOR TYPES FOR TEMP $=110 \mathrm{~F}$

4690 REM ONE CLAZINC, SELECTIVE

4710 LET $A . l=.568$

4730 LET A2=1.165

4750 LET $A .3=.945$

4770 CO TO 4910

4790 RE $\mid$ | TW TWO CLAZ [NG, NONSELECTIVE: SEE TEMP=1 $10 \mathrm{~F}$

4210 REM ONE CLAZING, NONSELECTIVE

4830 LET $A I=.503$

4850 LET $A 2=1.081$

4870 LET $A 3=.748$

4890 REM

4910 $D(150)=X 1$

$5010 \quad D(304)=M 4$

$5030 \mathrm{D}(305)=M 5$

$5050 \quad D(314)=I 4$

$5070 \mathrm{D}(315)=I 5$

5760 CALL ZOPTI

3430 PRINT

8450 I H' $F 4=1$ THE'N 3830

3470 PRE

8490 PRINT

8510 HKINT

$8530:$ MON'W

$8550:$

2570:

HOR. INSOL. A.V.DAILY BTU/E'2

3590 -PKINT USINC 85.30 .

3610 PRINT USINC E550,

8.530 PRINT USINC 8570 ,

3650 PRIN'T

$8570: \#$ : H \#

8690 FOIR $\mathrm{J}=1$ TO

8710 PRINT USING $8570, J, H(J), Y(J), I(J), L(J) \times 10^{\wedge} 6, Z(J)$

$8730 \mathrm{NEXT} \mathrm{J}$

8750: ANIUAL LOAD

8770: LOAD NIET EY SOLAR

8790 PKINT USINC $8750, L 2$

8810 PRIN'T USINC $8770, \mathrm{~S} 1$

8830 PRINT

8850 ['RINT

8990 PRIN'T
CORR.

FACTOR

$(R-B A R)$
MO. INSOL. $T I L T=L+15$ BTU/FT2
SPACE HEAT.

+HOT WAT. LOAD

BTU/10^5
FRACTION

MET BY

SOLAR 


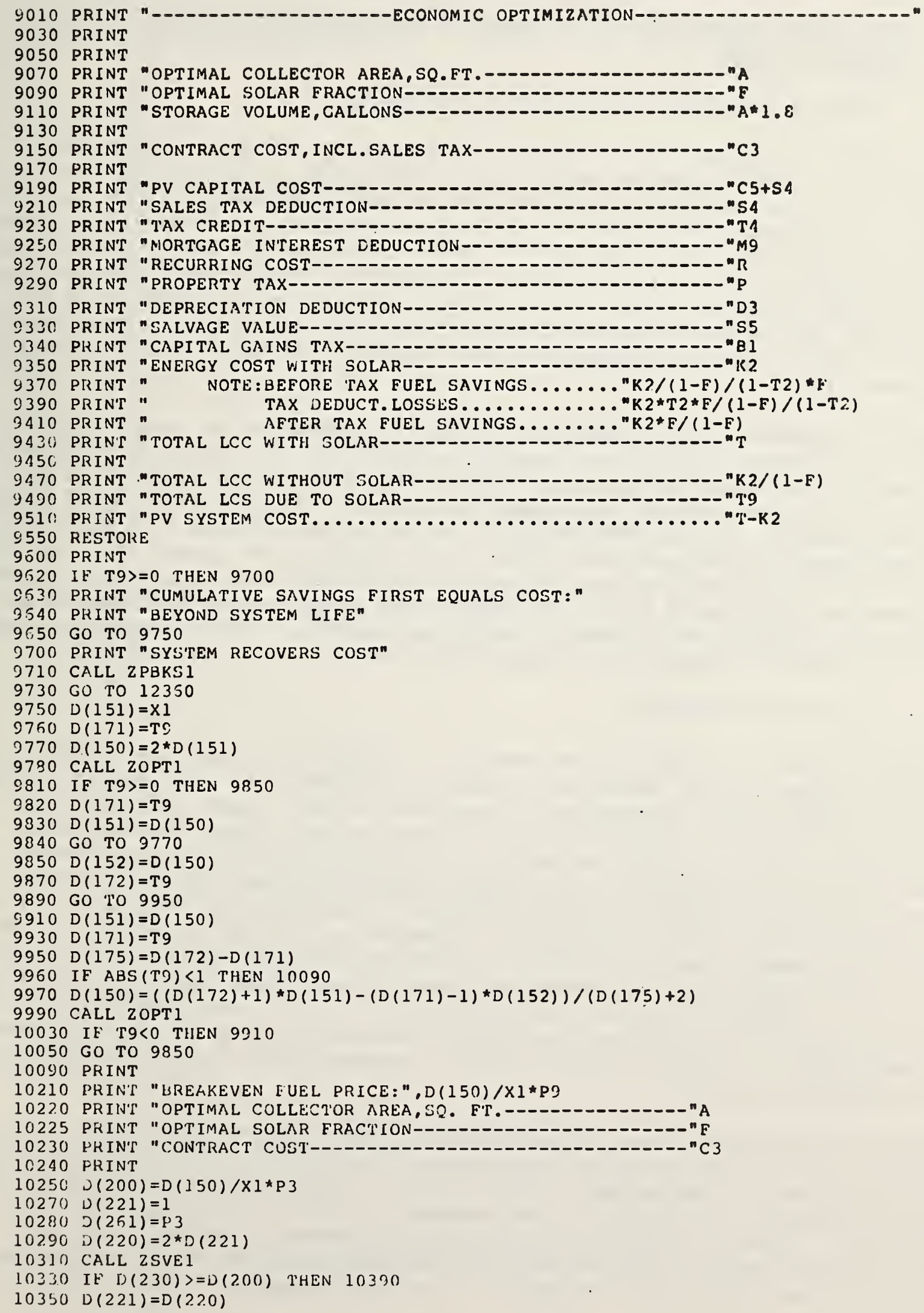




\subsection{CASE STUDY RESULTS FOR SOLAR COMBINED SPACE HEATING AND SERVICE WATER HEATING SYSTEMS}

\subsubsection{Results Compared for Two Sets of Assumptions}

The economic analyses of the combined space heating/hot water systems were Lnicialiy perforned based on energy price projections of early-1980, given in table 4.7. A substantial upward revision in base-year energy prices, particularly for oil, was made by DoE in mid-1980, reflecting the faster-than-projected short-run escalation in oil prices in 1980. Additionally, the Federal energy investment tax credit was raised from 10 percent to 15 percent. Selected case studies were repeated based on the revised energy price estimates given in table 4.8, and on the 15 percent Federal investment tax credit. Comparisons of the two sets of results demonstrates the volatility of solar economic feasibility over time.

Table 5.7 summarizes key measures of economic performance for four cities (col, 1) and three conventional energy sources (col. 2). The results shown in columns 3-5 are based on the early-1980 energy price projections (table 4.7) and the 10 percent. Federal investment tax credit. The results shown in columns 6-8 are based on the mid-1980 energy price projections (table 4.8) and the 15 percent Federal investment tax credit. The estimated net losses over the life cycle were considerably reduced by use of the revised data, and near break-even outcomes were estimated for the combined solar energy system in Bismarck and Phoenix as compared with electric resistance heating. (The estimated net losses Eor the other case studies were larger than those given in table 5.7).

\subsubsection{Break-even Analysis}

Tables 5.8 and 5.9 summarlze the results of a break-even analysis performed for initial energy prices, energy price escalation rates, and solar energy systems costs, holding other assumptions at base-case values. Table 5.8 gives the estimated break-even prices per unit of the nonsolar fuels. These are the initial prices of the Euels necessary to cause solar energy to be minimally cost effective, assuming that the initial prices will escalate at the rates forecasted in early 1980. It shows in col. 2, for example, that ofl would have to cost $\$ 1.55$ per gallon $(\$ 0.41 / \ell)$ in Bismarck in the base year (as compared with the assumed price of $\$ 0.788$ per gallon $(\$ 0.21 / \ell)$ in early 1980) in order for solar energy to be cost effective, other things being equal. It shows in col. 3, for example, that the estimated price of oil in early 1980 would have to escalate 1.82 times faster over the 20 year study period than was projected in early 1980 in order for solar energy to become cost effective in Bismarck in comparison with oil.

Table 5.9 indicates in col. 4 the estimated break-even value for solar energy system costs, given the other assumptions of early 1980. The break-even values are indicated as a percentage of the base-case system costs calculated according to the equations in table 4.3. For example, for the solar energy system to broak even relative to an oil-fired systen in Bismarck, the optimally sized solar energy system could cost no more than about half the amount estimated by table 4.3 cost equations. Relative to electric resistance heating (lower part 
1 REM***ZOPT $1 *$ *

$5760 B(2.98)=1$

$5775 B(299)=20000$

$5777 B(295)=B(299)-B(298)$

$5780 B(300)=B(298)+I N T(.45 * B(295))$

$5785 B(301)=B(298)+I N T(.55 \star B(295))$

5787 IE $B(295)<25$ THEN 7000

$5790 \quad A=B(300)$

5800 CALL ZSBEl

$5810 \quad B(200)=T$

$5820 \quad A=B(301)$

5830 CALL ZSBEI

$5840 \quad B(201)=T$

5900 IF $B(200)>B(201)$ THEN 6100

$5910 \quad B(2.99)=B(301)$

5920 GO TO 5777

$6100 \quad \mathrm{~B}(298)=\mathrm{B}(300)$

6110 GO TO 5777

$7000 \quad A=B(298)$

7010 CALL ZSBEI

$7020 \mathrm{~B}(250)=\mathrm{T}$

7050 FOR $B 9=B(298)$ TO $B(299)$

$7060 \quad \mathrm{~A}=\mathrm{B} 9+1$

7070 CALL ZSBEI

7080 IF $B(250)<=T$ T'HEN 7150

$7090 \quad B(250)=T$

7100 NEXT B9

$7150 \quad A=B 9$

7160 CALL ZSBEl

7230 T $9=K 2 /(1-F)-T$

7250 RETURN

14170 END

$1 \mathrm{REM} *$ * $2 \mathrm{PBKSI}$ * * *

30 FOR $B 9=1$ TO 7

$70 \mathrm{D}(300+\mathrm{B} 9)=0$

110 NEXT B9

$150 \quad \mathrm{D}(400)=\mathrm{T} 9$

$190 \mathrm{D}(399)=\mathrm{L}$

$230 \mathrm{D}(400)=\mathrm{D}(400)-55+\mathrm{B} 1$

$270 \mathrm{D}(301)=\mathrm{P} 9 *(1+W 1)$ * $(1+W 2) * L 2 /(E 1 * B)$

310 Q $2=1$

350 FOR $B 9=1$ TO P5

$39022=Q 2$ * $((1+E(B 9)) /(1+D))^{\wedge} N(B 9)$

430 NEX'T B9

$470 \mathrm{D}(301)=(1-T 2) * F * D(301) * Q 2$

510 IF $M<L$ THEN 710

$550 \mathrm{D}(302)=-(1-\mathrm{D} 2) \star 12 * R 6 * C 3 /(1+D){ }^{\star} L$

$590 \mathrm{D}(303)=(1+I / 12)^{\wedge}(12 \star L)-(1+I / 12) \wedge(12 \star L-12)$

$630 \mathrm{D}(303)=(\mathrm{D}(303) *(1-\mathrm{R} 6 * 12 / \mathrm{I})+12 * \mathrm{R} 6) /(1+\mathrm{D}) \star \mathrm{L}$

$670 \mathrm{D}(303)=\mathrm{T} 2 * \mathrm{D}(303) *(1-\mathrm{D} 2) * \mathrm{C} 3$

710 GO TO 750

$750 \mathrm{D}(305)=-(1-\mathrm{T} 2) * \mathrm{C} 3 * \mathrm{R} 2 *((1+\mathrm{P} 8) /(1+\mathrm{D}))^{\wedge} \mathrm{L}$

780 IF T3>D(399) THEN 830

$790 \mathrm{D}(306)=-(1-\mathrm{T} 2) * \mathrm{P} 4 * \mathrm{C} 3 * \mathrm{~S} 8 /(1+\mathrm{D})^{\wedge} \mathrm{L}$

830 IF $N<L$ THEN 870

870 FOR B $9=1$ TO 7

$910 \mathrm{D}(400)=\mathrm{D}(400)-\mathrm{D}(300+\mathrm{B} 9)$

950 NEX'T B9

$990 \mathrm{D}(401)=\mathrm{D}(400)$

1030 IF $M \angle D(399)$ THE'N 1190

$1070 \mathrm{D}(401)=((1+\mathrm{I} / 12) \wedge(12 * \mathrm{~L}-12) *(1-\mathrm{R} 6 * 12 / \mathrm{I})+\mathrm{R} 6 * 12 / \mathrm{I})$

$1110 \mathrm{D}(401)=(1-\mathrm{D} 2) * \mathrm{D}(401) /(1+\mathrm{D}) \wedge(\mathrm{L}-1)$

$1150 \mathrm{D}(401)=\mathrm{D}(400)-\mathrm{D}(401) * \mathrm{C} 3$

1190 IF $D(401)<0$ THEN 11000

1230 FUR $B 9=1$ TO $(L-1)$

$1270 \partial(399)=\mathrm{D}(399)-1$

$1310 \bigcirc(300)=3$

1350 IF $D(399)>=N(1)+N(2)$ THEN 1510

$1390 \quad 0(300)=2$

1430 IF $D(399)>=N(1)$ THEN 1510

$1470 Q(300)=1$ 


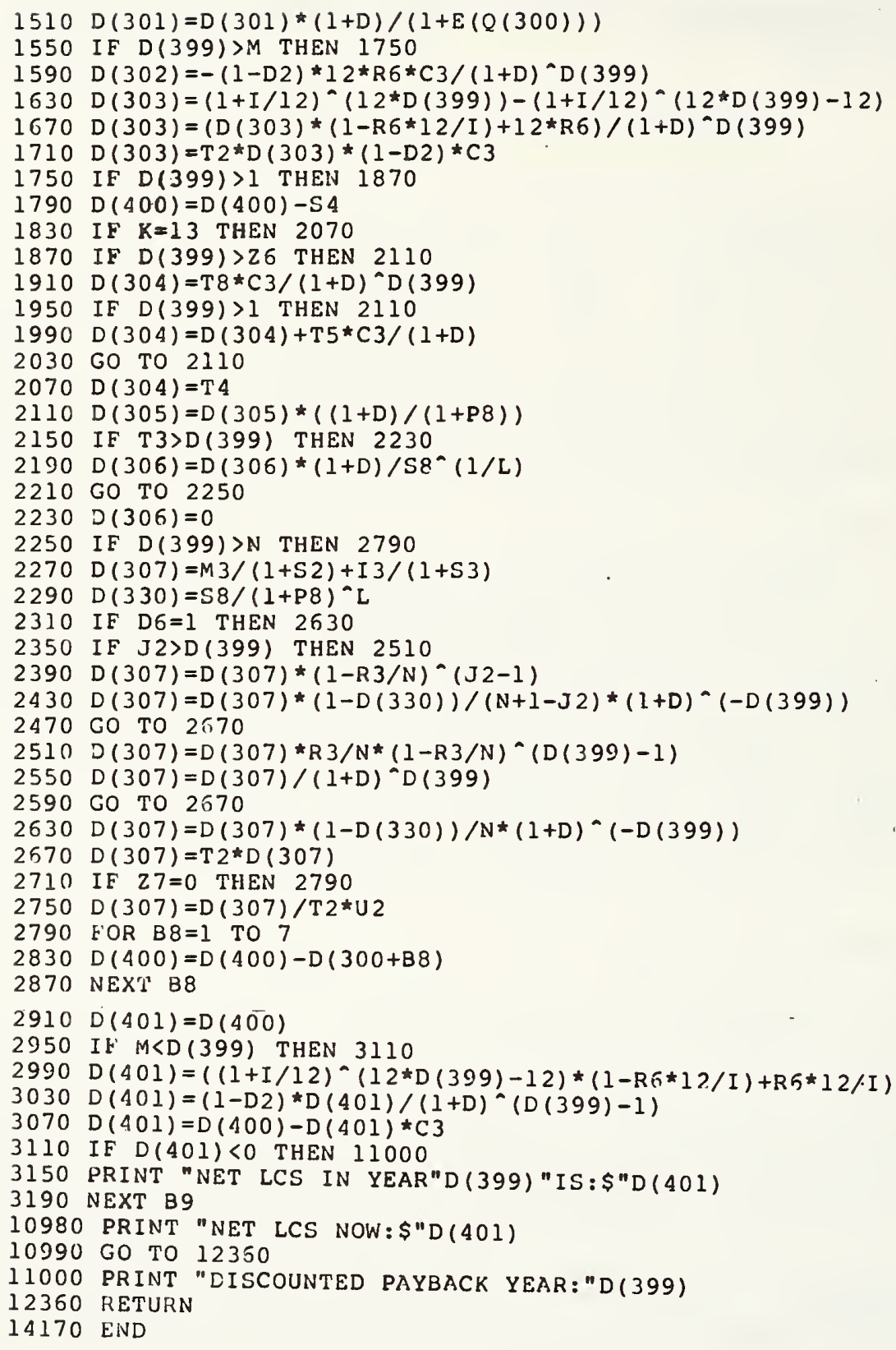




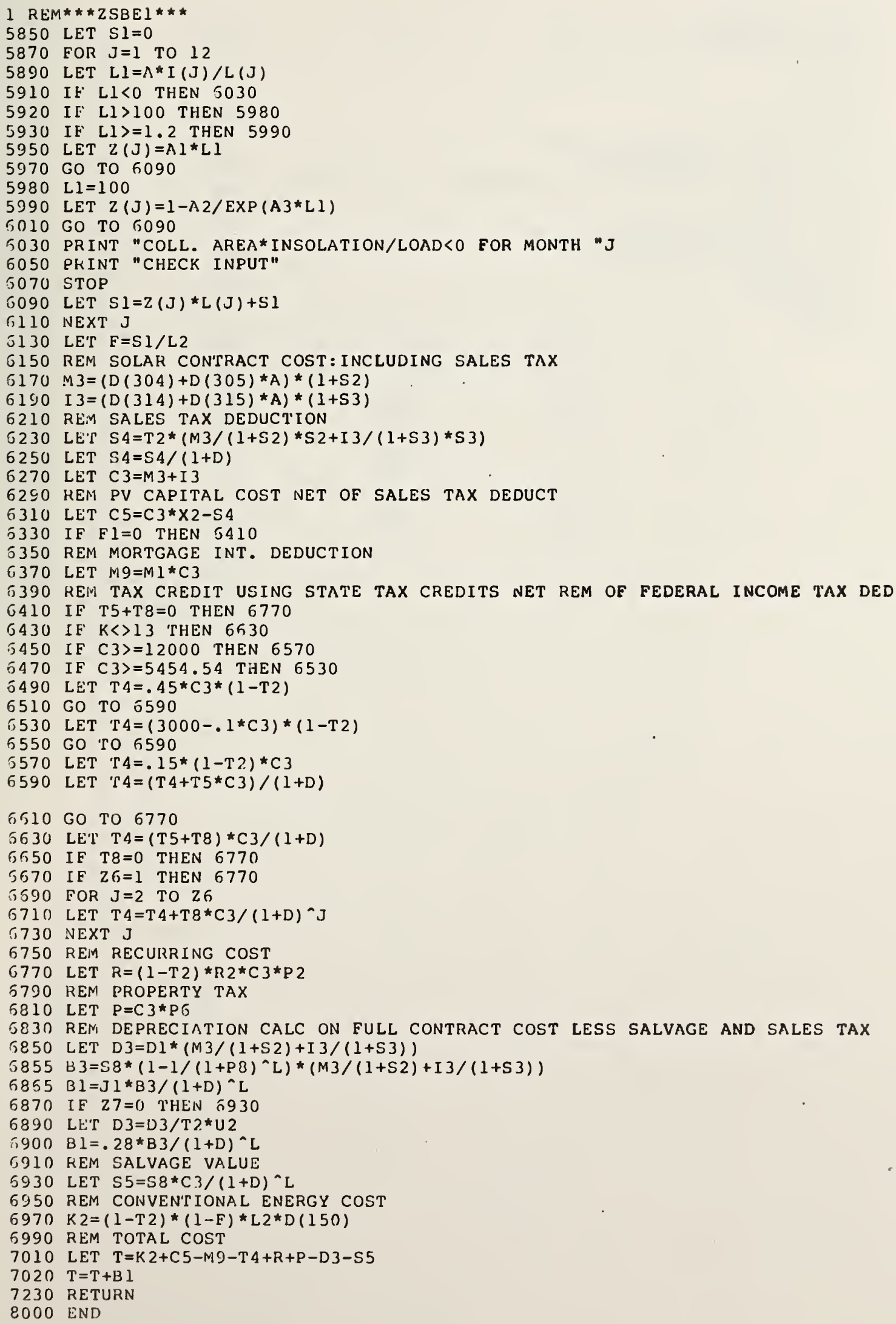


COMPUTER PROGRAM LISTING - (CONTINUED)

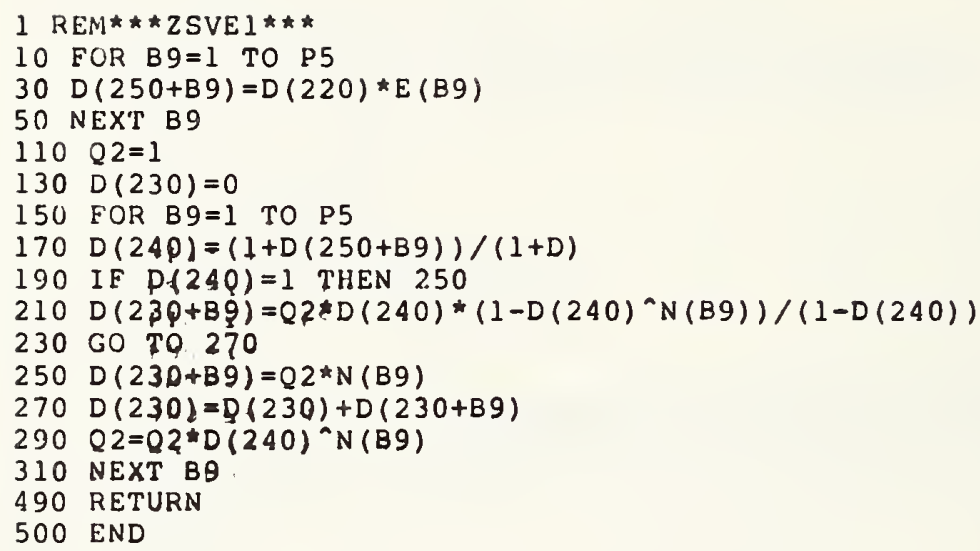




\begin{tabular}{|c|c|c|c|c|c|c|}
\hline 100 & 42.4 & 47.4 & & 49 & .05 & 0 \\
\hline 110 & 0 & 0 & & .126 & 11 & .513 \\
\hline $\begin{array}{l}120 \\
130\end{array}$ & $\begin{array}{l}.051 \\
505.5\end{array}$ & 14 & & 1 & .2 & \\
\hline 140 & 738 & .426 & & & & \\
\hline $\begin{array}{l}150 \\
160\end{array}$ & $\begin{array}{l}1057.1 \\
1355\end{array}$ & $\begin{array}{l}.445 \\
.438\end{array}$ & & & & \\
\hline 170 & 1769 & .499 & & & & \\
\hline 180 & 1864 & .495 & & & & \\
\hline 190 & 1860.5 & .507 & & & & \\
\hline 200 & 1570.1 & .48 & & & & \\
\hline 210 & 1267.5 & .477 & & & & \\
\hline 220 & 895.7 & .453 & & & & \\
\hline 230 & 635.8 & .372 & & & & \\
\hline 240 & 442.8 & .4 & & & & \\
\hline 250 & 41 & 41 & & 58 & 54 & \\
\hline 260 & 135.8 & 118 & 95.3 & 29.5 & 10.5 & \\
\hline 270 & 3.4 & 5.2 & 3 & 8. 6. & 27.2 & \\
\hline 280 & 53.4 & 112.7 & & & & \\
\hline 290 & 601.9 & 539 & & 5.39 .3 & 385.7 & 330.2 \\
\hline 300 & 177.9 & 180.4 & & 160 & 260.5 & 376 \\
\hline 310 & 462.3 & 575.1 & & & & \\
\hline 320 & 50.3 & 44 & & 39.8 & 17.7 & 6.6 \\
\hline 330 & 1.7 & 2 & & .8 & 4.4 & 14.4 \\
\hline 340 & 23 & 44.4 & & & & \\
\hline 350 & 147.2 & 131.2 & & 124.7 & 84.1 & 72.3 \\
\hline 360 & 48.5 & 48.9 & & 46 & 60.4 & 80.9 \\
\hline 370 & 99.5 & 136.8 & & & & \\
\hline 400 & 4.12 .953 & .089 & & & & \\
\hline 410 & .079 .101 & .083 & & & & \\
\hline 420 & .096 .091 & .103 & & & & \\
\hline 430 & .050 .058 & .022 & & & & \\
\hline 500 & 1.04 & & & & & \\
\hline
\end{tabular}


LFT I TIIIE, IIEIFFEES . . . . . . . . . . . . . .

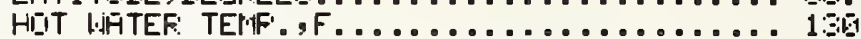
FUEFIFIE FHINUIFL SIIFFLY TEMF, ,F........ TG

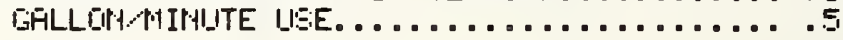

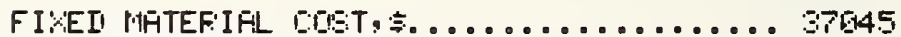
UAFIAELE MATEFIFL COST GOFT,CLLL....... FIXEI LAEDOF DIST ;

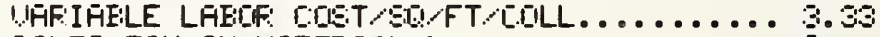
BFLES TAX GN WFTEFIFL $\% \ldots \ldots \ldots \ldots \ldots \ldots$ FIIEL TYFE IS: DIL

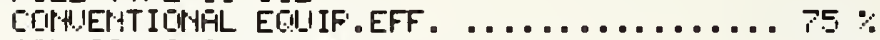

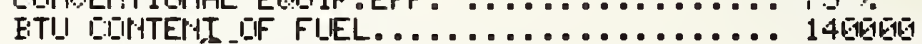

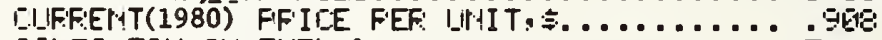

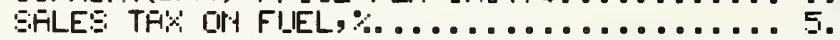
SFELIFL FUEL THY,

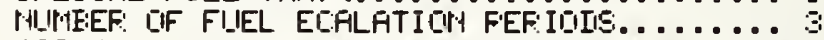

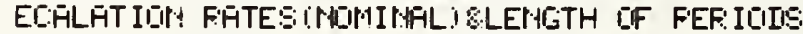

$$
.096
$$

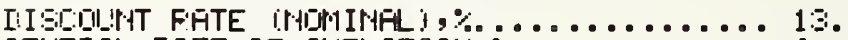

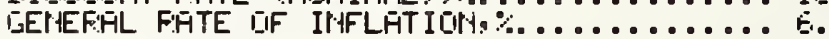
LIIFH IITTEFEST FITTE,...............

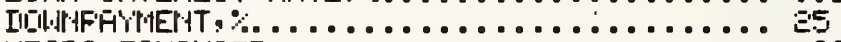

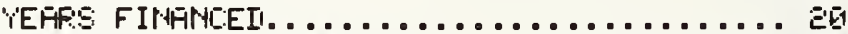
IEFFEL:IHTIOHA NETHOII-

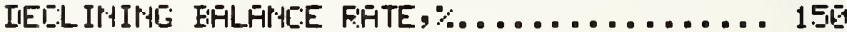

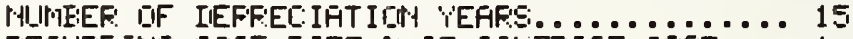

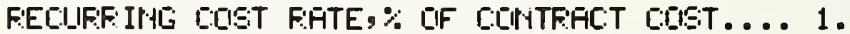

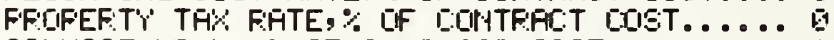

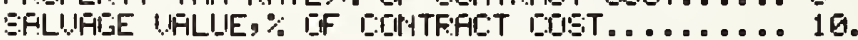

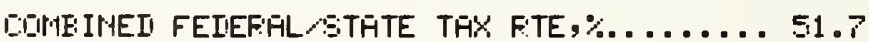

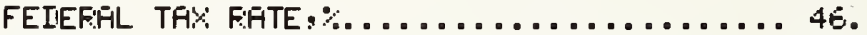

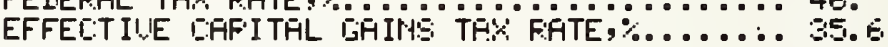

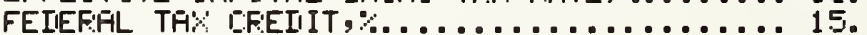
EFFECT IUE STRTE THY LEEIIT, ............. 1.9 \# IF YEAFE STHTE E.FEIIIT FFFLIES.......... STATE CFEIIT IN LIEU OF IEFFECIATICIN

THEFMAL HHALYSIS-

MIITH HLFE. IHAEIIL. HIU. IIHIL $\because$ E:TIIPTE

$\begin{array}{rl}1 & 11 \\ 5 & 1 \\ 4 & 1 \\ 5 & \end{array}$

F:IEF:F: FFETTE: (F:-E:F:?

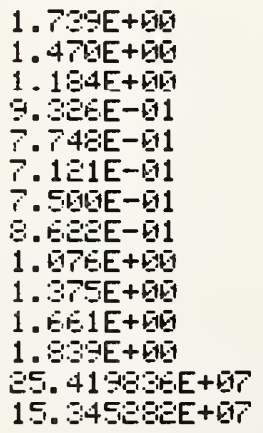

$$
\begin{aligned}
& \text { MII. IHEOIL. } \\
& \text { TILT=L+15: } \\
& \text { ETIIIFTE }
\end{aligned}
$$

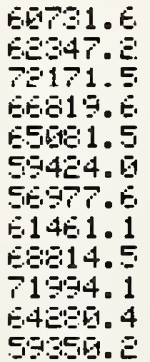

EF'ALE: HEAT. +HIIT WIHT. LEIFII ETLI IETE.

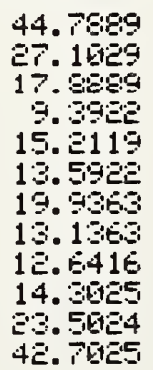

44. 7989 7 . 1 룰ㄹ 9.390 3.59 19.935 13.13 4. 305

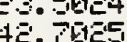

FFEII:TIOHA MET E'Y EILLF:

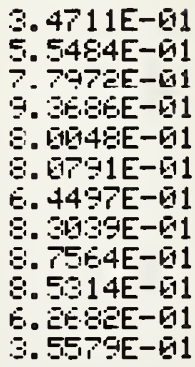

3. $4711 \mathrm{E}-\mathrm{E} 1$ 5. 5484E- 1 E'E- -1 6. $104 \mathrm{~B} E-01$ G. $071 \mathrm{E}-\mathrm{G}$ E. $44 \% \overline{C E}-\overline{1}$

G.

- $514 \mathrm{E}-\mathrm{E} 1$ E. EFE- GI 3. $55.7 \mathrm{E}-\mathrm{E} 1$ 


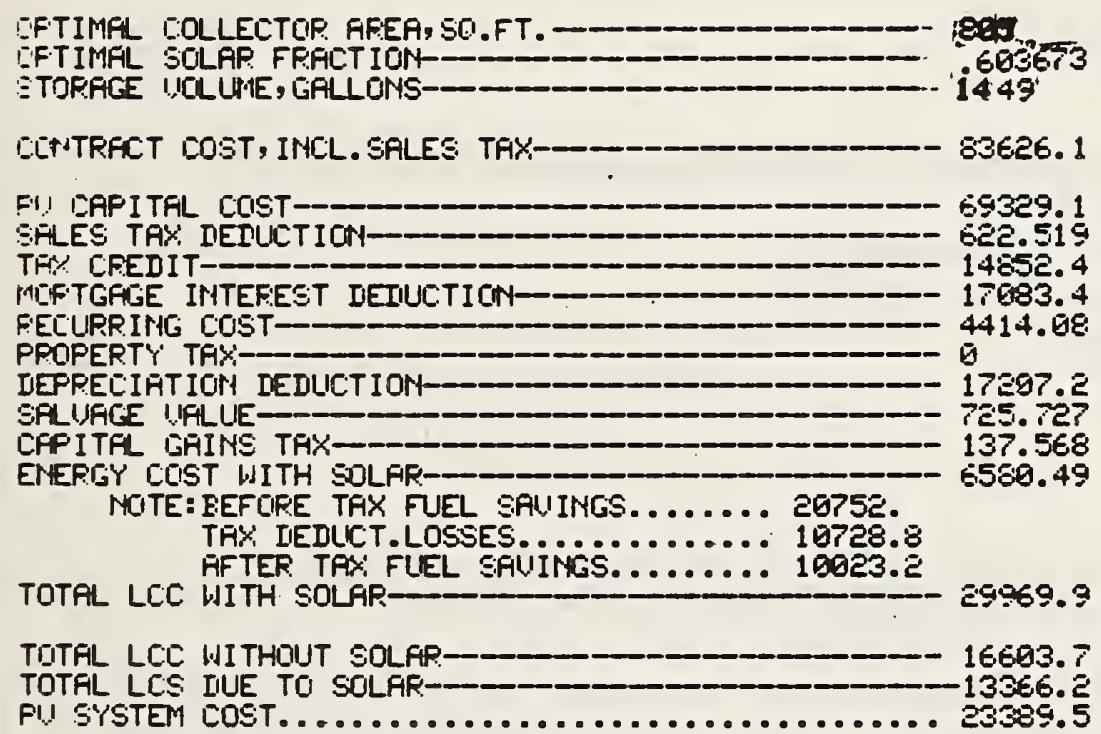

CUMULATIUE SFUINGS FIRST EQLALS COST: EEYOND SYSTEM LIFE

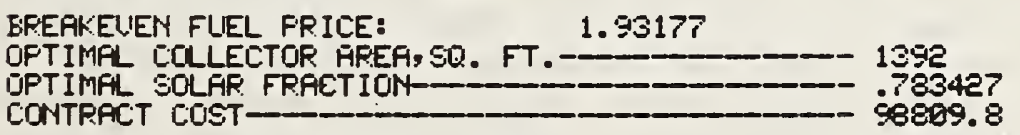

BFEFTKEUEN FUEL ESCALATION RATE:

1.81593 TIMES FROJECTED RATES

ESCFLFITION RATE FOR INTERUVLL $1 \ldots \ldots . .174329$

ESCALATION PATE FOR INTERUAL $2 \ldots \ldots . .168881$

ESCALFT ION FRTE FOR INTERUAL $3 \ldots \ldots .196672$

BPEAKEUEN SYSTEM FACTCR: .47D035 
U.S. DEPT. OF COMM.

BIBLIOGRAPHIC DATA

SHEET (See instructions)
1. PUBLICATION OR

NBSIR $82-2540$ \begin{tabular}{|l|r} 
2. Performing Organ. Report No. & $\begin{array}{r}\text { 3. Publication Date } \\
\text { July } 1982\end{array}$
\end{tabular}

4. TITLE AND SUBTITLE

Economic Evaluation of Solar Energy Systems in Commercial Buildings: Methodology and Case Studies

5. AUTHOR(S)

Rosalie T. Ruegg; G. Thomas Sav; Jeanne W. Powell; E. Thomas Pierce

6. PERFORMING ORGANIZATION (If joint or other than NBS, see instructions)

7. Contract/Grant No.

NATIONAL BUREAU OF STANDARDS

DEPARTMENT OF COMMERCE

WASHINGTON, D.C. 20234

8. Type of Report \& Period Covered Final

9. SPCHSORHG ORGAIHZATIOH NAIIE AND COMPLETE ADDRESS (Street, City, StOTe, ZIP)

U. S. Department of Energy

Office of Solar Heat Technologies

Active Heating and Cooling Division

Washington, D.C. 20585

10. SUPPLEMENTARY NOTES

Document describes a computer program; SF-185, FIPS Software Summary, is attached.

11. ABSTRACT (A 200-word or less factual summary of most significant information. If document includes a significant bibliography or literature survey. mention it here)

This report develops a comprehensive economic optimization model for evaluating the economic feasibility of active solar energy systems to provide service hot water and combined space heating/service hot water in commercial buildings. The model is demonstrated in a number of case studies for office buildings and retail stores. Data and assumptions for use in the model are compiled for the selected case studies. Using these data, the model is applied to estimate present value net savings (or net losses) of the solar energy systems over a 20-year life cycle. Break-even values for hot water loads, solar energy system costs, and current and future energy prices are also calculated to determine the minimum conditions under which the solar energy systems become cost effective for the selected buildings. Economic optimization paths which show the optimal solar collector areas and the corresponding present value of net savings (or net losses) associated with a range of hot water loads are developed in the case studies. Sensitivity analysis is conducted for key variables. The relationship between total live-cycle costs and the solar fraction is tested for selected cities to demonstrate how net savings (net losses) change as the solar fraction is increased. In its approach, this report is of interest to solar analysts; in its results, to the solar policy, research, and building communities.

12. KEY WORDS (Six to twelve entries; alphabetical order; capitalize only proper names; and separate key words by semicolons) building economics; commercial buildings; economic analysis; energy economics; life-cycle costing; solar energy

Order From Superintendent of Documents, U.S. Government Printing Office, Washington, D.C. 20402.

14. NO. OF PRINTED PAGES

\section{5}

15. Price

$\$ 18.00$

¿X Order From National Technical Information Service (NTIS), Springfield, VA. 2216I 
